

\section{The Imaginary Geography of Hollywood Cinema 1960-2000}





\title{
The Imaginary Geography of Hollywood Cinema 1960-2000
}

\author{
Christian B. Long
}

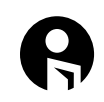

intellect Bristol, UK / Chicago, USA 
First published in the UK in 2017 by

Intellect, The Mill, Parnall Road, Fishponds, Bristol, BS16 3JG, UK

First published in the USA in 2017 by

Intellect, The University of Chicago Press, 1427 E. 60th Street,

Chicago, IL 60637, USA

This ebook is licensed under a Creative Commons CC-BY-NC-ND License.

To view a copy of this license, visit https://creativecommons.org/

licenses/by-nc-nd/4.0/

All rights reserved. No part of this publication may be reproduced, stored in a retrieval system, or transmitted, in any form or by any means, electronic, mechanical, photocopying, recording, or otherwise, without written permission.

A catalogue record for this book is available from the British Library.

Cover designer: Aleksandra Szumlas

Copy-editor: MPS Technologies

Production editor: Jessica Lovett

Typesetting: John Teehan

ISBN 978-1-78320-829-6

ePDF ISBN 978-1-78320-830-2

ePub ISBN 978-1-78320-831-9

Printed and bound by Short Run.

An electronic version of this book is freely available, thanks to the support of libraries working with Knowledge Unlatched. $\mathrm{KU}$ is a collaborative initiative designed to make high quality books Open Access for the public good. The Open Access ISBN for this book is 978-1-78320-830-2. More information about the initiative and links to the Open Access version can be found at www.knowledgeunlatched.org. 


\section{Contents}

Images and Maps vii

Acknowledgments $\quad$ xiii

Introduction: Where Is Hollywood Cinema? $\quad 1$

Chapter 1 Burt Reynolds Brings the New South to Hollywood 33

Chapter 2 New Hollywood, the Contemporary Midwest, and Collective Action 57

Chapter 3 Getting Around the Suburbs in the Blockbuster Era's Big Hits 93

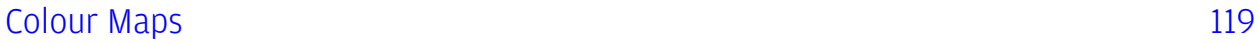

Chapter 4 Politics for Couch Potatoes: Video Rental Success Stories 135

Chapter 5 Imagining More for Medium-Sized Cities, 1975-2000 167

Chapter 6 It's Not Such a Small World After All: Disney Live Action Films in the 1960 s

Conclusion: Where Isn't Hollywood Cinema?

References

Notes

Index 



\section{Images and Maps}

Image 1. Malcolm X in Omaha, Nebraska.

Image 2. Malcolm X George Wallace in the school house door.

Image 3. Malcolm X US flag at Boston bussing protest.

Image 4. Malcolm X Nelson Mandela.

Image 5. Malcolm X travelling shot in crowd, scene 1.

Image 6. Malcolm X travelling shot in crowd, scene 2 .

Image 7. Deliverance building a hydroelectric dam.

Image 8. Sharky's Machine 'I'm freezing to death' in Atlanta.

Image 9. Sharky's Machine Peachtree Plaza Hotel and film title.

Image 10. Sharky's Machine surveillance, reflected buildings and highway.

Image 11. Sharky's Machine surveillance and Peachtree Plaza Hotel.

Image 12. Sharky's Machine Peachtree Plaza Hotel dissolve.

Image 13. Semi-Tough Miami establishing shot.

Image 14. Smokey and the Bandit Cledus's house.

Image 15. Sharky's Machine Sharky's childhood home. 
Image 16. Five Easy Pieces in southern California oil field.

Image 17. The Wild Angels oil field stretches out during credits.

Image 18. The Last Picture Show Duane's work truck, Marshal Oil Odessa.

Image 19. Badlands drilling for oil.

Image 20. Badlands trip gas from the pipeline.

Image 21. Medium Cool 'you want to talk to someone?'

Image 22. Medium Cool explanation with no reaction shot.

Image 23. Medium Cool first direct address.

Image 24. Medium Cool second direct address.

Image 25. Medium Cool second direct address, making finger gun.

Image 26. Medium Cool rhyming shot.

Image 27. Blue Collar capital dwarfs labour.

Image 28. Blue Collar final image in freeze frame.

Image 29. Ferris Bueller's Day Off Wrigley Field establishing shot.

Image 30. Wayne's World The Mirthmobile in the suburbs.

Image 31. Wayne's World cars on a spike sculpture.

Image 32. Wayne’s World Stan Mikita’s Donuts, Aurora, Illinois.

Image 33. The Flamingo Kid Marine Parkway Bridge.

Image 34. Gorky Park Lenin portrait makes Helsinki Moscow.

Image 35. Gorky Park Arkady’s apartment building.

Image 36. The Emerald Forest building a hydroelectric dam in Brazil. 
Image 37. Under Fire Chad, Africa, for the geographically illiterate.

Image 38. Under Fire Alex gets shot in POV shot.

Image 39. Nashville Welcome to Nashville.

Image 40. Coal Miner's Daughter Grand Ole Opry establishing shot 1.

Image 41. Coal Miner's Daughter Grand Ole Opry establishing shot 2.

Image 42. Wag the Dog Nashville skyline establishing shot.

Image 43. Wag the Dog Nashville establishing shot 2.

Image 44. Rain Man Las Vegas cranes.

Image 45. Casino Catholic School and baseball field.

Image 46. Bob Roberts limited view of Pittsburgh.

Image 47. In Search of the Castaways Māori carving with ping pong ball eyes.

Image 48. In Search of the Castaways Rangatira (Chief) Inia Te Wiata and marker pen mokod toa (warriors).

Image 49. Bon Voyage! Eiffel Tower in establishing shot.

Image 50. Bon Voyage! Eiffel Tower in home movies.

Image 51. Bon Voyage! peeping tom/Peeping Tom.

Image 52. Monkeys Go Home! slogan that echoes French revolution.

Image 53. Monkeys Go Home! slogan that echoes anti-imperialist call.

Image 54. Monkeys Go Home! free labour. 
Map 1. African Americans Nominated for an Oscar.

Map 2. Cities in Kerner Report and National Park Service Civil Rights Historic Sites.

Map 3. African American Prestige Films and History.

Map 4. Box Office Hits 1970-1981.

Map 5. Box Office Hits 1970-1981 - South.

Map 6. Box Office Hits 1970-1981 - South.

Map 7. New Hollywood Films.

Map 8. New Hollywood Films.

Map 9. Top 10 Hits before Jaws' Release.

Map 10. Top 10 Hits after Jaws' Release.

Map 11. Top 25 Video Rentals Compared to Top 25 Box Office.

Map 12. Top 25 Video Rentals Compared to Top 25 Box Office - New York Area.

Map 13. Top 25 Video Rentals Compared to Top 25 Box Office - Europe.

Map 14. Top 25 Video Rentals Compared to Top 25 Box Office - Central and South America.

Map 15. First-Fifth Order Cities (based on Borchert, 1967).

Map 16. Prestige Films Set in 20 Largest US Cities.

Map 17. Cities in the 100-Largest List that Do Not Appear in Prestige Films.

Map 18. Prestige Films Set in Medium-Sized Cities.

Map 19. Disney Films Setting.

Map 20. Disney Films Set in Europe. 
Images and Maps

Map 21. Disney Films Set in Asia-Pacific.

Map 22. Poorest Counties and Box Office and Prestige Film Settings. 



\section{Acknowledgments}

I've followed Jennifer Clement from New Hampshire to Nashville to Christchurch to Brisbane, and I'll keep following her anywhere she goes. Her love, patience, encouragement, and critical eye made this book possible and better.

Thanks and love to my parents, Brad Long and Paula Giallombardo, to my sisters, Megan, Colleen, and Killian, and to Dave, Rachel, Grace, Piper, Max, and Matt. Every three years isn't frequent enough to see everyone.

Three of my favourite people in the world died too young, first among them my mom, who did every good thing a person can do, and often. Vinnie Giallombardo was my best friend growing up, and Frank Ward was a far better friend than I deserved. They were my two main movie-watching companions, and it's lonelier in the theatre without them.

Thanks to my stateside friends John Foersterling, Rob Garcia, and Chris Simich. Mark Maguire, whether in New Zealand, Ireland, or Spain is aces.

More than anyone, Jonathan Lamb and Bridget Orr made moving to the Antipodes possible.

I'm lucky to have known Clarence. He was this man's best friend. All the critters I've shared the house with - Emma, Oswald, Armstrong, Castor, Pollux, Isa, and all the foster cats - have been great pals.

I love Christchurch, and it was hard to move away. My neighbours in Sumner were an inspiration after the February 2011 quake. Without the great people at that national treasure Alice in Videoland, film culture in Christchurch would be greatly diminished. I owe significant debts to Phil Armstrong, Dan Bedggood, Lloyd Carpenter, Gareth Cordery, Patrick Evans, Douglas Horrell, the late Howard McNaughton, Paul Millar, James Smithies, Christina Stucharski, Mary Wiles, Alan Wright, and Nicholas Wright. I owe an even larger debt to Jennifer Middendorf, who made sure that even in chaos, things got accomplished. Thanks to the Tertiary Education Union for winning a few fights. Thanks to Steve Malley for the tattoos and the guest lecture on noir. And thanks to Tom McLean in Dunedin.

Moving to Brisbane was made much easier by Alison Scott and Jane Stadler. Jason Jacobs made me an honorary research fellow at UQ. My co-workers in Academic Language and Learning at Queensland University of Technology, Peter Nelson, Karyn Gonano, and Sophie Abel, make me wonder why it took me so long to quit taking lousy semester-tosemester teaching gigs. 
Thanks to Ferrymead Bays Soccer Club in Christchurch: Erna Rogers and Duggie Rogers, Ken Beaumont, Neil Murphy, Simon Standeven, and all my teammates. Thanks to Kangaroo Point Rovers in Brisbane: Graeme Were and Mark Hodson for bringing me to the club, Tony Simpson, and all my teammates. Thanks to the doctors and nurses at Princess Alexandra Hospital for fixing my fractured larynx, bruised vocal cords, broken ribs, bruised liver, and broken arm.

Thanks to Paul Young, Sam Girgus, Cecelia Tichi, Catherine Jurca, Jay Clayton, Carolyn Dever, Colin Dyan, Deak Nabers, Dana Nelson, Kathryn Schwarz. Thanks as well to Doug Lanier, Monica Chiu, Bill McBride, Robert McLaughlin, Sally Parry, and E Kim Stone. Thanks to my teachers Jane Cristino, Paul Eisenbacher, Dave Engle, Joe Wolnski, and especially Pat Gordon. John Katzel has my thanks, gratitude, and admiration.

Thanks to my grad school cohort - Jeff Menne, Nicole Seymour, Katherine Fusco, Josh Epstein, and Ben Graydon - and Brian Rejack, Justin Haynes, Beau Baca, John Morrell, Jane Wanninger, Rebecca Chapman, Amanda Hagood, and Dan Spoth.

I presented an early version of my Burt Reynolds research at The Clinton Institute for American Studies Summer School at University College Dublin. Javad Alipur, Vladimir Dordevic, Brian Edwards, Rebecca Evans, Jamie Feigenbaum, Georgiana Lolea, Dietmar Meinel, Ben Miller, Will Mountz, Sriya Shrerth, and Adam Waterman provided feedback and encouragement. An earlier version of 'Burt Reynolds Brings the New South to Hollywood' appeared as 'Burt Reynolds, Hollywood's Southern Strategy' in Post45, who were a pleasure to work with. Parts of 'Introduction: Where Is Hollywood Cinema?' originally appeared, in a slightly different form, in 'Where Is France in French Cinema, 1976-2013?', in International Journal of Humanities and Arts Computing. Jennifer Gillan and Derek Nystrom answered my from-the-blue emails with insightful comments on draft versions of chapters. Thanks to Johan Andersson for inviting me to present an overview of the entire project at the King's College London geography department's human geography research seminar. Thanks to the three anonymous readers, who offered strong, fair, and useful criticism that was far less soul-crushing than I feared.

Thanks to Carpentersville, Illinois, for being a place that I couldn't quite explain to my New Zealand students through Hollywood films, and for making me take up this project.

I'd be lost without Jennifer. This book, imperfect as it is, is for her with love. 


\section{Introduction}

Where Is Hollywood Cinema? 

Placing a literary phenomenon in its specific space - mapping it - is not the conclusion of geographical work; it's the beginning. After which begins in fact the most challenging part of the whole enterprise: one looks at the map, and thinks.

Moretti (1998: 7)

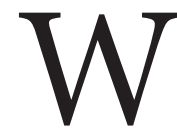

here do we mean when we say 'Hollywood cinema'? Do we mean contemporary suburban Los Angeles, 1970s New York, a mid-century Midwestern small town, a Gilded Age Wild West town, a Civil War plantation, somewhere in space, all of the above, or none of the above? Has Hollywood cinema been associated with the same places throughout its history? What are the privileged - and invisible - places in Hollywood cinema? Film has from its beginnings been a major part of urban - and, increasingly, suburban - life, in theatres, nickelodeons, picture palaces, and multiplexes. As film exhibition has migrated, have film settings migrated as well? Do box office blockbusters, minor hits, and year-end awards lists describe the same country? Because cinema, by virtue of its cinematographic apparatus, is always literally set somewhere, the public spaces that it affords for placing and locating stories act as home bases for a putative national identity, whether that space is 'real' like The French Connection's (Friedkin, 1971) New York or fantastic like Star Wars' (Lucas, 1977) Tatooine.

This book traces Hollywood cinema's narrative locations by mapping the popular and critical geography of Hollywood film from 1960 to 2000 to explore the ways in which Hollywood narrative cinema's history is located in shifting national, regional, and cityspecific locales. Mapping narrative locations is a complex endeavour. While online film databases like Internet Movie Database (IMDb), Turner Classic Movies (TCM), and even Wikipedia often provide extensive information on shooting locations, they do not provide information on narrative locations with nearly as much regularity and detail. The role of shooting locations in academic film studies is well-established; for example, industrial histories have tracked the ways in which industrial concerns like tax breaks, employerfriendly employment law, and the relative strength of the US dollar have informed trends in 'runaway productions', as Chris Lukinbeal, Richard Butler, and Ben Goldsmith, Susan Ward, and Tom O'Regan, among others, have detailed. But even if financial concerns motivate shooting locations, narrative locations - those with real-world referents such as an actual city or mountain and those that exist only in the realms of genre, the past, or the imaginary - always signify something about how we understand our place in our own 
world, including where that place is, and how it relates to other places. Taking a spatially and cartographically-driven approach to film history focuses attention on the changing ways in which film-makers have used narrative locations to construct an imaginary geography of the United States and the world. By revealing continuities and discontinuities in the settings for Hollywood films that American and international audiences have most watched and admired since 1960, this book will demarcate where Hollywood cinema has located - and not located - changing notions of the place 'America' and the idea of 'America' within and beyond the boundaries of the United States. In doing so, it will reveal the importance of narrative setting not only to landscape, but also to the national identities and ideologies such landscapes create.

\section{Spatial Film History Meets Ideological Criticism}

The Imaginary Geography of Hollywood Cinema 1960-2000 is a spatial film history project. I have created a number of maps, but the maps are not the project's raison dêtre, nor will geographic information systems (GIS) be the primary tool for analysis. Rather, I use digital cartography as the first step towards a spatial history of Hollywood film. By using digital cartography to guide the selection of representative and outlier films for in-depth analysis, this book re-orients and redraws the boundaries of Hollywood film history both literally and figuratively, cataloguing films' narrative locations on digital maps to examine where Hollywood locates its narratives and ideology over time. Hollywood is both an American cinema and a global cinema, a dual identity reflected in its worldwide reach and distribution. The United States has especial importance to Hollywood as its first - home - market, but globalization has made international box office increasingly important.

While this book uses maps as its first, distinguishing step, it takes a cultural materialist approach to film history. Hollywood films export 'America' as an ideology and a place to the world, but their geography is both circumscribed and, as yet, unmapped. Tracing the interactions of Hollywood cinema's narrative locations and the contemporary geography of the United States (and world) reveals previously invisible connections - and gaps - in the popular and critical geography of Hollywood film, and directs more focused attention to the importance of location to the films that Americans and international audiences have watched and admired. This book begins with the hypothesis that changes in the narrative locations of post-war box office hits and prestige pictures also register changes in US demographics, culture, and politics. The geographies of popularity and prestige this project maps represent the first steps towards a new way of understanding the film narratives that inform and undergird the spatial aspects of American identities and understandings of America throughout the second half of the twentieth century. In effect, this book combines textual analysis and an engagement with the role of the audience 
based on their ticket purchases to write a spatial history of the American landscape and identity in terms of the narrative settings of films American audiences were most likely to see and to perceive as both high quality and also indicative of American culture and values. The Imaginary Geography of Hollywood Cinema 1960-2000 imagines a new history of not just of the geography of the films that comprise Hollywood cinema, but of the physical locations that define and place the 'on-screen' America and American identity that Hollywood films represent.

To understand Hollywood films as both an expression and a shaper of the American way of life, many film histories such as this one take an ideological approach to film history. To give one example, in American Cinema of the 1960s Themes and Variations (2008), Barry Keith Grant faults films for not anticipating and speaking to the significant political events of the era (I have added the dates of the events Grant sees as key):

In August 1965 the Beatles played before 56,000 fans at New York's Shea Stadium, the same summer racial violence erupted in Los Angeles, Chicago, and other cities. But that year the big Oscar winner was the feel-good family film The Sound of Music - a work of calculated sentimental claptrap about the musical Von Trapp family that Pauline Kael almost alone disliked, referring to it as 'the sound of money.' Similarly, in 1968, the year of the Tet Offensive [30 January], the My Lai massacre [16 March], the police assaults on the Black Panthers [7 April], the assassinations of Martin Luther King [4 April] and Robert F. Kennedy [6 June], the stormy Democratic National Convention in Chicago [26-29 August], the forcible dispersal of the residents of Resurrection City in Washington [24 June], the election of Richard Nixon [5 November], the Prague Spring [Jan-June], the Soviet invasion of Czechoslovakia [21 August], and of course May '68 in France [May], when the country experienced a general strike that led to the eventual collapse of the De Galle regime [...]. [T] he films nominated for Best Picture were Franco Zeffirelli's picturesque Romeo and Juliet [8 October release], Funny Girl [19 September], The Lion in Winter [30 October], Rachel, Rachel [26 August], and Oliver! [10 December] the last being the year's big winner. Clearly Hollywood needed to do more to reach the youth audience.

(Grant 2008: 16-17)

Rachel, Rachel (Newman, 1968), based on a novel by the Canadian writer Margaret Laurence published in 1966, was released in the same week as the Democratic National Convention. Films do not appear immediately, but rather work their way through a preproduction, production, and post-production process that can easily take more than a year. And Rachel, Rachel is indeed a political film. As Molly Haskell wrote,

One 'woman's film' that seems to have been overlooked in the hysteria of the decade is Rachel, Rachel, starring Joanne Woodward (under Paul Newman's direction) as the thirty-five-year-old virgin schoolteacher who stands uneasily at the threshold of the 
second half of her life [...] [The film deals] sympathetically, and for purposes other than sheer melodrama, with the problems of a repressed and unglamorous woman.

(1987: 337)

Haskell's use of 'unglamorous' signals the importance of smaller, more personal films whose politics emerge not from grand gestures but from an accrual of meaningful small details. Granted, Grant correctly identifies the problem of a more or less monolithic Hollywood culture avoiding contemporary political issues. The late 1960s, like any postwar decade, featured a number of films that were quite square in their political stance. Films like The Sound of Music (Wise, 1965) and a large number of Disney live-action films did not make any contentious political points or intervene in contemporary debates - at least on their surfaces - and were very successful at the box office. But Grant's main concern seems to be that the films nominated for Best Picture in 1968 do not address his preferred political issues, as his dismissal of Rachel, Rachel makes clear. The militaristic The Green Berets (Wayne and Kellogg, 1968) was certainly a political film, but few critics shed tears over its exclusion from the Best Picture nominees.

It may be an obvious point, but the majority of films from any era are not box office successes, regardless of politics. Similarly, the bulk of films do not feature extensively in accounts of film history. As Drew Casper argues in his conceptualization of a revised canon for post-war Hollywood,

Most of these neglected films, however, are ideologically centrist, encapsulating Hollywood's genius at this time in making work appealing to both sides of the cultural cleft. Thus, a film like Mary Poppins (BV, 1964), barely receives a sentence or two. The ground-shattering Dr. Strangelove, Or: How I Learned to Stop Worrying and Love the Bomb (C), released the same year, elicits a chapter. Yet there is as much invention, though of a different kind, in Poppins as in Strangelove [...]. No book goes without a 2- to 75-page account of the masterwork Bonnie and Clyde (WB, 1967), which, if truth be known, questions its own anarchy, while the centrist consummate A Man for All Seasons (C, 1966), is lucky to nab two lines.

(2011: xvi)

One way to look at these exclusions is through an ideological lens, as do Grant and Casper. The tendency to equate left wing with good film and right wing with bad propaganda certainly informs some canon-policing. This is not to say that a non-confrontational, 'apolitical' film is guaranteed success; tame offerings like Bing Crosby's High Time (Edwards, 1960) and the Freed Unit musical Bells Are Ringing (Minnelli, 1960) lost money. By the same token, Spartacus (Kubrick, 1960), Doctor Zhivago (Lean, 1965), and Lawrence of Arabia (Lean, 1962), though historically 'remote', certainly deal with matters of global political import and topped the box office. To generate a more subtle, accurate film history 
that takes into account politics, popularity, prestige, and nationality, I want to introduce a different way to conceive of films, whatever their overt politics: geography, or, more precisely, setting. Setting has, for the most part, been touched on only lightly in past film histories. But as I argue here, setting matters in terms of narrative, form, and ideology.

After the spatial turn that started in the 1970s in France (notable figures include Henri Lefebvre and Michel Foucault) and took off in the 1980s and early 1990s in the United States (Marshall Berman, David Harvey, Fredric Jameson, Edward Soja, and Mike Davis, to name a few), in the twenty-first century, there has been an increased critical interest in the intersection of landscape and location in cultural productions (Shiel 2001: 5). Broadly speaking, one set of spatial approaches attends to the spaces in the text's narrative, as in Tom Conley's Cartographic Cinema (2007) and the works that make up Barbara Piatti and Lorenz Hurni's Literary Atlas of Europe (2012-2015). Such an approach is text-based, with cinematic/ literary representation of spaces at the heart of analysis, rather than the places themselves. Another set attends to the spaces of the text's reception, and the text's audiences, which can lose track of the represented places while paying close attention to the places where they are consumed. The New Cinema History, a sub-field that has taken on increased prevalence in the last ten years, seeks to bridge these two approaches. Examples of New Cinema History include Robert Allen's work in Going to the Show (2008), and the Mapping the Movies: The Changing Nature of Australia's Cinema Circuits and their Audiences 1956-1984 (2011) project headed by Richard Maltby. Maltby is perhaps the most significant figure in the field, as the author of the influential essay 'On the prospect of writing cinema history from below' (2006) and as the editor of collections such as Explorations in New Cinema History (2011) and Identifying Hollywood's Audiences: Cultural Identity and the Movies (co-edited with Melvyn Stokes, 2008). The New Cinema History, as Maltby describes it,

offers an account that complements and is informed by many aspects of film history, particularly by investigations of global conditions of production, of technical innovation and craft and of the multiple and interconnected cultures that characterise the film production industry. To these it adds knowledge of the historical operations of distribution and exhibition businesses worldwide, and of the ways in which these interconnected networks of global corporate interests, local franchises and other small businesses have together managed the flow of cinema product around the world's theatres and non-theatrical venues. It uses quantitative information, articulated through the apparatus of databases, spatial analysis and geovisualization, to advance a range of hypotheses about the relationship of cinemas to social groupings in the expectation that these hypotheses must be tested by other, qualitative means. In demonstrating the range of archival materials specific to these core areas of cinema's operational and institutional history, the new cinema history cautions strongly against the adequacy of a total history of cinema founded on the study of films. 
This extensive description is necessary, both for Maltby and for me, as it demonstrates the incredible breadth of material that goes into writing New Cinema History. By paying attention to the world around film, the cinema, and theatres - to everything that leads up to and makes possible the watching of a film - the New Cinema History 'offers a counterproposition to the assumption that what matters in the study of the audience experience should be restricted to "reception"' (Maltby 2011: 37). One key piece of what audiences receive, regardless of where and how they see a movie, is the film's location. Studies like Going to the Show and Mapping the Movies recognize the importance of where in terms of audience experience. The importance of the where in the movies these audiences see has, as yet, been less extensively treated.

But even as Maltby describes New Cinema History, directing attention away from the film on the screen and towards the world that the film entered, he keeps an eye on how to judge films as significant and worthy of study. As a history from below, New Cinema History seeks to destabilize the canon. As Maltby argues,

film history has been written almost in its entirety without regard to, and often with deliberate distaste for, the box office. Nowhere is film studies' genetic inheritance from literary analysis so much in evidence than in the deformities of attention that this produces. We need to be aware of the historical cost of this approach, and of how much has been omitted in the effort to construct film history as the story its historians want to tell: a story of crisis, innovation, anxiety, turbulence, and the elevation of the junior branch. As a means of writing the history of production, this symptomatic approach omits from serious consideration the great majority of cinema's most commercially successful products - in the case of Hollywood history, for example, the films of Janet Gaynor, Nelson Eddy, Betty Grable or Shirley Temple - perhaps because few of its historians have wanted to write the history of a cinema of complacency.

Here we see Maltby in agreement with Casper on the ways in which ideological concerns, as well as critical preference for particular kinds of films, make the canon a small and unrepresentative list. New Cinema History treats audiences and exhibition as central to the discussion of film history, which means that close textual analysis of films themselves do not figure extensively.

\section{Film Geography, Production Sites, and Narrative Locations}

Film geography is a relatively new field that seeks to apply the tools of geography to an understanding of the culture from which films emerge. Chris Lukinbeal and Stefan Zimmerman's The Geography of Cinema (2008) and Lukinbeal's 'Cinematic landscapes' (2005) pay close attention to shooting locations and landscape analysis, while Sébastien 
Caquard's 'Cartography I: Mapping narrative cartography' (2011) and Mapping Cinematographic Territories (2009-2016) direct their attention to mapping narrative settings, both on screen and places mentioned in dialogue. Lukinbeal, in particular, has published a great deal of material that confronts the role that literal places play in both film and its cultural significance. One particular interest in film geography deals with the geography of runaway productions. A Hollywood film is not always made in Hollywood, and usually economic reasons inform the decision to film elsewhere - whether in studios or on location or both. Lukinbeal identifies popular shooting locations like Florida, the San Francisco Bay area, Texas, North Carolina, and Chicago as North America's primary second-order production centres (Lukinbeal 2004: 311). In addition to second-order production centres, we find edge-centres, which

traditionally include those areas close to Los Angeles (Arizona, Nevada, San Diego, Salt Lake City, Portland, Seattle, and Vancouver) and New York City (New Jersey, Pennsylvania, Toronto). They thrive on economic runaway productions and compete with second-order centers for the variable flow of production.

In the 1980s and 1990s, 'edge-centers increased both their number of feature film productions [...] and their total percentage of annual feature film production' (Lukinbeal 2004: 314), which means that more Hollywood films were not filmed in Hollywood but rather a short flight away from Hollywood. But this increased shift to second-order production centres and edge-centres does not mean that those films were set in Florida, North Carolina, Salt Lake City, Portland, Seattle, and/or Vancouver. The economic exigencies of changing shooting locations do not tell the entire story. Lukinbeal argues in 'Runaway Hollywood: Cold Mountain, Romania' that the discourse of runaway productions shows a consistent tension: 'On the one hand, there is economics, which constrains and limits the creative decisions of a production. On the other hand, there is geographic realism which is needed to make a narrative plausible to the audience' (2006: 339). Geographic realism 'links a fictional narrative to a location's sense of place' (Lukinbeal 2006: 339), as sometimes a film has an intimate connection to its setting - for example, Vertigo (Hitchcock, 1958), where the film's narrative can move in a downhill direction thanks to its San Francisco setting (Pomerance 2004: 229) or Home Alone II (Columbus, 1992), where Kevin McAllister (Macaulay Culkin) is, as the film's subtitle promises, Lost in New York.

The verb 'to map' appears frequently in cultural analysis, and it is often used to refer not to something like cartography, but to a critical description and analysis. Critics who use the metaphors of mapping and borders use the spatial sense of 'where' to mean where and for whom a particular ideology has some purchase, rather than the actual place where a person would stand. In the first chapter of the three-volume The History of Cartography, J. B. Harley writes that mapping is 'communication about space' (1987: 1), 
and while ideologies certainly have spatial aspects, the two are not synonyms. Location matters - but in a way that has not yet been fully examined in film histories. Film narratives (with some rare exceptions) are set somewhere; the main narrative locations of Hollywood movies are what concern me here. For Peter Wollen, 'constructing a film narrative [...] involves constructing a mental map' (2002: 212), and likewise constructing a narrative of film history involves constructing not only mental, but literal maps as well. I want to make the case for privileging narrative location over narrative or film style by treating a film's where as an under-explored and powerful explanatory force, asking why through where. Do the films that succeed - either in terms of box office or in terms of critical acclaim - locate their narratives somewhere in particular? Do these settings change over time? When? Why? To find out the answers to these questions, I suggest, and use, a geospatial approach to film studies that treats Hollywood narrative as a geographic concept, as a set of places on the map that make it possible to conceive the parameters - the boundaries, even - of Hollywood as a national, nation-describing cinema, no matter how familiar, unfamiliar, big, or small that nation may turn out to be. In such an approach, maps reveal Hollywood's spatial organization of the world (and nation) on film and show how a geospatial approach can enable, direct, and redirect the critical construction of what particular spaces comprise the national in the United States' national cinema, Hollywood. The Imaginary Geography of Hollywood Cinema 1960-2000 thus uses the data visualization - maps - of box office hits and prestige films to analyse them, both formally as films and also ideologically as cultural productions, to generate a more nuanced spatial history of Hollywood cinema. ${ }^{1}$

\section{Box Office Hits and Prestige Pictures}

To write this spatial history of Hollywood cinema, I need a group of films on which I can base my claims. As Franco Moretti argues, 'no one has ever found a method by just reading more texts. That's not how theories come into being; they need a leap, a wager a hypothesis, to get started' (2013: 46, emphasis added). Therefore, I adopt Moretti's distant reading methodology to generate maps of the major narrative locations - not the shooting locations - of box office hits and prestige films from 1960 to 2000, from the end of the studio era into the last days of $35 \mathrm{~mm}$ as the medium in which film was most often exhibited. As Moretti describes distant reading, it takes 'the form of an experiment. You define a unit of analysis [...] and then follow its metamorphosis in a variety of environments' (2013: 53-54). The experiment this book conducts uses narrative location as its unit of analysis to explore how changes in the narrative locations register changes in US demographics, culture, and politics. As Moretti describes the process:

$[Y]$ ou reduce the text to a few elements, and abstract them from the narrative flow, and construct a new, artificial object like the maps [...] And with a little luck these maps 
will be more than the sum of their parts: they will possess 'emerging' qualities, which were not visible at the lower level.

The maps of the main narrative locations of a group of films are not this book's explanation, but rather 'bring some hidden patterns to the surface' (2005: 53-54) to show how particular locations appear frequently, or only over a brief period of time, or not at all, revealing the multiple centres of gravity in Hollywood's geographic imagination. From the spatial-geographic patterns visible in the maps, I then turn to particular films, to see how their narrative and formal aspects can aid in understanding how Hollywood films place their ideology in particular locations at particular points in history. ${ }^{2}$

This turn to selecting specific films after mapping a large set of films places me between two approaches: close reading and distant reading. I take part of the distant reading approach - its focus on sets of films (Moretti 2013: 48-49) - and combine this with close readings of particular films to regain a measure of the 'text itself' that disappears. Hollywood narrative locations, when placed on the map, should reveal both the common and outlier locations for popular and critically acclaimed films. In other words, I situate the narrative locations of groups of films in relation to the larger trends revealed by the location patterns in the large set to locate exactly where audiences were encountering 'America' (and elsewhere) when they watched movies.

I have chosen two different categories of films to map for distant and then close reading: the top-grossing films at the US 'domestic' box office (which includes Canada) and prestige films for the years 1960-2000 inclusive. I split the box office hits into two groups, the Top 25 and the Next 25; I concentrate on the top 25, the biggest hits, but on occasion include Next 25 films. In A Certain Tendency of the Hollywood Cinema, Robert Ray seeks to outline the thematic and formal tendencies that prevail in Hollywood, and rather than basing his claims on some version of a film's 'greatness', he writes that "popular" is a more verifiable term than "great" - after all, we have box office statistics' (1985: 20). Granted, popularity is no measure of merit, whether formal or thematic or ideological, but unlike 'greatness', which hinges on subjective matters of taste, it is an objective measure (however much it simplifies and cheapens matters). In this book I take up the work that Dudley Andrew proposes in 'Appraising French images':

Those concerned with the social ramifications of mass media are in a position today to claim that box office and video rental statistics have already judged and ranked the effectiveness of movies; academics should then explain and comment on the rankings.

Taking box office as a measure of relative importance and cultural profile means accounting for the taste regimes it reveals, including the ways in which a sense of national geography appears in films. My explanations and commentary on box office successes between 1960 
and 2000 begin with an engagement with their narrative settings. If hit movies account for the overwhelming majority of what the average movie-goer experiences as 'Hollywood cinema' in any given year (Krämer 2005: 125-26), then those hits can help to answer questions like: what places did domestic audiences see the most?; why might that be?; and what does the prevalence of those locations mean?

The prestige films come from the Oscar nominees for Best Picture as well as the films named in year-end-best lists from Roger Ebert, the New York Film Critics Circle, the National Board of Review, and the National Society of Film Critics, and the films released between 1960 and 2000 included in the American Film Institute's '100 Years 100 Movies' list. Peter Wollen admits that 'Lists seem trivial, but in fact they are crucial symptomatic indices of underlying struggles over taste, evaluation and the construction of a canon' (2002: 217). An Oscar may simply be an industry award, but the Oscars carry a significant amount of cultural capital in canon-formation and can help to generate box office (and ancillary-markets) capital. Gillian Roberts characterizes the Oscars' cultural capital as corresponding to Pierre Bourdieu's characterization of middlebrow culture, 'one that offers a negotiation between the accessibility of low culture and the prestige of high culture' (2003: 157). However, between 1960 and 2000, only five films were nominated for Best Picture every year; to expand the pool of prestige films with the middlebrow appeal of the Oscars, I include films named on the year-end best-of lists by the governmentfounded AFI, the historically minded National Board of Review, mass-circulation critic Roger Ebert, critics for New York publications, and the slightly more highbrow film critics in the National Society. I will say more about middlebrow taste later in this introduction, in my analysis of African American prestige films. These sets of films represent forty years of Hollywood representations of stories for domestic popular consumption, and stories recognized as 'quality' pictures by middlebrow critics and/or award panels. This sample size of a little more than 2200 films, when mapped, provides the basis for choosing significant representative or outlier films for closer analysis. I give extended attention to about 50 films, many of which do not occupy more than a line or two in most histories of Hollywood because part of my aim is to demonstrate how mapping narrative locations can serve to re-orient our perception of received film history - and even provide for fruitful 'misreadings' - to films that carry significant spatial importance to Hollywood's imaginary geography. Maps of the narrative locations of a large set of films will show consistencies and differences in narrative settings and generate the questions that would drive further investigation of what - or better yet, exactly where - America' means in Hollywood cinema.

\section{Establishing Shots and Cinema's Creative Geography}

As mentioned earlier, maps of the locations of these box office hits and prestige-list films are not the raison dêtre of the book. Rather, they are a means of data visualization that makes patterns in narrative location choice evident and thereby defamiliarizes canonical 
understandings of film history. For example, Hollywood films set in Paris inevitably begin with an establishing shot of the Eiffel Tower; see, for example, An American in Paris (Minnelli, 1951), Sabrina (Wilder, 1954), Anything Goes (Lewis, 1956), as well as later films like An American Werewolf in Paris (Waller, 1997), The Bourne Identity (Liman, 2002), and The Devil Wears Prada (Frankel, 2006), among many others. I have written elsewhere about the centrality of Paris locations to French cinema (Long 2015); my argument there is that in those films Paris appears as more than the Eiffel Tower, or Notre Dame, or the Champs Élysées, and closer to what Francois Penz describes as the 'city being itself' rather than a simple shorthand for 'Frenchness' (Penz 2010: 234). But the image of the city, and for much of the American film-going audience, begins with these landmarks and tourist spaces, rather than the more everyday spaces that French-made films use. Hollywood films do much the same thing for US cities: San Francisco and the Golden Gate Bridge, Manhattan's skyline and New York City, the White House or Capitol for Washington DC. Such a reduction of a city to an easily recognized landmark or icon makes the far away more accessible.

The establishing shot, as its name implies, establishes the setting for a scene, offering a sort of access to the scene both formally and thematically. As the glossary to David Bordwell and Kristin Thompson's textbook Film Art: An Introduction defines it, an establishing shot is 'a shot, usually involving a distant framing, that shows the spatial relations among the important figures, objects, and setting in a scene' (2010: 491). Beyond questions of formalism, spatial orientation, and the establishment of an alternative realm, an establishing shot can also do ideological work. In his analysis of Casablanca (Curtiz, 1942), Maltby argues that

[w] hat these 'establishing' or master shots establish is less the locale of the scene (which is equally recognizable in closer shots) than the spatial borders within which that scene will be enacted. The purpose of such shots is to define for the audience the limits of the scene's possibilities; characters may enter or leave this space, but for the duration of the scene events of narrative importance will take place only within its parameters, and within those parameters objects will obey the normative conventions of perspective.

This account of the role of the establishing shot applies more generally to Maltby's sense of the 'films of the consensus', those films that fall within the parameters of appropriate discussion of the political discourse of reformist populism. The spatial borders of the scene are both formal and thematic: where the scene can happen in a coherent manner and how it can play out within the movie's - and the space's - logic. Bordwell and Thompson, Maltby, and Alan Nadel all claim that establishing shots make clear the literal limits and borders of a scene within a film. In Flatlining on the Field of Dreams: Cultural Narratives in the Films of President Reagan's America (1997), Nadel offers an account of 
the establishing shot that expands into more cultural-political terrain. Nadel's description of the shot's importance is worth quoting at length. 'The establishing shot', he writes

is the vital cue to stabilize the continuity disrupted by the manipulation of time and space endemic to filmmaking. Typically a shot of a building, an institution, a town, or a human or natural environment, the establishing shot locates the place and often the time of the action. Without establishing shots, the discontinuity, disorientation, and arbitrariness of cinematic representation [...] would become a little more apparent. In many ways, in other words, the establishing shot is the representation of the Establishment, in that it presents the unchallenged assumptions necessary to allow the scene to unfold. It frames the framing of the subsequent shots by delimiting the imaginary space in which they are situated.

(Nadel 1997: 143)

The usual shot sequence of, for example, a dialogue scene, spends the majority of its duration in a location established by its briefest shot, the establishing shot. An establishing shot often condenses a location into an icon to, as Lukinbeal argues,

establish a cognitive map of the narrative's geographic location. This cognitive map depends on the audience understanding the central icons of a location (the Golden Gate, Transamerica Building, trolley cars). This does not mean that person needed to visit the location to understand these icons. The repetitious use of icons by film and television of particular places and building can create a representational legacy that works to construct and establish a cognitive map, a sense of place.

Thus while, as Nadel points out, an establishing shot makes clear both where the scene occurs and the spatial and ideological logic of that space, the establishing shot also makes clear where the scene takes place in a larger American geographical imaginary, a shared set of images and icons that identify particular cities or types of places and regions.

The iconography of architecture frequently appears in establishing shots, whether as the International style of the New York skyline or the neo-classical Palladian White House. But a city or any named and bounded place is more than its landmark architectdesigned buildings, and to understand it requires an engagement with its spatial practices. In Orientalism Edward Said writes that

[i]f one studies some of the major metropolitan cultures - England's, France's, and the United States', for instance - in the geographical context of their struggles for (and over) empires, a distinctive cultural topography becomes apparent. In using the phrase 'structures of attitude and reference' I have this topography in mind, as I also have in mind Raymond Williams' seminal phrase 'structures of feeling.' I am talking about a 
way in which structures of location and geographical reference appear in the cultural languages of literature, history, or ethnography, sometimes allusively and sometimes carefully plotted, across several individual works that are not otherwise connected to one another or to an official ideology of 'empire'.

Something close to Said's description of text-based approaches also appears in film. Thanks to the lack of film stock and equipment in the late-1910s Soviet Union, early Soviet film-makers built theories of editing based on repeated viewings of DW Griffith's Intolerance (1916) and The Birth of a Nation (1915). Through these viewings and later experiments, they discovered 'it was possible to create, solely through montage, a cinematic terrain that existed nowhere in reality [...]. [Lev] Kuleshov decided to term the effect "artificial landscape" (also known as "creative geography")' (Kuleshov 1974: 5-6). The narrative usefulness of creating 'the cinematic illusion of spatial and temporal unity' (Cook 1996: 137-38) emerges clearly out of the films the Soviets watched to build their theory: the last-second rescue in The Birth of a Nation generates its suspense precisely because the locations of the cabin and the Klansmen on horseback are connected through editing. Stavros Alifragkis and Francois Penz point out that 'creative geography' was in fact 'originally coined for use with continuity editing' (2015: 42), rather than for use with the intellectual montage associated with Soviet film-makers like Sergei Eisenstein. Unlike the way intellectual montage's meaning emerges metaphorically, in the disjoint between two images, creative geography generates meaning instead by creating the sense of seamless movement through time and space, in the sequential accretion of events and locations.

Continuity editing prevails in Hollywood, and the creative geography that appears throughout Hollywood films creates coherent cause-effect narratives and location worlds. Thom Anderson's 2003 documentary Los Angeles Plays Itself unearths a number of Los Angeles' identities through its film history. As he argues in the film's narration, 'If we can appreciate documentaries for their dramatic qualities, perhaps we can appreciate fiction films for their documentary revelations'. In doing so, Anderson provides a model of history that uses creative geographies as its starting point. Sometimes this takes the form of recognizing a city when it pretends to be somewhere else, as when Los Angeles does not play itself, but rather a 'strangely rural' Chicago in The Public Enemy (Wellman, 1931). Other times, location shooting of the city playing itself can generate creative geographies that diminish the city's complexity and internal logic. In an analysis of Death Wish 4: The Crackdown (Thompson, 1987), standing in for slapdash productions more generally, Anderson argues that, 'like dramatic license, geographic license is usually an alibi for laziness. Silly geography makes for silly movies [...]. why shouldn't the exit from a skating rink in Westwood open directly onto Fletcher Bower Square in downtown Los Angeles, 15 miles east?' As a Los Angeles partisan, both The Public Enemy and Death Wish 4: The Crackdown represent, to Anderson, a 'betrayal of the native city'. Much more than 
a concern over continuity or accurately representing the place itself, Anderson's critique of 'geographic license' clarifies how location and meaning are never separate, but inform each other.

The symbiotic nature of location and meaning forms the spine of Los Angeles Plays Itselfs description of the city, using cinema's creative geography to understand the pieces from which it is constructed. In the 'The City as Character' section of the film, Anderson looks at buildings and even neighbourhoods like Bunker Hill that are no longer in Los Angeles, using fiction films for their documentary qualities to reconstruct these lost geographical artefacts. The narrative settings of films provide documentary evidence in the background: 'old movies allow us to rediscover these icons, even to construct a documentary history of their evolution'. Francois Penz says much the same about French cinema and French cities:

[T] he French New Wave cinema offers material of great archival value to architectural and urban historians, often by letting the camera run for several seconds over street scenes with no fictional action, using wide angles, deep focus and long shots as in the tradition of the Italian neo-realist movement.

In Los Angeles Plays Itself, Anderson calls looking at the city in the background of films as a 'city symphony in reverse'. Anderson traces the creation of multiple - and sometimes lost or forgotten - Los Angeles through film editing's creative geography. The broader set of Hollywood films, box office hits and prestige pictures, similarly function as a national symphony in reverse, a symphony that plays some notes - New York, Los Angeles, the Wild West - more than others, as data visualizations of narrative locations show.

I have spent a bit of time concentrating on establishing shots and creative geography because what Maltby and Nadel call the locations, institutions, the Establishment, and imaginary spaces in which films take place - literally and ideologically - first appear in establishing shots. The shot of Monument Valley stands in not only for the physical boundaries of the Edwards family's ranch in The Searchers (Ford, 1956), but also for the ideological boundaries of the Western genre. The pastel-coloured tract houses all in a row in Edward Scissorhands (Burton, 1990) establish the unnamed suburban setting and the suburban closed-mindedness that Edward has to face. This conflation of spaces and ideologies begins with an establishing shot, an image that visually represents a set of assumptions not just about the landscape and/or built environment, but also about the ways of making sense of such a world. Maps of the narrative locations of a large set of films should, at worst, fruitfully misread that history in a way that calls attention to previously unasked questions. At their best such maps can show consistencies and differences in narrative settings and generate the questions that would complicate understandings of what - or better yet, where - the boundaries of the imaginary space and geography of 'America' mean in Hollywood cinema. 
A map can make the familiar unfamiliar at a variety of scales. In the introduction to Infinite City: A San Francisco Atlas, Rebecca Solnit writes that

[a]s a citizen of this city for some thirty years, I am constantly struck that no two people live in the same city. Your current surroundings exist in relation to your other places, your formative place and whatever place shaped your ethnic heritage and education, and in relation to your role in this current place.

Hollywood films operate in a slightly less highbrow register than Solnit does. Describing the power of Hollywood, Maltby writes, 'To the citizens of Manchester, Melbourne, and Mombasa, America's most recognizable landscapes are those of the Western and the inner city neighbourhood of the crime movie' (2003: 29). Indeed, crime films in the top 50 of box office hits - Bullitt (Yates, 1968), Dirty Harry (Siegel, 1974), The Enforcer (Fargo, 1976), Sudden Impact (Eastwood, 1983), 48 HRS. (Hill, 1982), and Basic Instinct (Verhoeven, 1992) from the top 10, Magnum Force (Post, 1973) from the top 20, The Dead Pool (Van Horn, 1988) from the top 30, and Point Blank (Boorman, 1967) and The Presidio (Hyams, 1988) from the top 50 - share a sense of the city's hills, bay, and built environment. But these ten films do not live in the same city, and cannot show all of San Francisco. To write Infinite City Solnit collaborated with four cartographers, twelve artists, eleven writers, three researchers, and an environmental organization, and film is likewise a collaborative art. Solnit and her collaborators created maps that re-imagine geography by placing seemingly disparate parts of the city in conversation with each other - murders and Monterey Cypresses, to name one pair - to better understand the city's complexity. Similarly, on a national level, placing a decade or more of film narrative locations should not only defamiliarize US geography, but also open it up for the sort of explorations of place identity, place making, and meaning that Solnit and her collaborators model.

\section{Mapping Hollywood as a National Cinema}

What I show, in this book, is that an archipelago of narrative locations makes up the nation that Hollywood cinema imagines. In From Caligari to Hitler, Siegfried Kracauer establishes some of the parameters for understanding a national cinema. He argues, 'The films of a nation reflect its mentality in a more direct way than other artistic media for two reasons: First, films are never the product of an individual [...]. Second, films address themselves, and appeal, to the anonymous multitude' (Kracauer 2004: 5). The anonymous multitude, in this project, is the box office, a connection that Kracauer more or less describes in terms of the 'marketplace of ideas' when he writes, 'To be sure, American audiences receive what Hollywood wants them to want; but in the long run public desires determine the nature of Hollywood films' (Kracauer 2004: 6, 8). But while Kracauer devotes his critical attention 
to matters of psychology, I wish to stay at a distance, to capture the multiple locations and sets of boundaries that make up the United States in Hollywood movies.

Much of the time when Hollywood cinema appears in discussions of national cinema in film criticism, it figures as something that other national cinemas are not. Hollywood cinema appears less frequently as the United States' national cinema (even though Canada, which has its own national cinema, is part of Hollywood 'domestic' box office). Hollywood studio ownership changed from American moguls to multinational corporations, but Hollywood cinema has remained an American cinema. Ian Christie writes in 'Where is national cinema today (and do we still need it)?' that in the late 1920s and 1930s, 'American cinema was not merely one among many: it had already become the mainstream - "the movies" - against which others were and continue to be defined by their localness or national identity' (2013: 21). This trend continued after World War II, since 'in the rest of the world, in the 1940s and 1950s, American cinema was most certainly received as a "national cinema," albeit a particularly powerful one' (Williams 2002: 17). Film critics continue to place Hollywood in opposition to other cinemas. In his investigation of the possibility and meaning of 'European cinema', Thomas Elsaesser notes 'how persistently the different national cinema (sic) have positioned themselves in opposition to Hollywood' and that critics not only repeat this positioning, but ascribe value to it: 'Indeed, in the set of binary oppositions that usually constitutes the field of academic cinema studies, the American cinema is invariably the significant (bad) Other, around which both national and "art/auteur"-cinema are defined' (2005: 16). On a specifically national scale, Susan Hayward establishes the national in French National Cinema in the observation that "Traditionally the "national" of a cinema is defined in terms of its difference from other cinemas of other nations, primarily in terms of its difference from the cinema of the United States (i.e., Hollywood)' (Hayward 2005: 8).

For the United States, from the early twentieth through the twenty-first century, trade followed film. Increasing access to international markets that engage in protectionism whether it is twentieth-century France or twenty-first-century China - works hand in hand with one of the ideological underpinnings of Hollywood film narratives. A Department of Commerce report on runaway productions 'adapted' an essay by Meryl Marshall, Chairman of the Board and CEO of the Academy of Television Arts and Science, to conflate free markets and free people, arguing for Hollywood's ability to spread American values and thereby make the world more free:

American films and television programs have helped promote freedom and democratic values, the same values that encouraged throngs of people throughout the world to rise up and challenge repressive governments, contributing to the end of the Cold War, the destruction of the Berlin Wall, and the events in Tiananmen Square before the crackdown.

(United States International Trade Association 2011: 8) 
A government report repeating an industry's self-representation shows the symbiotic relationship between Hollywood/the market and the government/nation. The ideology of Hollywood cinema emerges from the free market ideology that creates its global reach. Dudley Andrew argues that this shows that 'from the standpoint of economics, there is but one viable national cinema - Hollywood - and the world is its nation' (1995: 54). Half of the twenty highest-grossing films in Japanese box office history are Hollywood films, as are majority of the fifty highest-grossing films in French box office history. Thus, a definitive trait of Hollywood films is their industrial reach. Hollywood's global presence means that its films' 'aesthetic communicability is self evidently transnational [...]. whereas "national" cinemas are triumphant reflections of localized characteristics and conditions' (Cunningham 1983: np).

However, in investigations of national cinemas - including Hollywood - one of the localized characteristics and conditions that does not often figure is location. In Higson's formulation, discursive formations and aesthetic forms, not places, predominate. To examine what he calls 'the cultural identity' of a national cinema, critics must engage with 'the ways in which cinema inserts itself alongside other cultural practices, and the ways in which it draws on the existing cultural traditions of the producing nation, reformulating them in cinematic terms, appropriating them to build up its own generic conventions' (Higson 2002: 61-62). Similarly, Hayward's seven typologies of national cinema do not clearly identify film setting as playing a key role. She identifies narratives, genres, codes and conventions, gesturality and morphology, the star as sign, cinema of the centre and cinema of the periphery, and cinema as the mobilizer of the nation's myths and of the myth of the nation as most likely to effectively enunciate the national (Hayward 2005: 8-9). For Jonathan Rosenbaum, national cinema 'expresses something of the soul of the nation that it comes from: the lifestyle, the consciousness, the attitudes' (2002: 224). This fits in the Kracauer reading that held sway in the 1950s and 1960s, which Elsaesser describes as 'when national cinema connoted a nation's unconscious deep-structure' (2005: 64, original emphasis). Where this deep structure comes from - the nature of the film canon - is a matter of dispute. Andrew Higson notes that 'very often the concept of national cinema is used prescriptively rather than descriptively, citing what ought to be the national cinema, rather than describing the actual cinematic experience of popular audiences' (2002: 53, original emphasis). And Hayward critiques 'a predominant tendency to address the national cinema almost exclusively as those films which have been canonised by critics and historians of film' (2005: 1). Combining box office hits with films that succeeded in generating tokens of prestige can go a long way to avoiding this pitfall to get a sense of what Hollywood presents as 'American', not only in terms of ideology - terrain wellcovered throughout film criticism - but also its geography, something like a cinematic terroir.

I use terroir to illustrate a fairly obvious point that, appropriately enough, appears in Michael Billig's Banal Nationalism. For Billig, a national identity entails being situated physically, within a place, which in turn has a physical relationship to the world; he 
writes, 'Having a national identity also involves being situated physically, legally, socially, as well as emotionally: typically, it means being situated within a homeland, which is itself situated within the world of nations' (Billig 1995: 8). That is, nations are concrete places, and national cinemas emerge from and often take place in those literal places. In this light, the first characteristic to look for in a film would be its setting. Mujeres al borde de un ataque de nervios (Almodóvar, 1988) would take place in Spain; its setting is one aspect that makes it a 'Spanish movie'. Pedro Almodóvar's films are all set in Spain, but not all of Spain. Madrid predominates. Similarly, Hollywood films have a great diversity of locations from which to choose for their 'American' locations, to show what Jonathan Rosenbaum calls 'something of the soul of the nation that it comes from: the lifestyle, the consciousness, the attitudes' (2002: 224).

If we think of films as sources of geographic data of the locations of lifestyles, consciousness, and attitudes, the motifs that reappear in that data begin to resemble what Peter Gould and Rodney White describe in their book Mental Maps (1986). In particular, the pictorial motif of narrative location that audiences receive begins to reveal something like Gould and White's maps of residential desirability, maps that represent the relative desirability of locations in the United States for high school graduates. These maps of where students would most like to move show a degree of coherent regional chauvinism: 10 per cent of the Alabamans interviewed see New England as a desirable location, and Minnesotans feel much the same about the Deep South (Gould and White 1986: 56, 60). How do these Alabamans and Minnesotans come to know other regions if they do not travel extensively? Other American places are made knowable through shared cultural knowledge, of which cultural productions like Hollywood films are a key part. The places and ideas Hollywood narrative locations represent create a key and shared set of images and associations of the nation as it forms and changes over time. The hits and prestige pictures that come out of Hollywood constitute a cinema that gives form to not just the ideological, but also the physical contours of the United States.

\section{The Oscars and the Geography of African American Prestige Films}

If there is an accepted measure of 'greatness' for Hollywood films, beyond box office returns, it is most likely the award that the industry gives itself, the Oscar. For as easily dismissible the Oscars are, they retain some cultural capital, either as an affirmation of what Hollywood does well or what it has a great deal to work on. One measure of the Oscars' importance appears in the ceremony's television ratings. In the last quarter of the twentieth century, about forty million people watched the annual ceremony; only series finales like $M^{\star} A^{\star} S^{\star} H$ and Dallas and the Super Bowl saw larger audiences. In terms of box office, a 2001 piece in Economic Inquiry 'What's an Oscar Worth?' by Randy Nelson, Michael Donihue, Donald Waldman, and Calbraith Wheaton calculates that 'controlling for release date $[. .$.$] a nomination for best supporting actor/actress, best actress/actor,$ 
and best picture increases predicted box office revenues by $\$-147,131, \$ 476,617$, and $\$ 4,799,118$, respectively; the corresponding increases for an award are $\$ 1,612,939$, $\$ 4,035,023$, and $\$ 12,690,035$, respectively' (2001: 15). Another $\$ 12$ million for a film budgeted near the 1990s average budget of close to $\$ 60$ million would represent the cultural capital an Oscar represents turning into a wider audience.

Much of the criticism of the Oscars centres on their tendency to reward particular sorts of films and performances. In Bowfinger (Oz, 1999), frustrated over not getting Oscar recognition, Kit Ramsay (Eddie Murphy) sums up the Hollywood (and American) folk knowledge about how to win an Oscar, telling his agent,

White boys get all the Oscars. It's a fact. Did I get a nomination? No. And you know why? Cause I ain't played none of them slave roles and get my ass whipped. That's when you get the nomination. Black dude play a slave role or get his ass whipped he get the nomination. White boy play an idiot he get the Oscar. Maybe I should play - find me a script with a retarded slave, then I'll get the Oscar [...]. Go find that script. Buck the Wonder Slave.

Tropic Thunder's (Stiller, 2008) 'never go full retard' speech, delivered by a blackface Robert Downey Jr. as the extreme Method-acting Kirk Lazarus, enumerates examples of white actors who prove Ramsay's thesis (we might also add 'with drug/alcohol problem' and 'person with disability'). Such performances tend to visibly register if not the best acting, then at least the most acting, which fits into the taste regime that the Oscars help to establish. As Gillian Roberts puts it, 'Generally speaking, the kind of filmmaking celebrated by the Oscars corresponds to [Pierre] Bourdieu's characterization of middlebrow culture, namely as one that offers a negotiation between the accessibility of low culture and the prestige of high culture' (2003: 157).

Middlebrow films like Oscar nominees seek to create the greatest overlap in the Venn diagram of crowd-pleasing and critical acclaim. However, the usual route Hollywood films take to tackle the 'important' subjects that succeed in Oscar season leads to a distinct formula, what Manny Farber called 'white elephant art' (1971) and what Dwight MacDonald called 'Midcult' (1983). This approach, which MacDonald argues reveals 'something damnably American', has come about because the masses 'have come to demand such trivial and comfortable cultural products' (1983: 59, 72). Gordon Hutner's What America Read: Taste, Class, and the Novel, 1920-1960 deals with the Midcult books (and even some of the same authors) that McDonald dismisses in 'Masscult and Midcult'. But Hutner sees something important in those novels: 'Strongly pedagogical, these novels often meant to shape public awareness of cultural values as well as individual pursuits, and how they came together' (2009: 1). The case of Booth Tarkington's negligible place in the literary canon in light of the very good reviews books like Alice Adams received when published leads Hutner to argue that 
[i]t is impossible to say that Tarkington has been intentionally marginalized [...]. Tarkington is largely forgotten because the America he is said to have pictured so faithfully has been so thoroughly obliterated, whereas the America of Fitzgerald and Faulkner is imaginatively preserved. Why is this so?

Most Hollywood films imaginatively preserve their eras' middle-of-the-road vision and version of America. The films that receive Oscar recognition - as nominees or as winners - accordingly tend to register what Hutner calls the 'dull centrism of American democratic thought' (2009: 7) and what Farber calls, slightly less charitably, 'smarmy compassion' (1971: 140). Prestige pictures not only imaginatively preserve a particular formal approach to represent what happens to whom, but also where it happens.

I analyse Malcolm X (Lee, 1992), its narrative locations, and its relationships to other Oscar-nominated films and US history to provide an overview of how I will approach the history of Hollywood cinema. A very small number of African Americans and films about African Americans have been nominated for best picture, acting, directing, writing, editing, and musical contribution Oscars since 1960 (the lack of African Americans nominated in the technical categories underscores their exclusion from the industry). Sidney Poitier won the Best Actor award for Lilies of the Field (Nelson, 1963), the first black performer to win since Hattie McDowell in 1939, and two 'conscience liberal' films in which he played the lead, In the Heat of the Night (Jewison, 1967) and Guess Who's Coming to Dinner (Kramer, 1967), were nominated for Best Picture in 1967. The 1970s saw one film with an African American lead nominated for Best Picture, Sounder (Ritt, 1972). In the 1980s A Soldier's Story (Jewison, 1984), The Color Purple (Spielberg, 1985), Mississippi Burning (Parker, 1988), Driving Miss Daisy (Beresford, 1989) all dealt with African American life, but all were directed by white directors from Canada, the United States, England, and Australia respectively. The only African American nominee for Best Director in the twentieth century was John Singleton, for the Los Angeles-set Boyz $n$ the Hood (1991). African American actors combined for 28 nominations in Lilies of the Field, Guess Who's Coming to Dinner, The Great White Hope (Ritt, 1970), Lady Sings the Blues (Furie, 1972), Sounder, Claudine (Berry, 1974), Ragtime (Forman, 1981), An Officer and a Gentleman (Hackford, 1982), Cross Creek (Ritt, 1983), A Soldier's Story, The Color Purple, Round Midnight (Tavernier, 1986), Cry Freedom (Attenborough, 1987), Street Smart (Schatzberg, 1987), Glory (Zwick, 1989), Ghost (Zucker, 1990), Malcolm X, What's Love Got to Do With It (Gibson, 1993), Pulp Fiction (Tarantino, 1994), The Shawshank Redemption (Darabont, 1994), Jerry Maguire (Crowe, 1996), The Green Mile (Darabont, 1999), and The Hurricane (Jewison, 1999). In other categories, African Americans were nominated for Best Documentary (Adam Clayton Powell [Kilberg, 1989] and 4 Little Girls [Lee, 1997]), Best Screenplay or Adapted Screenplay (A Soldier's Story, Do the Right Thing [Lee, 1989], Lady Sings the Blues, Sounder), Best Editing (Midnight Cowboy [Schlesinger, 1969]). Finally, African American composers were nominated for Best Score eight times, and thirteen times for Best Song (Map 1). 
Location figures prominently in the two Poitier films nominated for Best Picture. ${ }^{3}$ Racial politics in In the Heat of the Night and Guess Who's Coming to Dinner are overdetermined, and location plays a part in this. Sparta, Mississippi in In the Heat of the Night and San Francisco in Guess Who's Coming to Dinner indicate the kind of political climate facing African Americans. San Francisco, as a cosmopolitan city, makes the Drayton family's inability to live up to their avowed political stances comic (and slightly pathetic) rather than disturbing. On the other hand, the wider cultural vision of the 'native', 'ingrained' bigotry of a place like Sparta makes the mistreatment of Virgil Tibbs (Poitier) as predictable as it is unjust. The map of narrative locations for the films for which African Americans were nominated for an Oscar alternates between the San Franciscos and the Spartas (with the odd international location). East-coast cities, west-coast cities, and especially the non-urban south constitute the majority of narrative locations for Oscarnominated films featuring African American performers and crew. Paula Massood writes that the frequency of urban settings for films featuring African American performers and telling African Americans' stories reveal 'the ways in which the history of AfricanAmerican movement and migration, and the rising importance of urban spaces in Black life contributed to contemporary Black popular culture, especially (though not limited to) the cinematic representation of African-American urban experiences' (2003: 203-204). In terms of specific urban settings, New York City appears across the 1970s, 1980s, and 1990s, but with the exception of parts of The Great White Hope and Lady Sings the Blues, the Oscar-nominated films set in the Los Angeles area are all from the 1990s; both cities have 'long histories of African-American occupancy and cultural (although not always material) ownership' (Massood 2003: 200). ${ }^{4}$ Southern small towns appear in the 1960s in To Kill a Mockingbird (Mulligan, 1962), In the Heat of the Night and The Reivers (Rydell, 1969), in the 1970s in Sounder, in the 1980s in Cross Creek, and the 1990s in What's Love Got to Do With It. Southern cities appear in Driving Miss Daisy (Atlanta, Georgia), 4 Little Girls (Birmingham, Alabama). As for the rest of the map, four regions are almost invisible the mountain west, the Pacific Northwest, the plains, and the industrial Midwest - often represented by only one film. Parts of An Officer and a Gentleman take place near Seattle. Jerry Maguire splits its time between Los Angeles (where Jerry works) and Phoenix. Chicago only appears briefly in 1993's What's Love Got to Do With It.

Given that it took until 2014 for a Hollywood film to be made about Dr Martin Luther King, it is not surprising that no films were made about most of the key moments in the Civil Rights movement in the 1960s and 1970s. But even as a trickle of films began to appear, their locations centred on the east and west coasts and the south. These locations create an impoverished image of the reach of the Civil Rights movement and African American life in the United States. As the National Park Service describes its National Register of historic places of the Civil Rights movement,

In visiting the 49 places listed in the National Register for their association with the modern civil rights movement, as well as the Selma-to-Montgomery March route - a 
Department of Transportation designated 'All-American Road' and a National Park Service designated National Historic Trail - two things will be apparent. First, although they had white supporters and sympathizers, the modern civil rights movement was designed, led, organized, and manned by African Americans, who placed themselves and their families on the front lines in the struggle for freedom. Their heroism was brought home to every American through newspaper, and later, television reports as their peaceful marches and demonstrations were violently attacked by law enforcement officers armed with batons, bullwhips, fire hoses, police dogs, and mass arrests. The second characteristic of the movement is that it was not monolithic, led by one or two men. Rather it was a dispersed, grass-roots campaign that attacked segregation in many different places using many different tactics.

(NPS 2015: para. 8)

The dispersed movement encompasses places like Little Rock, Arkansas, Topeka, Kansas, and Norman, Oklahoma where the African American community fought for equal access to education (Map 2). None of these places appear in Hollywood's imagination of African American life in the United States, and this book looks to explore and to understand the reasons behind these kinds of omissions and what that means for the boundaries of not just what, but where America means in Hollywood cinema (Map 3).

Poitier was at the centre of two of the five films nominated for Best Picture in 1967, but a film that engaged in any depth with African American life did not appear for another five years, Sounder, and subsequently not for more than ten years after that (more Swedish films were nominated for Best Picture during the same time). This disappearance from the industry's self-generated measure of greatness coincides with the continued social unrest and rioting that occurred after the Watts riots in 1965 and continued through 1967 across the country. In the summer of 1967, President Lyndon Johnson established the National Advisory Commission on Civil Disorders to study the causes of the widespread rioting. The report pays particular attention to urbanization and economic opportunity, noting that 'migration from the South will continue unless economic conditions there change dramatically' (Kerner Commission 1968: 6). In the report's 'Summary' section four data points describe the changing composition of cities in terms of African American migration from the rural south to urban centres, suburbanization, and white flight:

- Almost all Negro (sic) population growth (98 per cent from 1950 to 1966) is occurring within metropolitan areas, primarily within central cities.

- The vast majority of white population growth (78 per cent from 1960 to 1966) is occurring in suburban portions of metropolitan areas. Since 1960, white centralcity population has declined by 1.3 million.

- As a result, central cities are becoming more heavily Negro while the suburban fringes around them remain almost entirely white. 
- The 12 largest central cities now contain over two-thirds of the Negro (sic) population outside the South, and almost one-third of the Negro (sic) population total in the United States.

(Kerner Commission 1968: 6)

When the report breaks what it calls the 'disorders' down by national region, the East and Midwest account for almost three-quarters, and seven of the eight most violent and deadly riots (Kerner Commission 1968: 66). The size of city is quite varied, with an almost equal number of disorders occurring in cities under 50,000, from 50 to 100,000, from 100 to 250,000, and from 250 to 500,000 (Kerner Commission 1968: 66). The areas the report focuses its attention on in Chapter 1, 'Profiles of Disorder', are accordingly all in the eastern half of the country: Tampa, Cincinnati, Atlanta, Newark, northern New Jersey, Plainfield, New Brunswick, and Detroit (Map 2). The majority of locations analysed in the Kerner Report do not appear in any of the Oscar-nominated films that imagine African American life in the United States (Map 3).

Malcolm $X$ adheres to biopic conventions by following its subject across multiple locations, combining urban north-east settings with flashbacks to the Omaha, Nebraska of the 1920s, as well as a sequence in Mecca. Most of the film takes place in New York City, but a significant portion of it - the scenes that reveal some of Malcolm's psychologically formative experiences - occurs in a location no other Oscar-nominated film uses, Omaha, Nebraska, which stands out visually with its sepia tone and clothes that show the financial stress the Little family faced. Omaha presents a key entry in Malcolm X's politics. Nell Irvin Painter begins her essay 'Malcolm X across the genres' (1993) in the movie theatre.

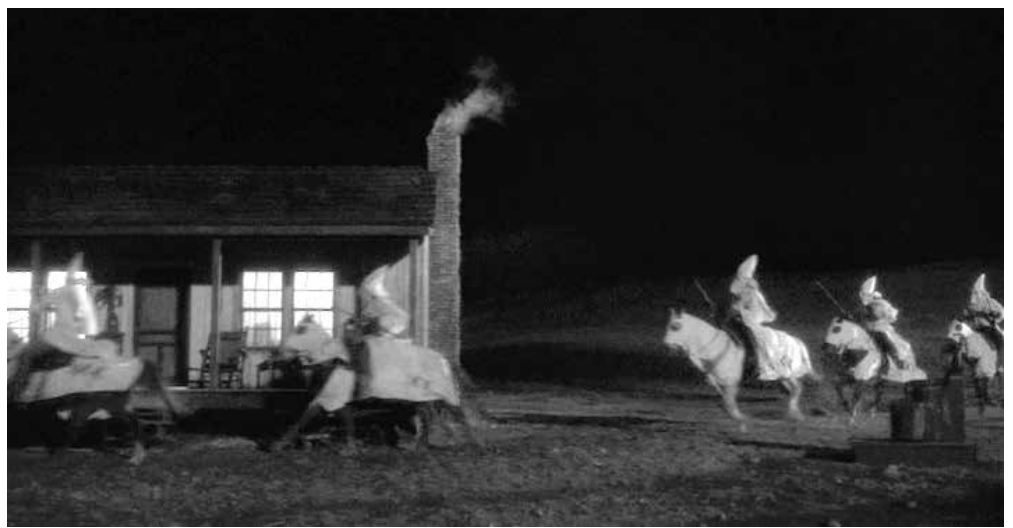

Image 1. Malcolm X in Omaha, Nebraska. 
'The historian in me', she writes, 'distrusted a dramatic early scene in Spike Lee's Malcolm $X$ that is set in Omaha. The Ku Klux Klan comes pounding up to the Little family's house on horseback' (1993: 432). Painter's description of her distrust bears quoting at length:

as soon as one recalls that this is supposed to be Omaha, Nebraska, in the 1920s, the sense of realism breaks down. I assumed this to be yet another employment of the iconography of southern white supremacy, which Americans still think of as the real white supremacy, to advance a narrative of black life anywhere in the United States [...]. Once more in film, or so it appeared, D.W. Griffith's images cancel out the unlikelihood of the twentieth-century, Midwestern, urban Klansmen making their rounds by horse. But I was wrong to think that Spike Lee had followed the dictates of film school; the image was not Lee's at all. The Autobiography of Malcolm X opens with this very scene. Lee and his screenwriters were following Malcolm X as though what he had said was history, which it was not.

(1993: 432, original emphasis)

Painter's introduction locates the source of her distrust geographically, and the short essay moves around the United States and the world. The Omaha setting exposes the tendency to place white supremacy exclusively in the south, for, 'if Malcolm X is to work as a racial symbol, it is best not to look at him too closely' (Painter 1993: 433). One sequence cuts Malcolm delivering a speech about the right to self-defence impressionistically against footage of lynching victims, police turning fire hoses on protestors, and Dr Martin Luther King. And, after Malcolm's assassination, his eulogy is read over a series of archival images, including a series that moves from George Wallace in the school house door to prevent the National Guard ensuring students' access, to a still of a man wielding the US flag on a pole as a weapon. This shift from the early 1960s south to a well-known image of racial violence outside of the south - in mid-1970s Boston during an anti-school integration protest - occupies four seconds between separate sections of archival footage of Malcolm himself, but in those four seconds Malcolm $X$ signals the necessity to locate American racial politics in more than the usual locations. Not only outside the south, in places like Boston and Omaha, but also globally, as when children in both the United States and Soweto say 'I am Malcolm X', and Nelson Mandela repeats Malcolm's words at the close of the film.

Malcolm $X$ resembles Studio and Classical-Hollywood biopics, as it is interested in a major political figure, rather than its contemporaries, which more frequently focus on an entertainer. Malcolm X did better at the box office than the other 1992 Hollywood biopics, the more traditional Hoffa (DeVito, 1992), The Babe (Hiller, 1992), and Chaplin (Attenborough, 1992). Of the three leads in the other biopics, only Robert Downey, Jr as Charlie Chaplin joined Denzel Washington as a Best Actor Oscar nominee. While Spike Lee's signature shot - the backwards-travelling shot that makes its subject appear to glide - appears to great effect, one of the key recurrent formal aspects to Malcolm X is 
Introduction: Where Is Hollywood Cinema?

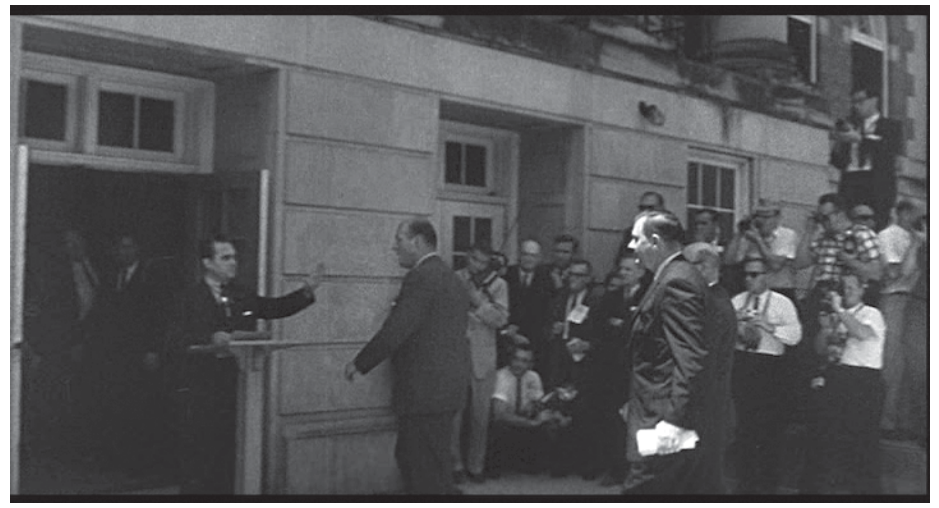

Image 2. Malcolm X George Wallace in the school house door.

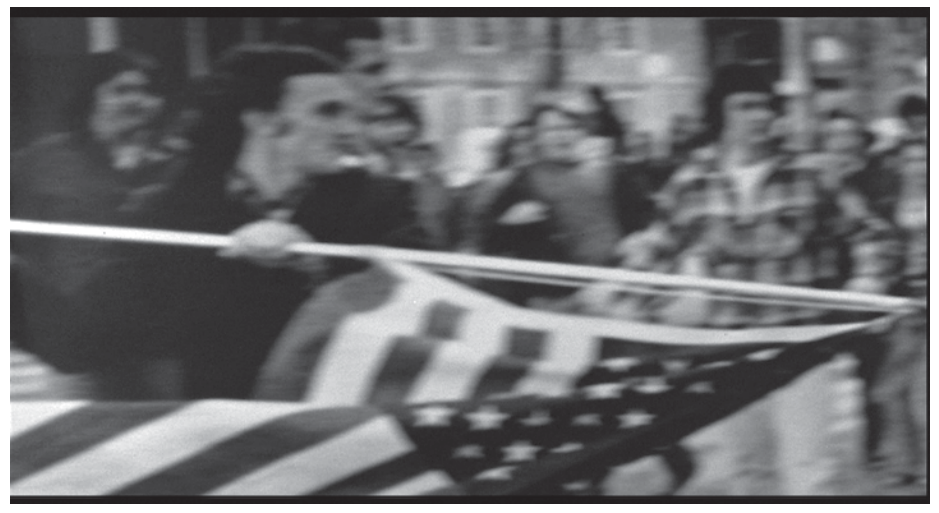

Image 3. Malcolm X US flag at Boston bussing protest.

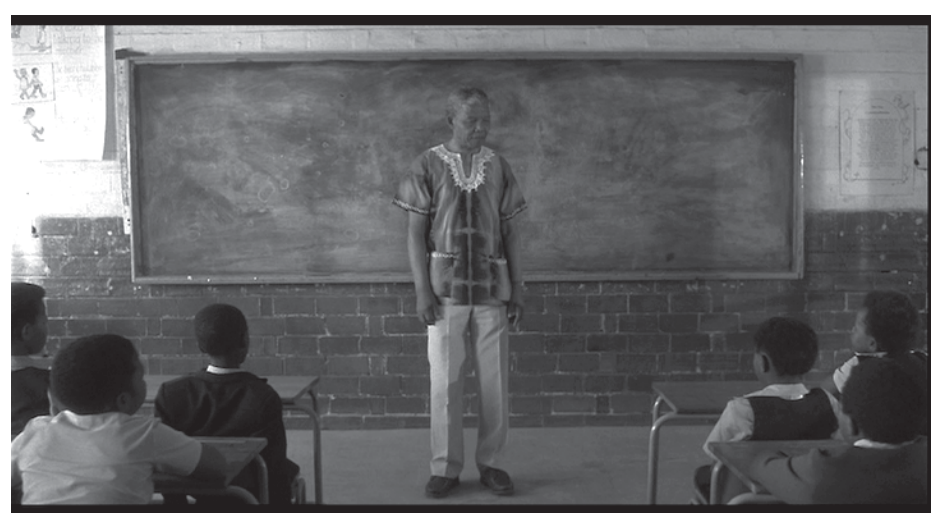

Image 4. Malcolm X Nelson Mandela. 
Lee's use of horizontal tracking/travelling shots that distinguish it from the other biopics. As in so many of the biopics, a cast of thousands forms around the biographical subject figure. The Babe has its Yankee Stadium, Hoffa its union halls, and Chaplin its movie sets, all of which are crowded with people. Other biopics of African American figures - the Oscar-nominated Lady Sings the Blues and What's Love Got to Do With It - use the concert tour to move around the country, but do not create spaces in the manner Lee does. At a number of key points in the film, as when Malcolm walks from police station to hospital with a crowd building behind him, Lee uses a travelling shot that follows Malcolm as he walks with a group of people, connecting Malcolm to the large number of people around him - in short, building a movement visually. The repeated horizontally-moving shots in

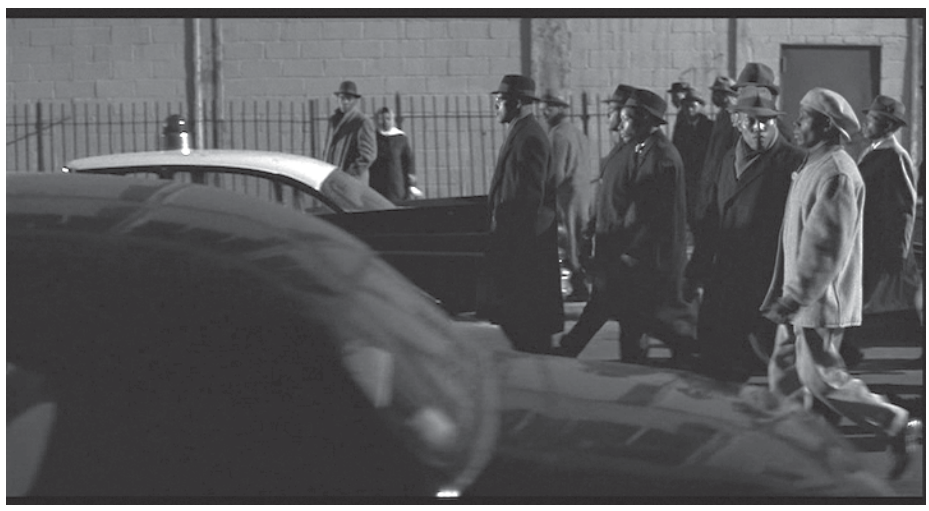

Image 5. Malcolm X travelling shot in crowd, scene 1.

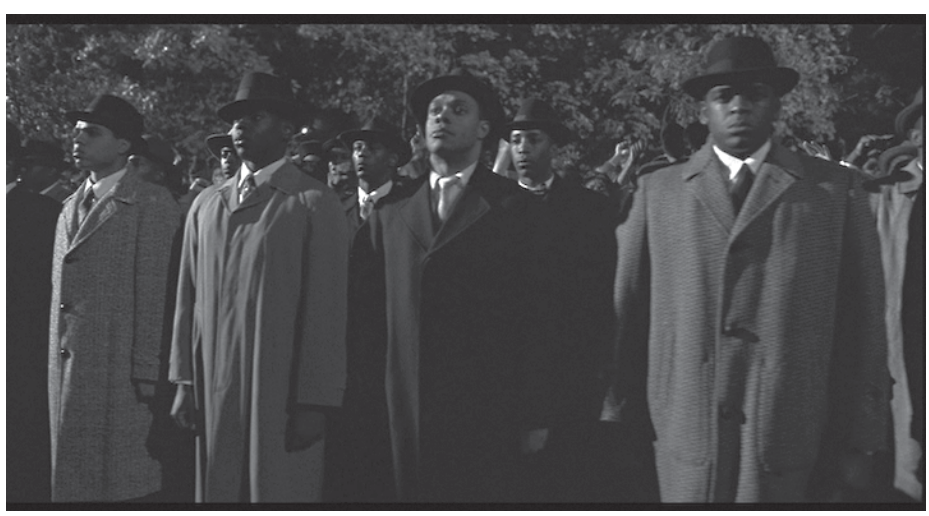

Image 6. Malcolm X travelling shot in crowd, scene 2 . 
Malcolm $X$ show, at multiple important moments of political action, crowds filled with black faces. Such shots function formally and ideologically, engaging with film history to show how even extras have defined Hollywood racially, and also making places like Harlem unmistakably 'black spaces' on screen and on the map.

This brief look at Malcolm X thus shows how looking first at narrative location can inform the selection of a film as worthy of analysis, and how maps of contemporary political and cultural phenomena can provide context with which to analyse the film. In addition, such an approach can also reveal not just where Hollywood locates its stories, but also where it does not locate them, which can open up room for investigations of non-Hollywood films in a comparative framework. Through the rest of this book, I consider the ways in which Hollywood films imagine an American ideology as connected to particular and shifting American and Americanized locations.

\section{Book Overview}

In the first chapter, 'Burt Reynolds Brings the New South to Hollywood', I argue that Burt Reynolds is the essential 1970s movie star because his films, more than any other performer or director, represent - which is to say they take place in - the 1970s' key region, the south. Reynolds may not occupy much space in the critical literature, but his hits throughout the 1970s show Hollywood adjusting to the south's increased economic and cultural importance. Reynolds' films replace the rural, agrarian, hillbilly, and racially segregated south with an urbanizing and suburbanizing south moving slowly out of its fraught past, a change that consistently appears in Reynolds' films, but in few other Hollywood hits. Reynolds' films are set in the heart of the nation's shift towards a more southern centre of gravity, making him more than the regional star of a cycle of Southsploitation films. Burt Reynolds, I argue, is the quintessential 1970s star because he is southern.

Burt Reynolds represents Hollywood's clearest example of mainstreaming of the south, a region New Hollywood film-makers either avoided or treated with scorn. In 'New Hollywood, the Contemporary Midwest, and Collective Action' I turn to two groups of films, road movies and Midwestern-city set films, to understand the fairly conservative individualist politics of the New Hollywood. Road movies take place in a landscape of oil and extractive industry infrastructure that stretches across the country, in California, Louisiana, Montana, and Alaska, showing that the individual conflicts that the road trip confronts and the freedom the road offers are locked into an oil-driven economy that would destroy that freedom, both in terms of film form and also national politics. Two New Hollywood films that are set away from the landscape of natural resource extraction, in contemporary Midwestern cities, move closer to a collective subject to confront largerscale political problems. Medium Cool (Wexler, 1969) and Blue Collar (Schrader, 1978) imagine Chicago and Detroit as places where collective political action might take place, although the success of that collective action seems unlikely. 
The New Hollywood's box office successes helped the studios to survive the end of the 1960s and 1970s, but by the end of the 1970s, a different sort of film held sway: the summer blockbuster. 'Getting Around the Suburbs in the Blockbuster Era's Big Hits' reconsiders the suburbs and the suburban in top-ten box office hits during the blockbuster era, between 1975 and 1992. Blockbuster movies appeal to a sub-urbane taste regime, but that regime shows a consistent tendency to locate its films outside of suburban settings. The top-ten hits of the blockbuster era that are set in the suburbs engage with the everyday life of children and adolescents in suburbia, and naturalize its advantages, but they also acknowledge the suburbs' shortcomings and affection for the city in terms of how children and adolescents navigate suburban space and the literal and figurative distance between cities and suburbs. Suburbs-set top-ten hits such as E.T.: The Extra-Terrestrial (Spielberg, 1982), Poltergeist (Hooper, 1982), The Bad News Bears (Ritchie, 1976), The Karate Kid (Avildson, 1984), The Amityville Horror (Rosenberg, 1979), Risky Business (Brickman, 1983), Ferris Bueller's Day Off (Hughes, 1986), and Wayne's World (Spheeris, 1992) show how the experience of moving around the suburbs can move both physical and ideological horizons of possibility, revealing that neither suburb nor city entirely embodies the periphery-centre, home-work, and responsibility-fun binaries that often organize discussions of suburbia.

When American suburbanites weren't navigating around their metropolitan regions, many of them watched films on video more frequently than they went to the theatre. In 'Politics for Couch Potatoes: Video Rental Success Stories', I turn to films that were not hits in theatres, but had success as video rentals. The success on video of The Flamingo Kid (Marshall, 1984), Gorky Park (Apted, 1983), The Emerald Forest (Boorman, 1985), and Under Fire (Spottiswoode, 1983) seems slightly unexpected, and not just because none of the four performed well in theatrical release. All four films also run counter to 1980s Reaganite ideology, in both domestic and especially foreign policy, offering an alternative to the dominance of conservative politics at the box office, and qualify the otherwise convincing story of the rise of Reaganite politics in Hollywood cinema when it comes to home entertainment. These video hits locate their politics in less-known places they make more knowable, and in the process of making spaces like private beaches outside New York City, Moscow, the Amazon rain forest, and Nicaragua accessible, smuggle in a reformist, anti-Reaganite ideology.

While my analysis of films set in suburbia concentrates on the suburban fringe of the United States' largest cities, 'Imagining More for Medium-Sized Cities, 1975-2000' analyses medium-sized cities, which is to say from the twenty-first to one-hundredthlargest cities as they appear in prestige films. While most prestige films set in mediumsized cities represent them as something close to single-biome planets like 'The Ice Planet Hoth' and 'The Forest Moon of Endor', such films also represent their medium-sized cities as centres, usually in terms of the city's single-biome appeal. While the films in this chapter push at the edges of their city's identity, they return to the importance of their single-biome planet identity, retaining music for Nashville in Nashville (Altman, 1975), Coal Miner's Daughter (Apted, 1980), and Wag the Dog (Levenson, 1997); gambling and 
glitz for Rain Man (Levenson, 1988), Bugsy (Levenson, 1991), and Casino (Scorsese, 1995); and steel and bridges for Groundhog Day (Ramis, 1993), Kalifornia (Sena, 1993), Bob Roberts (Robbins, 1992), and Wonder Boys (Hanson, 2000), which shows the difficulty in changing a city's identity. However, Wonder Boys shows the first steps of Pittsburgh's change from steel to service economy, the rare case of imagining a new identity - a sequel - for a medium-sized American city.

Finally, I turn away from United States locations to consider international locations in relation to a definitive slice of Americana, Disney. In 'Not Such a Small World After All: Disney Live-Action Films in the 1960s', I analyse Disney live-action films set outside of the United States. For In Search of the Castaways (Stevenson, 1962), Bon Voyage! (Neilson, 1961), and Monkeys Go Home! (McLagen, 1967), non-US locations are essential both narratively and ideologically, which means their narrative locations retain a distinctly local identity. Recognizing the specificity of their non-US settings allows these films to establish a triumphant American identity. The children's adventure In Search of the Castaways offers a detailed misrepresentation of Māori civilization; the family comedy Bon Voyage! places a salt-of-the-earth Midwesterner in France, where he can demonstrate American values to foreigners and cosmopolitans alike. Finally, the trained chimpanzee picture Monkeys Go Home! makes its case for American imperialism, but only after taking French cultural chauvinism seriously. By moving outside the United States' literal boundaries, Disney live-action films imagine the universal reach of an American ideology that is necessary precisely because other countries are, for the most part, so unlike small-town America.

After looking at the geography of places that do appear in hit movies and prestige pictures, in the conclusion I briefly consider the places that do not appear in maps of Hollywood films' narrative locations. The invisibility of the nation's twenty poorest counties is depressing but not exactly surprising. Beyond the country's poorest rural spaces, the absence of locations like Anchorage, Alaska, the Dakotas, Delaware, Michigan's Upper Peninsula, and Salt Lake City, Utah removes those places - and the people who live there - from not only the map of Hollywood settings but also the cultural imaginary. This invisibility, when paired with the century-long prevalence of New York and Los Angeles as major narrative settings, pushes these places into a particular vision of the past. By not appearing in widely seen Hollywood films since the 1960, these locations begin to occupy much less space in the popular imagination of what constitutes 'America'.

The geography of box office hits and prestige pictures that this book maps - both literally and critically - presents a new way of understanding the ways in which film narratives informed, represented, and came to terms with the changing spatial contours of America and American identities throughout the second half of the twentieth century. To begin with where re-orients critical attention, and locates arguments about the meanings of Hollywood cinema in sets of films previously sidelined or unengaged in film histories. To begin with where registers sets of literal locations that constitute the Hollywood cinema that audiences see, and starts to write the histories of the people, landscapes, boundaries, and ideologies that these films put on screen as 'America'. 



\section{Chapter 1}

Burt Reynolds Brings the New South to Hollywood 

B urt Reynolds' films, on the surface, address a particularly southern, regional, audience. But movie stardom, like a successful presidential campaign, expands from a regional stronghold to cover more of the entire map. Reynolds the movie star temporally and culturally bridges the period from Nixon to Reagan so perfectly by representing the changing orientation of American identity, not just in terms of ideology the reddening of America - but also in terms of physical space - the key region, its weather, architecture, and urbanization. Yet critical respect and Reynolds are near strangers to each other. Despite the fact that, by many measures, Reynolds was the most important movie star of the 1970s - indeed one of the most significant stars in Hollywood history his work and his career have rarely received careful attention. This is a mistake. Reynolds' movies brought to artistic realization a crucial social and political transformation in the post-war United States. Both his extraordinary success in the 1970s and his critical neglect since are symptomatic of this momentous transformation. Reynolds brought America the New South. Once the region came, during the Reagan era, to seem merely representative of the American nation as a whole, Reynolds' cultural relevance was over.

Stanley Cavell, in trying to understand changes in comedies of remarriage from their apogee in the 1930s to the 1970s, claims that,

I believe An Unmarried Woman is generally thought to be a better film than Starting Over, the comparison invited by the presence in both of Jill Clayburgh as the female lead. I think the reason for that opinion is a reluctance on the part of people of a certain cultivation to see how charming and perceptive a leading man Burt Reynolds can be, when not cast as a good old boy.

(1990: 26-27)

Cavell moves straight into an analysis of Kramer vs. Kramer (Benton, 1979), and Reynolds doesn't make another appearance in the book. Academic film criticism's reluctance to look at Reynolds appears in a standard MLA Bibliography subject search: 'Burt Reynolds' gets one hit. Other 1970s movie stars-turned-directors have garnered more critical attention: in a 2016 MLA search of their name as subject, Clint Eastwood generated 91 hits, Robert Redford 28, and Barbara Streisand 18.

Cavell's somewhat tossed-off line about how academic criticism treated/treats/would treat Reynolds describes perfectly the way Paul Young, in Fifty Key American Films, 
invokes his home-town theatre's extended run of Smokey and the Bandit (Needham, 1977), a run that squeezed out any chance of showing Star Wars (Lucas, 1977) (2009: 177-84). Young uses this anecdote to position his home town as not up-to-date. However, it was in no way weird for Centerville, Iowa's Majestic Theater to keep playing Smokey and the Bandit because Burt Reynolds was a gigantic movie star in 1977, with a track record of recent success that sci-fi could not match. ${ }^{5}$ Stars, Richard Dyer reminds us in Heavenly Bodies, 'are made for profit. In terms of the market, stars are part of the way films are sold' (1986: 5). Reynolds was one of the top-ten box office draws every year between 1973 and 1982, inclusive. Reynolds sold cultural power throughout the 1970s.

Dismissing Reynolds as just another good old boy means that he and his films do not show up in introductory-level film text books - David Bordwell and Kristin Thompson's Film Art (2010) has no mention of Reynolds, nor does James Monaco's How to Read a Film (2000). In cinema history, Reynolds has a greatly reduced profile. The decadespanning Hollywood Reborn: Movie Stars of the 1970s (2010), has a chapter on Divine (who starred in a total of three films in the decade), but not one on Reynolds; David Cook's The History of the American Cinema: Lost Illusions: American Cinema in the Shadow of Watergate and Vietnam,1970-1979 (2000) makes a few brief mentions of Reynolds, but nothing longer than one sentence. It's quite curious that Susan Jeffords' Hard Bodies: Hollywood Masculinity in the Reagan Era (1994) does not mention Reynolds at all - even though he was a box office champ and a sex symbol who posed for a centrefold in Cosmopolitan. Taking Burt Reynolds seriously reveals Hollywood coming to terms with the changing centre of gravity for American identity and moving towards a greater investment - narrative and institutional - in the south. In the history of Hollywood cinema from New Hollywood through the early years of the age of the blockbuster, few figures, if any, can match Reynolds' underappreciated and long-lasting cultural significance.

With Reynolds, Hollywood could pursue its own Southern Strategy. A map of the narrative locations of box office hits between 1970 and 1981 demonstrates that, for box office hits, the American South takes two forms: the past, and Burt Reynolds' playground (Map 4, Map 5, and Map 6). Although the south has often been represented on film as rural, agrarian, hillbilly, and racially segregated, Reynolds' films take place in an urbanized/suburbanized south that is a taken-for-granted political and economic force moving slowly out of its fraught past. Amongst 1970s and early 1980s films, this changing way of life appears almost exclusively in Reynolds' films, and their consistent national success places him at the centre of the United States' changing geography. Burt Reynolds quite literally resides in the heart of the emerging cultural trends of 1970s America - the cultural reddening fed by the rapidly increasing population of the south, generated by the generally non-union Sunbelt economy - that were the products of a geographic shift in the nation's political and cultural centre of gravity. 


\section{The South and the Past on Film}

It seems an oversimplification, but for the most part, for the south on film, the past is rural and the present is urban-suburban. In Dreaming of Dixie, Karen Cox looks at representations of the south through the end of World War II, finding that

regardless of the medium the image of the American south was consistent. Southern belles and gentlemen, mammies and uncles, white columned mansions, fields of cotton, and literally, moonlight and magnolias were employed to suggest Dixie.

(2011: ix)

Cox engages films that span 1915 to 1941, including Birth of a Nation (Griffith, 1915), Gone with the Wind (Fleming, 1939), Shirley Temple's The Little Colonel (Butler, 1935) and The Littlest Rebel (Butler, 1935), the predominantly African American-cast films Hearts in Dixie (Sloane, 1929) and Hallelujah (Vidor, 1929), as well as hillbilly films like Puddin' Head (Stanley, 1941) and Sis Hopkins (Stanley, 1941), and their belles, gentlemen, mammies, uncles, white-columned mansions, fields of cotton, moonlight, and magnolia combine to identify the south as the rural past. While the 1970s present the challenge of a change in approach to film distribution after the Jaws-driven switch from regional booking and road shows to saturation-wide release, the top-20 box office hits throughout the decade present a consistent picture of the rural past-ness of the south.

Between 1970 and 1981, hit movies with a narrative set in the south tend not to deviate from this past-rural/present-urban tendency (Map 5). To run quickly through the hits: Song of the South (Jackson and Foster, 1946, re-released in 1972) is set in antebellum Georgia, on a plantation. Sounder (Ritt, 1972) is set in the early 1930s, on a sharecropping farm in fictional Landsdown, Louisiana. Lady Sings the Blues (Furie, 1972) flashes back to the 1950s south. Ode to Billy Joe (Baer, 1976) is set in 1953, in rural Choctaw Ridge, Mississippi. The Godfather: Part II (Coppola, 1974) is set, among other places, in 1958 Miami. Mid-1970s Southsploitation hit Walking Tall (Karlson, 1973) takes place during the mid-1960s, in rural McNairy County, Tennessee. Lenny (Fosse, 1974) and Coal Miner's Daughter (Apted, 1980) are biopics, by definition a backwardlooking genre. Lenny spends some time in 1960s Miami while Coal Miner's Daughter's path-to-success narrative carries Loretta Lynn out of one rural south and into another. The film's end credits re-narrate Loretta Lynn's life story in terms of location. The film begins in the 1950s, in coal mining Butcher Hollow, Kentucky, then heads to rural Washington state, then, with Loretta's success, makes a stop at the Grand Ole Opry in 1960s Nashville, Tennessee, but leaves the city pretty quickly for the open spaces of the road on Loretta's tour bus throughout the 1970s. The end product of all this effort is the Double-L Ranch in rural Hurricane Mills, Tennessee. Thus, we see in these films a vision of the south as a predominantly rural-small-town place located temporally, at best, in the recent present. 
When the contemporary south appeared in a hit film without Burt Reynolds, it was likely to have either a tourist focus or a rural weigh-station setting (Map 5). The two Bond films Live and Let Die (Hamilton, 1973) and Moonraker (Gilbert, 1979) treat New Orleans and Cape Canaveral with the tourist vision common to Bond films. A group of New England friends vacation in rural Virginia in The Four Seasons (Alda, 1981). Airport '77 (Jameson, 1977) holds out hope for getting to a tourist-destination museum near Miami, but spends much of its time under the water in the Bermuda Triangle. Both The Jerk (Reiner, 1979) and The Muppet Movie (Frawley, 1979) begin in the south before fortuneseeking elsewhere. Few people would recall Deep Throat's (Damiano, 1971) Miami and Fort Lauderdale settings. Little Darlings (Maxwell, 1980) sets its coming-of-age narrative in a rural Georgia summer camp. Brubaker (Rosenberg, 1980) spends most of its time in a rural Arkansas prison farm, and Stripes (Reitman, 1981) is set on a fictionalized Fort Knox-like Army base that prepares the boys for duty in Czechoslovakia. All the President's Men (Pakula, 1976) takes place in the northern Virginia suburbs, but its one extended shot of non-monumental exteriors echoes an earlier shot of the Library of Congress reading room - reinforcing the film's 'claustrophobia' and interest in the things hidden in interiors rather than the 'impossible vision of totality' in exteriors. Only two nonReynolds hit films between 1970 and 1981 are set almost entirely in a contemporary urban south setting - the Sidney Poitier-Bill Cosby caper Let's Do It Again (Poitier, 1975), set in Atlanta and New Orleans, and the Paul Newman vehicle Absence of Malice (Pollack, 1981), set in Miami. All told, of those fourteen box office successes, nine explicitly engage the contemporary urbanized south that had become home to more than 60 per cent of its population. Burt Reynolds, between 1970 and 1981, starred in six films set in the contemporary urbanized south all on his own - with no southern period pieces to link him to the region's past.

\section{Burt Reynolds in the Contemporary South}

In terms of box office success, Reynolds has few peers in 1970s American cinema. Mapping the narrative locations of Reynolds' catalogue of box office hits reveals the geographical territory of his stardom and cultural importance and, it bears noting, also makes visible the quite politically significant southward drift of the national centre of gravity (Map 6). Industry-centric Quigley Publishing, publisher of International Motion Picture Almanac, places Reynolds at number two in 'All Time Number One Stars', tied with Bing Crosby, Clint Eastwood, and Tom Hanks, ahead of John Wayne and Robert Redford, and behind only Tom Cruise (QPMedia 2014). Not every star has as clear a regional identity as Reynolds, and no major star before or since has been so identified with the south. Wayne is a distinctly western star, Eastwood reached stardom through westerns (then moved to San Francisco to become Dirty Harry), and Doris Day had a fair number of New York-set hits, but it is quite difficult to locate other top-ten performers 
like Cruise, Crosby, and Hanks. We can, however, locate where Cruise, Crosby, Hanks, and Day are not: the south.

Burt Reynolds starred in six hits set in the south: Deliverance (Boorman, 1972), The Longest Yard (Aldrich, 1974), Semi-Tough (Ritchie, 1977), Smokey and the Bandit, Smokey and the Bandit II (Needham, 1980), and Sharky's Machine (Reynolds, 1981). He also starred in a trio of region-spanning Southsploitation films, White Lightning (Sargent, 1973) in Little Rock, WW and the Dixie Dancekings (Avildson, 1975) in Nashville, and Gator (Reynolds, 1976) in Savannah. Cannonball Run (Needham, 1981) shares a star, director, screenwriter, and genre, if not a location, with the southern Smokeys, and Hooper (Needham, 1978) transplants its southern good ole boys into Hollywood stunt work. Derek Nystrom, in Hard Hats, Rednecks, and Macho Men: Class in 1970s American Cinema, identifies a 'southern cycle' in American film, invoking the historian James C. Cobb's assessment of the 'crucial part played by Burt Reynolds' various 'good ole boys' roles' in recasting 'working-class white southerners' as 'harmless, fun-loving, and wellintentioned' (2009: 57). For Nystrom, the buried working-class politics of the southern cycle are so strong that they overcome Reynolds' lack of political engagement:

[T] he films of this cycle, for all their conservative elements, were often powered by the radical energies of working-class militancy and solidaristic action as well. Even the apolitical Burt Reynolds defined the typical hero of his films as 'a good ole boy who fights the system with dignity and, above all, a sense of humor.'

Thus for Nystrom, a film can be politically complex where Reynolds cannot. Deliverance's 'encounter and conflict between the hill people and the canoers can be read as the cinematic transcoding of the historical juncture between the civil rights era south and the Sunbelt that came to take the former's place in the national imaginary', while the 'apolitical' Reynolds is simply along for the ride (2009: 71). Yet even here, it is Reynolds' assertion of agency that marks the film's political pivot. It is his Lewis, after all, who takes decisive action when the hillbillies rape Bobby, intervening in the contemporary historical moment. In either case, Reynolds' films are compelling political documents, the very sort of thing major movie stars ought to produce. Reynolds might have had his name above the title in Deliverance, but his career up to 1972 more often found him in supporting roles on television and westerns or the lead in low-budget or exploitation films. After Deliverance, Reynolds was a big star. Whereas the 'where you goin' city boy?' rapists represent the violent hillbilly southerner we must leave behind, Reynolds embodies the type of southerner who will carry the region and the nation forward: a fairly forwardlooking professional-managerial class type with roots in a different soil.

Five years after Deliverance, Reynolds made his first of many films with director Hal Needham, Smokey and the Bandit. Bandit opened the same week as Star Wars and took in $\$ 126$ million at the box office by selling tickets to more than 56 million people, a quarter of the 
nation's population. Smokey and the Bandit was, in fact, a safer box office bet than Star Wars. As Quentin Tarantino says during his commentary track to True Romance (Scott, 2002):

When you listen to [Alabama's] answers to the questions, a little of them seem kind of like cool and retro but when I wrote it they weren't cool and - they were literally [...] [Clarence] says who's your favorite actor? And she says Burt Reynolds, alright? Well, Burt Reynolds was a big star when I wrote this script. You know, he was a star of the people - so it wasn't like this she was being all cool and retro, alright.

Reynolds later explained Smokey and the Bandit's (and his) trans-regional appeal in an interview with Film Comment:

People said to me, 'Smokey and the Bandit will only work south of the Mason-Dixon line.' It grossed $\$ 42$ million in the South, before they even opened it anywhere else. Then they released it up North and it did \$49 million. So they said, 'Wait a minute. We underestimated the North.' Well, we realized what we're doing was underestimating the film. It's funny, and funny is funny.

(McBride and Riley 1978: 20)

Reynolds appears to claim that the Mason-Dixon line presented no obstacle to Smokey's merits as a piece of film-making. But his incredibly specific dollar amounts and timeline to say nothing of the missing 35 million of the film's $\$ 126,000,000$ take (one would guess from the Midwest and West) - address the still-not-solidified-in-1978 cultural prominence of the south. A hit movie sells lots of tickets by expanding its appeal beyond a niche audience, to a wider audience - from Florida, from Detroit (like True Romance's Alabama and Clarence respectively), from Rancho Cucamonga. The same is true for a big movie star. Plenty of comedies get released every year, but a Burt Reynolds comedy promised certain kinds of things on top of the laughs - a different setting, and a new set of 'southern' cultural references on which some of the humour is based. That regional constellation would become simply 'American' by the mid-1980s.

\section{Deliverance, the Tennessee Valley Authority, and Air Conditioning}

In the 1970s the south experienced the greatest population growth in the nation while the north-east and Midwest barely grew at all. The 1970s' key regions were the declining Rust Belt and the ascendant Sun Belt, and their population changes spurred major economic and cultural shifts. In The Emerging Republican Majority, Kevin Phillips, the architect of Nixon's Southern Strategy, described the post-1968 electoral landscape of this south-andwest-driven population expansion as 
[u]nluck[y] for the Democrats, [because] their major impetus is centered in stagnant Northern industrial states [...] Because of this demographic pattern, the South and West are gaining electoral votes and national power at the expense of the northeast $[\ldots]$ the northeast is steadily losing relative political importance to the Sun Belt.

But James Cobb reminds us that,

the migration patterns of the 1970s favored the South, but the numerical importance of this influx of new citizens was exaggerated. Without fast-growing Florida, 65.5 percent of the Sunbelt South's population growth in the first half of the 1970s would have been the result of natural increase.

Indeed, the electoral college vote change between 1940 and 1980 was, in fact, small. Even though the south (I include border state Kentucky) gained but one vote in the electoral college (four if we include Texas) before the 1980 election, the industrial Midwest, New England, New York, and Pennsylvania lost a combined 24 electoral votes. Such a swing meant far greater relative power for the south beyond the legislative branch.

But even before the south started to pick presidents, the Federal government invested massive sums in the region in hopes of moving it out of its agrarian past and into the industrial present. I will offer three brief descriptions of factors in the south's growth after World War II. The first, the Tennessee Valley Authority (TVA), was established in 1933. As the TVA's kids-oriented website tells the story,

Even by Depression standards, the Tennessee Valley was in sad shape in 1933 [...] TVA built dams to harness the region's rivers. The dams controlled floods, improved navigation and generated electricity. TVA developed fertilizers, taught farmers how to improve crop yields and helped replant forests, control forest fires, and improve habitat for wildlife and fish. The most dramatic change in Valley life came from the electricity generated by TVA dams. Electric lights and modern appliances made life easier and farms more productive. Electricity also drew industries into the region, providing desperately needed jobs.

(2012: para. 1-2)

While the Rural Electrification Administration, established two years after the TVA, and the Rural Electrification Act of 1936 were concerned with bringing electricity to farms, the TVA was a far more comprehensive program, interested in not only electrification but also a general integration of technology into southern life, an approach made necessary by the region's relative poverty and underdevelopment: in 1930 the south-east census region's per capita income was $48 \%$ of the national average. By 1950 , aided in no 
small part by the TVA, the region showed marked improvement, with per capita income growing to $67 \%$ of the national average. All that government-generated electrical power enabled the increased spread of air conditioning throughout the region. Yet even as late as 1984, as Raymond Arsenault noted, 'With few exceptions, historical works on the twentieth-century South published during the last forty years make no mention of air conditioning or, for that matter of anything related to climate control' (Arsenault 1984: 597).

Such an omission is interesting because, without indulging in a climate-is-destiny argument, a hot, humid region like the south can benefit economically from nearuniversal climate control. Air conditioning spread slowly through the south, first in industrial locations before the 1920s, then into banks and theatres in the 1920s, then into railroad cars and hotels in the 1930s, then into department stores and shops in the 1940s, and finally, in the late 1950s into school buildings and the majority of new housing developments. The late arrival of air-conditioned houses can be explained in terms of government action. Recognizing the likely return on investment air conditioning offered the region, in 1957 the Federal Housing Authority changed its rules so that mortgages would cover central air conditioning, meaning that air-conditioned houses were much more within the reach of the less affluent. Perhaps unsurprisingly, the next thirteen years saw a 400 per cent increase in households with air conditioning, which, coupled with 'the cost advantages and favourable business conditions that made Dixie even more appealing to market-conscious industrialists', made the region a desirable location (Cobb 1993: 208).

The TVA and air conditioning, among other factors, helped to change the south's business climate, and out of this business climate came a change in political climate. Bruce Schulman identifies three key changes between 1950 and 1980, including two that undergird the Southern Strategy,

First, migrants arrived from outside the region. The same businessmen, professionals, and skilled workers who filled new positions in defense firms and research laboratories swelled the Republican rolls in the South [...] Native urban businessmen and southern migrants from small towns joined the transplanted Yankees to form Republican strongholds in the South's economically vital urban and suburban communities.

(1991: 214-15)

As Schulman makes clear, migration in this period was not solely non-southerners coming into the south; southerners were moving within the south as well. The jobs that the professional-managerial class (PMC) whites once held in Rust Belt central cities moved to Atlanta and Miami and their suburbs, and the professional-managerial class followed. The same white-flight pattern visible in cities like Chicago, Cleveland, and Detroit (all of which shrank between 1950 and 1980), appeared in the south, with 
suburbanization marching away from southern city centres one interstate highway exit at a time.

The changes developers and mass suburbanization write on the southern landscape are on view from the first moments of Deliverance, which takes the urbanization - or better yet, suburbanization - of the south as a given, as a precondition for what happens in the country. The opening credits run over a series of images showing the massive scale of a hydroelectric dam under construction, an ambivalent reminder of the TVA projects that increased industrialization across the previously agricultural south. However, the rapid post-war industrialization that allows suburbanites to pursue safe risks like white water rafting, skydiving, and survivalism - Lewis' (Reynolds) jacket is festooned with Boy Scout-like achievement badges - certainly brought real and significant improvements to the quality of life in the south, which was by far the poorest region of the United States when the TVA began. We can see this in the Aintry locals who feel slightly differently about what the dam means. When the three survivors of the canoeing trip wash up near Aintry, Lewis is severely injured. The taxi driver gives Ed (Jon Voight) and Bobby (Ned Beatty) a sense of Aintry's limited life on their way to the hospital:

Right there's the town hall. Right over there is the old fire station. Played a lot of checkers over there. Sure did. All this land gonna be covered with water. Best thing that happened to this town.

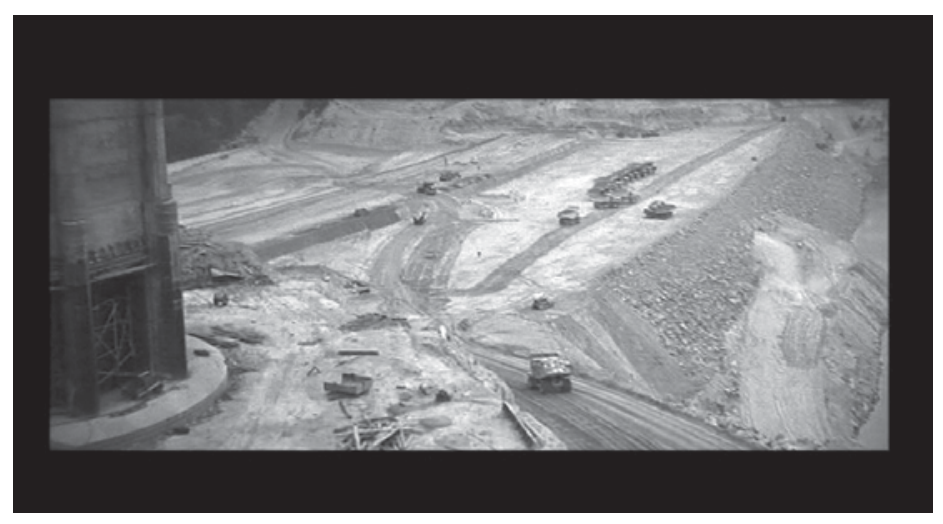

Image 7. Deliverance building a hydroelectric dam. 
The Sheriff (played by James Dickey, the novelist who wrote Deliverance) sums up the film's ambivalence over the trade-offs involved in major public works like dam building when he tells Ed: 'Don't ever do nothing like this again. Don't come back up here. I'd kinda like to see this town die peacefully'. The south on view in Deliverance exists as an ideological force working on the land - and across the land. Lewis gives a heavyhanded assessment of something worse than being lost when he mourns the disappearing wilderness, telling his buddies, 'we didn't lose it - we sold it'.

Before a human face appears on screen, Lewis introduces the south that he and his friends, the very people responsible for putting it into danger, will visit as tourists:

Just about the last wild, untamed, unpolluted, unfuckedup river in the south. Don't you understand what I'm sayin'? They gonna stop the river up. There ain't gonna be no more river. It's just gonna be a big dead [...] That ain't progress, that's shit! [...] You just push a little more power into Atlanta, little more air conditionings, for your smug little suburb and you know what's gonna happen? We gonna rape this whole goddamn landscape. We're gon' rape it!

The surface-level seriousness in the woods threatens to obscure the changing world that the film begins with. Nystrom, using the language of a 1975 Newsweek story on the changing south, describes the city boys as 'PMC canoers from the "glassy-massed office parks and instant subdivisions" of the Atlanta suburbs, the film presents us with the exemplars of the region's new order' (2009: 73). Lewis, Ed, Bobby, and Drew (Ronny Cox) are certainly professional middle-class Atlantans who enjoy the air conditioning that drives the need for hydroelectric dams, but the office parks and subdivisions are pure speculation. The film begins in medias road trip, on a lonely bit of Highway 23 in rural Georgia, and ends by moving Ed from the backwoods to the interior of his suburbanAtlanta house in a straight cut. We never see Atlanta, even though the growth of Atlanta is the motive force behind everything that happens. On the one hand, this formal disavowal mimics the troubling way in which Ed seems not to connect his ordeal in the wilderness with anything larger - showing that the quandary Lewis identifies in the film's first scene has no easy solution for the people in the new south.

\section{Football: The Longest Yard, Semi-Tough}

While white-water canoeing is a four-person bonding experience, football offers a shared experience on a much greater scale. As a professor in Atlanta, Ed would no doubt be familiar with college football's standing in the south. Throughout the 1970s, members of the SEC all played to sell-out crowds in sixty-thousand-plus capacity stadia. By the mid1970s professional football had established a strong presence in the south, with teams in Atlanta, Miami, New Orleans, and Tampa. Home town reflected glory; and, as so many 
pregame film packages labour to show, glory maters a great deal to a team's fans. Thus it's a bit shocking to see The Longest Yard begin with disgraced points-shaving ex-jock Paul Crewe (Reynolds) every inch the misogynistic good ole boy - getting drunk, hitting a woman, leading an extended car chase, and finally getting arrested. Crewe is sent to Citrus State Prison, where the guards gleefully chain him to Granville (Harry Caesar), a black prisoner, to 'humiliate' him. However, immediately after the white-black shackling, Caretaker (Jim Hampton) explains to Crewe that the other prisoners - white and black dislike him for class-based reasons:

Most of these old boys don't have nothin'. Never had nothin' to start with. You - you had it all. Then you let your teammates down, found yourself with your hand in the cookie jar [...] I ain't sayin' you did or you didn't. All I'm saying is that you coulda robbed banks, sold dope, or stole your grandmother's pension checks and none of us woulda minded. But shavin' points off a football game, man that's un-American.

As this exchange occurs early in the film, Crewe misunderstands Caretaker, replying, 'You take your football down here real serious, don't you?' For the prisoners, class solidarity and a chance to hit the guards in a football game trumps racial difference: that is to say, The Longest Yard repeats the old American story of regeneration through violence.

The formal expression of this regeneration comes across in a TV sports visual style that takes its cues from the class-based solidarity on view. For example, during a prisoners' team huddle, the film's multiple split-screens are cut in rhythm to the team's chant. The Longest Yard pushes ever so gently at the edges of formal orthodoxy. Robin Wood argues that The Longest Yard is also thematically outside the Hollywood norm. The Longest Yard, he argues,

is probably the closest the American commercial movie can get to a genuine revolutionary cinema - which is to say, scarcely closer than $Z$. Its subversiveness is qualified by characteristically Fascist overtones (the People turn out to be helpless without their Leader), but [Robert] Aldrich has certain useful negative prerequisites for the development of a revolutionary mentality - a natural coarseness of sensibility combined with a total lack of interest in the cultural tradition.

The mid-1970s south is an ideal location for this kind of ambivalent revolutionary spirit and rejection of a cultural tradition that has tended to exclude or marginalize the region. The Longest Yard's 'coarseness' - perhaps best exemplified in the sequence that repeats 'I think I broke his fucking neck' four times - emerges on a national scale, out of the south's longstanding distance and difference from the normalized American experience, and on a regional scale, from class-based difference within the south. Football helps class to cut across racial and regional identities, putting The Longest Yard in a position to enjoy transregional success. 
Three years after the success of The Longest Yard, Burt Reynolds made another football movie. Richard Dyer answers the critique of a star 'always playing himself or herself' by nothing that 'if you like [Gary] Cooper or [Doris] Day, then precisely what you value about them is that they are always "themselves" - no matter how different their roles, they bear witness to the continuousness of their own selves' (1986: 11). In many ways Reynolds could easily draw on his own experiences to play Semi-Tough's running back Billy Clyde Puckett: in addition to starring in The Longest Yard, he was a Florida State University player. (In 1983 he even became minority owner of the United States Football League's Tampa Bay Bandits, a team named after his character in the Smokey and the Bandit films.) In football terms, the film is ahead of the curve: Miami team owner Big Ed Bookman (Robert Preston) berates his 'Goddamn commie' kicker Vlada Kostov (Ron Silver) for loafing during practice by screaming, 'You think you're over here for détente?' Kostov responds by kicking a field goal from midfield, barefoot. In the late 1970s, there was détente, but there weren't any Eastern European players in the NFL (although the handful of foreign-born players were mostly kickers), nor was there an active barefoot, 'soccer-style' kicker. In addition to predicting changes in the kicking game, Semi-Tough takes the globalization of football for granted, even though it was not a part of the league's plan until the late 1980s. That is, Reynolds' star persona and commitment to filming in the south made plain the financial advantages of relocating the action from the novel's Los Angeles to the film's Miami. Because of this Semi-Tough builds on the expansion of the NFL into the south by linking it to another kind of expansion that would affect the entire nation: globalization.

\section{Sharky's Machine, the Weather, and Southern Architecture}

To understand the magnitude of Reynolds' stardom, consider the big summer 1981 releases. Twentieth Century Fox released one of its tent pole pictures, the Burt Reynolds vehicle The Cannonball Run, on the same weekend as Superman II (Lester, 1980) - and a week after Raiders of the Lost Ark (Spielberg, 1981). As the year's number six box office success, The Cannonball Run was hardly overwhelmed by the competition. Unlike Reynolds, Christopher Reeve and Harrison Ford did not have films coming out that winter as well. In December the 'Dirty Harry Goes to Atlanta' thriller Sharky's Machine starring and directed by Reynolds - was released. Four weeks later it was the top box office draw in America. To place Sharky's Machine in its particularly southern setting, and to establish the importance of Reynolds to that sense of place, it will help to consider Reynolds' directorial debut, Gator, the sequel to his earlier Southsploitation outing, White Lightning.

After the success of Deliverance, Reynolds used his star status to stay close to home - in the south - while still making movies. Scott Von Doviak's Hick Flicks: The Rise and Fall of 
Redneck Cinema offers a brief history of the role staying in the south played in the making of White Lightning:

When a routine action script titled McKlusky came his way, the actor was reluctant to sign on. The producers agreed to shoot the movie entirely in the South and populate it with southern actors, an idea that greatly appealed to Reynolds, and the movie that would become White Lightning was a go.

(2005: 20)

White Lightning is grubby Southsploitation, but amongst the moonshining and car chases, we have a villain, Sheriff J.C. Connors (Ned Beatty), who kills Gator's long-haired protestor brother, allowing the film to repudiate the Bull Connors of southern history. Again, so much for the apolitical Reynolds. Three years later, Reynolds was offered the chance to direct White Lightning's sequel. Moving Gator's action from fictional Bogan County, Arkansas to the Savannah, Georgia area seems an odd choice, but Gator's closing credits offer some insight: 'Our thanks to Gov. George Busbee, State of Georgia; Ed Spivia, Georgia Department of Community Development; Al Henderson, City of Savannah; The Cities of Savannah Beach, Valdosta and Lakeland, Ga. for their cooperation in the making of this film'. While Burt Reynolds used his limited power to infuse White Lightning with a greater sense of southern reality - the opening credits read 'Filmed in Arkansas' - the state of Georgia used Burt Reynolds (and vice versa) to infuse their state with Gator's Hollywood magic. By the 1990s it was common for states to offer incentives to film on location, but it was less common in the 1970s. The potential for a southern movie star like Burt Reynolds to make a movie in his backyard gave local government officials incentive to institutionalize their attempts to lure production to the south.

And so, familiar with the south, Reynolds directed the Atlanta-set Sharky's Machine, and in a brief bit of dialogue and set of visual clues reveals a great deal about everyday life in the south. As the opening credits run, Reynolds' Sergeant Tom Sharky walks through the rail yards and seedy neighbourhoods of Atlanta, finally stopping in a parking garage. There he meets drug kingpin Highball Mary (Hari Rhodes), and by way of greeting complains that he's cold, 'freezing to death', in fact. This complaint shows that there is indeed a winter in the south. It can get near freezing in Atlanta in the worst parts of winter - the average low for December, January, and February is in the mid-30s and it is not unthinkable for a little snow to fall. Not that you would know this from watching any of the other south-set films in the 1970s (or any other decade, to tell the truth). Much as the south has a time, it also has a season - summer. In spite of all of the air conditioning available, one shot that appears throughout southern films is the close-up of a sweaty browed face - and there is no shortage of such shots in Deliverance, White Lightning, and Gator. Not so in wintry Sharky's Machine, the exception that proves the generic convention: a gritty cop picture that doesn't take place in a northern city, which is also a southern-set film that doesn't take place in the hottest and most humid part of summer. 


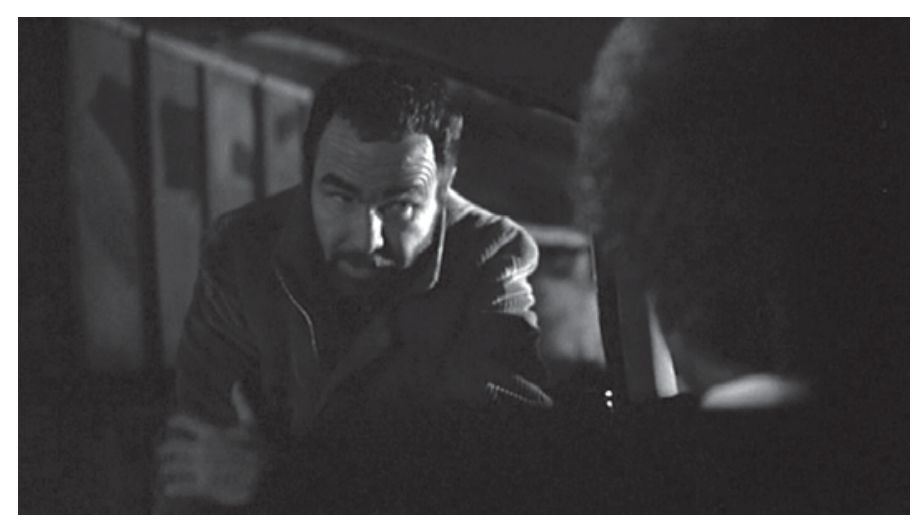

Image 8. Sharky's Machine 'I'm freezing to death' in Atlanta.

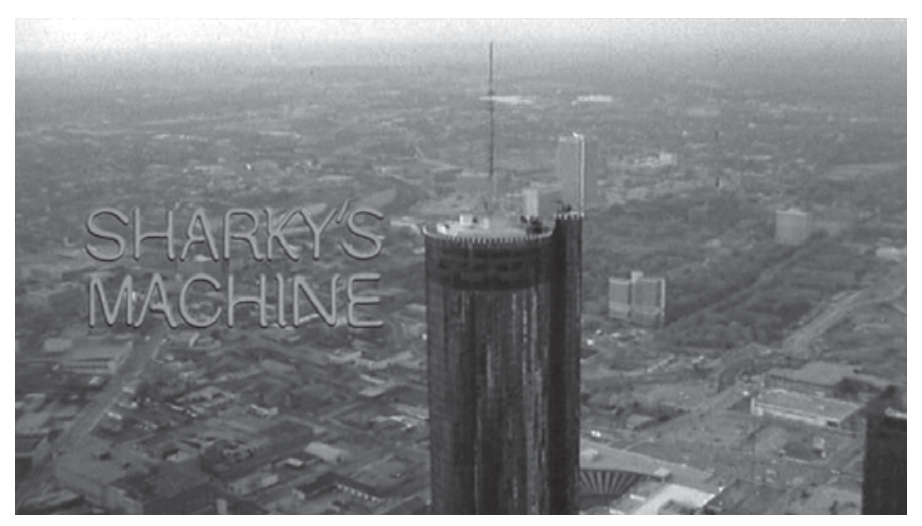

Image 9. Sharky's Machine Peachtree Plaza Hotel and film title.

Outside of the weather, Reynolds the director links himself to the south - Atlanta in particular - through his recurrent use of the Atlanta skyline. Sharky's Machine opens and closes on slowly zooming travelling shots of the skyline and the Peachtree Plaza, a building that announced Atlanta's 'arrival' as a global city, which Jay Watson details in 'Mapping out a postsouthern cinema: Three contemporary films' (2011). These opening shots simultaneously provide a general orientation and an insistent reminder of the film's specifically southern location. During Sharky's surveillance work, three key images combine again and again: Burt Reynolds' face with a set of binoculars, Atlanta's newest 


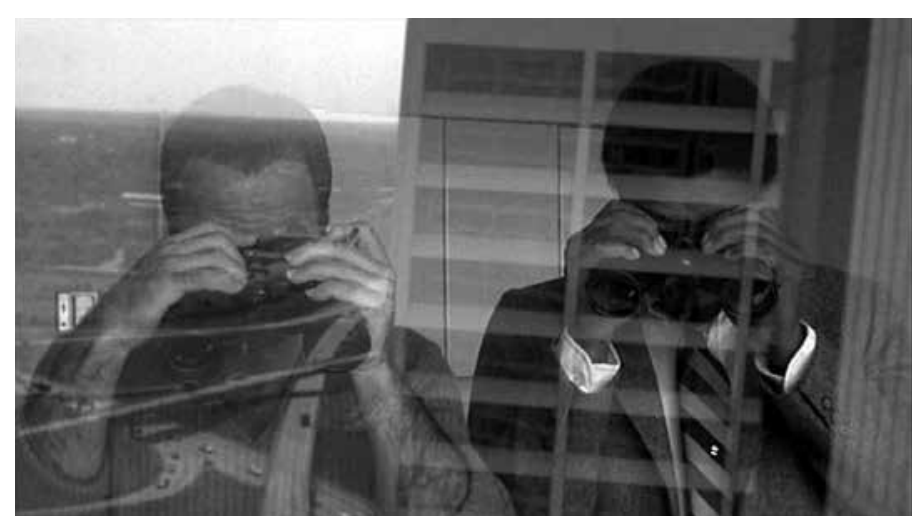

Image 10. Sharky's Machine surveillance, reflected buildings and highway.

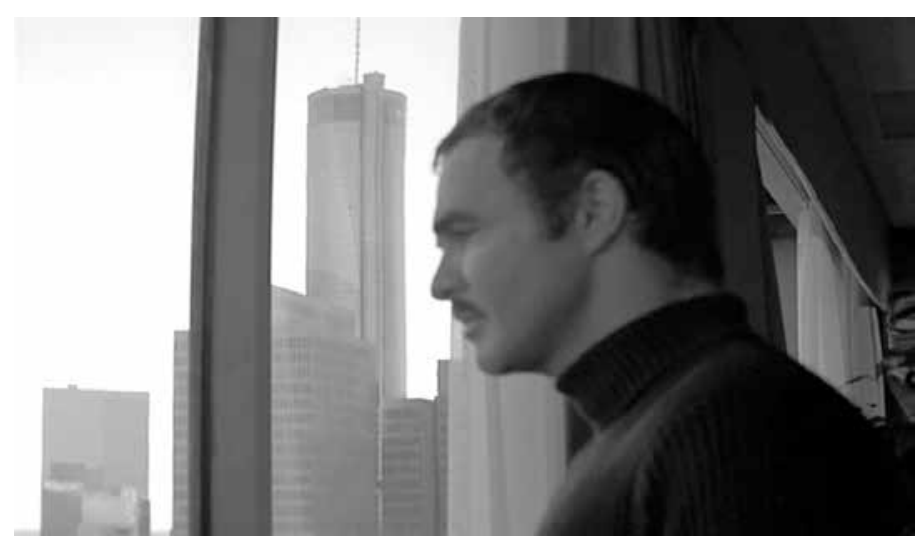

Image 11. Sharky's Machine surveillance and Peachtree Plaza Hotel.

and biggest architectural marvel, the Peachtree Plaza, and highway interchanges reflected in glass. This repeated Burt-building-byway combination reinforces the Atlanta-ness of Reynolds' film. In perhaps the most self-aggrandizing moment of the film, a sex scene dissolves from a shot of Sharky and Dominoe (Rachel Ward) in bed to a low-angle shot of the Peachtree Plaza, modestly equating Sharky's/Reynolds' erection with Atlanta's signature building. Burt Reynolds is some kind of southern man - a landmark of contemporary southern architecture. 


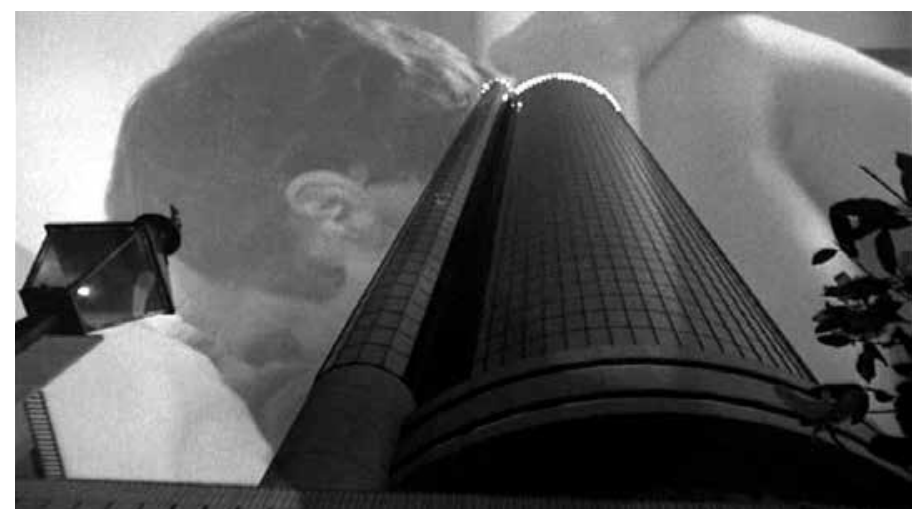

Image 12. Sharky's Machine Peachtree Plaza Hotel dissolve.

While the great majority of the recognizable major architectural works in the United States are in older, established cities like Chicago, New York, Washington, DC, and San Francisco, the south by and large lacks signature buildings. Part of the Chicago or New York identity emerges from the built environment - from fifth-floor walk-ups to the subway/El to iconic buildings. The difference in scale between cities like New York and Chicago and their hinterlands is essential to their cultural gravity. However, when it comes to the south,

[i]t can be said with a reasonable degree of accuracy that the South had within its borders no cultural and intellectual capitals of the sort that London was for Englishmen, Paris for the French, Berlin for the Germans, or Boston for the New Englanders. When the Southerner has gone to the metropolis, when he has felt the strong pull of the cultural and intellectual forces concentrated in a great city, it has been to what was in many respects to him a foreign land.

(Holman 1979: 268)

The south's later turn to urbanization can explain the low profile of its urban architectural identity and the more common conflation of the rural with southern identity. The architecture on view in Reynolds' hit films is different from that on view on most south-set films. The first establishing shot in Semi-Tough is of a Miami boulevard lined with fairly anonymous fifteen-storey apartment buildings. The Biscayne Bay-facing apartment Billy Clyde Puckett and Marvin Tiller (Kris Kristofferson) share is not part of a gloriously extravagant beast like the Fontainebleau, but a run-of-the-mill modern apartment building. The houses in The Longest Yard's opening scene in West Palm Beach, 


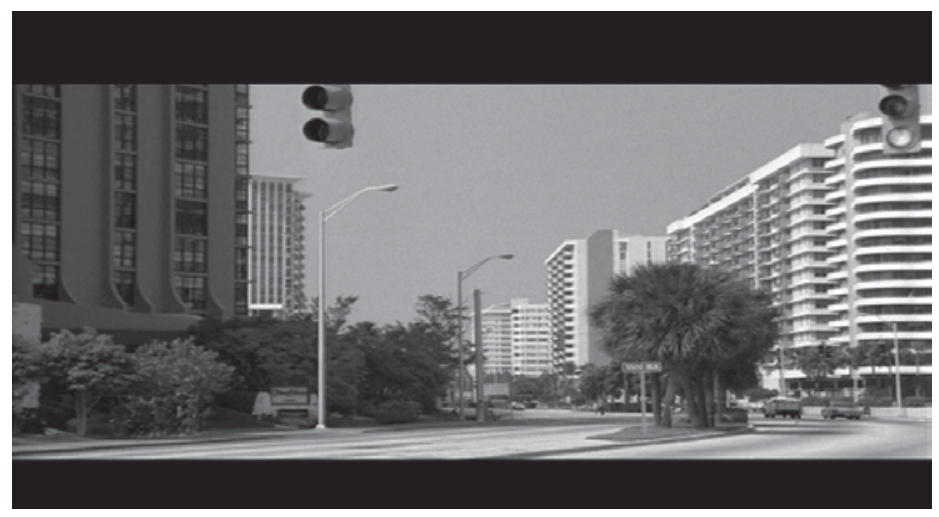

Image 13. Semi-Tough Miami establishing shot.

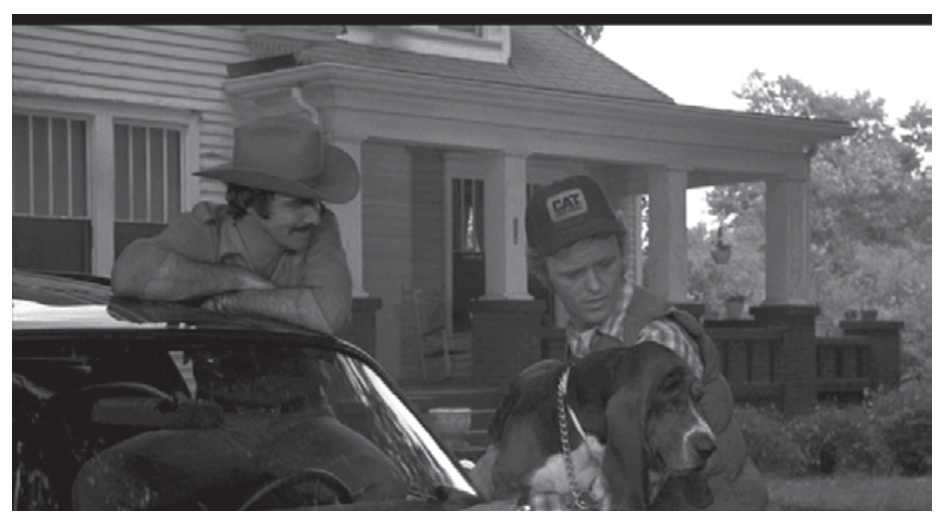

Image 14. Smokey and the Bandit Cledus' house.

Florida show a Beverly Hills-like French next to Spanish eclecticism. Cledus' (Jerry Reed) house in Smokey and the Bandit looks like every other house on his street: twostorey weatherboarded houses with a dash of local colour in the form of covered porches or verandas. Sharky's childhood house is much the same. The south has vernacular architecture - shotgun shacks at the low end and plantation big houses at the high end and recognizable monumental architecture like Biltmore. But neither group figures much in Burt Reynolds movies, which take place in an everyday middle-of-the-road south whose aesthetics owe just as much to the power of developers and mass suburbanization as any other region. 


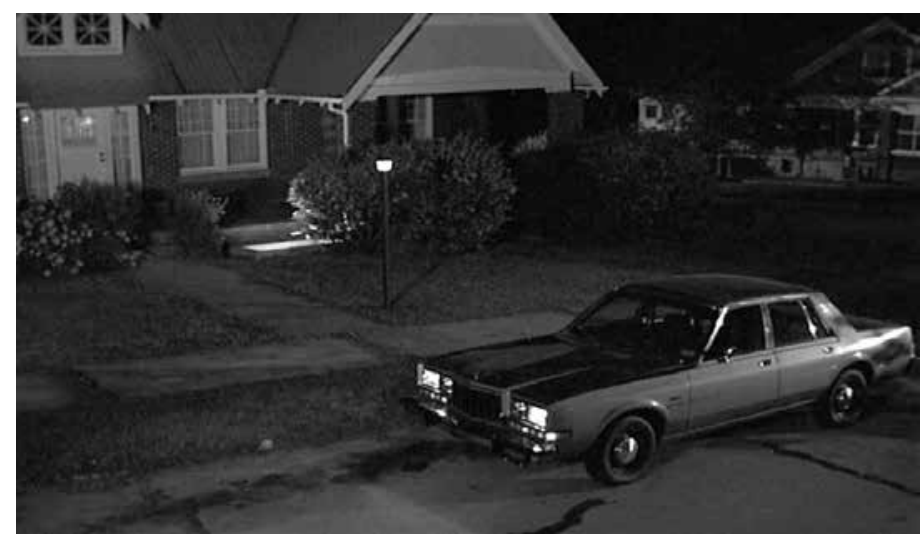

Image 15. Sharky's Machine Sharky's childhood home.

\section{Smokey and the Bandit I and II: The Decline of Burt Reynolds and the Rise of the South}

Smokey and the Bandit cleans up and suburbanizes the good old boy moonshining tropes found in Southsploitation films like Burt Reynolds' White Lightning and Gator. The Bandit films are fairly conventional in their use of the highway system to express freedom - but the freedom of the highway serves simultaneously to accentuate and dissolve regional differences. In Tico Romao's 'Guns and gas: Investigating the 1970s car chase film', Reynolds figures, without being named, in the definition of the 1970s car chase typology. A Reynolds film figures in each of Romao's three categories: police/crime (White Lightning), pursuit (Smokey and the Bandit series), and comedy chase (The Cannonball Run). While Romao concentrates his attention on the institutional (drive-ins, youth market) and technological (lenses, car rigs) changes in the 1970s that drove the evolution of car chases on film, Reynolds' chases on southern highways represent a narrative aspect that Romao notes, mostly in passing, as key to the 1970s car chase. As part of his discussion of the shift from process shots to moving-vehicle shots, Romao notes that

[t]he pursuit sequence in Bullitt [...] has been explicitly designed to showcase its ability to situate characters in their respective vehicles without relying on rear screen projection [...]. This ability to credibly situate characters in dangerous narrative contexts, be it car chases or other perilous scenarios, as character placement.

(2004: 132-34) 
Romao uses Smokey and the Bandit to demonstrate how 'one can distinguish the stunt as an instance of local spectacle from narration as the process in which different stunts are interlinked into a broader narrative chain' (2004: 146). But beyond the chase sequence's function in advancing the Smokey-versus-the-Bandit narrative, the moving-vehicle and driving-POV shots also perform character placement. Bandit behind the wheel is very much in the south. The south in which Reynolds is placed is the one visible from the interstate, the modernizing south, not the old south found on back roads.

In Smokey and the Bandit the excuse for the series of car chases is the 'commission' to ship a trailer of Coors from Texas to Atlanta; in Smokey and the Bandit II the excuse is the transport of a pregnant elephant from Miami to Dallas (to say nothing of Smokey and the Bandit's sequel-bait promise of a chowder-delivery service from the north-east to Atlanta). Smuggling in western-identified beer and trucking the Republican party symbol across the south enact the region's changing identity. The question of whether Smokey and the Bandit would work north of the Mason-Dixon line, mentioned above, becomes easier to understand when we consider the ways in which Bandit is a legend not only to southern whites, but also to African Americans, who come to Bandit's aid with a rolling roadblock at one point. Bandit may be a good ole boy moonshiner type, but he does not bring along the type's racist baggage, especially compared to his foil, Sheriff Buford T. Justice (Jackie Gleason) (sexism and homophobia, on the other hand, are present throughout the films). The Bandits, and other Reynolds hits, may be fairly monochromatic in casting the leads, but the roadblock, not to mention the cross-racial class solidarity in The Longest Yard, and the multiracial police force in Sharky's Machine reveal Reynolds in a contemporary south that was, as the Atlanta slogan put it, 'too busy to hate'.

As sloppy and lazy as Smokey and the Bandit II is, it does accurately predict the decline of Reynolds' stardom. Although Bandit and Frog (Sally Field) end the first film as a couple, in the second they have split up, only to be reunited in service of the elephant shipping run. As they chat in Bandit's Trans-Am, Bandit tells Frog that he is 'basic famous'. Not long after, a gas station attendant tells Bandit, 'If I was making a list of the great assholes of the twentieth century, you'd be in the top five'. Frog tries to drag Bandit away from the confrontation. Bandit pulls away and angrily tells the man, through a closed door, 'I'm practically an American folk hero [...] God damn it I'm one of the most beloved grass roots folk heroes of America!' Moments like this lead Frog to tire of Bandit; her kissoff to him could well be the kiss-off Reynolds got from film-going audiences: 'You're a fame junky. They might as well lock you up and give you intravenous feedings of People magazine and National Inquirer headlines and if you're a real good boy they give you the occasional Tonight Show enema. Reynolds was a frequent guest on The Tonight Show - a guest host even. In a Film Comment interview he couches his use for television talk shows in terms of what his charisma allows him to get away with: 
When I go on The Tonight Show and they say, 'What were you doing today?' and I say, 'I was on Hollywood Boulevard being a star', people love it. It's really self-deprecating joke. On The Tonight Show, ninety-nine percent of all the leading men come on to talk about their pictures and their voices get a little lower, you know. They start saying, 'I loved the director, I loved the leading lady [...]' Before me, nobody ever came on and said, 'It's a turkey'. I've had an enormous amount of success doing that. People love it [...] when you say this and people read it, they think, 'The ungrateful shit.' But on TV you can somehow verbalize it so it doesn't come out so strong. The guy on The Tonight Show, for me, is a character.

(McBride and Riley 1978: 21).

However, after six major box office successes, Burt Reynolds, like Smokey, started to run out of ideas, and what was once charming started to fade. Or, as Frog puts it, Bandit/ Reynolds 'got famous and then you felt you had to do more and more until you were doing what you didn't do best. And now I don't think you're even having any fun'. Reynolds got famous because he brought something different to the cinema: the contemporary south, with its burgeoning economic and political power. But by the mid-1980s, the south played a much greater part in the formation of a national identity, thanks in no small part to Reynolds' efforts in the cineplexes and old Majestics across America. In the political arena, Ronald Reagan won every southern state except Georgia to defeat Jimmy Carter in 1980. In 1984 Reagan won every state in the south on his way to his 49-state landslide. Phillips' predicted shift from the solid Democrat South to the GOP South was complete, and subsequent elections showed that the south was key to both Republican and Democratic presidential victories, as well as Congressional control. The 1980s also saw major industries like automobile manufacturing move southward; General Motors, Ford, Toyota, and Nissan opened plants outside the Michigan-Ohio centre of auto production. Reynolds' star did not fade because he was a jerk on talk shows, or because his movies got any worse (which they did). His star faded because what was previously new and noteworthy about what Reynolds brought to the cinema had become more visible and common.

Hollywood's shift to event pictures and blockbuster releases took firm root in the early 1980s, and while the change was not fatal to Reynolds' stardom, it's possible to see how it diminished his profile. In the introduction to his collection Movie Blockbusters, Julian Stringer admits the difficulty in pinning down a definition of 'blockbuster', settling on the 'money/spectacle nexus and, underpinning these two, the size factor and bigness and exceptionality as relational terms' (2003: 8). The creation of spectacle, as Tom Schatz characterizes it, leads to blockbusters that are, 'increasingly plot-driven, increasingly visceral, kinetic, and fast-paced, increasingly reliant on special effects, increasingly "fantastic" (and thus apolitical), and increasingly targeted at younger audiences' (2003: 29). This sounds quite a lot like a summary of Reynolds' hits, with their car crashes, punch-ups, and fairly two-dimensional characters. But one facet of blockbuster-ness 
remains: its 'event' status. If Reynolds' stardom had a significant weakness, it was in his increasing normalcy as the population and political centre of the nation moved south. In the 1980s, the contemporary south changed from a rare sight to something common. Burt Reynolds, in helping to build up NASCAR as an owner (he and Hal Needham owned the \#33 Skoal Bandit car), made the contemporary south more visible every race day, and thus reduced the special quality of his contemporary-south-set films. It is less of an event to see Burt out-drive Buford T. Justice when you can watch Harry Gant do the same thing to Dale Earnhardt. Thus the diminishing returns of the Bandit and Cannonball Run franchises emerge not solely from their declining aesthetic merits, but also from American culture's over-familiarity with the south and its good old boy types.

Beyond the effect the blockbuster mentality had on Reynolds' stardom, hit movies and solid earners turned to southern locations with slightly greater frequency, peeling away at Reynolds' specialness. Period films like The Color Purple (Spielberg, 1985) and Driving Miss Daisy (Beresford, 1989) were joined in the year-end top twenty by films set in and around southern military installations like Heartbreak Ridge (Eastwood, 1986), and in the everyday contemporary south of Cocoon (Howard, 1985) (Florida), Bull Durham (Shelton, 1988) (North Carolina), and Steel Magnolias (Ross, 1989) (Louisiana). On television, Nielsen winners Golden Girls, Miami Vice, Matlock, A Different World, and In the Heat of the Night were all set in the south.

\section{Conclusion}

The end of Burt Reynolds' extended run at the top doesn't look like an end: The Cannonball Run (1981) did exceptionally well at the box office, as did The Best Little Whorehouse in Texas (1982). But The Cannonball Run was the last of the Bandit-like films to be successful. Stroker Ace (Needham, 1983), Smokey and the Bandit Part 3 (Lowry, 1983), and Cannonball Run II (Needham, 1984) showed diminishing returns. The cop movies City Heat (Benjamin, 1984), Stick (Reynolds, 1985), Heat (Richards, 1986), Malone (Cokliss, 1987), and Rent-a-Cop (London, 1987) did progressively worse, with Rent-A-Cop bringing in less than one million dollars. After his decline as a movie star Reynolds found success in voice-over work, in All Dogs Go to Heaven (Bluth, Goldman and Kuenster, 1989), and in television - starring in the Florida-set and shot B.L. Stryker (1989-90) and the Arkansas-set Evening Shade (1990-94), in which he again played an ex-football player - before returning to film as a character actor. Reynolds' big screen comeback, in roles as a shady Congressman in Striptease (Bergman, 1996), an avuncular porn director Jack Horner in Boogie Nights (Anderson, 1997), and Boss Hogg in The Dukes of Hazzard (Chandrasekhar, 2005), and himself in the television series Archer (2009-16) reveal his enduring cultural appeal and value. Boogie Nights, Striptease, and Archer all use Reynolds to represent a recognizably outdated conception of male heterosexiness, since more than any other actor working, Burt Reynolds is the 1970s. Albert Brooks 
and Warren Beatty are said to have been offered the Jack Horner role. Beatty was a star in the 1970s, and Brooks was moderately successful. Robert DeNiro, Dustin Hoffman, Robert Redford, and Al Pacino are all still working after enjoying stardom in the 1970s. However, to see time is to miss space. Burt Reynolds' stardom, I repeat, was predicated on 'a promise of a certain kind of thing that you would see if you went to see the film. Unlike any of the other stars of the 1970s, Burt Reynolds came to represent - and get stuck in and as - the 1970s by being the only star to promise his audience the 1970s' key region, the south.

Derek Nystrom is right to identify Burt Reynolds as part of the 'Redneck cycle' of films in the 1970s that coincided with an increasingly southern and conservative turn in national political life, but he is more right than he is willing to argue. As Cavell points out, 'people of a certain cultivation', which is to say film scholars, are reluctant to see 'how charming and perceptive a leading man Burt Reynolds can be, when not cast as a good old boy. The romps through the south that established Burt Reynolds' star persona were almost the only widely seen films between 1970s and mid-1980s that treated the south's increased importance in contemporary national life as normal. Reynolds was not left behind because he had nothing to offer the new blockbuster-focused Hollywood, or because he lost his charisma, but because by the time Reagan was gearing up his 'Morning in America' re-election campaign, he no longer had something special to offer a national audience. The Southern Strategy aimed to bring the good old boys to the fore in national politics, and it succeeded. The regionally identifiable Reynolds gave way to 1980s stars linked to genre but not to region: Eddie Murphy (who starred in comedies set in Detroit, California, and New York), Harrison Ford (who starred action films set in space and outside the United States), Tom Cruise (action films and coming-of-age films set in California, Jamaica, Chicago, and on the road), and Arnold Schwarzenegger (action films set in Central America, Los Angeles, and various fantasy locations). In other words, Burt Reynolds is not just part of a cycle of Southsploitation Redneck films, nor is he just a performer with a limited regional appeal. He is a distinctly and quintessentially 1970s American movie star because he is in and of the south as it emerges as the region at the forefront of national life. 


\section{Chapter 2}

New Hollywood, the Contemporary Midwest, and Collective Action 

A man went looking for America ... And couldn't find it anywhere.

Easy Rider poster tagline

$\mathrm{P}$ eter Biskind's Easy Riders, Raging Bulls: How the Sex ' $n$ ' Drugs ' $n$ ' Rock ' $n$ ' Roll Generation Saved Hollywood (2007) tells a triumphalist tale of the 1960s changing of the guard in Hollywood. Between 1967 and 1975 it looked like an auteurist cinema might emerge out of a financially strapped Hollywood. In Biskind's gossipy account, the film school generation, when they weren't busy with drugs, drink, and sex, rescued a calcified Hollywood. In the place of the old order, a new group of film-makers put Hollywood back on the right track. But the history of Hollywood movies in the late 1960s and 1970s is not quite as simple as Biskind's out with the old, in with the new narrative. In Easy Riders, Raging Bulls' introduction, he claims that

The Sound of Music represented the last gasp of family entertainment, and in the half decade that followed, the war in Vietnam grew from a blip on the map somewhere in Southeast Asia to a reality that might easily claim the life of the boy next door.

(Biskind 2007: 20)

Such hyperbole mis-remembers actual box office returns. Between 1967 and 1973, a number of family-friendly films did very well at the box office. ${ }^{6}$ The continued success of 'family' entertainment coexisted with the success of films from a new generation of New Hollywood film-makers. ${ }^{7}$ On the surface, the family-friendly films show a tendency for animated, fantastic, and small town settings, and appear to be more conservative in their politics while the adult-oriented films are all set in the grit of the real world, splitting time between big cities and the West, with a more liberal politics.

In this chapter I first want to consider two threads that run through the films from the New Hollywood. Rather than addressing the existing Hollywood audience, the films hail an audience with a more 'metropolitan taste' informed by the European and Asian art cinema that made inroads in the 1950s and 1960s, especially in major cities and college towns, as Barbara Wilinsky details in Sure Seaters: The Emergence of Art House Cinema (2001). First, the more metropolitan taste in, for example, New Hollywood road movies led film-makers to repeatedly imagine a wide-ranging landscape of oil infrastructure in 
California and Louisiana, the gas lines in Montana, and even the imagined oil fields in Alaska. In addition to this landscape - in California, Alaska, the West, the Plains, and some of the south - New Hollywood films imagine life in New York, but overall spend very little time in the Midwest. Second, the New Hollywood films set in the Midwest did not see the same level of box office success, and coming to terms with this relative lack of success will be my second aim. While the substantial blind spots in New Hollywood films' straight white male politics are well known, and an ecocritical account of the wages of the road movie has emerged, the geography of the era's narrative settings reveals that the Midwest offers a significant geographical and ideological counterpoint to films set in the rest of the country. On the one hand, the success of New Hollywood road movies set throughout the United States can be understood in terms of their individualist focus. Though they're not exactly the goal-oriented protagonist of the Classical Hollywood cinema, New Hollywood narratives tend to focus on an individual (man) or a couple, which makes them comprehensible to an audience raised on Hollywood studio films. On the other hand, the Chicago-set Medium Cool (Wexler, 1969) and Detroit-set Blue Collar (Schrader, 1978) move closer to a collective subject (but certainly do not reach it), indicating not only formal difference, but also a political shift less likely to generate significant box office returns. The few Midwest-set films - Medium Cool and Blue Collar especially - confront problems of a much larger order than individualized disaffected middle-class white men common to New Hollywood, in large part by engaging with gender, race, and class in the de-industrializing, urban Midwest.

\section{Metropolitan Taste}

During the brief period in which it looked like a director's cinema would emerge from the wreckage of the studio system, a new, metropolitan taste established itself in Hollywood. Geoff King concisely describes the interaction of industrial and formal changes key to the New Hollywood (which he calls the Hollywood Renaissance):

A number of industrial factors combined to make possible the Hollywood Renaissance. A specific set of industrial circumstances enabled aspects of the social and historical context to find expression in Hollywood [....] The Hollywood Renaissance was also shaped by the influence of the stylistic experiments of a new generation of filmmakers outside Hollywood.

(King 2002: 35)

Among the stylistic changes were formal innovations drawn from a wider swath of film history. In the late-1960s, as Tom Schatz's 'The New Hollywood' tells it, 
With the blockbuster strategy stalled, the industry saw a period of widespread and unprecedented innovation, due largely to a new 'generation' of Hollywood film-makers like Robert Altman, Arthur Penn, Mike Nichols, and Bob Rafelson, who were turning out films that had as much in common with the European art cinema as with classical Hollywood.

Rather than the overstuffed excess of big musicals like Paint Your Wagon (Logan, 1969) or Doctor Dolittle (Fleischer, 1967) (for critics, the go-to examples of Hollywood decadence) or the empty danger-free fun of family comedies like The Love Bug (Stevenson, 1968), New Hollywood films worked through different genres. In addition to revisionist westerns, New Hollywood 'mobilized renovated versions of its traditional genres and heroes to satisfy the audience's schizophrenic impulses toward irony and nostalgia' (Ray 1985: 296). The key genre for New Hollywood was the road movie, which takes the form of 'journeys with complicated, rambling, usually aimless itineraries - journeys to nowhere, searches in which the real object of the search remains unidentified or uncertain' (Wood 2003: 26). Wood, even in a consideration of film form, cannot help but privilege the New Hollywood's distinct thematic, and perhaps ideological, approach. When the journey goes nowhere, it would seem that narrative location would matter little, when in fact it plays a major role in accounts of the New Hollywood.

If the location of a film does not occupy the majority of space in critical accounts of New Hollywood, the location of its audience - or presumed location of its audience - does. Andrew Sarris, who brought auteurist criticism to America, quipped, 'the battle was lost when Hollywood realized in 1970 that there was still a huge middle American audience for AIRPORT' (quoted in King 2002: 24), opposing New Hollywood films to the sorts of movies that appeal to middle American taste. In this formulation, Middle America is less an actual place than it is an ideology. Squares, or in Sarris' terms, middle Americans (the audience for the Disney live-action films I will cover in Chapter 6) are what the New Hollywood films present as their opposite. On the one hand, the metropolitan taste they embody seeks to épater l'Establishment, through their critical narrative engagement most clearly and self-regardingly in Easy Rider (Hopper, 1969). As Stephen Farber noted soon after it was released,

The images of Establishment America in Easy Rider are hysterical to say the least; a European seeing the film would get the impression that 'straight' Americans are waiting in the shadows for an opportunity to jump out and beat young longhairs to death, or that they spend idle moments driving along the highways shooting at any iconoclasts they happen to pass. 
On the other hand, the increasingly violent and sexual form of New Hollywood films critically engaged the historical strictures imposed by those square establishment figures the Hayes Code, the National Legion of Decency. These production codes were also based on geographic understandings of where morality and the movie-going audience lived. Ken Feil relates a story about a Joe Pasternak, producer who worked through the end of the 1960s, who said,

Our moral standards should not be set by New York, Chicago and Los Angeles ... The greatest movie audiences are in the smaller cities, towns and rural areas, and those people are offended by the filth that gets on the screen.

(2009: para. 17, ellipses in original)

The very concern that Pasternak voiced at the beginning of the New Hollywood era appears in the films themselves. If we look at just the films Jack Nicholson appeared in, the mores of smaller cities, towns, and rural areas are consistently figured as the problem, most powerfully when George Hanson makes a speech about freedom in Easy Rider only to be murdered in his sleep that night by angry, unfriendly locals. Part of the meaning of 'middle American values' comes from class position. However, this spatialization of cultural conservatism seems too narrow, and does not include places like ('Banned in') Boston, Massachusetts, and Provo, Utah, where Looking for Mr Goodbar (Brooks, 1977) faced an obscenity trial in the late 1970s.

Beyond the regionalization of cultural conservatism, much of the criticism and history surrounding the New Hollywood further spatializes its ideological stance. In Movie-Made America, Robert Sklar locates where proper movie-going happens:

Suburbanites may even have imagined movies were prospering. Handsome new theaters were going up in the shopping centers, and when people went out on Saturday night they found long lines for the movie they wanted to see. They weren't likely to pass by the scores of shuttered theaters in old downtown neighborhoods (urban renewal was probably razing them, anyway).

While Sklar does complicate this notion to a degree, he nonetheless presents a clear sense that the suburbs are not the Real Movie America; going to the movies happens in downtown urban picture houses, not in suburban multiplexes. Thomas Elsaesser invokes a similar suburban bogey movie-goer when he writes that New Hollywood films direct their 'cool mockery [and] detached satire [...] against the America of the silent majority' (2004: 286). Nixon delivered his 'Silent Majority' speech in November of 1969, giving a name to the people many of the canonical New Hollywood films like Bonnie and Clyde (Penn, 1967), The Graduate, Easy Rider, and Medium Cool sought to shock. By the process of elimination, this combination of suburbanites with debased film taste and the 
ideologically opposed silent majority members in the suburbs and small towns across America places New Hollywood films' 'home' in coastal metropolitan locations.

Thus the regional/spatial understanding of the Silent Majority, the Establishment, and other names for the New Hollywood's audience after the early 1960s performs ideologically, in that it reveals an imaginary relationship to the material conditions of cultural taste in America. The audience is middle American, in the suburbs of flyover country. Curiously, the suburbs of the Midwest are not particularly common in Hollywood studio productions (for squares) in the late 1960s and 1970s. As the case of Disney liveaction films will show later, the ideological work of family films makes any location safe for Walt's brand of conservatism. Something similar happens in New Hollywood films.

\section{New Hollywood's Map of America}

Films from New Hollywood present a problem of classification, as the requirements for entry into the group are unclear. Biskind's Easy Riders, Raging Bulls, and Maitland McDonagh's 'The exploitation generation. Or: How marginal movies came in from the cold' (2004) pay some attention to the role producers played in New Hollywood. But their account, like the ones found in David Cook's Lost Illusions: American Cinema in the Shadow of Watergate and Vietnam 1970-1979 (2000), Alexander Horwath's 'The impure cinema: New Hollywood 1967-1976' (2004), Glenn Man's Radical Visions: American Film Renaissance, 1967-1976 (1994), Thomas Schatz's often-anthologized 'The New Hollywood' (1993), David Thomson's 'Who killed the movies?' (1996), and David Bordwell and Kristin Thompson's Film Art: An Introduction's section on New Hollywood as well as their chapter on 1960-80 in Film History: An Introduction (2010) treat the New Hollywood as a director's cinema. In his revisionist history of the era, Hollywood Film 1963-1976: Years of Revolution and Reaction (2011), Drew Casper notes,

The records on file, whether dauntingly encyclopedic or unsatisfactorily skimpy, theoretically abstract or anecdotally superficial, bereft in varying degrees of a sustained contextualization of these movies, are also invariably myopic. They have concentrated upon and lauded the bold extension of thematics and tones, radical formal experimentation, product personality, and uncompromised liberalist critique as characteristics of this unique period. Moreover, these recollections have come up with a canon, including The Graduate (E, 1967), Alice's Restaurant (UA, 1969), $M^{*} A^{*}{ }^{*} H$ (TCF, 1970), Five Easy Pieces (C, 1970), and The Godfather I and II (P, 1972, 1974), as proof of this "Hollywood Renaissance." These reckonings, to my mind, reconstruct a sizable hunk of the Hollywood scene but, alas, not its entirety.

(2011: xv-Xvi) 
I am in sympathy with Casper's larger critique, if not every claim. For Casper, the semblance of left-wing politics stands out as one of the key traits for inclusion in the era's canon, which is borne out in the majority of the sources listed above. As Todd Berliner puts it,

Equating artistic value with progressive social values, several cultural studies of the period end up disparaging some memorable movies - such as Rocky (Avildson, 1976), Star Wars (Lucas, 1977), Heaven Can Wait (Beatty and Henry, 1978), and Kramer vs. Kramer (Benton, 1979) - and inevitably extolling some dull ones, such as Joe (Avildson, 1970) and Go Tell the Spartans (Post, 1978), that reflect ideas the critics consider important.

Such a focus on ideology writes a number of films out of film history and over-values others. Casper's critique of New Hollywood canon-formation - the circular reasoning of canon-inclusion and the over-emphasis on a small number of films - informs both the set of films I map in this chapter and the approach I take to the films I read closely.

Setting the start and end date for what constitutes the New Hollywood is a tricky piece of business. One version of the New Hollywood definition places the start date in the mid-to-late 1960s, linked to particular films and/or sets of films.

Many strong cases have been made for which films launched 'the new cinema', as Time dubbed it in 1967: The Pawnbroker (1965), The Chase (1965), Who's Afraid of Virginia Woolf? (1966), The Chelsea Girls (1966), Alfie (1966), Blow-Up (1966), The Shooting (1966), Point Blank (1967), The Graduate (1967), Bonnie and Clyde (1967), Targets (1968), Easy Rider (1969), Midnight Cowboy (1969), and many others.

(Feil 2009: para. 1)

This version of the New Hollywood lumps British films (Alfie), underground films (The Chelsea Girls), independent productions (Targets), and films made with Hollywood studios (Easy Rider) into one group. Another version of the definition of the New Hollywood is institutional, and tends to see the dividing line in institutional practice as somewhere in the mid-1970s. Thomas Schatz argues that

this post-1975 era best warrants the term 'the New Hollywood', and for essentially the same reasons associated with the classical era; both terms connote not only specific historical periods, but also characteristic qualities of the movie industry at the time particularly its economic and institutional structure, its mode of production, and its system of narrative conventions. 
The films that make up this New Hollywood respond to changes in the audience and how and where the audience encounters films. In this version, Jaws (Spielberg, 1975) is something like a crystallization of the lessons learned from the 1960s' serious downturn in business: 'In one sense the mid-1970s ascent of the New Hollywood marks the studios' eventual coming-to-terms with an increasingly fragmented entertainment industry - with its demographics and target audiences, its diversified "multi-media" conglomerates, its global(ized) markets and new delivery systems' (Schatz 1993: 9). In 'Hollywood corporate business practice and periodizing contemporary film history', the film historian Douglas Gomery argues, 'we must recognize that there have been two New Hollywoods' (1998: 54). This chapter maps both New Hollywoods to capture locations both when the first set of changes began to appear, in the mid-1960s, and when they were more established institutionally, up through 1980.

A map of New Hollywood films' narrative locations presents another entry point to unpick the connections between formal innovations and ideological position without losing track of literal location. To draw boundaries around the New Hollywood, Richard Armstrong begins with the boundaries of the United States. 'One of the most interesting aspects of that era of generational change we now call "New Hollywood", he writes, 'was the way American cinema seemed to become more "American" in scope and content' (2003: para. 1). This American-ness emerges not just in the films' 'scope and content', but also in their settings. Catch-22 (Nichols, 1970), $M^{\star} A^{\star}{ }^{\star}{ }^{\star} H$, Cabaret (Fosse, 1972), A Clockwork Orange (Kubrick, 1971), Sorcerer (Friedkin, 1977), Apocalypse Now (Coppola, 1979), and some scenes in Godfather and The Exorcist (Friedkin, 1973) are set abroad, but the overwhelming majority of New Hollywood films take place in the United States. Perhaps unsurprisingly for the film school generation, Hollywood and California in general occupy a major place in the films, Shampoo (Ashby, 1975), The Graduate, Chinatown, Harold and Maude (Ashby, 1971), Long Goodbye (Altman, 1973), Wild Angels (Corman, 1966), Shampoo, some of The Godfather, Bob \& Carol \& Ted \& Alice (Mazursky, 1969), They Shoot Horses Don't They?, Zabriskie Point (Antonioni, 1970), Coming Home (Ashby, 1978), Heaven Can Wait, and Point Blank (Boorman, 1967), among others, are all set in California. The West frequently appears in revisionist westerns like Wild Bunch, Little Big Man, Butch Cassidy and the Sundance Kid (Hill, 1969), McCabe and Mrs Miller (Altman, 1971). But for all the film school generation's love of genre, the contemporary West appears in more than road movies such as Easy Rider, Two-Lane Blacktop (Hellman, 1971), Sugarland Express (Spielberg, 1974), and Duel (Spielberg, 1971), in films like Alice Doesn't Live Here Anymore (Scorsese, 1974) and Brewster McCloud (Altman, 1970). Easy Rider moves from California to the West (and Texas) and then into the south. The south is consistently identified with the past, as in Boxcar Bertha (Scorsese, 1972) and Thieves Like Us (Altman, 1974), with infrequent forays into the contemporary moment like Deliverance and, as I showed earlier, the Burt Reynolds films that bring the New South to a wider, national audience (Map 7). 
To complete the circuit of the map of narrative locations, the east coast, most often New York, appears in The Godfather, Mean Streets (Scorsese, 1973), Midnight Cowboy, Taxi Driver, Dog Day Afternoon, Klute, All That Jazz, Raging Bull, Joe (Avildson, 1970), and Carnal Knowledge, among others. Biskind notes that importance of New York and New Yorkers to the New Hollywood: 'In fact, a lot of the energy that animated the New Hollywood came from New York; the '70s was the decade when New York swallowed Hollywood, when Hollywood was Gothamized' (Biskind 2007: 16). New Hollywood New Yorkers include Manhattan's Martin Scorsese, Bob Rafelson, Alan Pakula, Mike Nichols, Michael Cimino, Stanley Kubrick, Jack Nicholson, Jane Fonda, Robert DeNiro, Peter Fonda, Al Pacino, Robert Evans, and Irwin Winkler, a Brooklyn contingent of Paul Mazursky, Monte Hellman, Richard Dreyfuss, Barbara Streisand, Elliot Gould, Woody Allen, and the critic Andrew Sarris, Bronx-born James Caan and Alan Pakula, Francis Ford Coppola (who grew up in Queens), as well as John Voigt (Yonkers), and Peter Bogdanovich (Kingston). There aren't any major (or even minor) figures from Staten Island. Something as simple as the chapter titles in Derek Nystrom's excellent Hard Hats, Rednecks, and Macho Men: Class in 1970s American Cinema shows New York's cultural gravity. Whereas 'Deliverance: An allegory of the Sunbelt' and 'Keep on truckin': The southern cycle and the invention of the good ole boy' both clearly indicate their interest in the south, the section 'Macho Men and the New Nightlife Film' of the book leaves out any regional identity: 'Saturday Night Fever and the Queering of the White, Working-Class Male Body' and 'Extra Masculinity: Looking for Mr. Goodbar and Cruising. The queering of the white, working-class male body in Saturday Night Fever happens in Bay Ridge, Brooklyn. Cruising (Friedkin, 1980) moves through the leather bars of Manhattan. And Looking for Mr Goodbar (Brooks, 1977) moves through the singles bars of Chicago.

The 'American' scope and content of New Hollywood movies has ideological contours connected to location - both in the metropolitan taste centre of New York and in revisionist westerns. Accordingly, a large number of New Hollywood films are set in New York and in the West. A map of New Hollywood narrative settings from 1967 to 1980 shows plenty of films set on the coasts. There's a fair amount of a Hollywood west and the east coast. There are even some southern settings. But the map shows a sizable empty spot in the middle. On the one hand, movies like Easy Rider, Five Easy Pieces, The Last Picture Show (Bogdanovich, 1971), Badlands (Malick, 1973), Wild Angels, and Two-Lane Blacktop represent a trans-regional landscape key to the era. On the other, if we put aside period pictures like Paper Moon, Bonnie and Clyde, In Cold Blood (Brooks, 1967), Days of Heaven (Malick, 1978), Dillinger (Milius, 1973), and The Sting (Hill, 1973), there's not much Midwest. This mostly empty contemporary Midwest does not feature farms or suburbs, but rather the declining industrial centres of Chicago in Medium Cool and Detroit in Blue Collar (the mostly unseen Mickey One [Penn, 1965] takes place in Detroit and Chicago). This relative lack of films set in the contemporary Midwest (Map 8), and their relationship to the frequent appearance of a landscape of oil and resource- 
extraction in non-Midwest films, bears further investigation to accurately draw the literal, geographical boundaries of the New Hollywood's America.

\section{Jack Nicholson and New Hollywood's Landscape of Oil and Resource-Extraction}

Jack Nicholson emerged from the 1970s as one of Hollywood's biggest stars, and his persona almost perfectly matches the New Hollywood canon's sensibility (perhaps because he's in most of the canon). After the box office and critical success of Easy Rider, Nicholson appeared in a number of key New Hollywood films: Five Easy Pieces (Rafelson, 1970), Carnal Knowledge (Nichols, 1971), The King of Marvin Gardens (Rafelson, 1972), The Last Detail (Ashby, 1973), and Chinatown (Polanski, 1974). Nicholson's performances created a star persona that not only encapsulates much of the New Hollywood's appeal to a metropolitan taste, but also quite clearly locates that sensibility on the map.

The story behind a 1970s Hollywood role that Nicholson did not get begins to explain these boundaries. The role of the oceanographer Hooper in Jaws, eventually played by Richard Dreyfuss, was intended for Nicholson. Ryan Gilbey considers the clash of schedules to have been the best possible blessing, arguing with no little enthusiasm in It Don't Worry Me: Nashville, Jaws, Star Wars and Beyond that Spielberg should

fall on his knees nightly and give thanks that Nicholson was too busy directing Goin' South. He would very likely have made the movie an in-joke, a freakshow. Nicholson's mania, at least until The Pledge and About Schmidt, has always been comforting and vaudevillian. Dreyfuss is an ants-in-the-pants control freak, but his edginess is dulled and suburban where Nicholson's is exotic and Satanic.

(Gilbey 2003: 55)

The traits that made Jaws a mass-audience blockbuster - control, dulled edges - do not have a place in Nicholson's repertoire, whereas the undesirable traits that Dreyfuss embodies are linked to the suburban. Desirable traits go unmodified in terms of their location, but the plain location is the city, where the urbane, cosmopolitan taste that the New Hollywood aspired to reside in.

For all his success, Nicholson was a New Hollywood star, not a Hollywood star. Which is to say, the metropolitan taste he represented did not appeal to studio heads interested in what plays in Peoria. In his book on Chinatown, Michael Eaton makes clear that the sort of taste that Nicholson represented was not, in the mid-1970s, what Hollywood wisdom considered appealing to a mass audience.

Forget his current status, in the mid-1970s Jack Nicholson was anathema to the boardrooms of conservative, corporate Paramount. But eventually Nicholson's deal 
was to net him $\$ 500,000$ plus a percentage of the gross, an indication of his new standing in the industry as a mainstream leading man.

(Eaton 1997: 9)

The itineraries of road movies like Easy Rider and The Last Detail can explain the Paramount execs' initial reluctance and eventual acceptance of Nicholson. For the most part these films equate substantial portions of the map with the worst of America, and when they do locate a place for praise, it's uninhabited, which means the likely audience is quite small. As Barbara Klinger argues, Easy Rider

indulges in a regionalism according to 1960s politics. Not only is the West idealized, but the South is demonized. Easy Rider's South bears the burden for all of civilization's maladies, including small-town racial prejudice, xenophobia, and the negative effects of modernization, urbanization, and industrial growth.

(Klinger 1997: 192)

Michael Ryan and Douglas Kellner, in Camera Politica: The Politics and Ideology of Contemporary Hollywood Film, argue that in Easy Rider

the ambivalent ideology of sixties individualism is most evident. Such individualism is usually male and highly narcissistic. Consequently, the ride into nature which the bikers undertake is both a metaphor for the escape from urban oppression into the freedom of self-discovery and a synecdoche for male narcissistic regression to a warm, comforting maternal environment in the face of the constraints of modern mass life.

(1988: 23)

Twenty years later, Christie Milliken continues this line of thinking, writing that 'the foreboding demythologization of their quest telegraphed via increasingly tainted/ industrialized landscapes and the many bigots they encounter as they head farther east' (Milliken 2008: 227).

The equation of modernization, and industrialization with the south is curious the north-east and Midwest have traditionally been the industrial centre of the United States - but the role geography plays in The King of Marvin Gardens makes clear that deindustrialization also plays a part in New Hollywood's metropolitan taste. In 'Boardwalk Xanadu: Time and place in The King of Marvin Gardens and Atlantic City', Maria San Filippo first describes the city's fall from its place as the lungs of Philadelphia to its state in the early 1970s: 'No longer a bucolic getaway, Atlantic City is portrayed as largely similar to urban Philadelphia: both bleak and desolate, both pervaded by corruption and pollution' (2013: para. 12). This vision of the city resembles the one John McPhee described in The New Yorker in the same year The King of Marvin Gardens was released. He writes that Atlantic City's 'vast ghetto, the bulk of the city [...] looks like Metz in 1919, Cologne in 
1944. Nothing has actually exploded. It is not bomb damage. It is deep and complex decay' (McPhee 1972: 48). But Atlantic City's decay is symptomatic of larger, nationwide changes that became unmistakable in the 1970s. While the corruption emerges from The King of Marvin Gardens' narrative, the half-abandoned city's bleak winter suffuses the film's deep focus cinematography as a metaphor for the city's ill health that comes out of a larger reorganization of the nation's economic life, away from the north-east and Midwest. San Filippo notes that Atlantic City 'serves as a metaphorical representation of America itself at the beginning and end of the 1970s' (San Filippo 2013: para. 25). The neglected places like Atlantic City have a mirror image in the growing places of the United States. The King of Marvin Gardens sees no future in Atlantic City, as any potential to make it in the older, industrial part of the United States has driven Jason (Bruce Dern) and Sally (Ellen Burstyn) to their last nickel, and close to madness. If David (Nicholson) understands correctly, which is never quite clear, Jason's work entailed helping the gangster-like Lewis (Benjamin Scatman Crothers) to expand his operations southward, much like the US economy did in the 1960s and 1970s. When David meets with the kingpin Lewis about Jason's debts, he says, 'I had the impression that he opened up some territories for you. Places that you couldn't get into. Places in the South, like Daytona, Atlanta, New Orleans. Places that brought you a lot of money'. Like other New Hollywood characters - Easy Rider's Wyatt and Billy, Bonnie and Clyde, The Last Detail's Buddusky and Mulhall, and Carnal Knowledge's Jonathan and Sandy, Paper Moon's Moses and Addie - David and Jason Staebler do not produce, but rather tell stories and broker deals, a clear indication of the New Hollywood's embrace of the shift to an economy based on money as an abstraction and the provision of services rather than industrial production. ${ }^{8}$

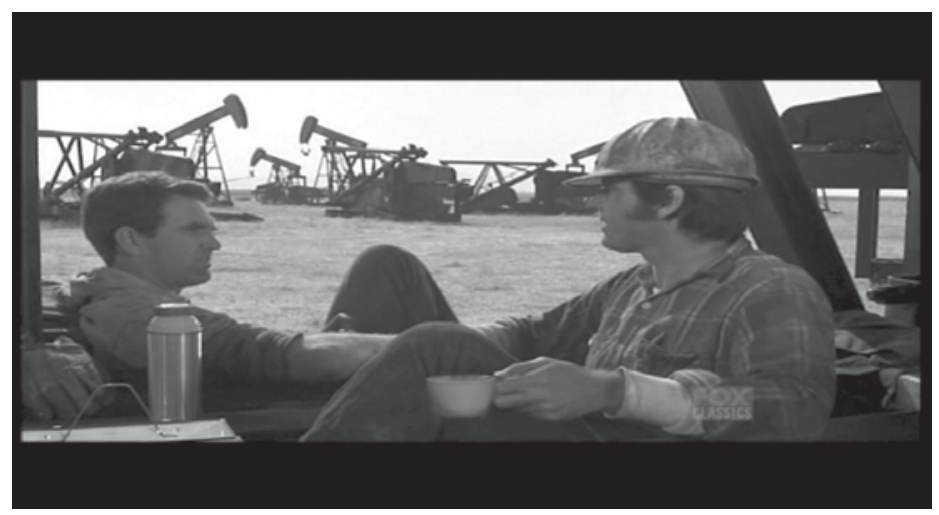

Image 16. Five Easy Pieces in southern California oil field. 
Which is not to say that New Hollywood films do not represent industrial production. However, this work often gets displaced in time or spoken of rather than shown in films and detached from particular locations in critical analyses. Days of Heaven begins in a Chicago foundry in the early twentieth century, and the 1950s-set The Last Picture Show brings Duane (Jeff Bridges) back into town in a Marshall Oil Odessa pickup truck. Five Easy Pieces' Bobby Dupea works and lives among oil, a consistency that Thom Anderson, in Los Angeles Plays Itself, sees across Los Angeles-set films: 'And most of them live next to an oil refinery. And in death they will rest next to an oil derrick'. Perhaps because of the New Hollywood's tendency to displace American ills onto Southern landscapes, Peter Cowie describes Bobby Dupea (Nicholson) as '[d]iscontented with the physical vulgarity of life in the South' (2004: 233). Bobby in fact lives and works in southern California, where the oil fields have played a role in California's economy for almost a century, and where he can credibly drive a short distance to a professional recording studio to meet with his sister, something that oil fields in Texas or Oklahoma or Louisiana cannot so readily provide. Noel King's reading is clearer in its schematic approach to the film, but he offers no location for the film's 'world of trailers, oil-rigs, bowling alleys' before describing 'the world of classical music and island homes in Puget Sound' (King 1983: 38). None of the characters are particularly enthusiastic about their jobs or potential jobs in industrial labour, which seems to be more in line with New Hollywood distrust of the square world than it does with the work itself. What appears in a fair number of New Hollywood films The Last Picture Show, The Wild Angels, Badlands, Five Easy Pieces - is the oil industry as an important part of everyday life, not just in the form of gas stations that fuel the cars in road movies, but as part of the industrial infrastructure of the nation.

A number of critics have contended with Five Easy Pieces' ending, when Bobby leaves Rayette (Karen Black) behind in Washington, jumping into a tractor-trailer that has pulled into the gas station where they've stopped. Jeff Menne reads the ending allegorically:

The film makes 'defection' more literal, we might say, in that Robert Dupea deserts his country, and his girlfriend and family, as he hitchhikes into Canada, an act that would fully resonate, in 1970, with those refusing their state's call during the Vietnam draft.

(Menne 2011: 53)

Peter Lev reads it psychologically: 'Bobby may, in fact, be heading for death at the end of the film. The driver warns him. "Where we're going, it's colder than hell"' (2000: 21). In his book on road movies, David Laderman writes that when Bobby catches a ride with the trucker, it shows that ' $[w]$ herever Bobby is, he is homeless. His confusion drives him [...] psychologically, emotionally, and literally, he is a drifter' (2002: 93). Mimi White echoes Lev's psychological reading, but opens up another possible reading, arguing that the truck driver's line offers 'the sense that the film's aimless, unmotivated, disconnected anti-hero is not really seeking anything at all, except perhaps escape and self-damnation (especially if one takes the trucker's observation literally)' (2007: 40). If we take the 
trucker literally, he's saying that the truck is heading north. Alaska can get 'colder than hell', and this very literal reading of the dialogue moves the ending of Five Easy Pieces out of the consumption-based auto vernacular landscape and towards the landscape of oil and resource-extraction.

The hitchhikers that Bobby picks up prepare the ground for his eventual flight north to Alaska. Peter Lev reads Five Easy Pieces as a road movie that considers the importance of literal spaces of possibility. 'Bobby's geographical displacements', he writes, 'do not bring him happiness, fulfilment, or peace. The closing of the frontier is announced metonymically within the film when Bobby picks up two female hitchhikers headed for Alaska' (Lev 2000: 18). Lev reads the hitchhikers' desire to go to Alaska to escape mindless consumerism - 'I had to leave this place because I got depressed seeing all the crap. And the thing is they're making more crap, you know [...] Pretty soon there won't be any room for man. They're selling more crap that people go and buy [...] filthy with Coke bottles and whiskey [...] It's just filthy' - as the closing of the frontier. Lev also notes that Bobby 'hitches a ride on a logging truck bound for ... Alaska. Bobby may understand the futility of escape, but he cannot get beyond it' (2000: 18, ellipses in original). However, such a reading focuses too narrowly on the personal experience of alienation that Helen feels. However, when she first gets in the car and announces her desire to live in Alaska because it's cleaner, Bobby replies, 'That was before the big thaw'. The big thaw, as any polar bear can attest, is caused not by weather, but by the climate change fed by the burning of fossil fuels like oil.

The number of operating Alaskan oil fields was growing when Five Easy Pieces was made, and within the narrative it would make sense for a trained oil worker to see Alaska as a place to escape to. The oil industry was fairly well established in Alaska by 1969 . The Cook Inlet had sixteen active offshore fields by 1964. Middle Ground oil field production began in 1965, and Granite Point, McArthur River, and Trading Bay production began in 1967. In the three years leading up to Five Easy Pieces' release, the Alaskan oil industry was expanding. The Beaver Creek Kenai Peninsula oil field was discovered 1967. Soon after, in March, 1968 the Prudhoe Bay oil field, the biggest oil field in America, was discovered by Humble Oil (now part of Exxon) and Atlantic Richfield (now known as ARCO), and offices and barracks were in place at Prudhoe Bay in 1969. While the US government and private prospectors had been looking for oil (among other resources) in Alaska since the 1920s, the discovery of the Prudhoe Bay reserves led to 33 new wells, increased prospecting that identified the Endicott, Kuparuk River, Lisburne, and Niakik fields, and a lease sale that drew close to one billion dollars in bids (Banet 1991: 6-7). Obviously, the ambiguity of Bobby's direction of travel is all that Five Easy Pieces provides, and speculation on where the truck stops moves beyond the scope of what can be proved through reference to film evidence. But the expansion in possible drilling locations and the money flowing into the state, when paired, would have made Alaska an appealing destination for oil workers like the restless Bobby Dupea, who offhandedly reveals as much to his passengers. 


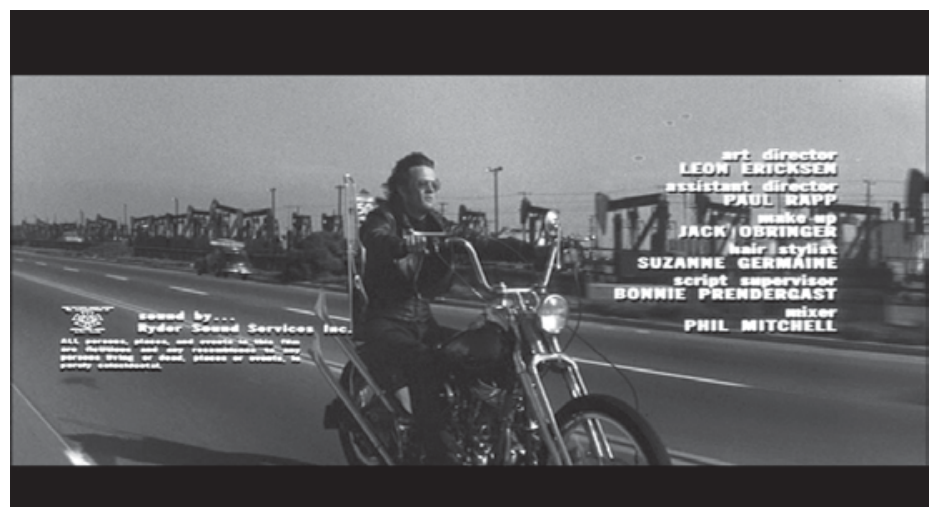

Image 17. The Wild Angels oil field stretches out during credits.

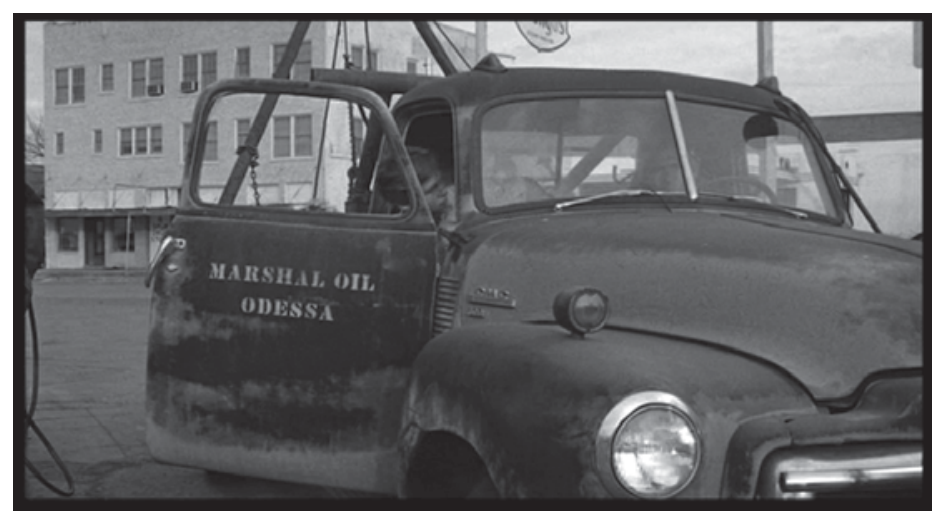

Image 18. The Last Picture Show Duane's work truck, Marshal Oil Odessa.

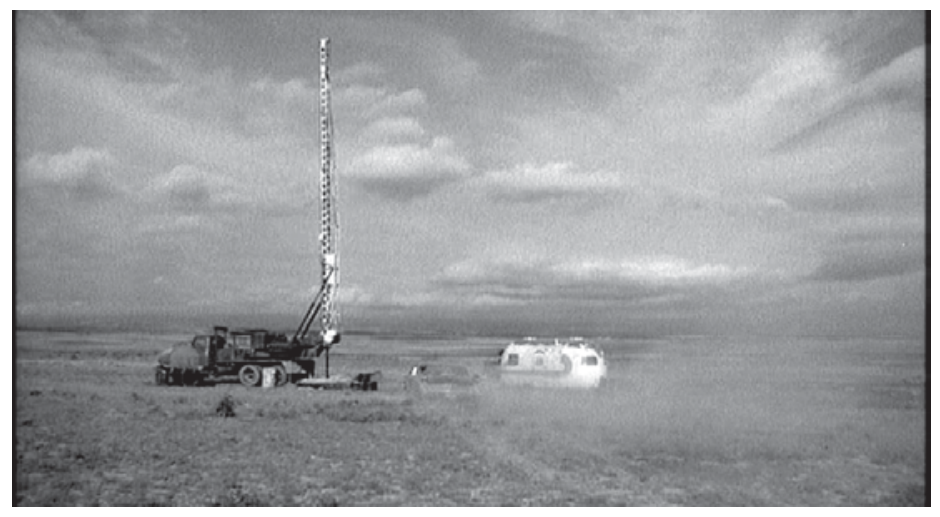

Image 19. Badlands drilling for oil. 


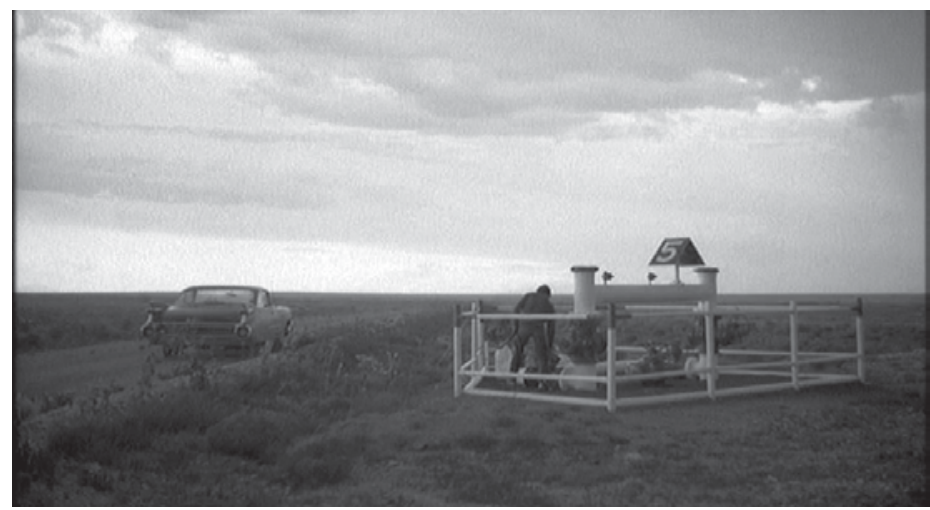

Image 20. Badlands trip gas from the pipeline.

The importance of oil, often represented in the landscape of oil and resource-extraction, recurs throughout New Hollywood films, usually offering something like a job. In The Graduate, Mr McGuire advises Benjamin to get into plastics. The title sequence in The Wild Angels uses thirteen shots over one minute and twenty seconds to move Blues (Peter Fonda) from Venice, California to an oil field. Once Blues reaches the oil field, a more than 40 -second travelling shot of Blues lazily riding his motorcycle past derricks demonstrates the oil field's size. Then Blues pulls into the work site, where he climbs right up on a rig to look for his friend, Loser (Bruce Dern). In short order, Blues helps Loser to get fired, but being a roughneck means always having work: Loser's had four jobs in six months (not bad for a hot-tempered Hells Angel). In The Last Picture Show Duane finds a job straight out of high school with Odessa Oil. In Badlands the police catch Kit (Martin Sheen) and Holly (Sissy Spacek) in the middle of a field where a new well is being drilled. Holly and Kit's flight from South Dakota through Montana presents other encounters with natural resource extraction, in the form of a refinery - 'that night we moved closer to the border, and clear across the prairie, at the very edge of the horizon, we could make out the gas fires at the refineries at Missoula, while to the south we could see the lights of Cheyenne, a city bigger and grander than I'd ever seen' - and fuel for their car - 'for gas we used the leakage from the valves of the pipelines we found along the way. Trip gas is what it's called in that part of the country'. Sugarland Express finds roadside business - gas stations, fast food joints - ideal for the Poplins' slow highway escape. All these oil and gas locations are on line; away from the city, people can work in oil and natural resource extraction.

Bobby Dupea's flight to Alaska addresses a tendency for Jack Nicholson's films, and New Hollywood road movies more broadly, to remove locations from the map of desirable places in America. In King of Marvin Gardens, Atlantic City is a dead end. In Easy Rider, Texas and the US south are stifling places that kill dreamers. The Last Detail uses its wintertime 
setting to make almost every place the three visit - Norfolk, Washington DC, New York, Boston, Portsmouth - inhospitable, cold, and unwelcoming. Five Easy Pieces finds inland southern California unappealing, most of the California Bobby drives through beautiful but not worth stopping in, and Washington state uptight. Chinatown is ambivalent at best about Los Angeles - 'forget it Jake, it's Chinatown' - and Carnal Knowledge doesn't make Manhattan look too appealing. Is there anywhere worth living in the United States? New Hollywood road movies do their best to find somewhere worth staying, but find the United States filled with squares and establishment figures who make places from suburban southern California to rural Washington to the rural south to even many of the cities on the eastern seaboard unsuitable. And at no point does the Midwest appear.

\section{The Missing Contemporary Midwest}

When the Midwest appears in a number of New Hollywood films, it is often as the past. According to the US Census Bureau, the Midwest includes Ohio, Michigan, Indiana, Illinois, Wisconsin, Missouri, Iowa, Minnesota, Kansas, Nebraska, South Dakota and North Dakota. Bonnie \& Clyde, In Cold Blood, Dillinger, Days of Heaven (briefly), The Sting, and Paper Moon are thus all Midwestern films, and all are set in the past. Of the six films, four take place during the Depression, and are set in small towns - places where it's easier to rob a bank or swindle marks. In Cold Blood is set in the recent past, in a rural-small town setting, and Days of Heaven leaves the foundries of early twentiethcentury Chicago for the Texas panhandle. Against this predominantly white, small-town, economically straitened past, the contemporary Midwest appears in New Hollywood films as two large, racially diverse cities: Chicago, in Medium Cool, and Detroit, in Blue Collar (Mickey One is set in both Detroit and Chicago, but was not widely distributed or seen). Medium Cool combines documentary and fiction film-making, and Blue Collar didactically uses freeze frames and offers no hero in its narrative, so both display a metropolitan aesthetic sensibility. In addition, these films take place in the poverty of slum housing and engage the stresses of working-class life. Most powerfully, they attempt to show how people relegated to the margins of other New Hollywood films - African Americans - understand that political action as putting representation to work in individual and collective action.

Film critics recognized Medium Cool's formal innovations immediately. Newspaper critics like Vincent Canby and Roger Ebert both noted the film's innovations. Ebert was more enthusiastic and positive; Canby couches his distaste for the film in formal terms. In the end, Medium Cool

is much less complex than it looks. The story of the gradual emotional and political awakening of John Casellis is somehow dwarfed by the emotional and political meaning of the events themselves, which we, in the audience, experience first hand, 
rather than through the movie protagonist. This is a fundamental problem in the kind of movie-making that attempts to homogenize fact and fiction, particularly when the fiction has the oversimplified shape of nineteen-thirties social protest drama and the fact is so obviously of a later, more complicated world.

(Canby 1969: para. 6)

But where Canby sees the deployment of earlier forms of political art into the current moment as misguided, Ebert sees the same phenomenon as indicative of the New Hollywood, devoting a substantial portion of his review to popular film education. He opens his review by admitting, 'I don't think I exactly want to review Haskell Wexler's "Medium Cool". He writes,

The national magazines are full of photos of [Wexler's] characters: the TV cameraman, his sidekick, his girl and her remarkable 12-year-old son. And by this stage of the game you don't want to read another rehash. So instead, I'd like to discuss the form of 'Medium Cool.' [...] Five years ago, this film would have been considered incomprehensible to a general movie audience.

(Ebert 1969: para. 2-3)

Instead of an extended review of the film, Ebert explains how a major studio could release a film like Medium Cool by explaining a shot from The Graduate. Ebert conceives of New Hollywood's integration of European, Asian, and experimental film form as showing that 'moviemakers have at last figured out how bright the average moviegoer is. By that I don't mean they're making more "intelligent" pictures. I mean they understand how quickly we can catch onto things' (Ebert 1969: para. 4). This ability to cut films differently and be understood opened 'things' up. And by 'things', Ebert means formal innovation.

Critics working with slightly more temporal distance from Medium Cool's (not particularly successful) theatrical run retain a focus on its formal innovations, but increasingly turn to its political valences. In an essay on New Hollywood films in a 1970 issue of Film Quarterly, Stephen Farber argues that, compared to Easy Rider, Midnight Cowboy, and Alice's Restaurant, 'Medium Cool contains the fullest and most precise record of the way in which present-day America oppresses us all' (Farber 1969-70: 12). The same approach that Canby found lacking in the riot scenes, to Farber, achieves a significant political outcome: 'Wexler uses footage from the 1968 Chicago police riots in a non-documentary, intensely subjective way, to enlist a passionate response of terror and outrage' (Farber 1969-70: 12). While the film is not perfect, its unabashed political nature distinguishes Medium Cool as 'an angry, passionate indictment of the forces of repression in contemporary America' (Farber 1969-70: 3). In the late 1980s, Robert Sklar began the push to locate Medium Cool at the centre of the history of American film. He argues that the film is 
an exemplary work with which to begin a reconsideration of American films in the 1960s. It stands at the crossroads of so many esthetic and ideological strands of the era: the merging of documentary and fiction, the interplay of politics and public theater, and the attempt of a radical independent filmmaker to present his work through the dominant distribution and publicity system.

(Sklar 1987: 51)

Also writing in the late 1980s, Ryan and Kellner similarly argue for Medium Cool as an essential piece of US film culture, in their account just as much for its political content as for its formal innovations (Ryan and Keller 1988: 35). Writing in the twenty-first century, Christie Milliken places Medium Cool next to the film that proved to Hollywood that formally and thematically innovative films could make money: 'many films reflected the counter-culture and Hollywood's brief flirtation with overt left-leaning subject matter. Two films that epitomized this ethos are Medium Cool, directed by cinematographer Haskell Wexler, and Easy Rider' (Milliken 2008: 222-23). But while Easy Rider's politics are more individualist, Medium Cool's are much more self-consciously collective and national in scope.

However, amidst all the discussion of Medium Cools formal and ideological innovations, an absence comes into view - a neglect of any discussion of the African Americans who appear in the film. To again proceed chronologically, Vincent Canby's New York Times review never mentions African Americans, but does note that the child actor Harold Blankenship 'really is an Appalachian refugee and has the stunted look of generations of deprivation in his physique, in his eyes and in a profile that is hard as a hickory nut' (Canby 1969: para. 7). Ebert's review notes the fact-fiction slippage - 'There is a series of set-up situations that pretend to be real (women taking marksmanship practice, the TV crew confronting black militants)' (Ebert 1969: para. 15) - only to get it backwards: the black militants confront the TV crew. In addition, the two examples he cites come in reverse chronological order: the scene in which black militants confront the TV crew is immediately followed by the shooting range sequence, a not-too-subtle cause-effect chain built into the montage. Stephen Farber notes,

An irony about the film is that although Wexler feels obliged to refer to all of the social cataclysms of 1968 - the police brutality, the Negro revolution, the King and Kennedy assassinations, the war, the violence of white backlash - his most memorable scenes are not the documentary records or the scenes of social protest, but the tender, affectionate scenes with the Appalachian woman and her child.

(Farber 1969-70: 12-13)

Curiously, Farber doesn't deal with any aspect of the 'Negro revolution', he simply notes that it is one cataclysm among many fighting for space. The primary cataclysm, across criticism of Medium Cool, takes the form of the protests outside the Democratic National 
Convention. For Sklar, 'Perhaps the primary virtue of Wexler's film is that it forces us to question' whether 'the visual record of [the protesters'] ordeal will establish their rectitude' and that 'the camera functions as a moral watchdog' (Sklar 1987: 51). In this formulation, the protestors are the centre of the film, and the camera's role in the creation of images of Chicago 68, taken to mean riots associated with the convention, the ideological question in formal terms. As Ryan and Kellner put the formal-ideological overlap, Medium Cool

was a major statement of the radical position. It depicts the coming to political consciousness of an apolitical news cameraman. This trajectory is rendered as a move from fiction to documentary in the narrative, as if the character's conversion consisted of a departure from a fictional universe and entry into a more real world.

(Ryan and Kellner 1988: 35)

A curious privileging of traditional narrative form sits at the centre of this appraisal, treating the ending of the movie as the most important part of the film. But if formal innovation is to mean anything, then treating the film's ending as the summary of its 'message' misses key moments at other points. In the film's 111-minute running time, John goes to an African American neighbourhood about 45 minutes into the film, and the scene that follows lasts a little more than ten minutes. And while Ryan and Kellner argue that the film drives towards its formal and ideological statement in the convention's police riot, the scene in the African American neighbourhood is literally and figuratively at the centre of the film, the key ten per cent of the film's run time. But, curiously for critics of Ryan and Kellner's political leanings, they perceive 'real-world' politics as centred on a national party convention and the reaction to it. Their account of Medium Cool thus neglects a clear case of politics emerging from the bottom up. That is to say, the protesters in Grant Park are not the only people engaged in political action in 1968 Chicago.

The scene in which the cameraman John Casellis (Robert Forster) meets Eileen (Verna Bloom) when he returns a homing pigeon to a recently-arrived-in-Chicago Appalachian boy does not immediately lead to the fictional narrative's romance, as you might expect in a Hollywood narrative, but rather turns towards its political heart. As he makes awkward conversation with Eileen, John gets a page from the office, sending him to an interview. When John and his sound man Gus (Peter Bonerz) arrive at a taxi garage, Gus badgers a black man washing the cars, quickly escalating from questions to a shouted command: 'Would you mind shutting this off? We gotta make sound here would you shut this off? Shut it off!' The police exhibit a similarly antagonistic relationship with Frank Baker (Sid McCoy), an honest cab driver who returned $\$ 10,000$ left on the floor of his cab, and whom they do not believe because he's black. During the police interrogation of Frank the good Samaritan, John and Gus stay in the background, living up to John's claims that they shoot the news rather than make it. John later talks to Carlin (William Sickingen), a local news director, and asks to do a follow-up interview with Frank, but Carlin turns him down because, 
I got a convention coming up. Plus I got a war. Plus I got baseball. Plus I got a nervous city. Plus, I got chickenshit cameramen that are afraid to go into the ghetto without police protection. No. N. O. You stay outta those neighborhoods until I send you in.

However, the next shot indicates that John and Gus disobey Carlin's order. In a travelling shot, a group of African American pre-teens run down the street, shouting greetings to the 'TV man' behind the car/Wexler's moving camera. But John gets more than he bargained for when he goes to a black neighbourhood to interview Frank again. Before John arrives, Wexler shows the interior of Frank's place, where his activist friends and neighbours forcefully question his decision to return the money. One friend asks if Frank knows what the $\$ 10,000$ he found could have bought, and Frank can only admit that he's not quite at the buying guns and ammo portion of his political consciousness. The highly politicized discussion taking place makes clear that John will meet a houseful of people who can and will detail exactly how and why they have historically been erased and excluded from the image-making system John represents - and exactly why that situation must end.

John's follow-up interview with Frank is at the heart of the film's fictional narrative, and scene signals its own artifice as soon as John and Gus arrive at Frank's place. When John knocks on the door, one of the men inside, Jack, walks up to the door and stops. He puts on a pair of sunglasses and waits for a theatrical moment, making the visitors wait outside the door. Upon opening the door, Jack repeats John's questions back to him, aggressively (but humorously) short circuiting the communication. John meets Jack's self-conscious performance with earnest requests to speak with Frank, and Frank soon appears to rescue John from any further discomfort at the doorway. Wexler leaves Gus at the door and moves John and Frank into the kitchen, and cuts between the two conversations. In the kitchen, Frank tells John that since finding the money, his life has become 'total confusion'. At the door, Jack needles Gus, especially his pageboy. When Gus admits that the pageboy is a one-way system that gives him orders, Jack delivers a line of dialogue that loudly announces its metaphoric function: 'he means he's a receiver and not a sender. The contrast between John's failed attempt to get more of Frank's story out (for reasons that are never made clear) and Jack's neat description of what the film-andsound guys really are - instruments of the media complex's instructions - lays bare the logic behind the news director Carlin's decision not to support John's follow-up interview.

Up to the point of John arriving and speaking to Frank, the entire scene is shot and edited as a fiction film. When John loses his possible follow-up interview, a chance to represent Frank, the film begins to move away from fiction, and towards documentary. A confrontation between John and a black woman whose name is never mentioned (played by Barbara Johnson) narratively masks the move from fiction to documentary. After failing to convince Frank to do the follow-up, John just wants to leave - there's nothing else for him on the South Side. But the people in the apartment act together to show him otherwise. First, the black woman introduces a critique of 'TV man' John's complicity in 
the media's exclusion of black people. She reminds him, 'you said you wanted somebody. So you want to talk to somebody. You want to hear what's being good - you know, what's going on. What black people are doing. When John tries to give her the brush off, she and a man stop him, with the man saying, 'No. You gotta start respecting our women'. When John tries to blame his schedule, the man says 'make time', an idea the woman expands on in terms of a black presence in media: 'I want to talk to you about what I'd like to do. You see you people are always busy putting your kind of people on and what you want. So I want to talk to you about what I want to do. The entire sequence plays out in a long shot, equally shared by the three figures, the woman at the centre. Even though she makes a number of gestures that a fiction film might accentuate with a close-up - her reaction

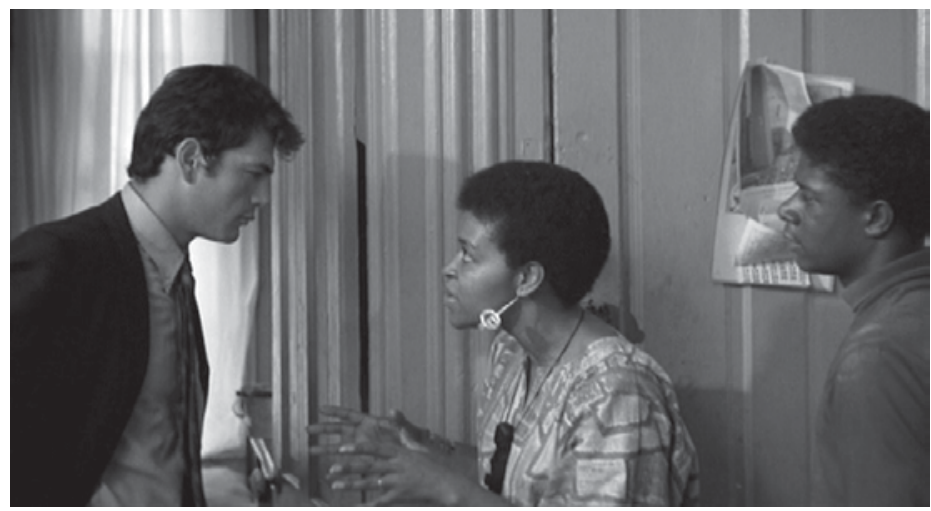

Image 21. Medium Cool 'you want to talk to someone?'

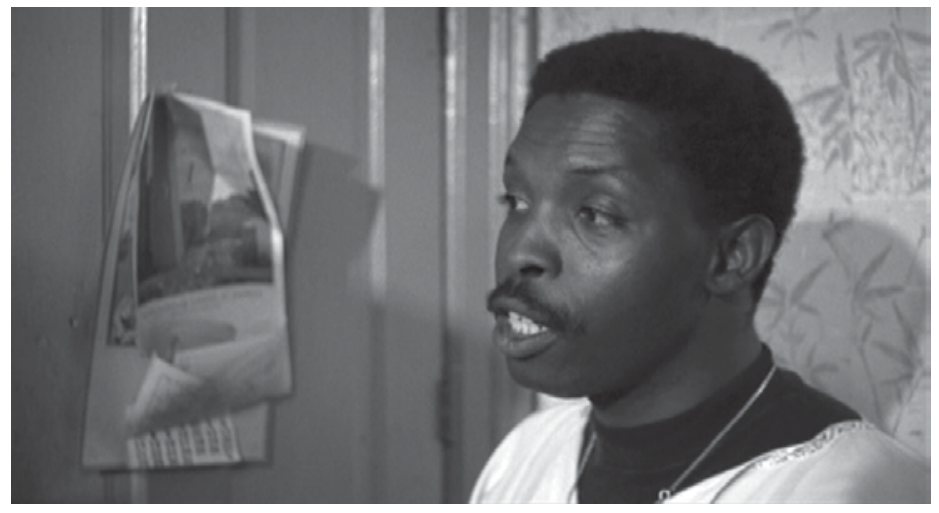

Image 22. Medium Cool explanation with no reaction shot. 
to John's repeated use of 'honey' and her ironic hand-framing of her face when she says 'your kind of people' - the scene plays out in one take. Only when John, for a fifth time, speaks dismissively to the woman does the scene cut away, to two men who react to the sound of raised voices. They both move quickly to defuse what almost escalates to a fight. The woman confronts John within the film's fictional narrative, and establishes a systemic critique of the system that John represents, and also John's complicity in it. The nevernamed man who steps in to calm the anger of the woman and man not only stops potential violence, but also demystifies the image-making process. The shot begins as a medium two-shot, and then the camera moves slightly to the right, away from John and towards the unnamed man. Upon turning to the man, the camera zooms into a close-up, which makes the man a version of a talking head, explaining what just happened to John.

You came down here to do some sort of jive interview. You did that. You came down here with fifteen minutes of a black sensibility. So you don't understand that. You came down here to shoot fifteen minutes of what has taken three hundred years to develop. Grief, you know. And all we're trying to explain to you is that you don't understand.

John replies, 'I do something. You see I do it well. That's my job'. At the reply, 'No, but you don't do it black enough. You can't, because you're not black. We are, and further explanation to John, rather than cutting back to John offering a reply, Wexler cuts to a close-up of another black man talking directly to the camera. In this cut the fictional narrative gives way to documentary footage of political speeches that take place not on the convention floor of the International Amphitheatre, but in an apartment.

In a number of critical accounts of Medium Cool, the interaction of media and politics centres on the Democratic National Convention, not the people in Frank's apartment. Even when critics engage with the scenes in Frank's apartment, they treat them as secondary matters. In James Chandler's piece on 'the future of Critical Inquiry and its place in criticism' he describes Medium Cool as 'a film almost as much about the policing of race politics on the South Side of Chicago as it was about the policing of national media politics' (Chandler 2004: 356, emphasis added), which seems to confine the scene's concerns to South Side when the claims made by the people who speak directly to the camera say something much more national in scope. New Hollywood films might have been formally innovative, but not so innovative as to discard completely a beginning, a middle, and an end that ties the film together. The 'radical position' that Ryan and Kellner read in the film's last section in fact occurs during the scene at Frank's place, most plainly in the turn to direct address of the camera. In the first direct-address shot, a man picks apart the two parts of 'human interest' that John claims for his possible interview with Frank and then sketches the spatial contours of the representational power of which John is a part, calmly saying, 'when you walked in you brought LaSalle Street with you, City Hall, and all the mass communications media. And you are the exploiters. You are the ones who distort and ridicule and emasculate us. The second direct-address sequence 


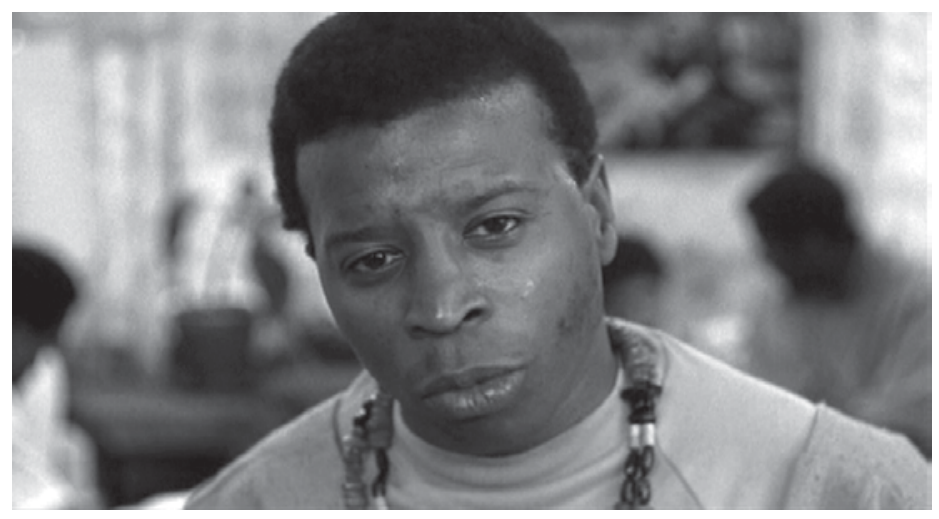

Image 23. Medium Cool first direct address.

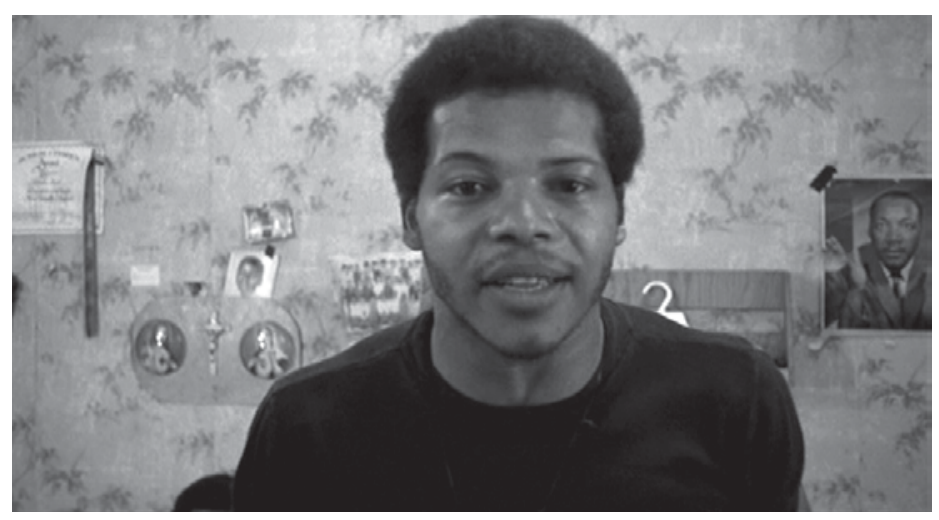

Image 24. Medium Cool second direct address.

builds on the first's concern with media representation and the multiple meanings of 'human interest'. It starts as a medium shot of a black man in a black t-shirt, sitting on the arm of a couch. He begins, 'You don't want to know, man. You don't know the people. You don't show the people, Jack. I mean, dig, here's some cat who's down and out. He stands, and the camera adjusts, framing him in close-up. He continues,

I mean he's nobody. So he says to his old man, you know he says, man like I'm nobody. I mean, you know I'ma die and ain't nobody even know I lived, you dig? So the cat finds a brick and he throws it through Charlie's window, you understand. Or he takes a gun and he shoots. 


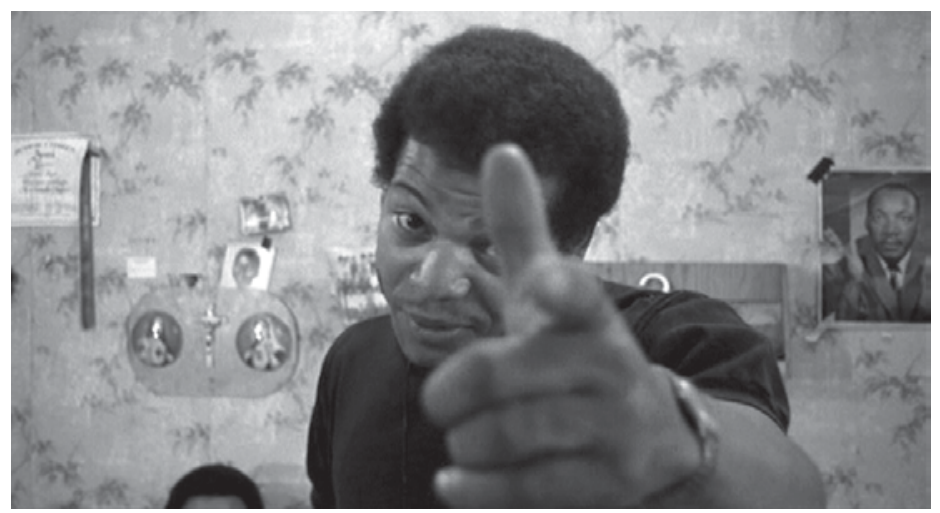

Image 25. Medium Cool second direct address, making finger gun.

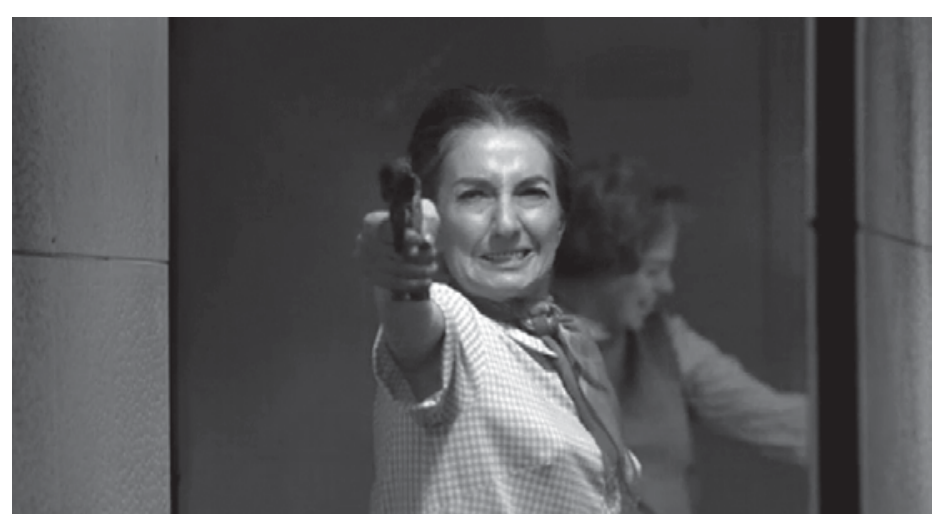

Image 26. Medium Cool rhyming shot.

At 'shoots' the man points a finger gun right into the camera and pulls the imaginary trigger in an exaggerated motion. After signifying on shoot, the man, like the previous speaker, concludes with an analysis of the media's power of representation.

Then the cat lives, man. He really lives, you dig? A hundred million people see the cat on the tube, man. And they say oooh the former invisible man lives, everybody knows where he went to school, well they know about his wife and kids and everything. You dig? Because the tube is life, man. Life. You make him an Emmy, man. You make him TV star of the hour. On the six the ten and the twelve oclock news. Cause what the cat is saying is truth. Why don't you find out what really is? Why you always got to wait till somebody get killed, man? Cause somebody is gonna get killed! 
As he says 'killed', a sound bridge of a gunshot coincides with a direct cut to a close-up of a middle-aged white woman squeezing a trigger, followed by a left-to-right move of the camera to show a number of women, all white, taking target practice. On the one hand, this cut pulls the film out of the documentary form it had briefly inhabited and moves it back into the fictional. On the other hand, the juxtaposition amplifies the perceived danger in the man's speech and the culture it describes.

The four major speeches in Frank's apartment - the 'people like me on the screen' and 'I saved your life' speeches in the fictional narrative and the direct addresses in the more documentary moments - clearly echo an earlier scene of a cocktail party. While John is the only white person in Frank's apartment, at the cocktail party only one black person is present. During the cocktail party, John flutters about, getting drinks for people while well-dressed white people discuss the role of the media and the impact of what appears in the media. However, the two sequences do not echo each other formally: the cocktail party features overlapping dialogue and bodies passing between the action and the camera, whereas the sequence in Frank's place features conversation, not chatter, and a simple mise-en-scène. In Frank's apartment, the four never-named black people discuss the same thing as the cocktail party folk, but John cannot lark away to get more drinks. It seems to me that the direct-address sequence presents John's point of view, through the camera. In a more pessimistic reading he films the material as a way to finally get out of the apartment; in a more politically optimistic reading the speeches he records document part of his coming to consciousness.

In this optimistic reading, Medium Cool points towards an urban politics that makes change from the margins. Allan Siegel sees films such as Medium Cool, Battle of Algiers (Pontecorvo, 1967), Z (Costa-Gavras, 1969), Blow-Up (Antonioni, 1966), Weekend (Godard, 1967), Hour of the Furnaces (Solanas and Getino 1968) as part of a late 1960s global sense of the importance of urban politics to the crisis of capitalism. For Siegel, these films

narrativized a visual and psychological geography that was both specific to particular locales but also symptomatic of a larger global complexity. These films presented us with a series of compacted urban representations which strategically examined destabilized social relations and the ambivalent nature of social space.

(Siegel 2003: 147)

But if John comes to consciousness, his fatal car accident soon after seems too pessimistic, especially if we are to follow critics who read the film's ending as its primary, summative political statement. Describing films in the late 1960s and 1970s, especially New Hollywood films like Medium Cool, Bert Cardullo links form and ideology, but overemphasizes the importance of endings: 
in this sophisticated epoch, unhappy endings that confirmed our previously-arrived-at unhappy conclusions about the state of society were more than acceptable. In this way, a film like Medium Cool was certain to have its protagonists die as a more or less direct result of the evil, in the form of a brutal police-action, unleashed at the Democratic National Convention in Chicago in 1968.

(Cardullo 2010: 98-99)

The police do not 'more or less' kill John and Eileen, who die in a car accident caused by momentary blindness, not by the police or national guard. And if any characters would be certain to die as a direct result of evil to confirm the parlous state of society, it would be the politically militant and active African American men and women in Frank's apartment, not a couple of white people. Medium Cool has much the same ending as Easy Rider, but what John and the media he represents 'blew' is much more substantial, especially given his apparent coming to political consciousness. Coming as it does at the last, John and Eileen's deaths register as the product of the political strife the film has shown, but the systemic racism of the media apparatus and larger American culture does not register with the same power. But reading only the ending misses Medium Cools desire to show the creation, maintenance, and critique of the political power in media representation, as happens in the (fictional) collective explanations and in the (documentary) directaddress scenes. Thus, representational power appears not just as end product - news coverage of large-scale public moments the whole world is watching - but also in the everyday exclusions, sidelinings, and whitewashings of the disempowered.

\section{Blue Collar}

In Blue Collar three Detroit auto workers - Zeke (Richard Pryor), Smokey (Yaphet Kotto), and Jerry (Harvey Keitel) - decide to rob their union headquarters both to solve their own financial problems and to strike a blow against a union that is not representing them adequately. Their robbery only nets a few dollars, but it does land them a notebook filled with evidence of the union's illegal activities. Their plan to blackmail the union gets Smokey killed in a workplace 'accident', which leads Zeke to accept the union's hushmoney promotion, and Jerry to reluctantly agree to testify against the union, causing the violent and racially charged confrontation between Zeke and Jerry that ends the film. Blue Collar's non-coastal ('truly' cosmopolitan), non-south (different history), nonwestern (film genre constraints) Midwestern location places de-industrialization and the intersection of racial and class politics at its heart, both in what it does on screen and the cultural memory of the former Arsenal of Democracy.

Blue Collar, in its outlines, resembles a number of key events in the intersections of class and race in the 1970s. Broadly speaking, 'Detroit has a long history of principled rank and file insurgency, not just reactive attempts to rip and run' (Russell et al. 1978: 28), as early 
as the 1937 conflict between the United Auto Workers and Henry Ford's Pinkertons. In Hard Hats, Rednecks, and Macho Men: Class in 1970s American Cinema (2009) Derek Nystrom links Blue Collar with the late 1960s Detroit-based League of Revolutionary Black Workers, a group which emerged out of a wildcat strike that responded to a situation similar to Blue Collar's line speedup. Later (and outside of Detroit, in north-east Ohio), the 1972 Lordstown strike was led by a young and multiracial group of auto workers like Zeke, Smokey, and Jerry. These historical and contemporary industrial actions are refracted throughout Blue Collar. Nystrom's account of the political appeal of Blue Collar to a wider audience focuses on the potential of class politics:

what is often at the heart of the middle-class's fascination with representations of working-class life and experience is the forms of political association, resistance, and struggle these cinematic subjects bring to life - forms of political being that the middle class has trouble imagining itself inhabiting.

(Nystrom 2009: 178)

I want to build on Nystrom's reading of Blue Collar by concentrating on the film's location as the driving force behind its conflicted politics and imagination of forms of political being, and why, like Medium Cool, a film set in the industrial Midwest has only appeared on the edges of New Hollywood histories.

The majority of Blue Collar was shot in Kalamazoo, Michigan, not Detroit, but the film's representation of Detroit hinges less on actual locations than on a combination of a recognizable industry and that industry's declining fortunes in the US economy. Michele Russell's Cineaste feature 'Blue collar: Detroit moviegoers have their say' (1978) features a series of interviews with residents of the city where Blue Collar is set, all of whom consider Detroit both as a literal place and as an abstract sensibility. Jeff Goodman, 'a former auto worker presently teaching sociology part-time in Detroit area community colleges', offers the most optimistic of readings, praising both the solidarity the workers show and their individual intelligence:

The three heroes of the movie are the kind of workers who abound in cities like Detroit. They have an ingenuous American moral sincerity, a cameraderie (sic) that transcends personal racism, drive that defies resignation, and a refusal to be suckered.

(Russell et al. 1978: 31)

Another former auto worker, Martin Glaberman, provides an insight into the way in which the difference between the film's shooting location and narrative setting registers, but that difference does not change the nature of industrial labour in Detroit. 'Because the film was made at the Checker Cab plant in Kalamazoo', he explains, 'the technology is considerably behind auto production in the "big three." Nevertheless, the feel of the oppression of the line was there. So was the feel of the oppression in daily life' (Russell et 
al. 1978: 28). The Spark, a publication from a plant organizing group, echoes Glaberman and Goodman's assessment of the film's imagination of the internal life of line workers, and connects that affect, with no small amount of resignation, to the need for collective action:

[I]t shows what life is like for workers. And it shows that individual solutions don't work. It shows that the solutions that workers tried to find for their problems didn't work. In this way the movie is very accurate. But it leaves you feeling like this is the way that it has to be.

(Russell et al. 1978: 31)

On the one hand, the specific knowledge of how the auto industry production line works is centred in Detroit, which means the film's Detroit audience can recognize the difference between production line speeds by company. On the other hand, those same Detroit auto workers replace the actual work on the shop floor - the physical toil - with more abstract ideas like drive, 'feel of oppression' and a feeling generated by a lack of concrete change. The conflict between the specifically Detroit industry and the larger questions the film poses address a specific history of the auto industry's union actions, such as the Lordstown strike, and the more general deterioration of working-class life in the de-industrializing US economy.

In the issue immediately after their canvassing of Detroit movie-goers, Cineaste features $\mathrm{Al}$ Auster and Leonard Quart's review of Blue Collar and another union-centred film, F.I.S.T. (Jewison, 1978), which bemoans the 'old melodramatic formulas' that drive Blue Collar (1978: 7). The role genre plays in Blue Collar appears consistently in academic criticism; Nystrom notes, 'much of the disappointment in the film for many activists (and a number of film critics) was its failure to build upon its hard-won realism and offer something other than a genre exercise' (Nystrom 2009: 163). The generic necessity of the robbery, the fallout, and the crime's solution certainly drives the film's plot, and short-circuits a more radical systemic critique. Before getting tied up in the necessities of a genre caper picture, Blue Collar locates the stresses of working-class life on white and black working bodies. Zeke's first complaint to his union concerns his perpetually broken locker, which leads to a small and daily injury to his finger. Similarly, Jerry describes his job welding as 'a god damn killer, Miller. I'm getting brain cancer'. Working-class kids also bear stress bodily. Jerry's son Bobby is still hungry after dinner and his daughter Debbie injures herself when she tries to hand-make the braces Jerry cannot afford. Even the scale of the power working-class bodies struggle against registers in Blue Collar's mise-en-scène. When discussing paying for safecracking expertise, Smokey and Zeke are shot in an extreme high-angle long shot in which the plant's machinery looms over them, capital dwarfing workers. And in most scenes on the shop floor, only part of any worker appears in the frame, the rest obscured by an assembly line designed for the car's ease of motion, not the workers'. While it does not escape its entertainment cinema generic 


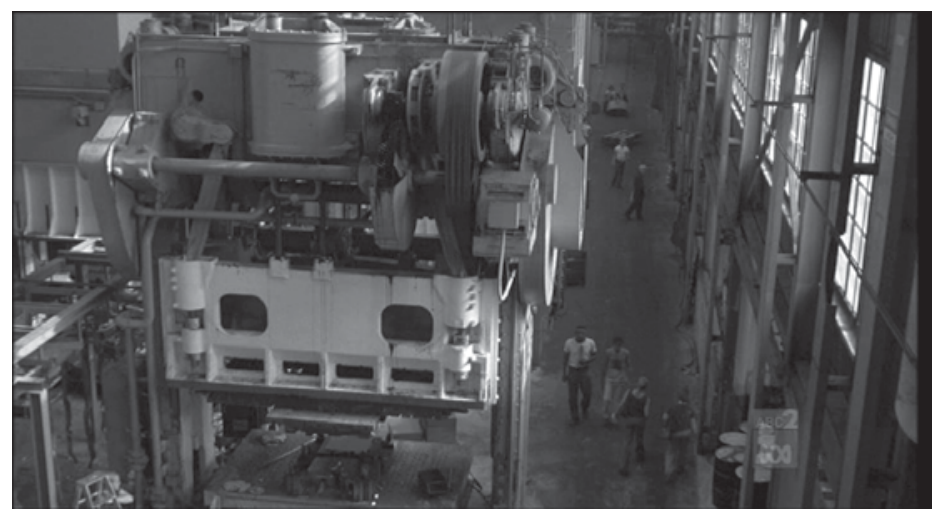

Image 27. Blue Collar capital dwarfs labour.

constraints, Blue Collar's narrative setting links its caper motive and meaning to larger cultural narratives that Detroit's declining fortunes signal.

Blue Collar was not the only film to consider the role unions might play in American economic life moving into the 1980s. The auto industry in Blue Collar and textile industry in Norma Rae (Jewison, 1979) both have significant connections to particular locations and to their regions: Detroit and the industrial Midwest, and North Carolina and the right-to-work south. Zeke's understanding that, 'the plant just short for plant-ation' equates the systemic racial oppression in the plantation south with the industrial Midwest, where many southern African Americans relocated during the twentieth century's great migration. In this manner, Blue Collar, in places, contributes to the union-friendly films of the era's tendency to see 'the limits placed on a radical class imaginary by any vision of the working class that sees the white, blue-collar male as a synecdoche for the whole' (Nystrom 2009: 178). In addition to conceiving of unions as more than white, blue-collar males, these films, especially Blue Collar, also trouble the Treaty of Detroit model of unionization that trades shop floor militancy for negotiation, steady wage increases, and job security. This approach, pursued by the UAW (and the fictional union in Blue Collar) leads to what Jerry describes as, 'House. Fridge. Dishwasher. Washer. Dryer. TV. Stereo. Motorcycle. Car. Buy this shit. Buy that shit. All you got's a bunch of shit. You don't even own it. Can't give it back cause it's already broke down'. There's no small amount of irony in Jerry coming to this realization after a cocaine-fuelled orgy, but his understanding of the emptiness of the mass consumption appears in a recurrent piece of set dressing that combines bodies and business unionism with an ironic reference to the shop floor: safety signs. When the workers punch out, a little sign next to the time clock at the bottom left of the image reminds the workers to 'Talk About Safety'. When the foreman 'Dogshit' Miller 
(Borah Silver) chases the workers off their lunch break two signs about safety - a big green 'Think - Practice Safety' sign with a little black-and-white 'Safety First' sign beneath it - are to Miller's left in a long shot. In the reverse shot of the workers, another 'Think - Practice Safety' sign is in the background of another long shot, this one with more about twenty workers moving through the frame where Miller was alone. Safety, as the film makes clear, does not concern bodily health - Zeke's finger is hurt, Jerry's inhaling noxious fumes - but what little the union can offer: the barest sort of economic safety.

Medium Cool plainly understands the concerns of Chicago's African American people as significant - their direct address to the camera/audience surrogate midway through the film establishes the importance of the formal fiction-documentary rupture that the later riot uses to further advance the film's position. But their midstream placement in a more or less narrative film means that their concerns stay in the background. Blue Collar seems to get around this trouble by placing the African American Zeke in conflict with the white Jerry in the film's final scene. The film-closing racially charged verbal showdown concerns who made the correct choice - Zeke, who accepted the union's offer of a promotion to stop investigating their illegal doings, or Jerry, who will testify against the union:

Jerry: I ain't the one who sold out, nigger, you are.

Zeke: Yeah? You jive honky. You ain't lookin' out for nobody but number one, that's you ain't it? Jive white boy.

Jerry: You ain't nothing now you fuckin' nigger.

Zeke: I hope your mother and father there protect your ass, cause you gonna fall.

Jerry: Fuckin' nigger!

The escalating tension and anger in the scene finally breaks, with Jerry and Zeke attacking each other, their fight stopped by a freeze frame that turns to red as the credits roll. At the freeze frame, Schrader adds in a voice-over. And not just any voice-over, but a repetition of previous line of dialogue from Smokey: 'They pit the lifers against the new boys, the young against the old, the black against the white. Everything they do is to keep us in our place. On the face of it, Smokey's description of the situation explains the freeze frame, summing up the film's fatalism and pessimism; the fight represents the squabbling for crumbs that serves the bosses' (union and management) interest. But two changes to Smokey's voice-over complicate the film's apparent fatalism and pessimism and signal that the middle of the film matters as much, if not more, than the end. First, a significant portion of Smokey's earlier speech is trimmed away. In the earlier speech he begins by asking Zeke and Jerry, 


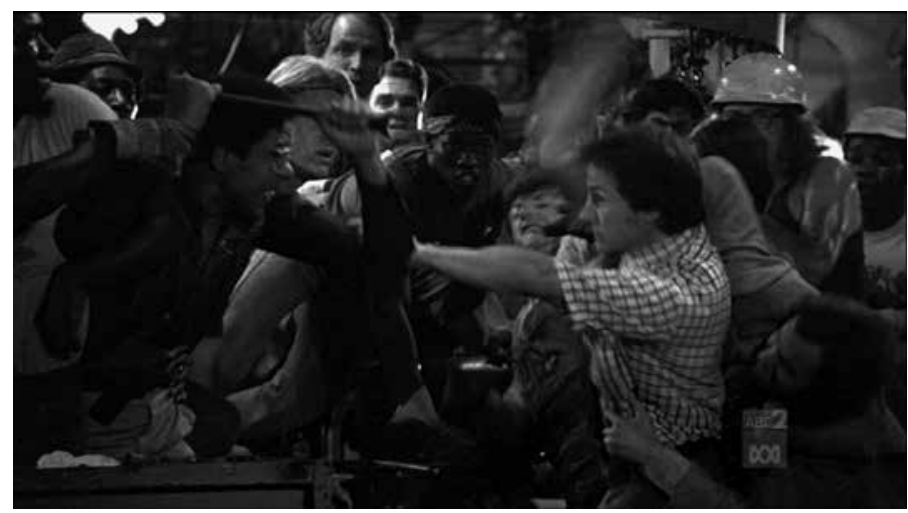

Image 28. Blue Collar final image, in freeze frame.

Why do you go to the line every Friday? [...] Because the finance man is going to be at your house on Saturday, right? [...] And that's exactly what the company wants. To keep you on the line they'll do anything to keep you on their line.

This first change reduces the amount of criticism that bosses and the 'House. Fridge. Dishwasher' consumerist culture face in trapping workers. Schrader's second change shows more cynicism. In the earlier scene, Smokey says, 'Everybody to keep us in our place. The change to 'everything they do', acts as more than a trick of memory, but as a way to shift responsibility away from the system and towards supervisors like 'Dogshit' Miller and, now, Zeke. A great deal of the film's dialogue is clearly post-dubbed, so the earlier scene's use of 'Everybody to keep us in our place', which barely makes sense grammatically, signifies Smokey's frustration with something much larger than the union that takes on racial significance by virtue of its placement directly after 'the black against the white. The change to 'Everything they do' in the voice-over narrows the scope of the final violent confrontation and reduces its connection to systemic racism. Nystrom's critique of Blue Collar also serves as a wider critique of New Hollywood films: 'racial concerns [in some films] were almost always subordinated to the cycle's focus on white, middle-class disaffiliation (Swope is the exception that proves the rule)' (Nystrom 2009: 161). Blue Collar confronts us with the intersection of class and race in contemporary life and politics by returning to Smokey's film-midpoint insights accompanying the final image, but edits them to create a false memory of Smokey's thinking that de-emphasizes race. This lost opportunity to contend with the changing fortunes of Detroit certainly makes Blue Collar an imperfect film, but it also makes it a compelling symptomatic text. 
While Blue Collar does not approach the insight of Thomas Sugrue's The Origins of the Urban Crisis: Race and Inequality in Postwar Detroit (1996), it takes a few steps away from the white male navel gazing about alienation common to New Hollywood films in favour of an imperfect first step towards contending with de-industrialization's effects on the sort of people found in Detroit in the late 1970s, working-class blacks (and whites) just holding on.

\section{Conclusion}

For all the formal innovation in many of the most-studied New Hollywood films, they share with Studio Hollywood films a fairly consistent focus on middle-class heterosexual white men. New Hollywood films certainly took on more explicitly political subject matter, but the individualist focus of most New Hollywood films treat politics as a matter of personal psychology. In other words, in most of the canonical New Hollywood movies, heroes (and anti-heroes) do not really act beyond the individual, who tends to look like a white, middle-class heterosexual man. Such an individualist freedom, in many New Hollywood films, takes the form of the private motorcar on the highway. New Hollywood films register an ambivalence about the cost of this freedom in the frequency with which the landscape of oil and resource-extraction appears across multiple regions of the United States, none of which seem to offer a place worth living. On the other hand, though they are set at the geographic 'centre' of the United States, Medium Cool and Blue Collar appear as geographic outliers among New Hollywood films. Medium Cool and Blue Collar link formal and ideological innovation to groups who were not at the centre of power, tackling sociocultural and political issues that extend beyond the individual and into the potential for and problems of collective action.

Judging by the New Hollywood films set there, the western, eastern, and southern edges of the United States aren't so radical. The films set there may formally be innovative and narratively interesting, but their road tripping up and down the coasts and through the empty west and south of road trip freedom is locked into a petro economy that, after 1973, was not only a declining 'power', but also just as responsible for the end of the New Hollywood as Jaws' success and the turn towards corporate blockbusters. The home of all those people who liked Airport, flyover country, ends up being the place where actual political action that extends beyond individual men wrestling with their alienation (usually blaming and villainizing women along the way) takes place. The absence of the Midwest emerges as a product of New Hollywood film-makers abjecting Square American cultural conservatism. But Middle America is more than an ideological abstraction or mystification for conservative ends, given form in a particular aesthetic taste regime. There is more to the contemporary Midwest than farms and small towns, and more than the Chicago and Detroit New Hollywood films represent. These literal places, where key events in the last half of the twentieth century happened - the 1968 
Democratic Convention, major de-industrialization, the solidification of the Great Northern Migration population shifts, and much more - witnessed collective action in a way that the strategic setting of films can take advantage of. Medium Cool and Blue Collar show that by pushing away a perceived, debased Midwestern 'square' taste, the actual political action that the unionized industrial Midwest did so well - a history of collective action and its thwarting - New Hollywood in the end substantially narrowed its political horizons. 



\section{Chapter 3}

Getting Around the Suburbs in the Blockbuster Era's Big Hits 


the article's first 200 words he identifies the villains responsible for the parlous state of late-1990s Hollywood cinema.

This is not just a lamentation that movies are in a very bad state. Rather, I fear the medium has sunk beyond anything we dreamed of, leaving us stranded, a race of dreamers. This is more and worse than a bad cycle. This is something like the loss of feeling, and I blame Spielberg and Lucas.

Many are the crimes that Thomson details over the next four thousand words, but foremost among them is the crime he identifies in the first few sentences: the end of New Hollywood's dreaming and the arrival of soulless films. But it was not always this way with Lucas and Spielberg. Before they became villains, Lucas and Spielberg were very much a part of the New Hollywood film school generation. Lucas even made a film that a major studio, Warner Bros., hated because it was not at all commercially promising (Biskind 2007: 98). So how did Spielberg and Lucas, both of whom were film school brats, kill the movies? It was the runaway box office success of Star Wars (Lucas, 1977) on the heels of Jaws (Spielberg, 1975) wot did it. 'These films did such business that the business itself shifted its focus. As never before', Thomson mourns, Hollywood 'developed disdain for "small" pictures' (1996: 53). Thomson notes the passing (or at least de-emphasizing) of the sombre endings and in-camera effects of smaller, human-scaled films. After Spielberg and Lucas, the potential to make 'reasonably adult pictures', was replaced by 'an orthodoxy in which all American movies must be good-humored, positive, and big bucks' (Thomson 1996: 54, 58). In formal and ideological terms, New Hollywood films opened up space for personal films that ran counter to hegemonic thinking; the blockbuster success of Star Wars and Jaws spurred an institutional reaction that drove a different set of formal shifts in film-making that, in turn, led to an ideological shift of its own.

Steven Spielberg goes the farthest towards combining suburban settings (or at least settings that look suburban) and suburban ideology to appeal to 'suburban' taste. That is to say, the suburban nature of the blockbuster is not so much a matter of narrative settings, but ideology. As Lester Friedman summarizes the argument, 
Read any extended account of his work, and you will quickly recognize the party line echoed by most academic writers: Spielberg (along with his pal George Lucas) is responsible for two of the greatest sins in modern cinema history - the Blockbuster mentality that permeates the commercial film industry, and the infantalization of contemporary movies.

(Friedman 2006: 2)

Thus, the blockbuster-era growth of cinema-building displaces city-based urban art houses with suburban multiplexes showing Spielberg-like films, cheapening film-goers' taste. But what are the suburban-set films of the blockbuster era, and what - which is to say, where - can we see in them? The sorts of things you find in the American cultural imagination of suburbia - family, kids, stability, comfort - are not exactly the stuff of blockbuster formula. In fact, the appeal of suburbia emerges from the very lack of things that build blockbuster films - difference, conflict - and a surfeit of narrative poison: stability. The importance of stability thus drives many suburban films, and that stability often takes the form of the built environment or as the triumph of suburban (familycentred, domestic) ideology over the dangers posed by urban spaces.

In this chapter I look at a group of films that were among the top-ten box office hits between 1975 and 1992, blockbuster hits in the blockbuster era. I use 1992 as it closes off a formal era in Hollywood film-making. The extensive use of computer-generated imagery in Terminator 2: Judgment Day (Cameron, 1991), combined with the introduction of digital sound in 1993 offers as useful a cut-off date as any in the shift towards digital cinema. ${ }^{9}$ As Jon Lewis writes, the turn to blockbuster cinema created a Hollywood cinema that, by the 1990s meant that

while most of the studios maintain corporate offices in Los Angeles, the financing, production, distribution, and exhibition of so-called American films have become so complex and international these days that geographic borders seem quite beside the point $[\ldots]$. American cinema in the nineties, in terms of investment as well as onscreen talent, was a global affair.

(Lewis 2001: 4-5)

But for all the international investment - studios have been owned by Japanese, French, Australian, Canadian, Italian, and American conglomerates since the 1970s, the very American 'Lucas-Spielberg-Disney nexus clearly dominates from 1977 to 1997' (Krämer 2005: 128). Critics in both academic and popular film criticism argue that Spielberg-Lucas blockbuster movies appeal to a sub-urban - quite literally sub-urbane - taste regime, but that regime shows a consistent tendency to locate its films in urban (or remote) rather than suburban settings.

The bulk of the top-ten hits of the blockbuster era set in the suburbs engage with the everyday life of children and adolescents (and adults-as-adolescents) in suburbia, their 
interest in and affection for parts of the city, and naturalize the suburban ideology. Thus, it is not terribly surprising that top-ten box office hits set in the suburbs - films such as The Bad News Bears (Ritchie, 1976), The Amityville Horror (Rosenberg, 1979), E.T.: The ExtraTerrestrial (Spielberg, 1982), Poltergeist (Hooper, 1982), Risky Business (Brickman, 1983), The Karate Kid (Avildsen, 1984), Back to the Future (Zemeckis, 1985), Ferris Bueller's Day Off (Hughes, 1986), Big (Marshall, 1988), and Wayne's World (Spheeris, 1992) - do not represent an anxious suburban identity, nor do they offer anything resembling a critique of the suburbs. The interactions the suburbanites have with the city do, with a bit of regularity, equate the city with crime and/or other 'dangers' to order, but by and large the city exists apart from the conflicts of everyday suburban life. In most of the big suburbsset hits, the suburbs are not monolithic, and the differences between suburbs loom large in the imagination of their residents. In the first twenty years of the blockbuster era, topten hits set in the suburbs adhere closely to the American sense of the suburbs as a place of nuclear-family-centred stability for adults and their children, in opposition to the city as a place of hedonistic escape for carefree young people. The Saturday Night Live adapted film Wayne's World sees the world the other way round, treating the suburbs as a place of fun and parties, as opposed to the city's more restricting responsibility and rules. Wayne's World re-organizes the suburbs and the city in the same way that the other suburbs-set films in this chapter affirm the American suburbs' ideological hegemony: in the way in which people encounter suburban spaces and the way in which they navigate the literal and figurative distance within and between the suburbs and the city.

\section{Steven Spielberg and the Who, What and Where of the 'Suburban'}

The 'what' and the 'where' of the suburbs on film are not the same thing, as a great deal of academic criticism of Steven Spielberg makes clear. In both the films and the criticism, a conservative nuclear family-centred, domestic ideology and a built form of single-family tract houses represent the suburban. At varying times in the films and their criticism the 'what' and the 'where' take precedence. In The Science Fiction and Fantasy Films of Steven Spielberg, Andrew Gordon calls Close Encounters, E.T., and the Tobe Hooper-directed but Spielberg-identified Poltergeist 'Spielberg's signature films, in which he forged his characteristic style and subject matter, becoming our wizard of the suburbs, transforming contemporary tract homes into fairy-tale cottages' (Gordon 2007: 56). In Gordon's more approving view of Spielberg, the wizard of suburbia 'anchors his fantasies in reality by setting them in the present, usually in an easily recognizable American suburb. For example, Muncie, Indiana, the famous "Middletown," is the primary location in Close Encounters' (Gordon 2007: 57). For Gordon, the 'where' comes first, the necessary ingredient to make Spielberg's narratives and ideological work possible. But Gordon's designation of Muncie as a suburb reveals how ideology can shape perceptions of the built environment. Roy Neary (Richard Dreyfuss) lives with his family (before he runs 
off to Devil's Tower) in a house that looks 'suburban': a brick ranch alone on a quarteracre lot, station wagon in the driveway (and boat on trailer across the street), with a little garden in the back. However, other establishing shots of Muncie show a farmhouse in a large field, and a high angle extreme long shot of grid street pattern, with no centre city in sight. Muncie's mid-century housing may resemble suburbia, and Roy's family situation may resemble the traditional image of suburban life, but Muncie is in fact the main city of the 326th largest independent metropolitan statistical area in the United States (about the same size as Lawrence, Kansas). Muncie is more than fifty miles away from Indianapolis and it is not on an interstate, which means that it was neither a city of 60,000 nor a part of the Indianapolis metropolitan region when the system was designed in the mid-century. While this may seem like nitpicking, though suburban form and suburban ideology may be linked, they are not synonymous. Treating a place like Muncie as a suburb treats the ideological 'suburban' as synonymous with the spatial 'suburban'.

A film's ideology can be suburban, and a film's narrative can privilege the suburbs, even if the film takes place outside of the suburbs. Lester Friedman takes just such a position in his analysis of Spielberg, arguing,

While critics dismissively cite Spielberg's obsession with home and family, his male figures usually appear most comfortable defending their homes far away from them on foreign soil, islands, highways, oceans, and battlefields. Their rose-colored visions of domesticity are illusions based on how family life should be, manufactured fantasies often directly contradicted by the facts of their lives as they are.

(2006: 8)

In other words, suburban ideology does not deliver on its promises, thanks to personal shortcomings, alien forces, or some combination of the two. Steven Spielberg certainly made suburban-set films early in his career, but the tendency for critics to identify a suburban nature in his films has more to do with taste and ideology. In the last paragraph of Nigel Morris' book The Cinema of Steven Spielberg, he writes that 'Spielberg's ordinary theme of the ordinary person escaping the sterility of suburbia or other frustration underscores life's dissatisfactions and keeps alive the dream of escape' (2007: 393). In Spielberg's most suburban films, escape means leaving the suburbs: both Roy Neary and E.T. want to board a spaceship and Poltergeist's Freeling family wants to get as far away from their suburb as possible. Taken literally, as locations, Spielberg's films share with urbane film critics a distance from the suburbs. Spielberg's films certainly imagine escape from literal domestic routine, but that escape, in the end, serves to reinforce the importance of family and domesticity, even when that family and domesticity is beyond the boundaries of the suburbs. The Family of Man continues in space (Close Encounters), and the Freeling family clings to each other on the road (Poltergeist). Only Elliott's (Henry Thomas) family in E.T. stays in the suburbs. That is to say, Spielberg's 'suburban' films may turn away from literal suburban space, but root their appeal in a specific 
part of the suburban ideology: moving around in the suburbs. Spielberg's films celebrate transportation in and around the suburbs as: from the bicycles that fly to freedom in E.T. and Jeff Shaw carrying and dropping a case of beer on a bicycle in Poltergeist, to the cars in which the Freeling family escapes their doom; Roy speeds down the highway, racing with lights in Close Encounters; and Michael discovers cosmic freedom, even if it's just down the block, in E.T. In every case, the possibilities of the suburbs emerge in moving around, in and through them.

\section{The Blockbuster}

The suburbs have a definition that floats between ideology and built form (or none at all, in the case of the US Census [Kolko 2015]), and blockbuster has an equally hard to pin down definition of its own. In Hollywood cinema, the term 'blockbuster' invokes an industrial process, a product, and an outcome. A blockbuster production does not guarantee a blockbuster outcome, and sometimes a non-blockbuster product can have a blockbuster outcome, as in the case of The Blair Witch Project (1999, Myrick and Sanchez). Charles Acland connects an earlier use of blockbuster to its film use to good effect:

Blockbuster originated in World War II as a way newspaper reporters described the new, large, four-thousand-pound bombs dropped by Allied forces on enemy cities [...]. [L]ike those massive explosive devices, blockbuster movies allude to tonnage that is, outsized production budgets, elaborate promotional campaigns, and significant box-office results. Only one of those attributes is required, so one hears of low-budget blockbuster hits and high-budget blockbusters that are box-office flops.

Acland notes the centrality of the lavish production in Hollywood history, but devotes his attention to the discursive life of the term: 'Blockbuster, so tightly woven into our everyday language about popular cinema [...] function[s] as a mechanism through which the operations of film culture and industry have circulated and been understood broadly for years' (2013: 12-13). To conceive of films as blockbusters is to take part in a language 'built in part on orchestrated traffic between corporate agents, cultural and industrial commentators, and movie-going audiences' (Acland 2013: 18). In other words, the prevailing use of the term blockbuster has made money the main way Americans discuss film - from production budget blowouts to weekend box office figures that appear like league tables, and annual 'grosses gloss' features in serious film periodicals like Film Comment that categorize films as hits, misses, and in-betweens (with sub-categories like recoupers, write-downs, and specialized underachievers) and offer a 'Redeemed by Foreign Performance' list (Klady 1997: 50-54). 
In 'The Blockbuster: Everything connects, but not everything goes', Thomas Elsaesser situates the three key parts of the term blockbuster that Acland identified - production budgets, promotional campaigns, and box-office returns - in a wider social and economic context, in terms of the scale at which analysis operates:

the blockbuster in its contemporary form combines (in the most exemplary, but also the most efficient and evolved form) the two systems (film-as-production/cinema-asexperience), the two levels (macro-level of capitalism/micro-level of desire), and the two aggregate states of the cinema experience (commodity/service).

(Elsaesser 2001: 276)

These distinctions can be mapped onto narrative location in a fairly straightforward and illuminating manner. To return to the example of Burt Reynolds, in the 1970s, in terms of 'systems' Hollywood favoured the (contemporary) south for film-as-production (thanks to tax breaks among other things); similarly, in terms of 'levels' the south was capitalism's space on the macro level. However, in terms of 'experience', the commodities coming out of Hollywood weren't located in the contemporary south. The cinema-as-experience that Burt Reynolds films offered at the micro-level of desire, wherever the service of film exhibition was available, show that while Hollywood in general lagged in its recognition of the contemporary south as a narrative location, Reynolds' films in particular addressed and leveraged this macro-driven micro-level desire into major box office returns. Smokey and the Bandit was a major box office hit, with a box office take of over $\$ 125$ million from an approximately $\$ 5$ million budget (Star Wars had a budget of around $\$ 13$ million). Smokey and the Bandit was not a blockbuster production, nor did it have an elaborate promotional campaign. But it did sell something close to fifty million tickets. Box office returns provide a measure of the system of cinema-as-experience at the micro-level of desire - regardless of the scale of the film-as-production or promotion. Or, as Robert Ray argues in A Certain Tendency of the Hollywood Cinema, "popular" is a more verifiable term than "great" - after all, we have box office statistics' (1985: 20).

The industrial approach to blockbuster production and promotion, and the hoped-for blockbuster box office returns, seems to preclude the presence of suburbs as narrative locations. To answer what characterizes a blockbuster, Elsaesser identifies three key traits, the first of which mostly writes out American suburbs as a narrative location: 'a big subject and a big budget (world war, disaster, end of the planet, monster from the deep, holocaust, death battle in the galaxy)' (2001: 16). Marco Cucco argues for the importance of 'a new visual experience with more and more spacecraft, fighting soldiers, cities in ruins (wow factor)' (2009: 218, italics in original). At no point in any of the descriptions of what a 'wow factor' production-based blockbuster contains does any critic include a mention of the suburbs. Even in terms of visual style, the small scale of the suburban family house does not fit in the blockbuster form. 'From The Godfather to Jaws to Star Wars', Tom Schatz writes, 'we see films that are increasingly plot-driven, increasingly visceral, 
kinetic, and fast-paced, increasingly reliant on special effects, increasingly "fantastic" (and thus apolitical), and increasingly targeted at younger audiences' (2003: 29-30). At the completion of the blockbuster form, room for the suburbs appears. The formal aspects that make a blockbuster production address a younger, apolitical audience - the children for whom parents moved to the suburbs.

While there is a sizable literature on the bigness of blockbuster productions, there is less about the bigness of box office returns for films set in the suburbs. But in the fifteen or so years after Jaws, films predominantly set in the suburbs, without a cast of thousands, or urban destruction, have on occasion appeared in the box office top ten. The majority of top-ten box office hits feature exotic, 'wow factor' large-scale vistas. But not all of them. If, as a rule, large and spectacular vistas of spectacular attractions present an economic advantage, and domestic imagery a disadvantage, then how do top-ten box office hits set in the suburbs, which operate from a relative disadvantage, differ from those norms?

\section{The Top-Ten Box Office: Pre-Jaws, post-Jaws}

While Jaws offers a convenient, single turning point in the appearance of blockbuster cinema, change was already afoot, and well before the late 1970s. Thomas Schatz, in 'The New Hollywood', notes that in the late 1950s and 1960s, box office returns show a clear tendency towards star-driven location-shot films with an eye on the international market (1993: 19-20). Of the ten box office blockbusters Schatz lists, Around the World in Eighty Days (Anderson, 1956), The Bridge on the River Kwai (Lean, 1957), South Pacific (Logan, 1958), Ben-Hur (Wyler, 1959), Lawrence of Arabia (Lean, 1962), The Longest Day (Annakin, Marton, Wicki, 1962), Cleopatra (Mankiewicz, 1963), Goldfinger (Hamilton, 1964), Thunderball (Young, 1965), Dr. Zhivago (Lean, 1965), the only ones partly set in the United States are British spy movies and Around the World in 80 Days (Anderson, 1956). The other seven are set in England, France, Spain, India, Hong Kong, Japan, Burma, Sri Lanka (Ceylon), Samoa, ancient Rome and Palestine, Egypt, Saudi Arabia, and Russia. Steve Neale, in 'Hollywood blockbusters: Historical dimensions', follows this trend of bigbudget pictures coming out of late classical Hollywood through the 1960s. He admits that ' $[\mathrm{b}] \mathrm{y}$ no means all of the films produced were epics, colossal, or blockbusters. But their numbers increased markedly through the 1950s and 1960s as they proved central to most of these strategies' (2005: 50). Neale's list of big-ticket productions shows how non-urban and non-US set these earlier films were. In addition to the ancient-Rome-set Quo Vadis, 1950s and 1960s blockbusters included The Robe (Koster, 1953), The Ten Commandments (de Mille, 1956), The King and I (Lang, 1956), Raintree County (Dmytryk, 1957), BenHur (Wyler, 1959), Exodus (Preminger, 1960), Spartacus (Kubrick, 1960), The Alamo (Wayne, 1960), The Longest Day (Annakin, Marton, Wicki, 1962), Lawrence of Arabia (Lean, 1962), How the West Was Won (Ford, 1963), It's a Mad, Mad, Mad, Mad World (Kramer, 1963), Battle of the Bulge (Annakin, 1965), The Sound of Music (Wise, 1965), 
Grand Prix (Frankenheimer, 1967), Krakatoa, East of Java (Kowalski, 1969), Hello, Dolly (Kelly, 1969), Paint Your Wagon (Logan, 1969), and Patton (Schaffner, 1970) (Neale 2005: 50). Of the twenty films he lists, only six are set in the United States, only one is set in the contemporary United States, and only one is set in an American metropolitan area. This relative focus on international locations appears not just in the films that had a large budget (and expectations), but in the films in the yearly top-ten box office in general. The top ten between 1960 and 1975 includes extensive European settings, in England, Ireland, Portugal, Spain, France, Belgium, Netherlands, Germany, Switzerland, Italy, Austria, Yugoslavia (Serbia), Greece, Turkey, Soviet Union (Russia/Belarus/Ukraine/ Moldova); Middle Eastern locations include Cyprus, Israel-Palestine, Egypt, Jordan, and Saudi Arabia. Asia is less common on screen, with only Hong Kong, Philippines, Japan, Vietnam, and an animated India appearing. Australia appears in one film, and islands across the South Pacific appear, both as themselves and as unnamed deserted islands. Three African locations appear in three widely divergent genres: Tanzania, Kenya, and Ethiopia. The Caribbean appears as the Bahamas, Cuba, Jamaica, and two South American locations appear in the top ten, the ocean near Cape Horn and Devil's Island in French Guiana. Closest to the United States, and somewhat curiously, neither Mexico nor Canada appear in any top-ten box office hit between 1960 and 1992, although they do appear lower down the list.

It may be tempting to say that US movie-goers rejected the country's isolationist, inward-looking tendencies for a more outward-looking cosmopolitan approach to culture, but the truth is far more prosaic. While Hollywood found ready markets for its backlog of films in early post-war Europe, the film market changed in Europe in particular. As Peter Lev explains,

Protectionist laws [in western Europe] included import quotas, screen quotas (reserving a certain number of weeks at every theater for national productions), fees and taxes on imports, subsidies for national film companies, and blocked funds. The 'blocking' of funds or currency meant that a portion of the income earned in film distribution could only be spent in the country in which it was earned.

(2003: 148)

Rather than wait until the laws changed or changing their business model, film studios put their blocked money to work by shooting movies in Europe. 'For the Hollywood studios, production abroad allowed them to invest otherwise unavailable funds in films that could then be shown in American and international markets' (Lev 2003: 149). Paul Monaco connects this approach to the economics of the 1980s, writing that

[b]y the 1980s, those business strategies would become common in other sectors of the American economy, as terms like 'outsourcing' and 'downsizing' came to describe 
manufacturers moving production abroad to hold down costs in an increasingly competitive global economy.

(2001: 11-12)

While it took other manufacturers longer to see the advantages of outsourcing, the legal regimes in place in Europe in the 1950s and 1960s meant that

Hollywood pioneered the practices of shifting production to places where labor was abundant and cheap and where local government offered substantial subsidies and tax breaks $[. .$.$] . There was a strong economic imperative for producers to seek lower labor$ costs in feature film production, and there were credible aesthetic arguments in favor of actually filming many movie in authentic locales as well.

$(2001: 11,12)$

What the hits of the late 1950s and 1960s reveal is an institutional investment in runaway productions, but a very particular sort of runaway production: one that used the cheap foreign locations in service of the narrative - films that used the Spanish landscape and army to stage epics, or the sites near battles to make war pictures.

However, after two decades, the pace of runaway productions slowed, and films returned to the United States, both in production and setting. Starting in the late 1960s, the top-ten hits increasingly come to be set in the United States, especially its cities (Map 9). This trend did not end, even when multinational (or at least non-US) corporations began to buy film studios. Writing in 1991, Timothy Corrigan argued that Australian, Italian, and Japanese ownership of studios led Hollywood to continue

to enlarge and perhaps vary the international weave of its fabric and that, at least for the American audience, international complicity is a better model of the conditions informing their viewing than cultural difference.

(1991: 5).

One of the cases in which national cinema seems pertinent takes the form of the films that people see the most. Tax laws and currency controls indirectly caused an increased presence of European settings in 1960s hits, but the ownership change to multinationals usually so adept at finding advantage in financial regulation - caused a similar change in locations. On the one hand, some states began to create incentives for film production; Colorado was the first in 1969, and the professional group the Association of Film Commissioners International was founded in 1975. On the other hand, the relocation of big movies to the United States functioned as a risk-avoidance strategy in an industry where Dennis Hopper can disappear into Peru with a million dollars and no oversight.

Whereas 1950s and 1960s major hits tended to be outside of the United States and outside of cities, the 1970s return to US settings included a much greater emphasis 
on urban settings. Using Jaws as a dividing line, late 1960s and early 1970s hits set in urban locations included Bullitt (Yates, 1968), Airport (Seaton, 1970), Love Story (Hiller, 1970), The French Connection (Friedkin, 1971), The Godfather (Coppola, 1972), The Sting (Hill, 1973), The Exorcist (Friedkin, 1973), Chinatown (Polanski, 1974), and Earthquake (Robson, 1974). A small number of hits were in small towns or remote settings - a rereleased Gone With the Wind (Fleming, 1939), The Andromeda Strain (Wise, 1971), The Poseidon Adventure (Neame, 1972), Planet of the Apes (Schaffner, 1968) - and an even smaller number in a small city, namely American Graffiti (Lucas, 1973). Yours Mine and Ours (Shavelson, 1968) is set in Alameda, California, and the rest of the Bay Area. A number of films are set throughout the Los Angeles area - The Graduate (Nichols, 1968) and Bob \& Carol \& Ted \& Alice (Mazursky, 1969) in Pasadena, The Love Bug (Stevenson, 1968) in Riverside, and The Way We Were (Pollack, 1973) in Malibu. The opening sequence in The Longest Yard (Aldrich, 1974) takes place in suburban Palm Beach, Florida, but the majority of the film takes place in a rural prison. Two period films were set in suburbs, The Sting in Joliet, Illinois and The Great Gatsby in the fictional Long Island town of West Egg, New York. That is to say, in spite of the massive growth of suburbs in the preceding 25 years, no film in the box office top ten was set exclusively in the suburbs (if we consider Cambridge, Massachusetts part of Boston and Georgetown part of Washington DC, which seems fair).

The importance of cities to blockbusters clearly appears in the presence of cities throughout the major hits in the 1980s and early 1990s, especially the twenty largest cities (Map 10). In 1975, the year small resort-town set Jaws came out, the majority of the top ten was city-set: The Godfather Part II (Coppola, 1974), Towering Inferno (Guillermin, 1974), and Funny Lady (Ross, 1975), as well as the Beverly Hills and Los Angeles-set Shampoo (Ashby, 1975). A suburbs-set film appeared as well, Benji (Camp, 1974). New York appeared in early versions of the blockbuster form (and box office) in films like Soylent Green (Fleischer, 1973) and Planet of the Apes, and is the birthplace of the comic book adaptation blockbusters Superman (Donner, 1978), Superman II (Lester, 1980), Batman (Burton, 1989), and Batman Returns (Burton, 1992), as well as King Kong (Guillermin, 1976), parts of Rocky III (Stallone, 1982), Splash (Howard, 1984), Ghostbusters (Reitman, 1984), Crocodile Dundee (Faiman, 1986), Fatal Attraction (Lyne, 1987), Big (Marshall, 1988), Look Who's Talking (Heckerling, 1989), Teenage Mutant Ninja Turtles (Barron, 1990), and Home Alone II: Lost in New York (Columbus, 1992). Los Angeles-set top-ten films included Beverly Hills Cop (Brest, 1984), Lethal Weapon (Donner, 1987), Die Hard (McTiernan, 1988), Twins (Reitman, 1988), Who Framed Roger Rabbit? (Zemeckis, 1988), Pretty Woman (Marshall, 1990), Total Recall (Verhoeven, 1990), and The Bodyguard (Jackson, 1992). Chicago appeared in The Blues Brothers (Landis, 1980) and The Untouchables (DePalma, 1987). Philadelphia appeared in Rocky II (Stallone, 1979), parts of Rocky III, and parts of Rocky IV (Stallone, 1985). Both Beverly Hills Cop and Beverly Hills Cop II (Scott, 1987) have Detroit passages, and San Francisco appears in Sudden Impact (Eastwood, 1983), and 48 HRS. (Hill, 1982). 
Washington DC does not really ramp up its presence until the mid-1990s, something that often gets attributed to President Clinton coming into office, but can also be attributed to the increased box office of action-adventure films in a time when urban settings were also more common. Action films like Die Hard 2 (Harlin, 1990) and Hunt for Red October (McTiernan, 1990) involve the nation's centre of political gravity. ${ }^{10}$ Dick Tracy (Beatty, 1990) takes place in a fantasy city. A League of Their Own visits smaller Midwestern cities like Rockford, Illinois and Racine, Wisconsin. Small towns did appear in the top ten as main narrative locations, in The Goonies (Donner, 1985) (Astoria, Oregon) and often as fictional small towns: Footloose (Ross, 1984) in Missouri, Beetlejuice (Burton, 1988) in Vermont, and Gremlins (Dante, 1984) in New York.

Compared to the top-ten hits before 1975, suburbs begin to appear in major hits much more frequently after 1975. Parenthood (Howard, 1989) stands out among the suburban-set films, as it takes place in suburban St Louis, an area that, Meet Me in St Louis (Minnelli, 1944) aside, does not appear with great frequency in Hollywood films. The highest-grossing film of the 1980s, E.T.: The Extra-Terrestrial takes place in California suburbia, as do the hits The Bad News Bears (Ritchie, 1976), Poltergeist (Hooper, 1982), The Karate Kid (Avildsen, 1984), Back to the Future (Zemeckis, 1985), Ruthless People (Abrahams, Zucker and Zucker, 1986), Hook (Spielberg, 1991), and Father of the Bride (Shyer, 1991). New York suburbs appear in The Amityville Horror (Rosenberg, 1979), Big, briefly in Fatal Attraction and perhaps The Addams Family. Mr Mom (Dragoti, 1983) takes place in suburban Detroit, while Risky Business (Brickman, 1983), Ferris Bueller's Day Off (Hughes, 1986), and Wayne's World (Spheeris, 1992) take place in suburban Chicago (Map 10). ${ }^{11}$

\section{Commuting: Big and Risky Business}

Suburbanites tend to do a lot of commuting, living in the suburbs and working in the city. Post-war suburban ideology gendered the residential suburbs female - the domestic sphere where women raise children - and the city male - the place where men work. Shuttling back and forth between city and suburb was the price workers paid for suburban amenities like a house, yard, and 'good schools'. New York in particular seems not to be the kind of place that you want to raise kids in a Hollywood movie. For example, Please Don't Eat the Daisies (Walters, 1960) does not focus on Jean Kerr's stories of an urbane woman's ironic take on suburban family life but rather focuses on getting her family out of the city and into the suburbs. The film visualizes this necessity quite clearly when Jean (Doris Day) - now called Kate McKay - and her husband Laurence (David Niven) argue about their plans to leave their Manhattan apartment for the suburbs. In the living room of their apartment, Kate turns left and walks to the front-left of the frame, towards where a little baby is sitting. Turning towards the baby at the end of their argument shows Kate's investment in suburbia as a place to raise children. On the other hand, her husband turns 
towards the window and the city streets. But he does not make the image symmetrical by going all the way to the right of the frame. Rather, he stands by the window in the middle of the frame, not moving completely away from Kate and the baby. He tries to keep one foot in both camps. Commuting. Two major suburb-set hit movies, Big and Risky Business repeat this dance between city and suburb for the sake of children, showing that while the city might be the middle of things for professional advancement, the suburbs are important for growing up and family stability.

In Big the differences in mobility and the scale of the built environment between lowrise Cliffside Heights and high-rise New York motivate visibly young Josh Baskin's (David Moscow) wish to be big. One way in which Josh can be big is by proving his manhood. At the carnival, Josh wants to prove his manhood by riding the scariest ride, but he is too short. This literal lack of bigness makes him look foolish in front of his crush, Cindy, who has a boyfriend who drives. Thus, Josh's physical smallness and his lack of a driver's licence, a precious commodity in the suburbs (if not in New York City), mark him as little according to suburban standards. Visibly adult Josh's (Tom Hanks) sojourn in the big city condenses the post-war maturation narrative for boys into a few weeks: he leaves home, gets his first job in the big city, meets a nice girl, and goes back to live in the suburbs to raise kids. It is just that the kid is Josh himself. Going to the city helps him to grow up, but the final stage of growing up means leaving the city-exclusive life for a life of commuting from the suburbs. ${ }^{12}$

In New York, Josh moves up the corporate ladder quickly, and his limousine ride with Susan (Elizabeth Perkins) through Manhattan seems to prove his success and his maturity. Josh finally got big. But his domestic loft space and office workspace are almost indistinguishable - both are stuffed with toys, which is to say, work. The city-work/citydomestic balance that commuting offers eludes him. Josh's first return trip to Cliffside Park, where he sees kids playing in the leaves, kids getting class pictures, kids piled into a car, kids playing in the park, has no clear means of transportation between New York and New Jersey - he moves in a cut. The commuter in Big is not Josh, but his best friend, the twelve-year-old Billy (Jared Rushton). Josh lives and works in the big city, whereas Billy goes between the suburbs to the city, on a fairly regular schedule, like an overworked shared-custody parent. This role reversal reveals that the real work that Josh must learn to do in order to grow up is not toy development, but rather domestic, family labour. By never showing Billy going between the suburbs and the city, and showing Josh as a passenger in his girlfriend's car for his final return trip from the city to suburb, Big locates growing up in the very first challenge that made Josh want to be big: driving a car. When Josh returns to the suburbs for good, or at least for the time being, he still has no transport of his own. His partner Susan drives him from the city for the suburbs. Josh ends the film a kid again, a pedestrian walking to the park to play. To be big, an adult, in the suburbs, you need the mobility a car provides.

Like Big, Risky Business is a young man's coming of age, but one that considers a rite of passage that for Joel (Tom Cruise) comes after getting a licence, losing your virginity. 
Joel may have a driver's licence, but that does not make driving any safer. At first, Joel simply takes his father's Porsche out to impress suburban girls close to home. The next time Joel takes the Porsche out he drives into Chicago to look for Lana (Rebecca DeMornay), the call girl with whom he had sex earlier, and ends up in a high-speed chase on the interstate and on the surface streets of his suburb with her pimp, Guido (Joe Pantoliano). The third time he takes the Porsche out, he drives to the lakefront in the city, where the Porsche falls through the dock into the lake. Joel's experiences with the Porsche show that a suburban boy's car-based mobility can lead to sex, but can also generate its own problems. Losing access to the Porsche unmans Joel to the extent that he must walk to school. To get to Lana's place in Chicago for comfort and advice, he must travel by bicycle, then train, then taxi. The necessity of replacing the car leads Joel to sign on to Lana's plan to turn his suburban house into a brothel. While Joel does all the sales work in the suburban field out of the family station wagon, Lana does all the office work in the city. The one-night brothel succeeds, enabling Joel to pay for the Porsche to be restored, and after dealing with the still-angry Guido, Joel ends the film in a romantic couple with Lana. Risky Business ends in the city, where Joel sees his future in 'human fulfilment', which is to say pandering and pimping. He might export his business to the suburbs, but Joel will work from the city.

Like Big, Risky Business accelerates Joel's coming of age, moving him through citybased work, a romantic partner, and work success that means he can return to the suburbs to settle down as an entrepreneur in 'human fulfilment'. In Big Billy and Josh move between Cliffside Park and New York City on a bus, and in Risky Business Joel also uses public transit, the Metra commuter rail, and the CTA El, to get into and around the city for business purposes. Both movies thus adhere to an older - and more plainly recognizable - vision of commuting by public transit, like Laurence Mackay in Please Don't Eat the Daisies and Tom Rath (Gregory Peck) in The Man in the Gray Flannel Suit (Johnson, 1955), and in doing so accept (even embrace) the suburban status quo of work in the city and home in the suburbs.

\section{Visiting the City to Avoid Suburban Roads: Ferris Bueller's Day Off}

Ferris Bueller's Day Off also quite likes the suburban status quo. The level of professional success the movie's parents enjoy generates not just financial comfort and the advantage of a good school district (funded by their valuable houses' property taxes) in Ferris (Matthew Broderick), Cameron (Alan Ruck), Sloan (Mia Sara), and Jeannie's (Jennifer Grey) present, but also guaranteed college tuition and family financial support in the future. Ferris is not unimpressed with suburban life, but he feels hemmed in. Comfort in Shermer spurs him to indulge in con artistry on a scale that needs a large canvas like Chicago. Ferris explains the ideological and physical boundaries of suburban life in his opening address to the camera: 'life moves pretty fast - if you don't stop and look around 
once and a while, you could miss it'. The 'life' Ferris wants to 'look around' at is not his comfortable but peripheral suburban home town, but rather the central city of Chicago. To get to Chicago, Ferris needs his best friend Cameron.

Ferris needs Cameron because of his constitutive lack as a suburbanite: he does not have a car. The post-war American suburbs are premised on automobility. For as much as the suburbs depend on cars, the central young adult characters in hit movies set in the suburbs tend to be carless. Some suburbanites in major hits set in suburbia are too young to drive: Elliott in E.T., Josh and Billy in Big, the Freeling children in Poltergeist, the Lutz children in The Amityville Horror, and the kids in The Bad News Bears. The Karate Kid's Daniel LaRusso (Ralph Macchio) has to get a ride from his mother to go on a date. Wayne's World's Wayne Campbell (Mike Meyers) does not have his own car; he rides shotgun in his best friend Garth Algar's (Dana Carvey) car. Only Joel in Risky Business has a car to drive, and his trip into the city leads to a dangerous car chase. In formal terms, a protagonist without a car creates room for a sidekick, someone to talk to. In more abstract terms, the lack of a car of one's own makes getting away from the restrictions of suburban life - trips to the city - difficult to achieve, and thus any trip beyond the bounds of suburbia that much sweeter. Ferris continually complains about not having a car (he mentions not having a car three times during his direct address to the camera), and has to bully Cameron into giving him a ride.

The hardest part of Ferris' day off involves dealing with transportation issues, not parents or school officials. The ease with which Ferris pulls the wool over school officials' eyes positions him as an exemplary1980s suburbanite. In Flatlining on the Field of Dreams, Nadel positions Ferris as one of the decade's 'children of a political and cultural exchange between Margaret Thatcher and Ronald Reagan' (1997: 154), and Ferris is indeed a natural but naïve Reaganite - if not quite the natural entrepreneur Risky Business' Joel is. Ferris Bueller's Day Off's villain, Dean Ed Rooney (Jeffrey Jones), is equally Reaganite: like Walter Peck from the Environmental Protection Agency in Ghostbusters, he is a government employee who gets in the way of the entrepreneurial spirit. Rooney is not wrong about Ferris; in fact he is exactly right. But he is just so unreasonable. Upon realizing that Ferris is pulling a major con, Rooney explains the problem to his secretary Grace in terms of governance:

What is so dangerous about a character like Ferris Bueller is he gives good kids bad ideas. Last thing I need at this point in my career is fifteen hundred Ferris Bueller disciples running around these halls. He jeopardizes my ability to effectively govern this student body.

As the film's villain, Rooney stands between Ferris and his pleasure, but Rooney proves ineffective because Ferris' pleasures exist beyond Rooney's suburban school jurisdiction, in the city of Chicago. All Ferris requires is a means to move past that (school district) boundary. A car - Mr Frye's Ferrari - does not just grant freedom of movement, it makes Ferris impossible to govern. 


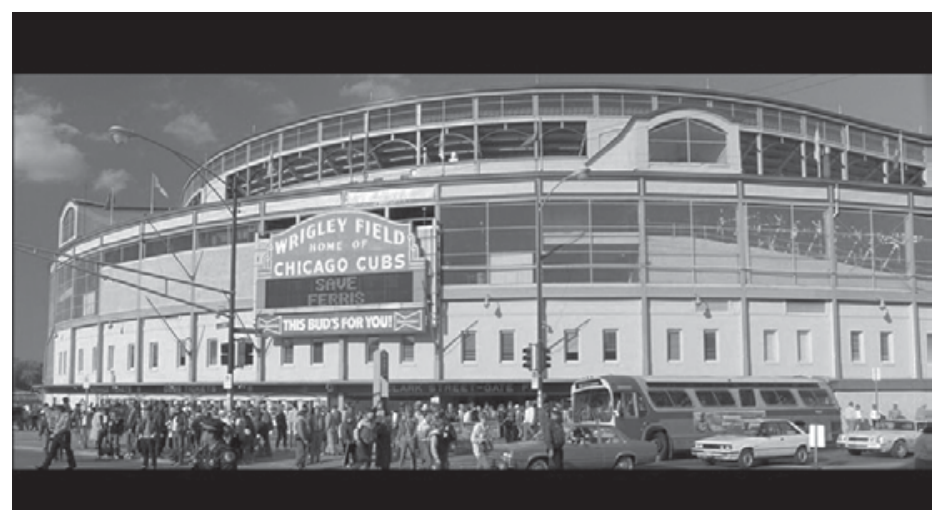

Image 29. Ferris Bueller's Day Off Wrigley Field establishing shot.

Once Ferris has his transport out of the suburbs figured out, Ferris Bueller's Day Off views the city like a suburban visitor, as a series of tourist destinations. The Sears Tower establishing shot does not show the ground-level entrance to the building, rather the top third of the building and the lakefront as seen from a helicopter. At the Board of Trade, a glass wall turns the trading floor into a floor show. When Ferris, Cameron, and Sloan go to a Cubs game, the exterior of Wrigley Field does not show any of the buildings that surround it, making Wrigley Field look more like a stadium built during the post-war era, surrounded by parking lots, rather an early-century park built in the middle of an urban residential neighbourhood. The Shermer kids' approach to the Art Institute of Chicago registers high culture with a low-angle establishing shot. In terms of real geography, Ferris, Cameron, and Sloan cover between fifteen and twenty miles during their trip to Chicago, but very little of their movement between locations appears. They walk out of the parking garage, and a cut carries them to the Sears Tower. Similarly, a cut transfers them from the Sears Tower to the Board of Trade, and another cut to Chez Quis. They get in a taxi to ride from Chez Quis to Wrigley Field. No transport is shown for their trip to the Art Institute (a curious omission, as the $\mathrm{El}$ is a distinctly Chicago sight), and a taxi ride takes them from the Art Institute to near North Dearborn Street, where they walk in a parade. Finally, they walk back to the parking garage so that they can drive back to the suburbs. As I have argued elsewhere, sometimes travel sequences disappear in cuts to elide economic inequalities (Long 2013). But in Ferris Bueller's Day Off the elision of travel in Chicago accomplishes two different goals. Formally, it makes the film move faster. Ideologically, the ease and seamlessness of travel affirms the pleasure the city provides tourists.

The ease of travel in the city looks even better when compared to most of the travel in the suburbs in Ferris Bueller's Day Off. Before going to the city, a Ferrari-driving Ferris 
can almost magically appear from behind a school bus, and drive past his high school's athletic fields unmolested. After Ferris goes to Chicago, moving around the suburbs poses many dangers to him, his family, and his neighbours. In the final act race to the house, Ferris runs through Shermer's backyards, upsetting barbecues and startling families. When Ferris runs along Shermer's residential streets, first his sister Jeannie almost runs him over, then Ferris almost runs into his father's car. After the near-contact between $\mathrm{Mr}$ Bueller and Ferris, Mr Bueller (Lyman Ward) almost crashes into another car and gets stuck behind an elderly driver who weaves dangerously from one lane to the other. After almost running over Ferris, Jeannie drives wildly and ends up with 'another' speeding ticket. Traffic moves pretty fast in a suburb - if you don't stop and look around once and a while, you could miss it and get in an accident. But such a constant, low-level set of driving hazards is simply the cost of getting around the suburbs. For Ferris, eating pancreas is more noteworthy than the dangers everyday travel in the suburbs poses.

\section{Keeping a Distance from the City: Real Estate Horror and Sports Inspiration}

The teenage boys in Big and Risky Business move between suburb and city as part of their coming-of-age narratives, but in The Amityville Horror (Rosenberg, 1979) and Poltergeist (Hooper, 1982), the protagonists are already full-grown adults. Buying a house (or, in the more common use 'buying a home') serves as the rite of passage for both films. Neither film's family commutes back and forth from a centre city, but instead spends all their time in the suburbs, discovering that owning a house in the suburbs creates its own kind of horror. The Amityville Horror and Poltergeist both fit into the 'real estate horror' cycle that includes The Shining (Kubrick, 1980), The Fog (Carpenter, 1980), Pacific Heights (Schlesinger, 1990), The Hand that Rocks the Cradle (Hanson, 1992), Single White Female (Schroeder, 1992), Unlawful Entry (Kaplan, 1992), and Sliver (Noyce, 1993) (Sobchack 1986; Grant 1998; Humphries 2002; Leyda 2014; Snelson 2014). The emphasis both The Amityville Horror and Poltergeist place on the family home - on real estate - shrinks the world down to the small corner of a suburban street. The Amityville Horror frequently shows the dock and boat house at the Lutz house, but there's very little sailing to be had. The Amityville Horror shows the highway that runs through Amityville, but the Lutzes stay in the suburbs, only visiting the hospital and the bar. Similarly, while Poltergeist begins with a number of extreme long shots of the layout of the suburban development where the Freelings live, almost the entire movie takes place in the Freeling house and the (next) cemetery to be moved to make room for sprawl. Before the Freelings flee down I74, most car trips appear as a car pulling into the driveway. ${ }^{13}$ During the Freeling's escape, one of the last exterior images in Poltergeist shows a sign that says, with unrelenting irony 'You are now leaving Cuesta Verde. We'll miss you!' The Amityville Horror so focuses on the house that their escape does not even show a flight, but instead gets reported with a title card: 'George and Kathleen Lutz and the family never reclaimed their house 
or their personal belongings. Today they live in another state. Showing a minimum of transportation within the suburbs or between the city and suburbs does more than generate the claustrophobia key to horror, it also shows how the pressures of suburban home ownership can remove other places from the map, shrinking the world to the four walls of a house in the suburbs.

While nobody ever wrote a song about a pile of rent receipts, nobody ever wrote a horror movie about a family with a pile of rent receipts either. The kids' sports movies The Bad News Bears and The Karate Kid, surprising but sizable hits, both centre on lowermiddle-class and working-class suburbanites who rent in the San Fernando Valley. Both films connect their renting suburbanites more closely to 'nature' than to the more urban parts of Los Angeles. If anything, renters like Morris Buttermaker (Walter Matthau) and Lucille (Randee Heller) and Daniel LaRusso experience the suburbs more like the bourgeois utopia of a house-in-a-park than homeowners like the Lutzes and Freelings, thanks to the closeness of the San Fernando Valley to undeveloped land. The Bad News Bears begins with a series of shots that accentuate how baseball fits comfortably into the near-pastoral landscape of the San Fernando Valley: beyond the outfield fences, hills without a single building on them spread across the background of the opening images. The Karate Kid presents similar views of the foothills beyond the athletic fields of Daniel's high school, frequently keeping the hills in the frame during Daniel's first gym class at his new school. Both movies' suburbs are on the very edge of suburbia, bringing them close to nature and the benefits it offers over places like the urban Newark the LaRussos left behind.

The Newark LaRussos go west, looking to find their fortune in the San Fernando Valley, where Lucille works 'in computers'. Southern California, as Lucille's job shows, is home to more than the film industry; it's also home to the aeronautics and defence industries, making it an ideal place to seek upward mobility. Before Los Angeles' post-war suburban expansion, films were frequently shot in the San Fernando Valley, especially westerns, in places like Chatsworth. The San Fernando Valley of the 1970s and 1980s provides an apt setting for a film about baseball in the suburbs, as the Los Angeles area was instrumental in the suburbanization of the game after World War II. The Los Angeles region had a lot of appeal for a professional sports team after WWII - it was a growing and economically powerful region. The Chatsworth-Reseda-Sherman Oaks-Tarzana area that Bad News Bears is set in quintupled in population in the fifteen years after WWII, offering a substantial potential fan base for a team like the Brooklyn Dodgers. Matthew Gandy writes that the way in which the San Fernando Valley renegotiates the boundaries between nature and culture makes it in many respects an axiomatic example of the American landscape' (2003: 253). And if the suburban Valley is the American physical landscape, it also represents the political landscape, as '[d]uring the 1970s the wealthy communities of the San Fernando Valley became part of the vanguard for the Reaganite anti-liberal backlash in public policy-making' (Gandy 2003: 242). The Bad News Bears codes the politics of growing suburbia in its costuming and casting. The 
Bad News Bears, sponsored by a bail bondsman, look more like the upstart afros-andmoustaches Oakland A's of the early 1970s than the establishment clean-shaven, shorthaired New York Yankees of the same era; unsurprisingly, the Bad News Bears' rivals wear pinstripes, like the Yankees. And whereas the little league Yankees are an all-white team representative of anti-liberal backlash, the Bad News Bears are a multiracial, multiethnic, mixed-gender team, or in Tanner's (Chris Barnes) impolitic reaction when ace pitcher Amanda (Tatum O’Neal) joins, 'Jews, spics, niggers, and now a girl!?' Writing soon after the film was released, Dana Polan sees in The Bad News Bears director Michael Ritchie's 'critique of the evils of the world in which most of his audience lives' (Polan 1977: para. 2). The Bad News Bears locates its critiques on the little league diamond, but also in the San Fernando Valley. Buttermaker is a drunk; the kids smoke and gamble and get in fights. These are the film's heroes. The Bad News Bears shows the diversity of the suburbs. In particular, the class divide in the suburbs appears when Buttermaker drives the team around the San Fernando Valley, combining a trip to a rundown batting cage with a trip to a fancy house in the hills, where he puts the team to work cleaning a pool and making him martinis. During the pool cleaning, he also delivers the team its uniform, the marker of the Bears players' shared identity. The early-season drive through the Valley that shows them the Valley's places of advantage starts the process of building the team's shared class - identity as the sort of people who do not live in houses with pools.

Daniel LaRusso's experience of the San Fernando Valley suburbs resembles the Bad News Bears', although he comes of age rather than to political and class consciousness. Daniel's apartment complex has a pool, but the pool is empty; and Daniel also depends on his coach and his mother for rides around the suburbs. The Karate Kid begins with the LaRussos leaving Newark, a city shown in extreme long shots as row houses, shipping containers, storage tanks, a steel bridge, brick smokestacks, and leafless tress. The LaRussos drive across the country in a series of much more colourful images: green plains, then golden orange southwest. Their cross-country trip takes up almost three-and-a-half minutes of screen time, but their arrival in the Los Angeles area shows none of the area's highways and traffic; the first shot of California shows three palm trees behind power lines. The camera pulls back to reveal the South Seas, a low-end apartment complex. As Lucille parks the car, she says, 'This is the end of the line', and Daniel shoots back, 'You're telling me. Daniel gets wise to the local geography pretty quick - he immediately recognizes that Reseda is not a Beverly Hills of swimming pools and movie stars. It even pales in comparison to nearby Encino. At one point Daniel tells Ali (Elizabeth Shue): 'yeah, we're different, I'm from Reseda and you're from the hills'. Daniel finds it difficult to get to the hills, as he needs his mother to act as driver for his date with Ali. When Daniel first arrives at Ali's house, a low-angle establishing shot of the house's face of columns plays up how impressive the house and Ali are to Daniel. For a brief moment, Daniel reveals a further gradation to the suburbs. Ali's Encino may be nicer than Reseda, but the entrance area brick that Daniel knocks loose while making awkward small talk shows that Encino does not sit at the top of the suburban hierarchy. Daniel does not have any time to register this, 
as his mother's station wagon will not start, and they have to push start the car. Daniel's karate instructor and father figure Mr Miyagi (Noriyuki 'Pat' Morita) does not need to push start his cars. During the course of Daniel's training, Mr Miyagi lets Daniel drive his truck to a house outside of Reseda, where Daniel sands the floor, paints the fence, and waxes Mr Miyagi's large collection of classic cars. Mr Miyagi also teaches Daniel balance at the Chatsworth Reservoir, a place of natural beauty. As Daniel practices punches and the sun sets, any evidence of Daniel's problems in Reseda disappears. The idyllic part of the Los Angeles area that has not yet been brought into the current suburban order provides an escape from all the stresses Daniel faces, but Daniel can only reach that location with the use Mr Miyagi's truck. The Karate Kid, like Big and Risky Business, tells a coming-of-age story. Daniel's ability to grow up in the suburbs - to date and to learn self-control through karate (both of which are aided by the presence of nearby nature) - depends on access to a car that allows him to move around the suburbs independently.

\section{Wayne's Two Worlds}

Wayne's World imagines the suburbs as a place for young adults to express themselves and imagines the city as a place of professional responsibility and compromise. Unlike the other major hits set in the suburbs, Wayne's World does not equate the suburbs with schools and family space; instead, it equates the suburbs with the production of entertainment. The city remains central, but the level of professionalization that it demands leeches all the fun out of creations native to the suburbs. Creations such as the amateur public access show Wayne's World and its creators, the grown children of suburbia (at least as grown up as Wayne Campbell and Garth Algar ever manage). Wayne and Garth's experiences of the streets within the suburbs and between the suburbs and the city may represent the suburbs as a more desirable space to live and to work, but they do not do so at the expense of what the city can offer.

The perception of the city as a place of serious professional responsibility appears in Wayne's opening monologue. As soon as he and Garth finish filming an episode of Wayne's World in the Campbell family basement, Wayne talks directly to the camera. 'Let me bring you up to speed' he says as he walks from the basement, through the house, and onto the house's driveway.

My name is Wayne Campbell. I live in Aurora, Illinois, which is a suburb of Chicago. Excellent. I've had plenty of Joe-jobs. Nothing I'd call a career. Let me put it this way: I have an extensive collection of name tags and hairnets. Ok, so I still live with my parents, which I admit is bogus and sad. However, I do have a cable access show, and I still know how to party. But what I'd really like is to do Wayne's World for a living. It might happen. Yeah, and monkeys might fly out of my butt. 


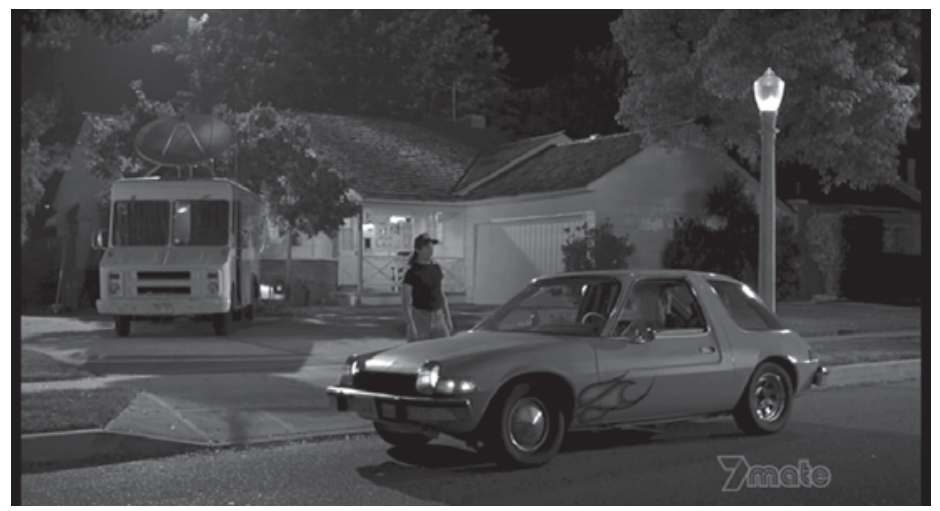

Image 30. Wayne's World The Mirthmobile in the suburbs.

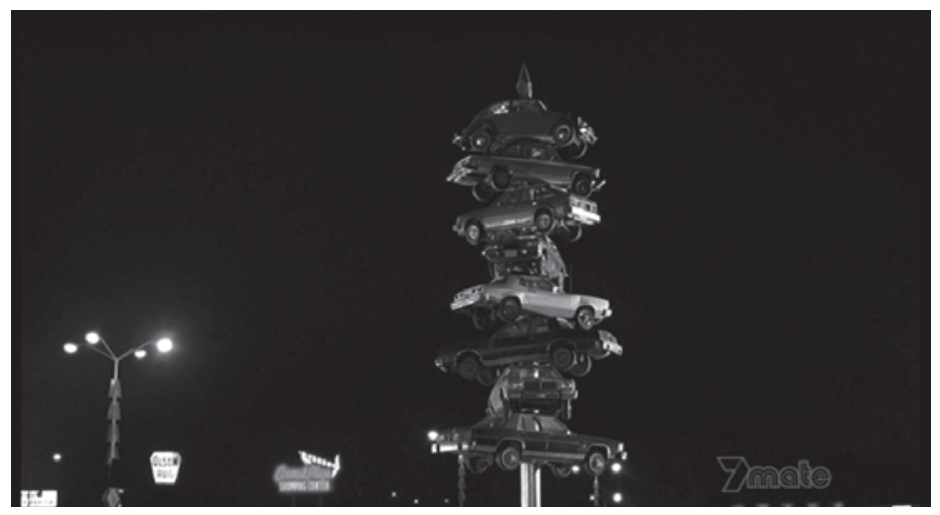

Image 31. Wayne's World cars on a spike sculpture.

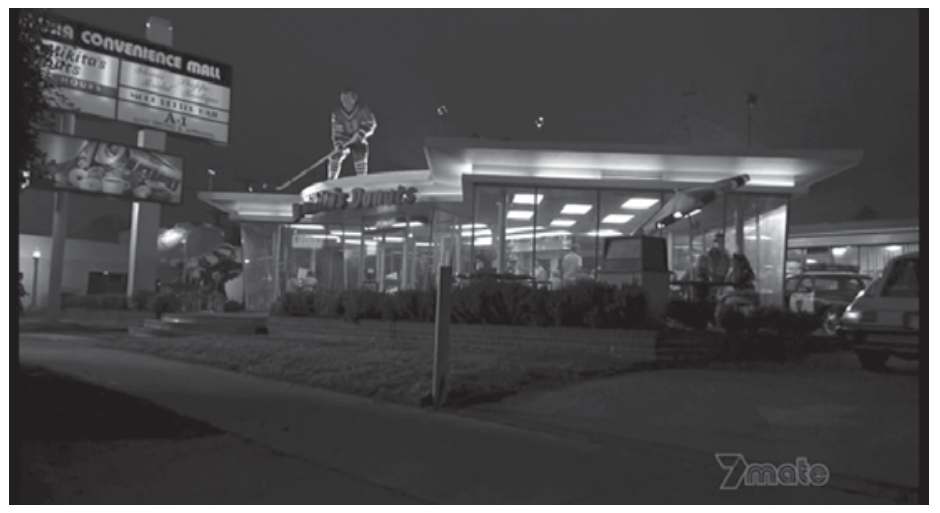

Image 32. Wayne's World Stan Mikita’s Donuts, Aurora, Illinois. 
Wayne's 'partying' takes form immediately, as Garth picks him up in 'The Mirthmobile', an AMC Pacer with flames painted on its doors. They drive around singing along to Queen's 'Bohemian Rhapsody' in a well-rehearsed manner that suggests they cruise and sing together often. Their drive through Aurora passes a series of visually striking places a massive sculpture of cars on a spike, a large 50s neon sign, an Indian statue on the top of a building - as well as smaller-scale Chicago-themed places like Scathell's Beef Stand and Chicago Joe's. Their destination, Stan Mikita's Donuts, provides a logical end point to a drive through Aurora that featured only two chain stores. The first drive in Wayne's World does not represent Aurora as a place of mass-produced suburban conformity. The drive also makes clear Aurora's civic affection for and connection to Chicago, right down to Wayne and Garth's local, the Chicago Blackhawks-associated Stan Mikita's Donuts.

When the Chicago television producer Benjamin (Rob Lowe) arrives to turn Wayne's World into a commercial show, Aurora's distinctive entertainment identity remains key to Wayne and Garth's happiness and the mise-en-scène. Benjamin, Wayne, and Garth discuss the show at an Aurora tiki bar, where Wayne and Garth sign a contract for $\$ 5000$ and rush out to celebrate not on Rush Street in Chicago, but at the Aurora metal club The Gasworks. At the end of that night Wayne and Garth have a heart-to-heart chat while they lay on the hood of the Mirthmobile to watch planes fly overhead. Garth admits to Wayne, 'Sometimes I wish I could boldly go where no man has gone before. But I'll probably stay in Aurora. The overhead shot of Wayne and Garth lying on the hood of the Mirthmobile does not so much shrink them, as put them under careful scrutiny. The complementary shot to the overhead shot of Wayne and Garth on the Mirthmobile hood comes when a plane flies directly over them: a point-of-view shot of the underside of the plane. This shot, and their screaming, excited reaction, shows that not leaving the suburbs is not a death sentence for them. It would be nice to leave, but if it is not in the cards, that's OK. The proximity to the city - and to a local airport like the Aurora Municipal Airport simply adds to Aurora's appeal.

In addition to the opening cruise through Aurora, Wayne and Garth's drives around the suburbs affirm the film's genuine affection for the suburbs as a place of fun and possibility, while transportation into the suburbs appears as a mere function of the film's narrative. For example, Wayne drives around with the musician Cassandra (Tia Carrere) on their first date, leading to a capella duo of 'Hey Mickie' that shows how suited they are for each other. A little later, during a drive up to Milwaukee to see an Alice Cooper show, the Mirthmobile's ceiling-mounted liquorice rope dispenser, and the sudden appearance of the Laverne and Shirley Shotz Brewery, make the trip along the interstate much more fun than Chinese takeout at Benjamin's place. Whereas Penelope Spheeris consistently represents moving through suburban space as a good time, she shows almost no travel into or within Chicago. The establishing shot of Benjamin's apartment begins with the Mirthmobile driving the last few yards to its parking lot, then turns to an extreme low-angle shot of the tower, contrasting the verticality of Benjamin's Chicago with the horizontality of suburban Aurora. When Wayne and Garth return to Chicago 
from the Alice Cooper show, their trip occurs in two cuts: the first to an extreme long shot establishing shot of the Chicago skyline, the second to a long shot establishing shot of Oliver Communications, their studio. In fact, Wayne and Garth repeatedly appear in Chicago with no travel represented, only to encounter the restrictions professionalization offers. All three trips to rehearsals begin with a cut, not a travel scene. In the first their new producer drills them on the correct way to do a countdown, in the second Garth tells Benjamin, 'we fear change' in response to changes to Wayne's World's format, and in the third, Benjamin, Wayne, and Garth cannot see eye to eye about 'the nature of the beast', that is, product placement. As a contrast to the fun that driving around the suburbs offers Wayne and Garth (and Cassandra), the near-total invisibility of travel into the city identifies the suburb-city commuting pattern as a loss to the pleasure suburbanites can feel thanks to their car. But the solution for Wayne and Garth is not to move to the city Benjamin threatens them with, 'You can stay here in the big leagues, and play by the rules. Or you can go back to the farm club in Aurora' - but rather to hold tight to the suburb they love. Wayne's World conceives of the city as a place of responsibility and the suburbs, at least for young men in Wayne and Garth's position, as a place both to party and to express oneself creatively, and the film likewise obliges by imagining an almost chainstore-free Aurora with lots of live music venues and public access TV, a utopian vision of the suburbs for boys who have a car, but do not want to grow up.

\section{Conclusion}

Suburbs-set top-ten hits tend not to show much anxiety over suburban life in America. The conflicts in Big, Risky Business, Ferris Bueller's Day Off, The Amityville Horror, Poltergeist, The Bad News Bears, The Karate Kid, and Wayne's World are, like New Hollywood films, almost entirely young men's personal problems, not the major political concerns of the day. In the face of the source and setting of these minor problems, like most Hollywood films, suburbs-set hits propose incremental changes to what appears as an essentially just system. But Big, Risky Business, and The Karate Kid's coming of age, Ferris Bueller's Day Off's tourist fantasy, The Amityville Horror and Poltergeist's horror, The Bad News Bears' inspirational coming-to-class consciousness, and Wayne's World's never-comingof-age use transportation within the suburbs and between suburb and city to open up space for both praise and critique of suburbs, cities, and the relationship between the two. Neither suburb nor city entirely embodies the periphery-centre, home-work, and responsibility-fun binaries that often organize discussions of suburbia. Rather, in many of the blockbuster era's big hits set in the suburbs, the relative merits of the suburbs and the city appear as a matter of finding the right kinds of transportation for the moment. The standard reading that graduating from a bicycle to a car makes available the full measure of what suburbia can offer its residents holds, but so too do a number of variations on the theme. Driving in the suburbs is dangerous; driving between the city and suburbs is 
dangerous. Car trips through the suburbs can cement friendships and test them. Trains are sexy. Adults who do not drive out of the suburbs experience it as horror. Kids driven around the suburbs quickly learn to see them as non-monolithic and hierarchical. A nondriving teenager can enjoy the city's cultural life and capital just as easily as one who drives.

In the blockbuster era, the suburbs of major hits make a few advances on the ideological spaces created by Disney movies, as Chapter 6 will show. For the most part, the suburbs in these major hits exhibit an often-racialized suspicion of cities and a little more hope and goodwill towards 'nature'. But unlike the uniformly white, middle-class, nuclear-family suburbs present in Disney movies - even and especially the ones set outside of the US suburbs - blockbuster-era hits set in the suburbs reveal a more varied suburban identity than the ticky-tack houses all in a row myth. The multi-ethnic tenuously lower-middle class kids in The Bad News Bears and The Karate Kid and Big, the never-quite-secure middle-class city dwellers contending with the suburbs (and vice versa) in The Amityville Horror and Wayne's World, and comfortably middle-class Risky Business and Ferris Bueller's Day Off are all suburbanites. For as different as they are in class position (to name one identity category), they all share a suburban way of life mediated by transportation. The inescapable role of transportation choices for coming of age and even survival shows that while the car-centric form of suburban development was an ideological undertaking, the suburbs are not solely the ideological spaces created by their planned-unplanned design and textual representation. They are also actual concrete spaces with a range of ideological positions on the horizon of possibility, positions made clear in how people move through their suburban home towns, the suburbs' sprawl into and away from the city, and the city itself. 



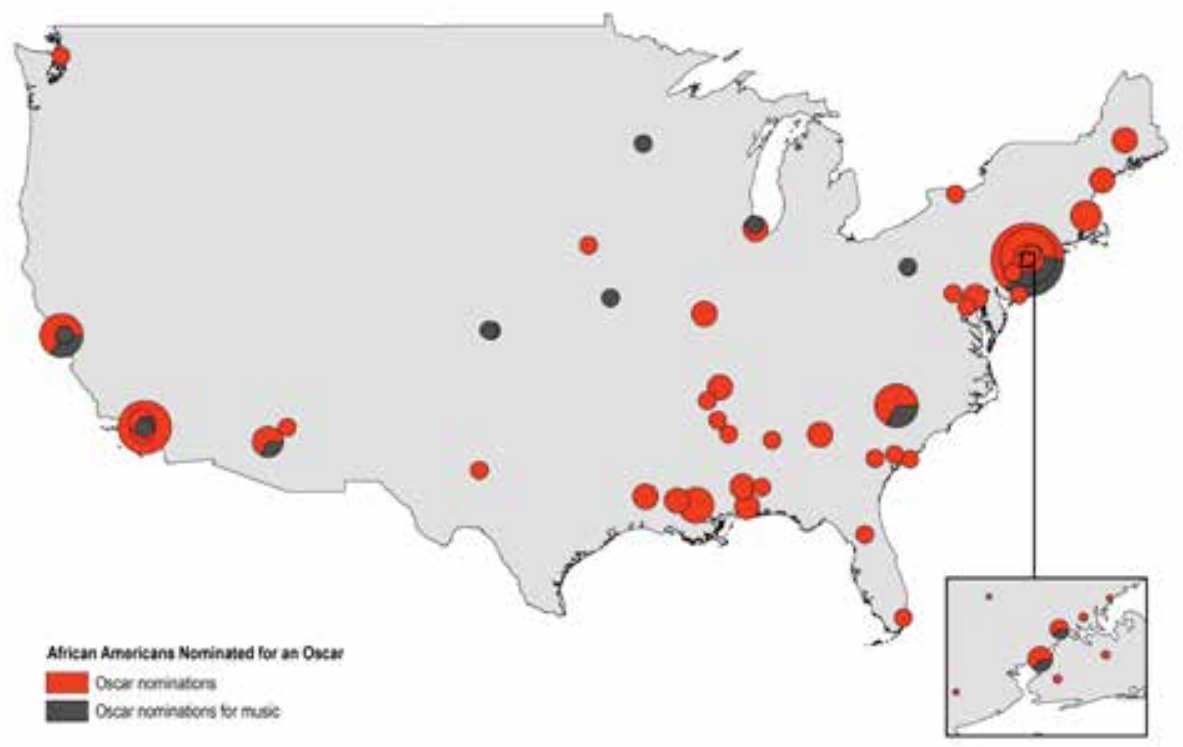

Map 1. African Americans Nominated for an Oscar.

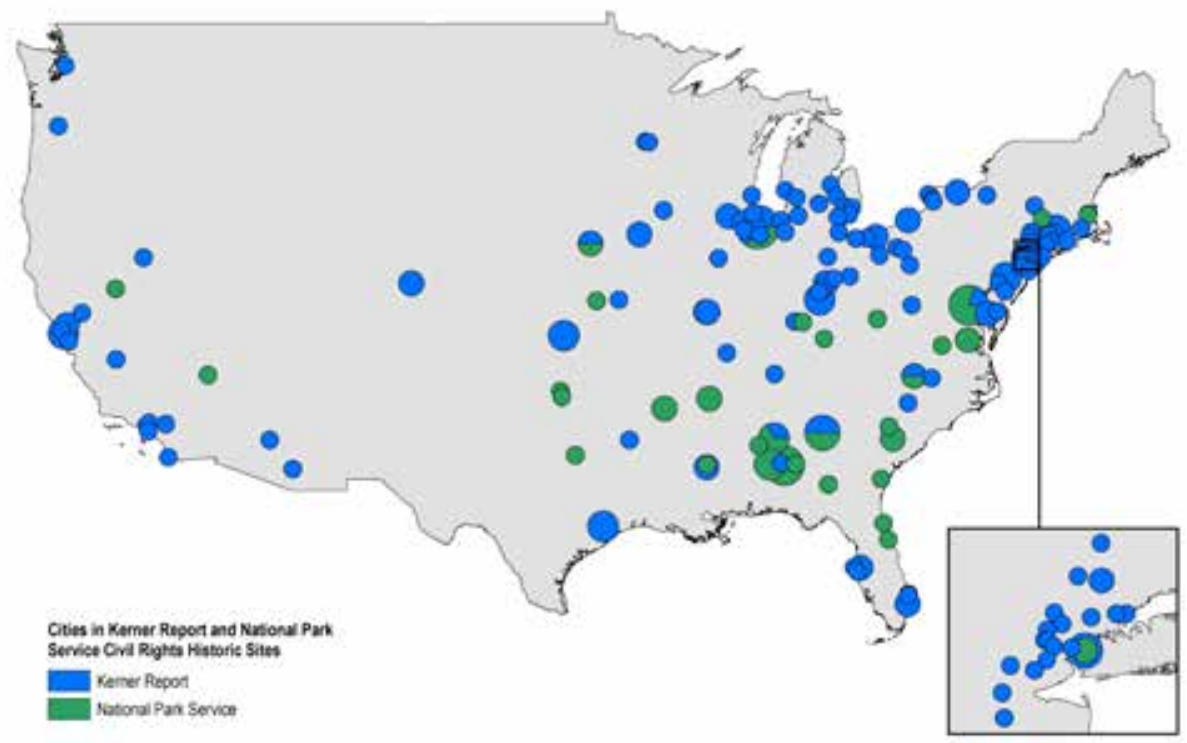

Map 2. Cities in Kerner Report and National Park Service Civil Rights Historic Sites. 


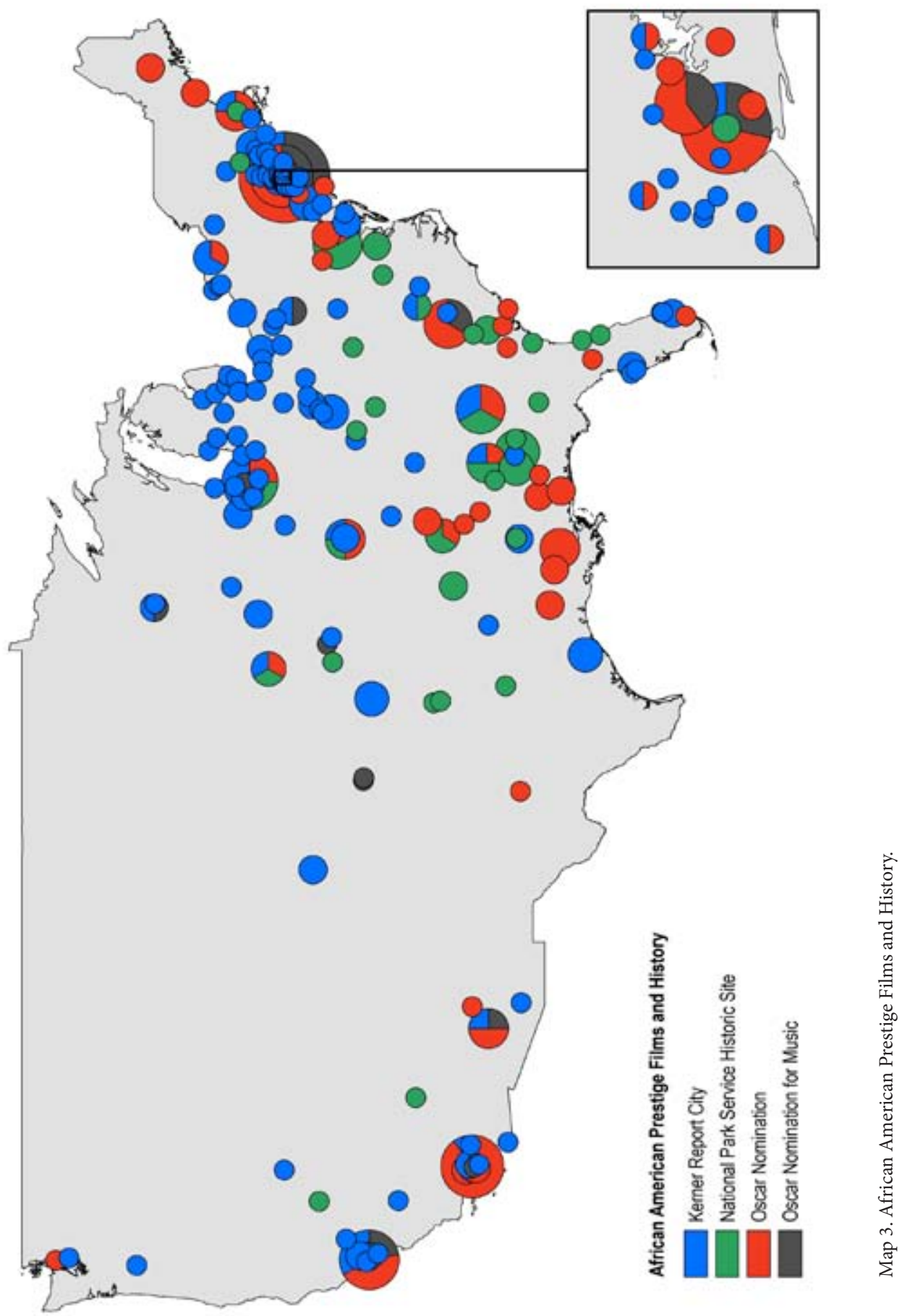




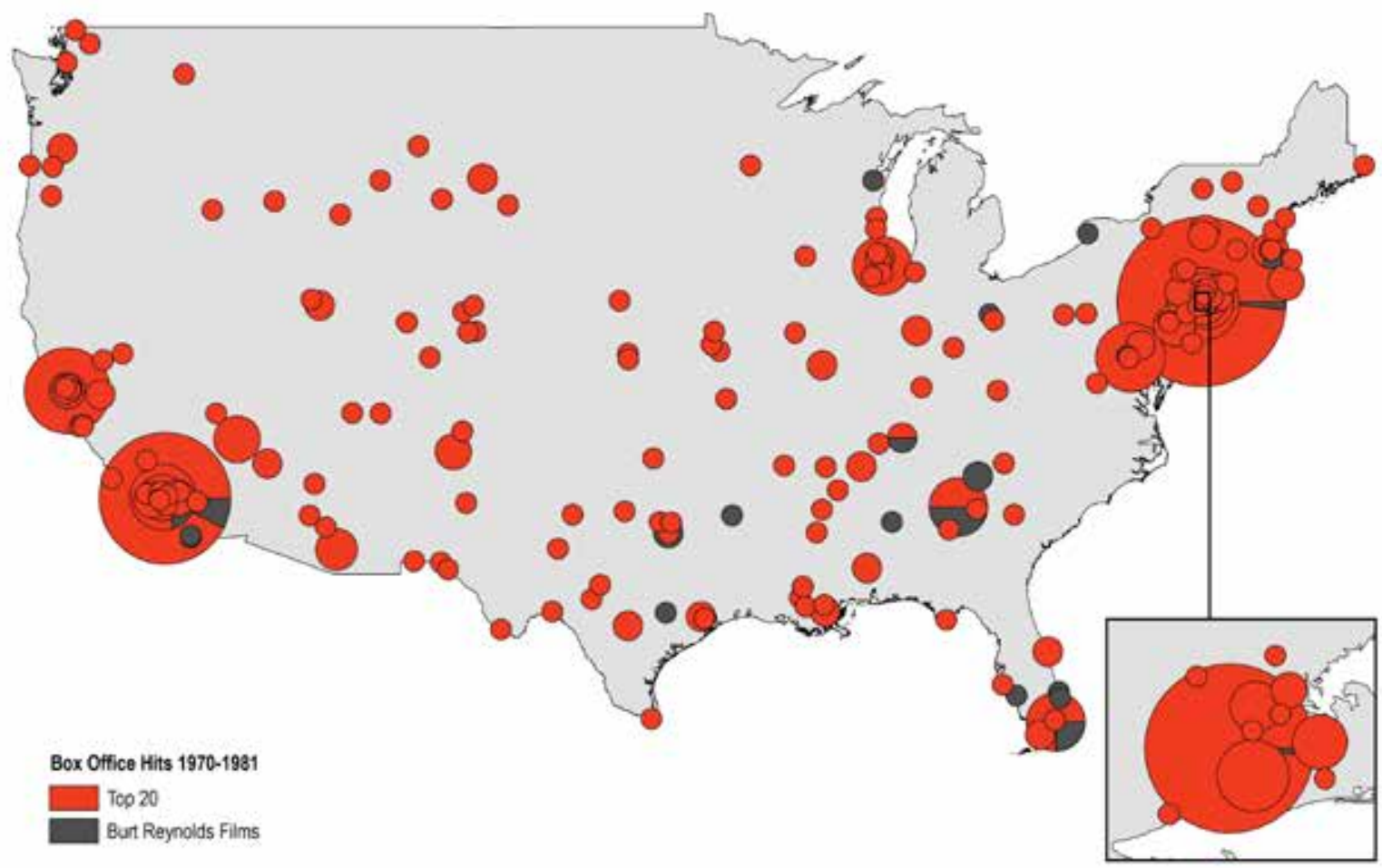

Map 4. Box Office Hits 1970-1981. 


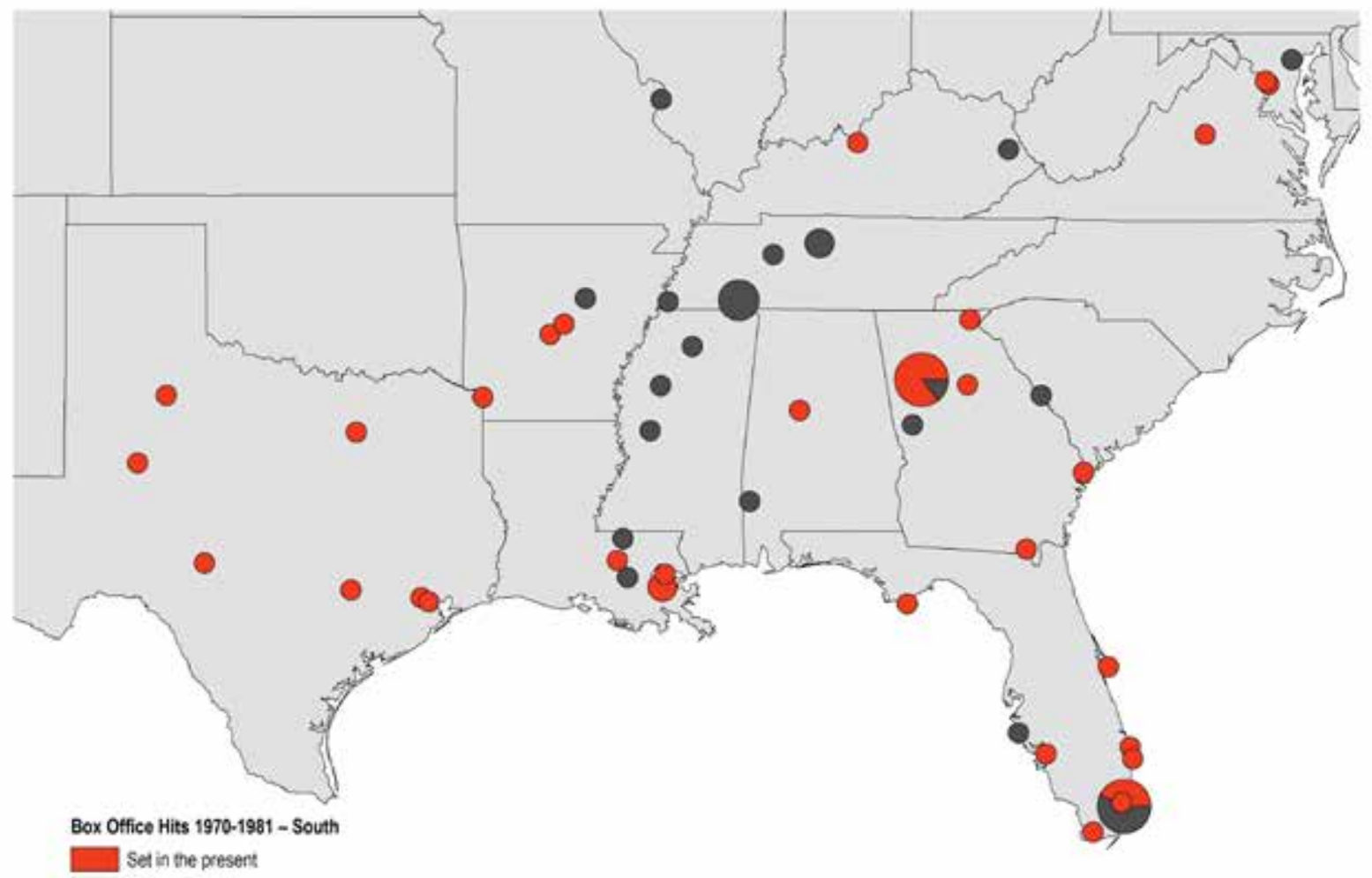

Set in the past

Map 5. Box Office Hits 1970-1981 - South. 


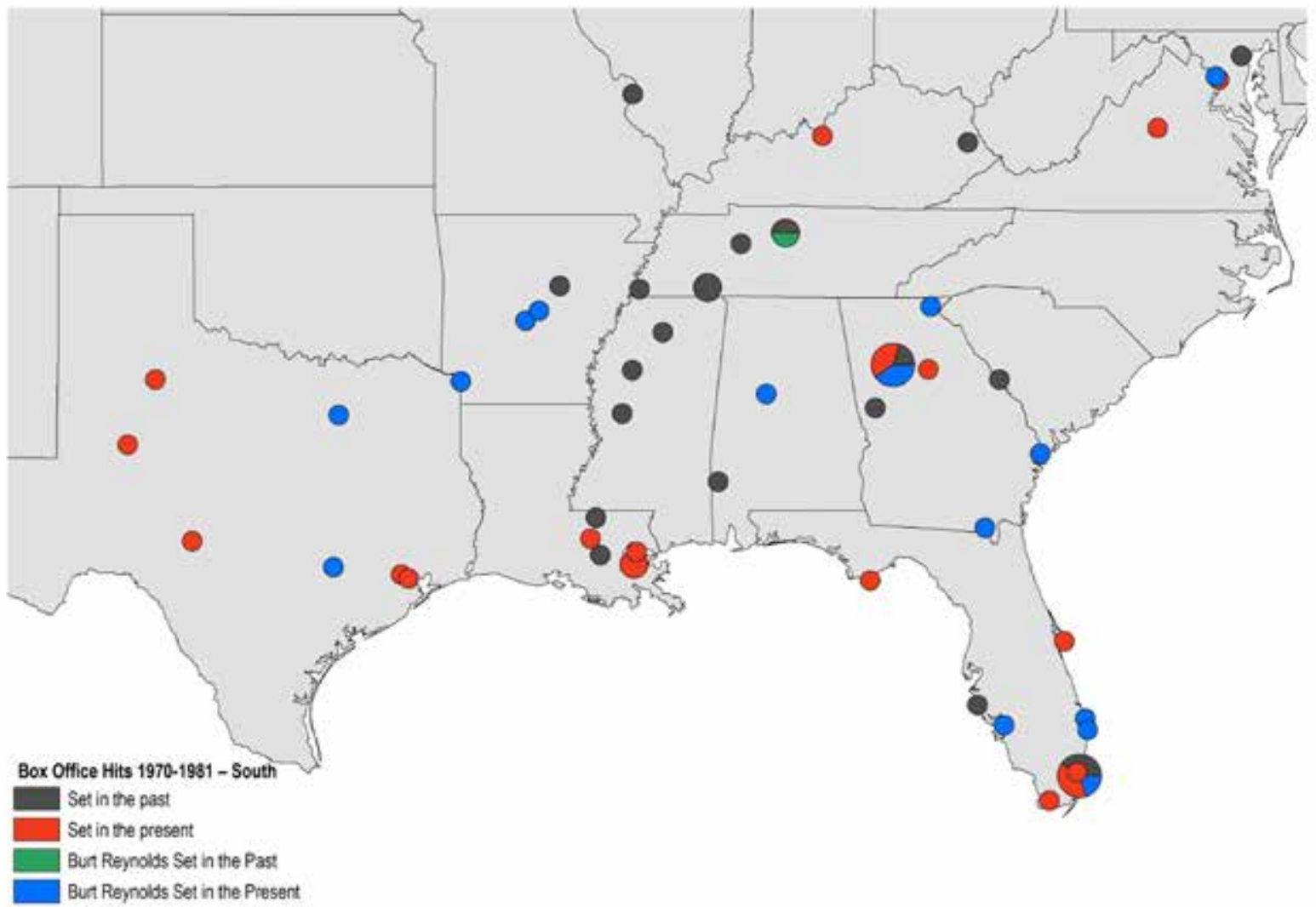

Map 6. Box Office Hits 1970-1981 - South. 


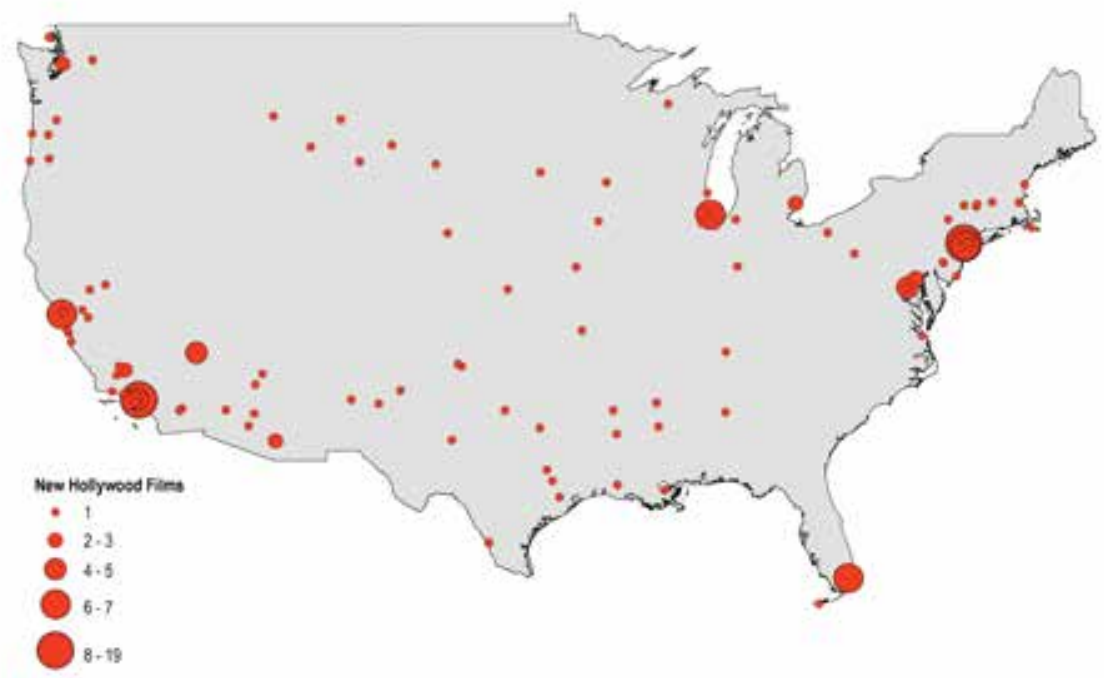

Map 7. New Hollywood Films.

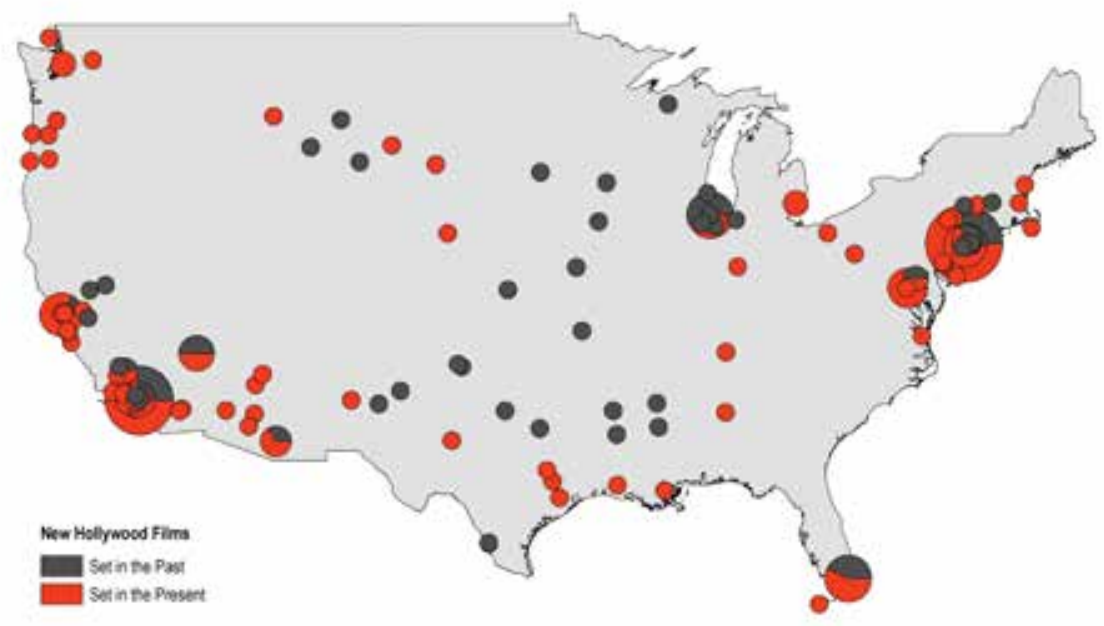

Map 8. New Hollywood Films. 


\section{Colour Maps}

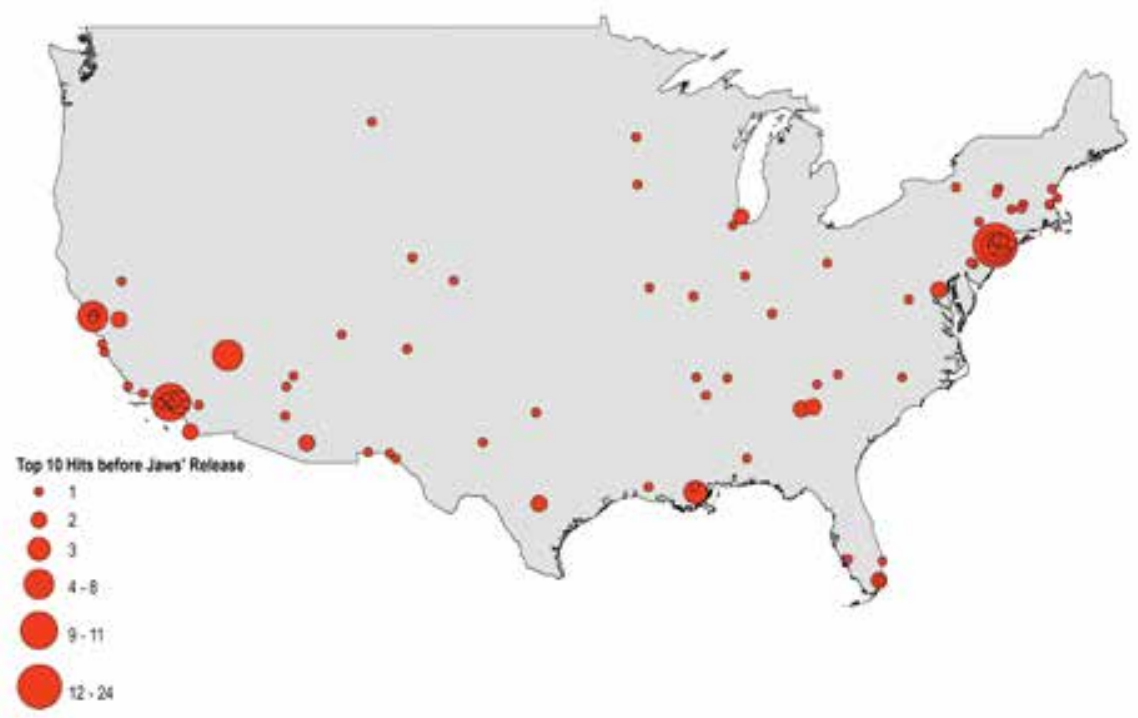

Map 9. Top 10 Hits before Jaws' Release.

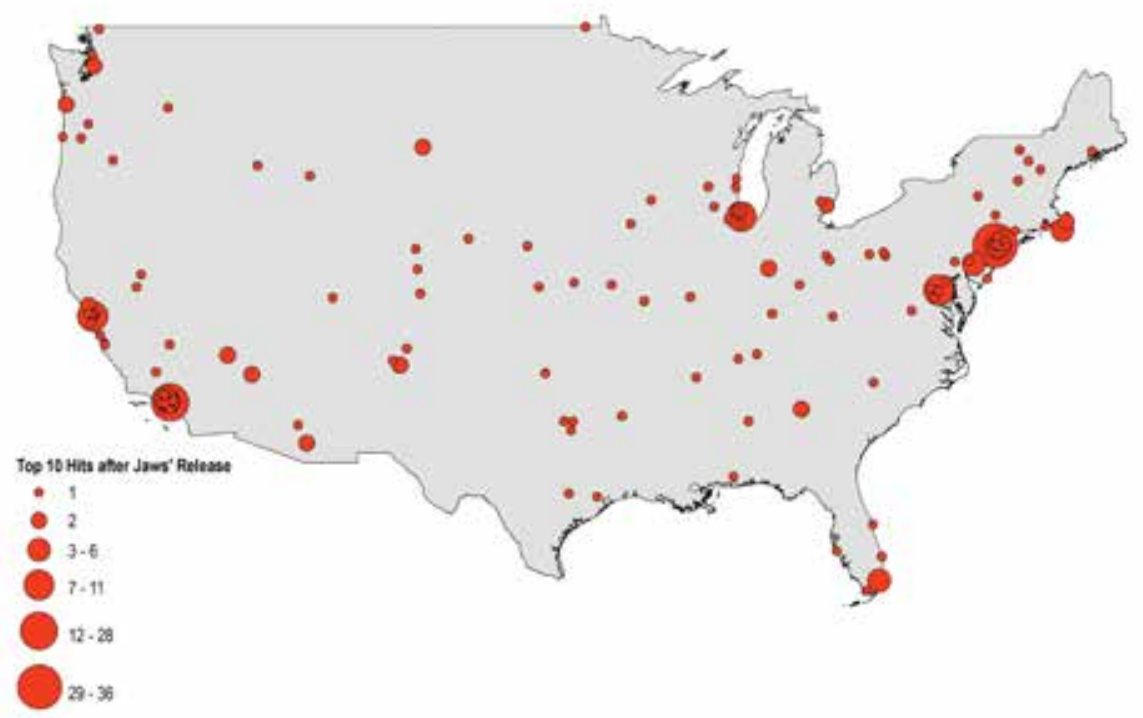

Map 10. Top 10 Hits after Jaws' Release. 

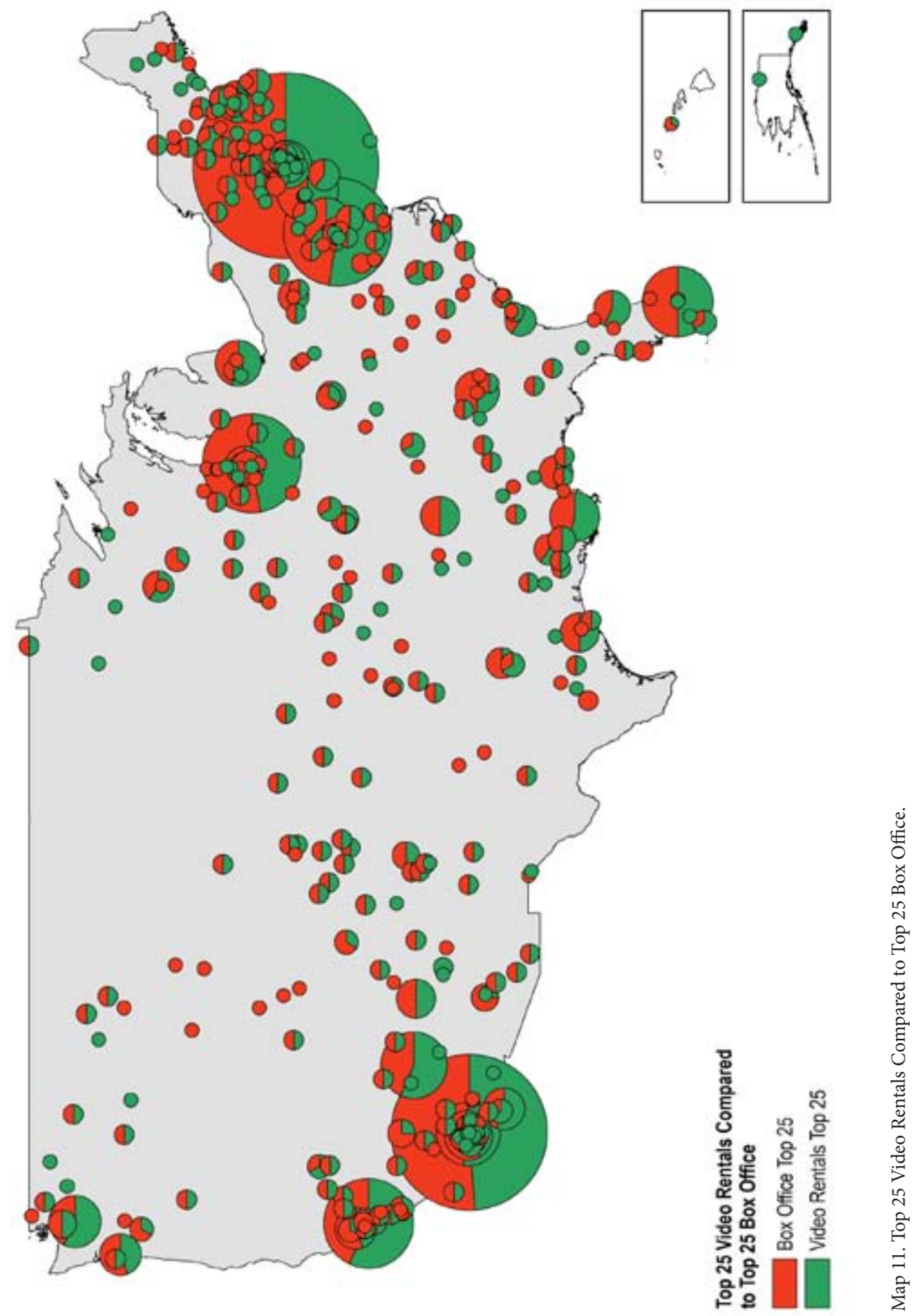


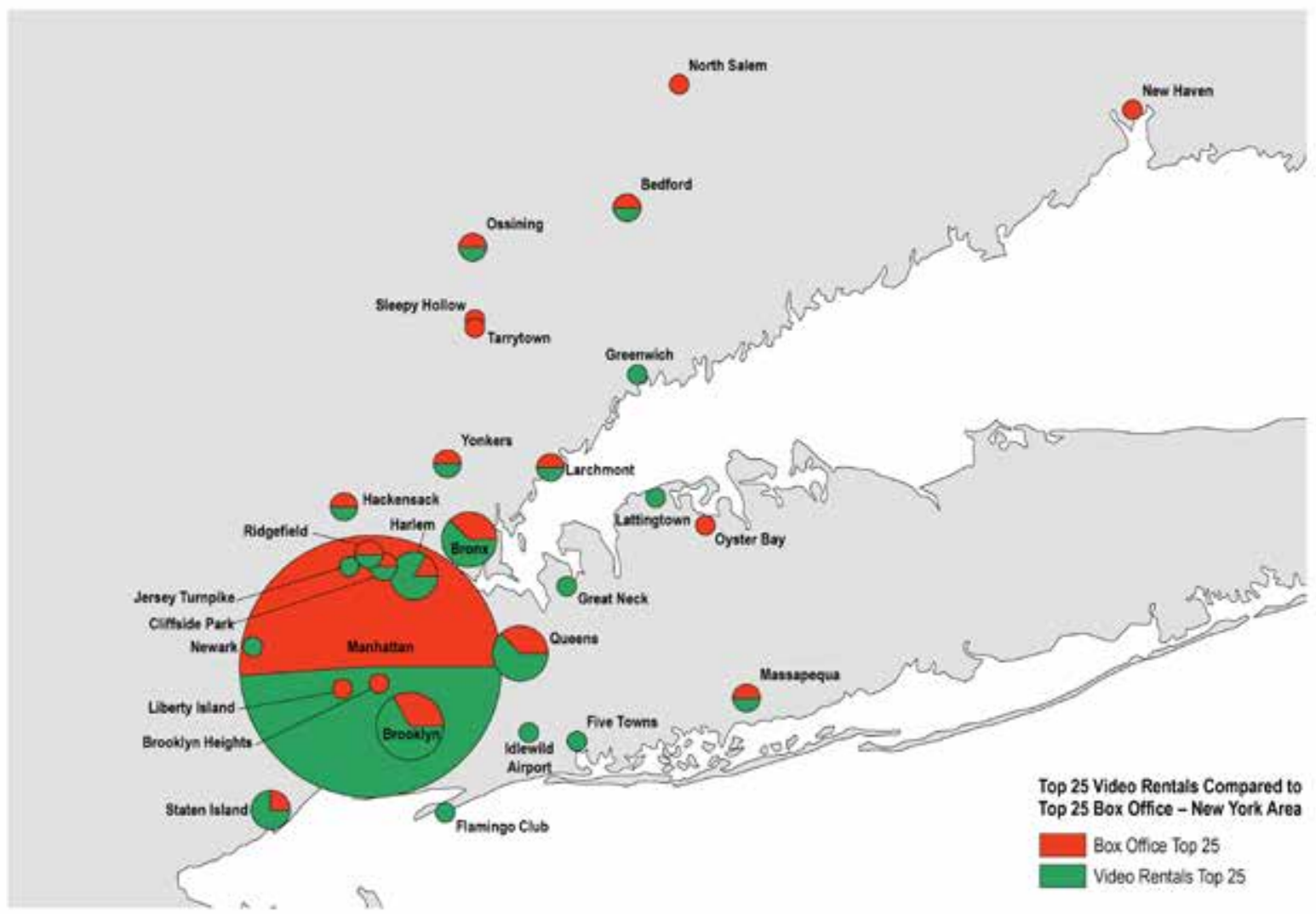

Map 12. Top 25 Video Rentals Compared to Top 25 Box Office - New York Area. 


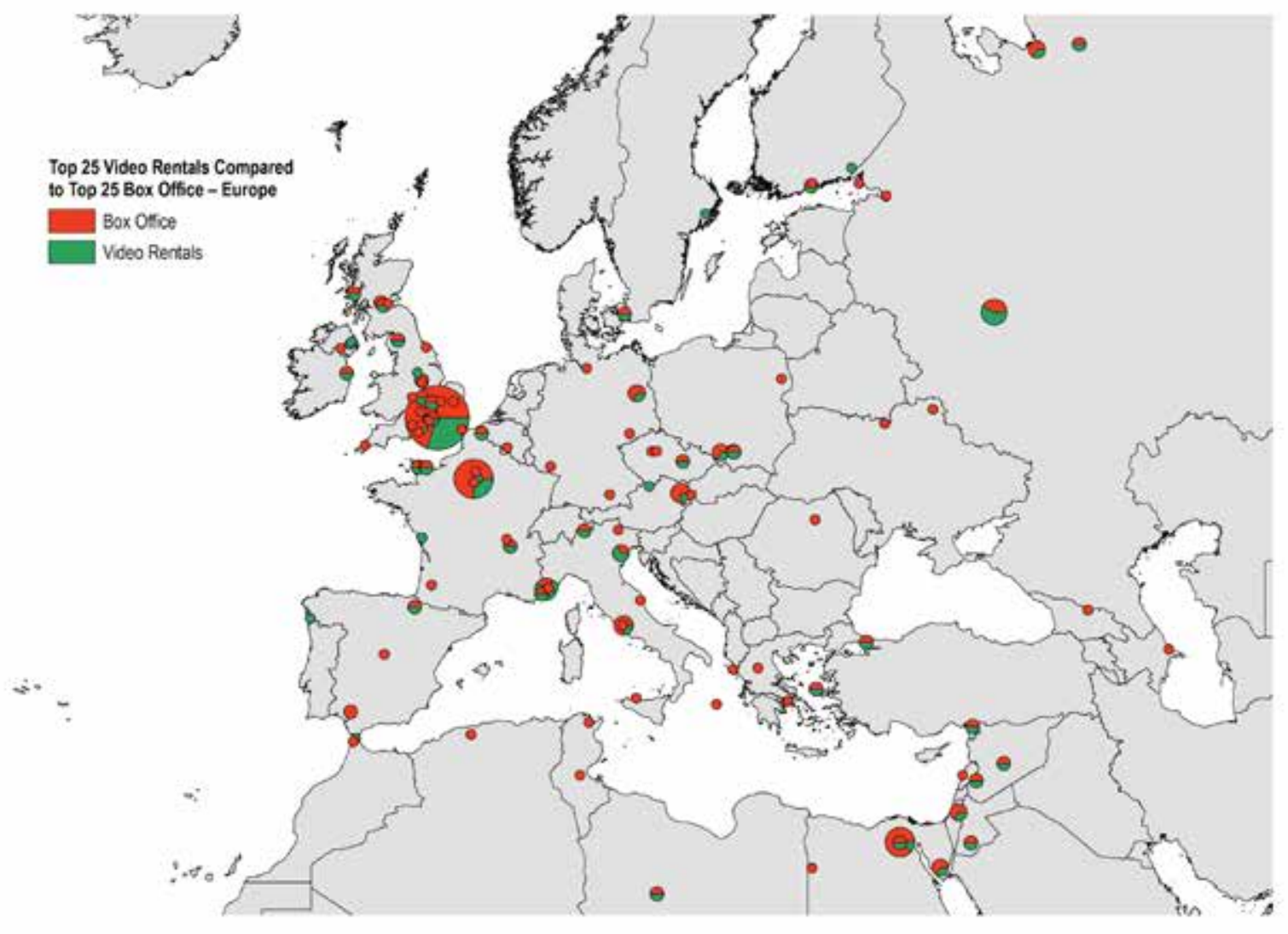

Map 13. Top 25 Video Rentals Compared to Top 25 Box Office - Europe. 


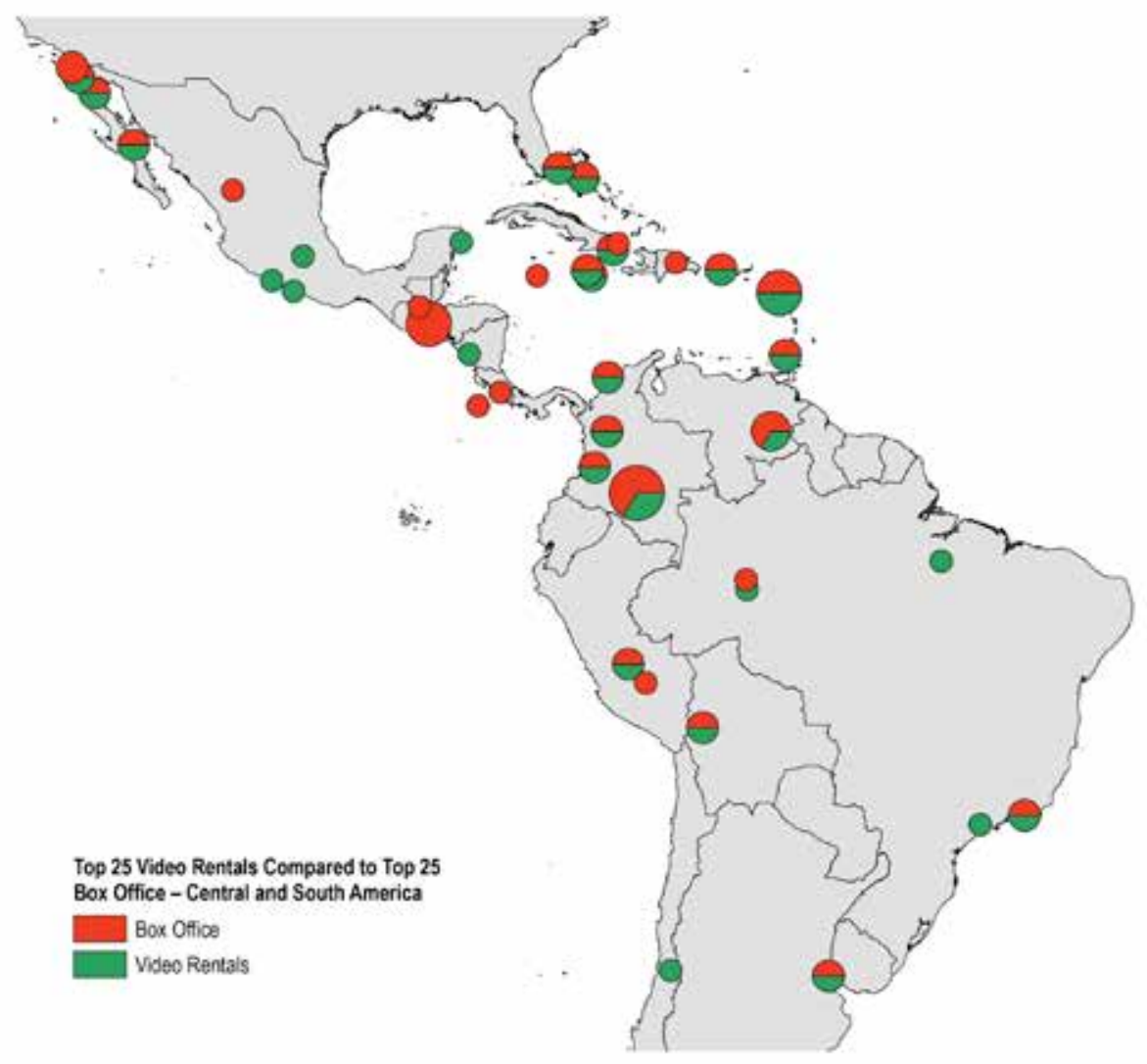

Map 14. Top 25 Video Rentals Compared to Top 25 Box Office - Central and South America. 


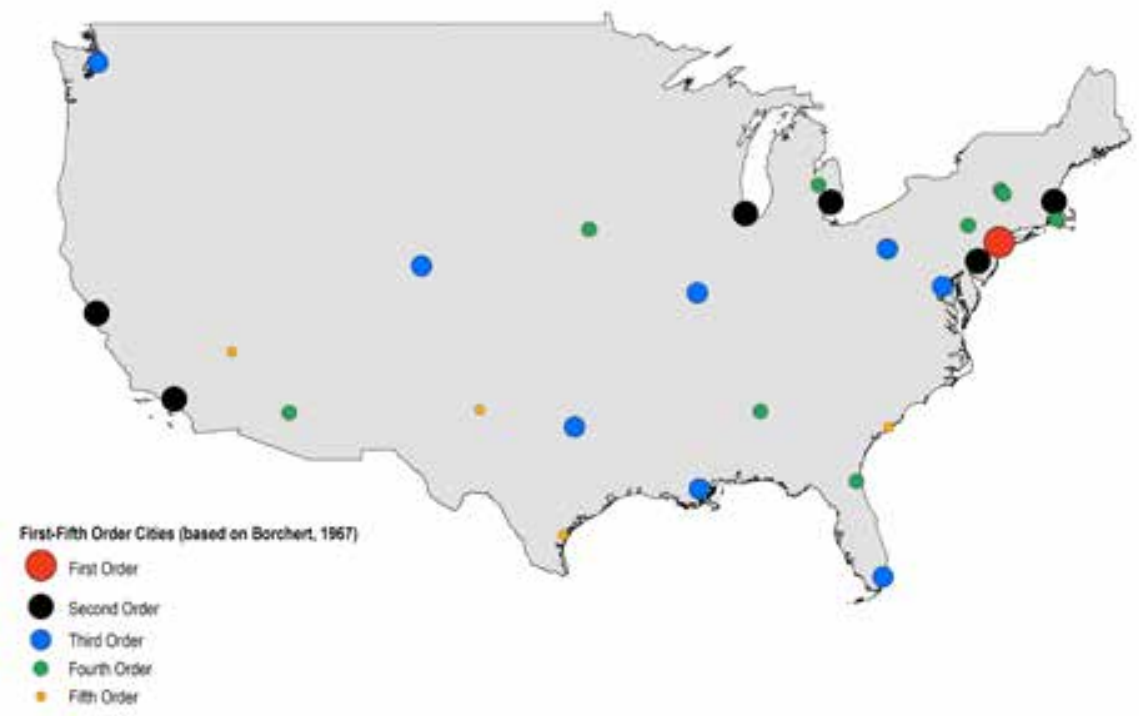

Map 15. First-Fifth Order Cities (based on Borchert, 1967).

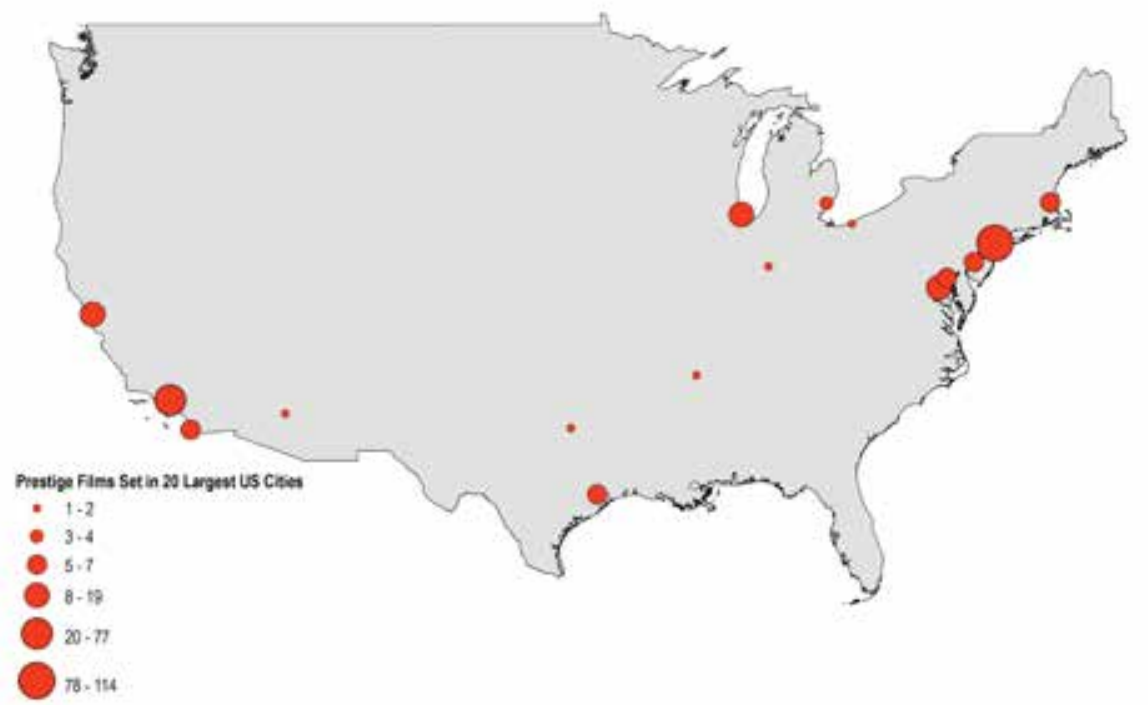

Map 16. Prestige Films Set in 20 Largest US Cities. 


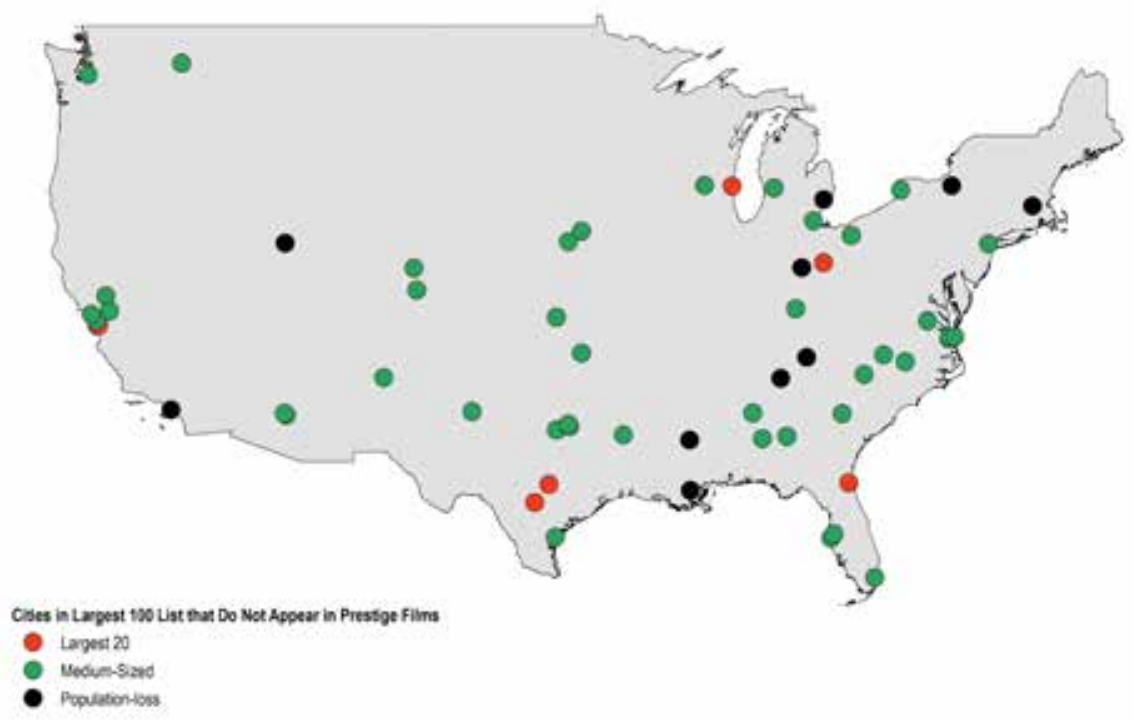

Map 17. Cities in the 100-Largest List that Do Not Appear in Prestige Films.

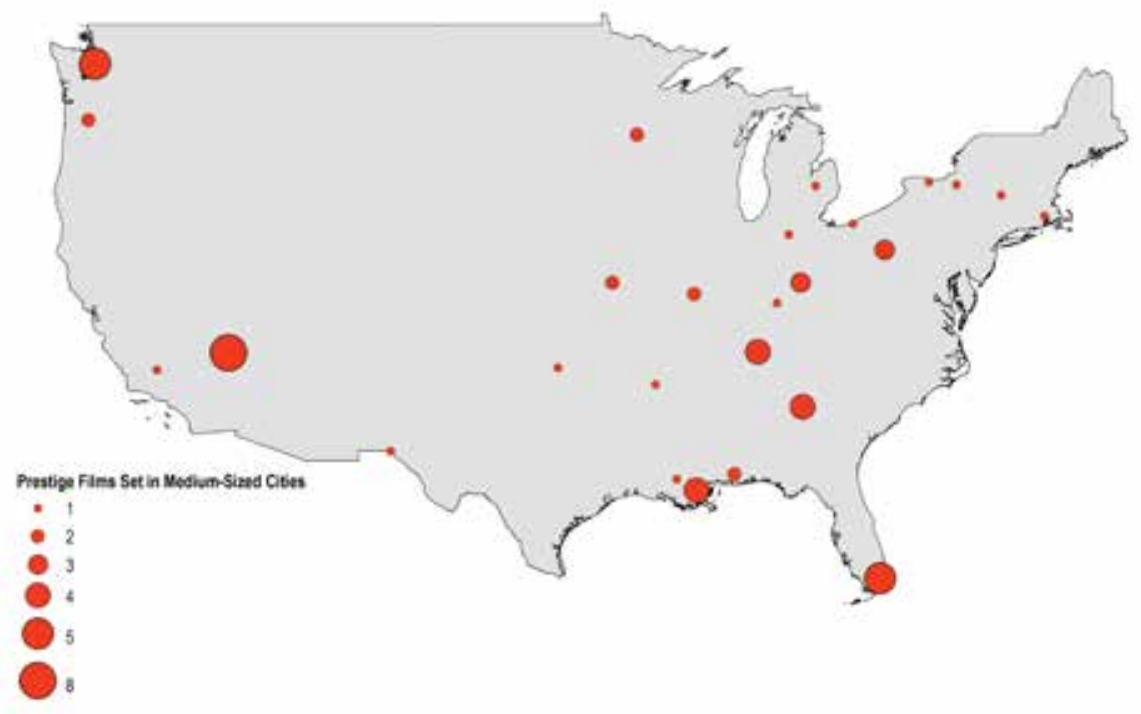

Map 18. Prestige Films Set in Medium-Sized Cities. 
The Imaginary Geography of Hollywood Cinema 1960-2000

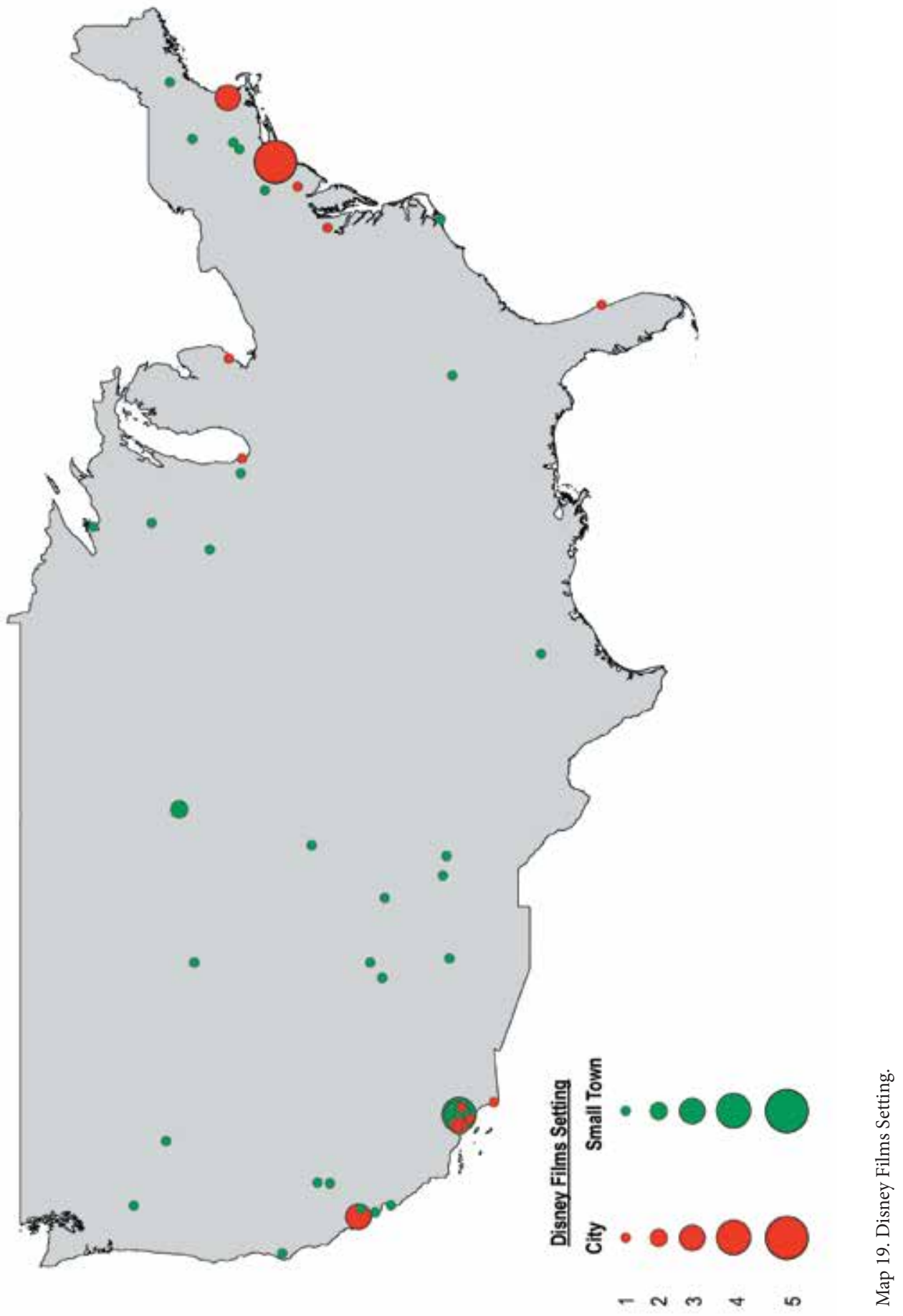




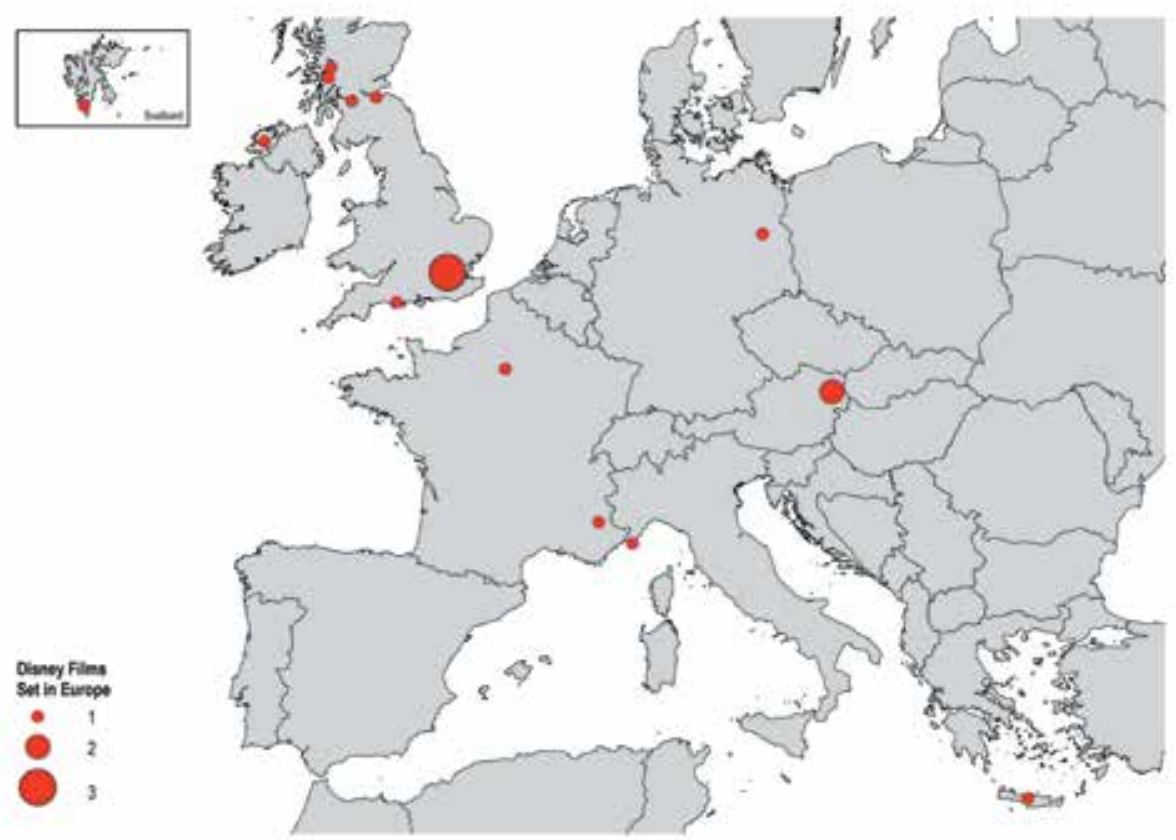

Map 20. Disney Films Set in Europe.

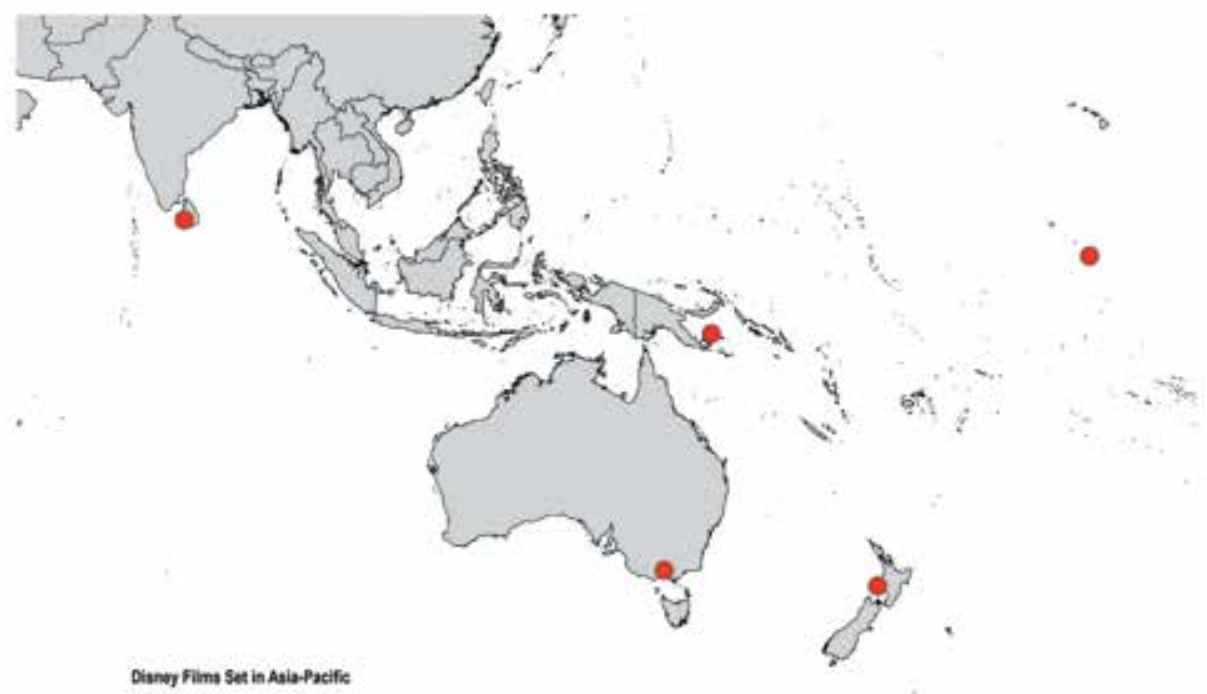

Map 21. Disney Films Set in Asia-Pacific. 

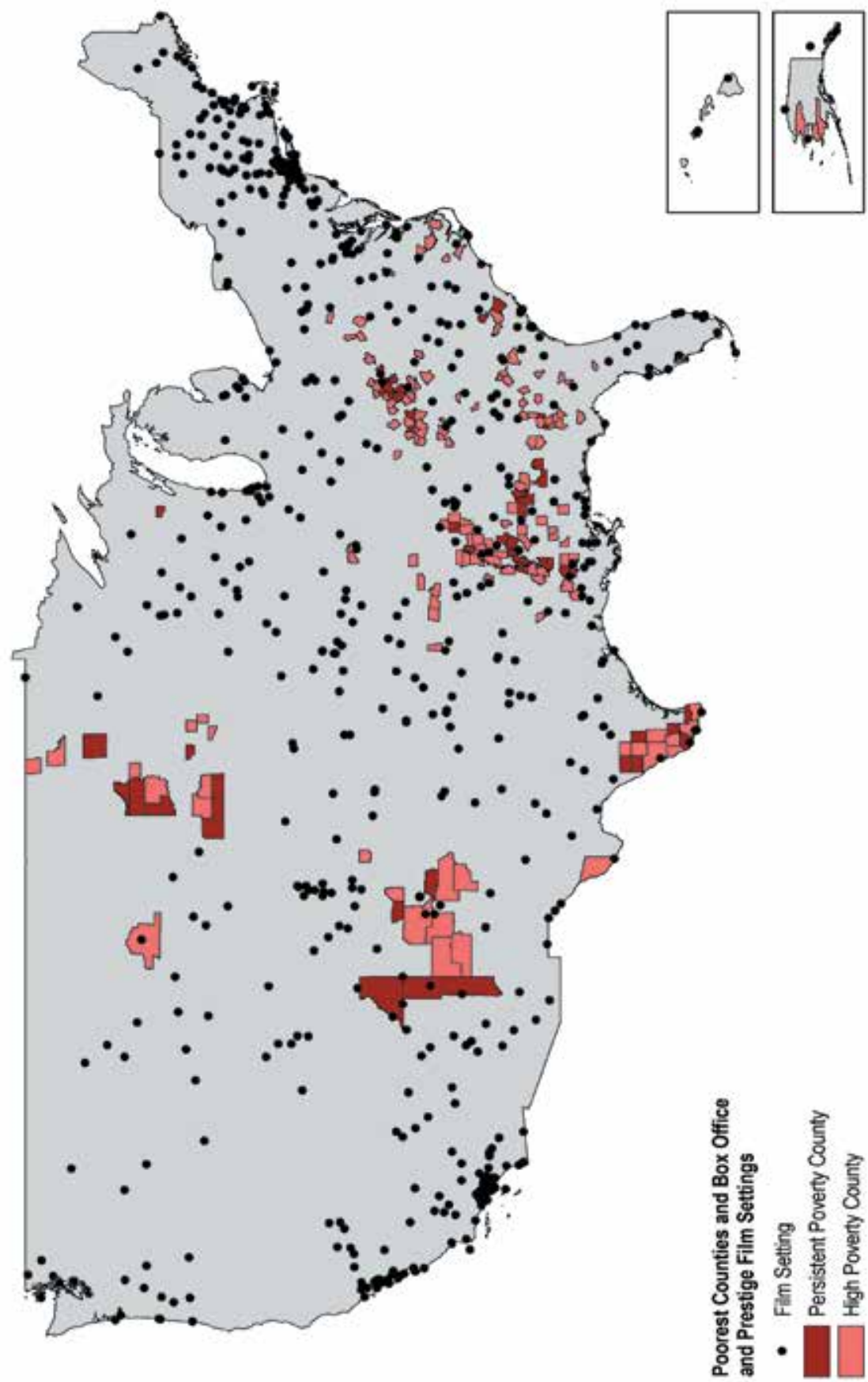

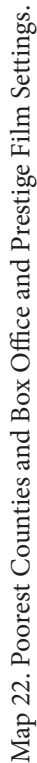




\section{Chapter 4}

Politics for Couch Potatoes: Video Rental Success Stories 

7 hat the 1980s are frequently referred to as The Reagan Era testifies to the shift Ronald Reagan brought to American political culture, and American culture in general. ${ }^{14}$ Policies like supply-side 'trickle-down' economics, deregulation, unionbusting, the rollback of environmental protections, cuts to the Department of Education, a war on drugs, inattention to AIDS, anti-communism, and military build-up, including the 'Star Wars' missile defence shield project, characterized the decade. This conservative turn in American politics also appears in Hollywood films of the period. Michael Ryan and Douglas Kellner's Camera Politica: The Politics and Ideology of Contemporary Hollywood Film (1988) was one of the first histories of the Reagan Era on film. In it, Ryan and Kellner frame the period's successful films as conservative:

The most popular films of the early to mid-eighties [...] suggest that conservative values, escapist fantasies, and cinematic regressions to traditional social forms were resonating with audiences by now exhausted by economic crises and the resulting insecurity and ready to identify with images of a reinvigorated patriarchal family ( On Golden Pond), a revived male-centered romantic couple (An Officer and a Gentleman), a renewed military (the Star Wars series), new stronger male heroes (Indiana Jones), and triumphant Americanism (the return-to-Vietnam films).

(Ryan and Kellner 1988: 11-12)

Ryan and Kellner develop a clear case for the relationship between film and social history, for the most part, by linking ideology to film form in widely seen films. Thus, they note, even though 'the social movements of the sixties carried over into the seventies and eighties, and significant cinematic statements against social injustice, nuclear weapons, and U.S. foreign policy continued to be made (WarGames, Missing, Silkwood, Under Fire, Salvador)' (Ryan and Kellner 1988: 12), a generally conservative trend prevails.

But if a film shows in a theatre and no one sees it, does it make a political sound? For all its criticism of American foreign policy in Central America - including a fiveminute scene in which James Woods delivers a history of American interventions on behalf of dictators in the region - fewer than half a million people saw Salvador (1986, Stone) at the theatre (with an average ticket price of $\$ 3.71$ in 1986, Salvador's $\$ 1.5$ million take translates to an audience of 400,000 out of a population of close to 240 million). In addition, Ryan and Kellner seem to understand social movements of the 1960s as exclusively left-wing. The right-wing anti-communist John Birch Society was also a part 
of the 1960s. In her history of the New American Right in Orange County, California, Lisa McGirr writes, that in the late 1950s and early 1960s,

in any one week, an interested citizen might have chosen from two, and possibly three, showings of such films as Communism on the Map or Operation Abolition, a controversial film put together by the House Committee on Un-American Activities.

(McGirr 2001: 62)

If for VI Lenin cinema was the most important of the arts, for Birchers, film was one media tool of many. Such use of films in non-theatrical settings to instil American patriotism was not without recent precedent in the political mainstream. In the 1940s, Frank Capra's 'Why We Fight' series 'played widely in a " $16 \mathrm{~mm}$ circuit" comprising church basements, lodges, and factory assembly halls' and was compulsory viewing for all members of the armed forces (Doherty 1999: 407). The $16 \mathrm{~mm}$ circuit played a role in educating with film through the 1960s, 1970s, and into the 1980s. At the opposite end of the political spectrum to the John Birch Society, Julia Lesage writes that some

feminist filmmakers deliberately used a traditional "realist" documentary structure [...] because they saw making these films as an urgent public act and wished to enter the $16 \mathrm{~mm}$ circuit of educational films especially through libraries, schools, churches, unions, and YWCAs to bring feminist analysis to many women it might otherwise never reach.

(Lesage 1990: 223)

In the 1980s, technological change meant that a new means of watching films, home video, had the potential to displace public, and often political, $16 \mathrm{~mm}$ showings, with private viewing of Hollywood productions. ${ }^{15}$

However, a number of films that did not succeed at the box office found an audience in a private setting: home video. While many video hits - both in terms of sales and rentals were simply the previous years' box office hits seen from the couch, some films went from poor showings at the box office to the top 25 of rentals. Some of these deal with current political events and, though they do not go terribly far down the road of political critique or outside the boundaries of American imperial, incrementalist, reformist do-gooder policy, they do in fact push (gently, tentatively) against contemporary governmental policy.

Hollywood film's imaginary geography in the early video years has a slightly more politically charged set of locations/places than box office hits - perhaps because first, video was at first geared towards adult viewers and second, the privacy and time-shifting of videotape made possible the success of the sorts of films that, traditionally, have not done as well at the box office. In this chapter I look at four movies that, after not getting near the top 25 box office, all appeared in the top 25 of video rentals in the year of their 
home video release. The Flamingo Kid (Marshall, 1984), Gorky Park (Apted, 1983), The Emerald Forest (Boorman, 1985), and Under Fire (Spottiswoode, 1983) do not occupy much space in histories of 1980s film and culture. However, as I show here, by staging some of the main domestic and foreign policy questions of the early 1980s in locations that infrequently appear in Hollywood movies, all of these films take clear stands on contemporary political issues - on the organization of the economy, on the environment and energy, on foreign policy both towards the Soviet Union and the developing world that run counter to significant facets of Reaganite ideology. I argue that paying attention to the surprising success of certain films on video gives us a counter-narrative to the dominance of conservative politics at the box office, and troubles the simple story of the rise of Reaganite politics in Hollywood cinema when it became private home, rather than public theatre, entertainment.

\section{Home Video Brings Some of the World to Your Couch}

The technology for home video was in place in the 1950s, but it was not until the mid1970s that the technology was affordable enough to expand beyond television studios for home use (for a high-end market segment). Betamax and VHS both came to the market in the 1970s, but the studios were not immediately convinced of video's possible benefits. Indeed, Universal and Disney took Sony to court, claiming that recordable video represented a copyright infringement. However, by the end of 1981, Universal, Disney, and all the other major studios stopped treating video as a problem and were involved in video distribution.

Video was expensive at first, which explains its very small presence in American households, barely over 1 per cent at the start of the decade. However, with increasing affordability, by 1987, 50 per cent of homes had a VCR, a percentage that increased to 80 per cent in 1987, and reached more than 90 per cent in the twenty-first century. In tracing video's growing importance to Hollywood, Bruce Austin notes that the studios first approached the money-making potential of video rental in a convoluted way (1990: 335-36). Eventually a priced-for-rental and priced-for-sale system took hold, with studios pricing many films at the high end of the spectrum that video stores would purchase, rent out, and sell used later, and pricing some films for personal purchase.

Broadly speaking, throughout the 1980s and 1990s, video sales skewed younger. Reflecting on video sales between 1992 and 1997, Judith McCourt observed in the Video Store Journal that '[v]ideos that appeal to children continue to dominate the Top 100 sellers. There are 30 animated titles on the list, which account for 40.4 per-cent of total unit shipments' (1998: 22). Video versions of theatrically released movies like Lady and the Tramp and other Disney animated features address a younger audience and sell in greater numbers or, as Harold Vogel's Entertainment Industry Economics: A Guide for Financial Analysis put it, "For "evergreen" titles, such as many of the Disney animations, the 
decision is normally to go for sell-through because the arithmetic can be so compelling' (2007: 130). Sell-through - consumer sales - allows the adult in the home to purchase a video that the kids watch over and over rather than renting the same video repeatedly. In a Billboard year-in-video feature, Trudi Miller Rosenblum writes that 1994 found studios

assiduously combing their libraries for titles to satisfy Hollywood's newest passion: family entertainment [...]. This means duplicating the retail dress of the King of Wholesome, Disney. So [Fox and Warner] have been enclosing family-entertainment releases in white-vinyl clamshell boxes adorned with colorful graphics. It works.

In addition to Disney's Aladdin (Clemens and Musker, 1992), its direct-to-video sequel The Return of Jafar (Shelton, Jones and Zaslove, 1994), The Fox and the Hound (Berman, Rich and Stevens, 1981), Beauty and the Beast, and Pinocchio, 1994's top 50 in video sales included three non-Disney animated features and six family-friendly live-action films. ${ }^{16}$ A similar back-catalogue combing happened for adult-audience films in the 1980s. A small group of critically acclaimed back-catalogue films sold well enough to make the top twenty of film sales: Rear Window (Hitchcock, 1954) (1984), Gone With the Wind (Fleming, 1939) (1985, 1986) and Singin' in the Rain (Donen and Kelly, 1952) (1986), Casablanca (Curtiz, 1942) (1986, 1993), The King and I (Lang, 1956), The Sound of Music (Wise, 1965) (1986, 1989, 1991), White Christmas (Curtiz, 1954) (1986), The Wizard of Oz (Fleming, 1939) (1986, 1988, 1990), The Godfather (Coppola, 1972) (1988), Doctor Zhivago (Lean, 1965) (1989), Harvey (Koster, 1950) (1990), and, as something of an outlier, Pink Flamingos (Waters, 1972) (1997).

Back-catalogue rather than blockbuster sales continued to be important through the 1990s, because, while sales of box office hits

may drive customers into stores and rack up millions in sales [...] it's catalog sales that really drive profits for retailers and suppliers. On average, between $50 \%$ and $60 \%$ of a supplier's revenue is generated by catalog titles, which can be repriced rentals or obscure movies dug up from the studio vaults.

(Fitzpatrick 1998: 62)

That is, while a box office hit is likely to repeat its financial success when it hits video, video creates a second market for films that appeal to adventurous or curious renters (and possibly buyers). For instance, in the 1990s, a number of films pitched to an African American audience that did moderately well at the box office, perhaps in the top 50, sold well enough on video to make the top twenty or better. In 1998, Soul Food (Tillman, 1997), a film with an African American cast, directed by an African American man, produced by African Americans, and set in a predominantly African American neighbourhood in Chicago, was among the year's top-twenty best-selling videos. Soul Food's success was not 
unprecedented; as Seth Goldstein notes in Billboard's summary of 1998 on video, two years earlier 'Fox racked up sales of between 4 million and 5 million copies of "Waiting to Exhale," another all-black feature with cross-over appeal. The studio sees no problem in lighting striking twice' (Goldstein 1998: 56). Between 1982, when Star Trek II: The Wrath of Khan (Meyer, 1982) popularized the sell-through approach for adult-audience film, and 1998, when DVD technology came into wide use, the majority of the top twenty fell into four categories: (1) animated features, (2) Jane Fonda workout tapes and Playboy videos, and (3) box office successes. The fourth category, middling-to-poor box office performers doing well on video, represents the smallest proportion of the top selling videos, the elusive 'video hit' second life.

While sales skewed towards a younger audience, video rentals throughout the $1980 \mathrm{~s}$ and 1990s skewed older, towards adult-oriented films (not pornography). The Shawshank Redemption (Darabont, 1994) was not even in the top 50 of 1994's box office; it made less money than the Pauly Shore vehicle In the Army Now (Petrie, 1994). But it found success on home video and television broadcast. Video Store Magazine quantified Shawshank Redemption's performance in terms of the number of times a particular video copy was rented over the course of the year. A copy of the film would have been rented out 57.8 turns per copy, with more than 362 total turns per year, the highest rate between 1992 and 1998 (McCourt \& Saccone1999). In other words, the average video store rented a copy of The Shawshank Redemption every day of the year bar three (days the store was likely shut). The Shawshank Redemption exhibits many of the formal changes that, according to Thomas Schatz, video demands of film:

Visual and spatial scale are downsized, action is repetitiously fore-grounded and centered, pace and transitions are quicker, music and montage are more prevalent, and slick production values and special effects abound.

(Schatz 2003: 38)

Though it doesn't thrill with special effects or speedy pacing, The Shawshank Redemption's prison downsizes scale, much of its action occurs centred in the foreground of the frame, it condenses time by montage, music signals obvious emotional cues, and its period costuming and set design are fairly extensive. Most of all, the detail afforded the love story between Andy and Red plays out in dialogue scenes that take advantage of the close-up scale television rewards.

The Shawshank Redemption's successful second life on video makes clear how a viewer's experience of film form differs in a theatre and on video. Of the top 50 return on investment videos between 1992 and 1998, 31 were direct-to-video titles, 11 were theatrically released films, four were television productions, and four were pro wrestling pay-per-views. Among the theatrically released films, the highest-grossing of the eleven was 187 (Reynolds, 1997) with $\$ 5.7$ million (McCourt with Saccone 1998: 17). Kevin Reynolds made 187 (1997) after directing the troubled mega-production Waterworld 
(1995), and explained his choice of the script saying, 'people won't believe this, but it's the truth: I wanted to do a smaller picture, something that was a performance piece, something creative, something where I could revive my soul as a filmmaker [...] I didn't want to think about logistics' (Brennan 1997: para. 10). When a film that finished as the $142^{\text {nd }}$-highest grossing film the year of its release offers a better return on investment than any of the year's top-ten box office hits, it's safe to say that something about video makes action blockbusters less than ideally suited for home viewing. Geoff King sees that

[t]here appears to be a paradox [...] in the economic basis of contemporary Hollywood's blockbuster production. The large vistas of spectacular attraction are designed to work at their best on the big screen. But the bulk of revenues are currently earned through viewing on the small screen.

(King 2003: 116)

The personal, small, non-logistics-driven film - 187 and Shawshank Redemption rather than The Matrix (Wachowski and Wachowski 1999) (\#49 rental in 1999) or Titanic (Cameron, 1997) (\#54 rental in 1998) - matches the size of the screen that has traditionally been associated with video.

Video's emergence as a common film-viewing medium came at a time when televisions were not particularly large, especially when compared to the size of screens commonly found in American homes in the first decade of the twenty-first century. Projection screen television technology increased the scale possible in home entertainment during the 1980s. A 1985 New York Times trend piece looks at the increasing size of television screens, noting that 'projection TV sets with their huge screens carry correspondingly large price tags (roughly $\$ 1500$ to $\$ 4000$ )' (Fantel 1985: para. 2). The 'sense of involvement in the action on screen' (Fantel 1985: para. 3) that projection screens offer seeks to replicate the movie-going experience that King connects with 'the large-scale illusion of presence' that big-screen theatrical exhibition makes possible (2003: 33, italics in original). Three projection-screen televisions are noted in particular: one with a 37-inch screen, one with a 40 -inch screen, and one with a 46 -inch screen. They cost $\$ 2600, \$ 2850$, and $\$ 3200$ respectively, when the median income was a little more than $\$ 21,000$; in 2015 dollars those prices translate to $\$ 5800, \$ 6300$, and $\$ 7100$. In 2015 , you could buy a 46 inch Samsung television at Wal-Mart for about $\$ 650$ (about $\$ 300$ in 1985 dollars), or less than one-tenth of what a cumbersome projection screen system would have cost in 1985. That is to say, most video watchers were likely watching on a screen that was less than 30 inches, smaller than the median size of television sold in the United States in the 2000s (Yau 2015), and not in high definition.

In spite of the reduced scale that television viewing demands of video, in particular on 1980s and 1990s televisions, most box office hits repeated their success on home video, in both sales and rentals. For example: Ghost (Zucker, 1990), \#2 box office in 1990 and \#1 rental in 1991; Sister Act (Ardolino, 1992), \#6 box office in 1992, \#1 rental in 1993; 
Fugitive (Davis, 1993), \#3 box office in 1993, \#5 rental in 1994; and Saving Private Ryan (Spielberg, 1998), \#1 box office in 1998, \#4 rental in 1999. The majority of films that performed better on video skews away from spectacular, large-scale action films. Some of the films from 1980 to 2000 that landed higher on the video rental charts than on the box office chart include Last Starfighter (Castle, 1984), 9 1/2 Weeks (Lyne, 1986), The Morning After (Lumet, 1986), Angel Heart (Parker, 1987), Harry and the Hendersons (Dear, 1987), The Princess Bride (Reiner, 1987), Raising Arizona (Coen Brothers, 1987), My Stepmother is an Alien (Benjamin, 1988), Green Card (Weir, 1990), Consenting Adults (Pakula, 1992), The Ref (Demme, 1994), Copycat (Amiel, 1995), From Dusk Till Dawn (Rodriguez, 1996), Showgirls (Verhoeven, 1995), Donnie Brasco (Newell, 1997), Murder at 1600 (Little, 1997), Chasing Amy (Smith, 1997), The Devil's Advocate (Hackford, 1997), $8 M M$ (Schumacher, 1999), American History X (Kaye, 1998), Meet Joe Black (Brest, 1998), Rushmore (Anderson, 1998), Snake Eyes (DePalma, 1998), Arlington Road (Pellington, 1999), Dogma (Smith, 1999), Stir of Echoes (Koepp, 1999), and Summer of Sam (Lee, 1999). The majority of these films are less dependent on a 'the large-scale illusion of presence', and thus do not suffer from the 'low audio-visual impact of television and video. The Last Starfighter's space battles, Harry and the Hendersons and From Dusk Till Dawn's makeup effects, Showgirls' big numbers, and Snake Eyes and Summer of Sam's virtuoso style may play slightly better theatrically. The novel locations in these films are on a small scale: Kevin Smith films are among the select few set in the Jersey Shore (as well as McHenry, Illinois), The Last Starfighter takes place in a California trailer park before leaving for space, and The Devil's Advocate briefly looks at Gainesville, Florida. Otherwise, the films are set in common locations, usually in major urban regions or generically familiar remote locations: New York (multiple times), Los Angeles (multiple times), San Francisco, Chicago, Washington DC, New Orleans, Seattle, Las Vegas, Atlantic City, suburban Houston, suburban Connecticut, suburban Tempe Arizona, Fairfax Virginia, Venice California, the border region near El Paso, Texas, and space (as well as a fantasy location) (Map 11).

Video as a medium for film watching had a shorter run than the $16 \mathrm{~mm}$ circuit. By 1988 Hollywood was already looking to the next thing, and by the end of the 1990s was releasing films on DVD. But the mid-to-late 1980s saw the movies shift from public, social entertainment to private, home entertainment. The four films I look at in detail in this chapter share a number of important traits that inform my argument. First, they performed much better on video than in theatrical release. Second, they are set in locations that appear less frequently in box office hits. And third, they are mass audience movies with ideological positions that run counter to Reaganite positions, from the more coded The Flamingo Kid and The Emerald Forest to the Soviet-hero Gorky Park and Sandinista-friendly Under Fire. First, Flamingo Kid, which is set in Brooklyn, the Long Island suburbs, and the fictional Club Flamingo on the Rockaway Peninsula, New York, uses the past to gently critique changes in domestic economic policy (Map 12). Then I will turn my attention to films that push against the prevailing foreign policy of the 1980s. 
Gorky Park, set for the most part in contemporary Moscow, uses genre to normalize rather than demonize the Soviet Union (Map 13). The Parà, Brazil-set The Emerald Forest also uses genre to address obliquely the United States' role in its own hemisphere. Finally, Under Fire, the worst box office performer in the four key films to this chapter, critiques American foreign policy in Central America in general and Nicaragua in particular (Map 14). All four films offer the 'large vistas of spectacular attraction' and 'large-scale illusion of presence' King sees as theatrical exhibition's strength and appeal (2003: 33, 116), but also, by using the old Hollywood approach of reducing large-scale conflicts to the scale of the romantic couple, place their conflicts and politics in narratives that match the quotidian scale that video seen on television demands.

\section{The Flamingo Kid: Public Beaches, Card Games, and Financialization}

The Flamingo Kid belongs to a group of 1980s youth nostalgia films, most of them comedies, set in the late 1950s and early-to-mid 1960s. The most popular of these films was probably Dirty Dancing (Ardolino, 1988), set in 1963, which was the top-grossing film released in 1988 and also the most rented video in 1989. Other nostalgia films from the period include the 1959-set Diner (Levenson, 1982) and Stand By Me (Reiner, 1986); the 1960-set Peggy Sue Got Married (Coppola, 1986); the 1963-set Shag: The Movie (Barron, 1989); the 1965-set Heaven Help Us (Dinner, 1985); and more serious films like the 1965set The Outsiders (Coppola, 1983). The 1963-set The Flamingo Kid finished its theatrical run at the lower end of the top 50 (\#43), tying with another film about high-school-aged characters, Sixteen Candles (Hughes, 1984), and coming in behind high school movies The Breakfast Club (Hughes, 1984) and Teachers (Hiller, 1984). The voice-over in The Flamingo Kid's trailer describes a familiar, and nostalgic, narrative:

I remember the day me and the guys first took Jeffrey to the Club Flamingo. He fell into a terrific job. He fell for this dynamite girl. Come to think of it, he fell in love with a whole new way of life. Now Jeffrey had never been more than three blocks from home. So he had a lot to learn. Yeah I'll never forget it. Jeffrey Willis walked in a bright-eyed kid from Brooklyn and he became a legend. From then on, he was the Flamingo Kid. ${ }^{17}$

The Flamingo Kid found an audience on video, ending 1985 at the twenty-fifth most rented video, well ahead of similarly youth-oriented movies Sixteen Candles, The Breakfast Club, and Footloose (Ross, 1984). The 'whole new way of life' that Jeffrey discovers in The Flamingo Kid features two key threads that make its 1963 setting speak to the mid-1980s of its video release. First, its narrative setting moves away from public spaces and towards private, business spaces. And second, its representation of gin rummy card games allegorizes changes to the American economy. In both cases, like Reagan The Flamingo Kid uses a story set in the past to come to terms with problems in the present. 


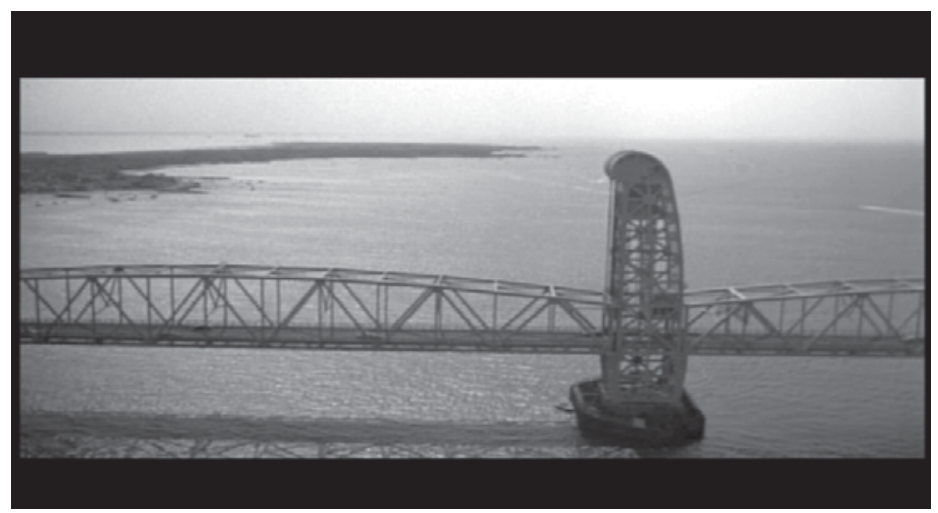

Image 33. The Flamingo Kid Marine Parkway Bridge.

The Flamingo Kid begins in Brooklyn. Jeffrey (Matt Dillon) talks to his friends at a shoe shine stand, then lounges on a chair a furniture store displays out on the sidewalk. Then, as he walks down the street, his friends pull up in a convertible and invite him to the Club Flamingo. Jeffrey accepts and they head out of Brooklyn, crossing over a bridge in a helicopter shot that is directly followed by a canted-angle shot of a sign that reads 'Welcome to Colorful El Flamingo Beach Club and Cabana Resort', followed by a brief shot of their car entering the parking lot. Finally, the door on the parking lot attendant's station - and its 'Members Only' sign - slams shut (like the characters in the film, I will refer to the El Flamingo Club as 'the Flamingo'). Inside of five minutes of screen time Jeffrey has gone from the brick and concrete of Brooklyn to the pastel pink and blue open spaces of the club. The difference between Brooklyn and the Flamingo registers visually and sonically. The first image of the film is the underside of an elevated train line; it's notable that a train, its tracks, or the sound of a train on the tracks occurs a total of five times in the opening scene in Brooklyn. When the three friends drive away, they pass under the elevated tracks, and a straight cut moves them from an image enclosed from the top by the train line to a travelling shot looking out on a patch of water, revealing a bridge in the distance. As Jeffrey relaxes in the back seat of the car, he looks up and a reverse shot shows the steel work of the bridge, followed by an extreme long shot of the distinctive towers of the Marine Parkway Bridge, a vertical lift bridge, which means the friends are driving south out of Brooklyn, to the Rockaway Peninsula.

But the friends do not end up at the peninsula's public Jacob Riis Park, with its art deco changing room and public beach designed for 'everyone' as part of Robert Moses' city plan. Well, not everyone. 
By banning public transportation, [Moses] had barred the poor from state parks. In the same way, he was barring the poor from the best of the city's parks, the big parks on the city's outskirts such as Jacob Riis and Alley Pond.

(Caro 1975: 492)

Going to the club constitutes a 'learning experience', as Jeffrey's friend Hawk (Fisher Stevens) puts it, because it would have taken friends with a car for a kid without a car from Brooklyn to get out to the Rockaway Peninsula, as buses and trains were not connected. But once the friends arrive on the peninsula, they do not go to the public beach; instead, they go to the private Flamingo Club. By using the distinctive towers of the Marine Bridge Parkway, and by showing the Flamingo rather than the art deco changing rooms of the massive public beach and park, The Flamingo Kid uses the past to indicate the importance of learning about how privatized space functions in its present.

Whether it was an office job arranged by his plumber father or service roles at the Flamingo, for working-class Jeffrey, summer vacation is already set to teach him about the economy. Jeffrey, like Baby (Jennifer Grey) in Dirty Dancing, goes behind the scenes of a leisure space and in doing so learns that the flash of the haves is often bogus and built on deception. In The Flamingo Kid gin rummy card games at the Flamingo allegorize the workings of parts of the economy that are new to Jeffrey. Phil Brody (Richard Crenna), the best gin rummy player at the club, takes Jeffrey under his wing, arguing for the importance of salesmanship over literature and philosophy. Midway through the film, Brody tells Jeffrey, 'God put certain people on this earth to give you money, and your responsibility in life is to go out there and take it'. This proto 'greed is good' (or 'always be closing') speech ostensibly concerns the relative merits of winning high-stakes card games over inferior players, which means that the talented card player Jeffrey is intrigued and briefly intoxicated by what Brody represents. But Jeffrey ends up rejecting Brody's philosophy when he learns that behind Brody's 'great' fortune is the crime of cheating at cards. During the last gin rummy game of the year, Jeffrey deduces - in a series of silent POV shots - that Brody and Big Sid (Irving Metzman) collude, which is to say cheat, to make Brody unbeatable. In the film's climactic all-night card game, Jeffrey plays the decisive hand against Brody. At one tense point, Jeffrey turns and looks over his left shoulder, the camera following his gaze with a slight pan and tilt. 'What are you looking for?' Jeffrey asks Brody. 'Big Sid isn't here anymore Phil. It's just you and me. Part of The Flamingo Kid's happy ending is the affirmation that honesty pays. After the game, Jeffrey first admonishes Brody, 'you can't go around screwing your friends', and then, in a very 1980s economy twist, Jeffrey launders the gin rummy game's dirty money by giving it to his friend and co-worker, Fortune.

In giving the gin rummy-money gift to Fortune, a college-bound African American, Jeffrey reveals his commitment to and investment in racial harmony, at least on a personal level. Ryan and Kellner read The Flamingo Kid as particularly illustrative of Hollywood films, arguing that it 
falls short of an indictment of the class system as such. It dramatizes one available instrument for those outside power who do not organize collectively - the refusal of the logic of individual mobility. The shortcoming of this necessarily limited alternative is that it must compensate for what is refused by idealizing working-class family life. The celebration of family and community has a strong appeal, but in its social context it is tantamount to putting daisies on the chains.

(Ryan and Kellner 1988: 111)

Ryan and Kellner, it seems to me, want The Flamingo Kid to be a different movie. In the film as it is, when Jeffrey defeats and turns away from Brody, he does not turn to his father's trade, plumbing, but rather returns to his working-class family with the implicit plan to go to college to be an engineer (after giving his friend money for his college education). In this manner, The Flamingo Kid adheres to the American ideal of education, not collective organization, as a key to upward mobility and racial harmony. However, in turning away from the flashy new-money Brody, Jeffrey tells the other card players about the cheating; he's a whistleblower against 'the system'. Reading the film allegorically, Jeffrey cleans up a corrupt ersatz upper-class world built on white collar financial crime. In this manner, The Flamingo Kid's nostalgia for the 1960s economy is informed by the contemporary economic recovery of the 1980s that promoted the 'nontradable sectors like real estate, financial services, and defense' that hobbled tradable manufacturing and agriculture (Stein 2010: 267). While the film does not provide a class-based critique of all that Brody represents, it still provides a critique of the increased potential for cheating that the financialization of the economy brings with it, and sees that mobility as suspect.

For The Flamingo Kid, sales and financialization may glitter, but dishonesty makes it necessary to be careful and honest, not to reject all sales and financialization. Timothy Shary notes that youth films set in the 1960s seem to use 1963 'to mark the division of the prosperous post-World War II '50s from the cynical Vietnam War '60s' (2002: 290). The nostalgia that pervades The Flamingo Kid tries to split the difference between the post-war's world of upward mobility through GI Bill-driven affordable education and skilled trade, making the more service- and speculation-oriented jobs as one option among others. Keeping all the options on the table certainly adheres to the resistancecontainment model, but also captures emerging changes to the American economy. In the 1980s, as Paul Krugman writes, the economy had 'created new professions, like risk arbitrage, which seem [ed] mysteriously lucrative, and turned previously obscure sins, like insider trading, into major sources of concern' (1990: 163). Poker, as a game of chance, would have been a little too on-the-nose for the kind of speculation and insider trading that became commonplace on Wall Street in the 1980s; gin rummy, a game that entails keeping all eleven cards in your hand until the end, shows skill and planning, making it an apt metaphor for the film's overall valorisation of hard work, whether it's plumbing or sales. The film's politics likewise depend on the particular geography at the end of the Marine Parkway Bridge: the difference between the El Flamingo Club and Jacob Riis Park 
is a right turn at the end of the bridge rather than a left turn, but both options remain in place. Rigged card games at a private club that sits at the other end of the beach from one of the great public beaches combines nostalgia and a distrust of the contemporary move towards financialization of the economy and privatization of public spaces that nouveau riche/yuppie types like Brody exploit.

\section{Gorky Park: A Smaller Moscow, a Familiar Detective}

Gorky Park was released at the end of 1983, a few months after Korean Airlines Flight 7 was shot down by a Soviet interceptor aircraft over Sakhalin Island, leading to a significant increase in tensions between the United States and Soviet Union throughout the autumn. A New York Times human interest story captures the diffuse anger some Americans felt, describing restaurant and liquor store owners who stopped selling vodka made in the Soviet Union as a mode of protest (McCarthy 1983: CN2). While it is unlikely any 1983 movie-goer would be unfamiliar with the Soviet Union as a geopolitical rival, the recent flare up in the cold war may have had some impact on Gorky Park's box office performance. Gorky Park ended up as the forty-seventh highest-grossing film released in 1983, behind the last Sean Connery Bond film, Never Say Never Again (Kershner, 1983), Max Dugan Returns (Ross, 1983), and Spacehunter: Adventures in the Forbidden Zone (Johnson, 1983). But a year later, on video, Gorky Park finished 1984 as the twenty-first most popular video rental, ahead of Never Say Never Again and generational-statement The Big Chill (Kasdan, 1983). Gorky Park's locations - both narrative and shooting and generic conventions shrink the Soviet Union to a scale appropriate not only for an American audience hostile to the country and its politics, but also to the televisions of its video rental audience.

Gorky Park is set in a curiously small-scale Moscow. This lack of monumentalism can be explained by the fact that the film was shot in Helsinki, Finland, not Moscow. As Susanna Paasonen writes in World Film Locations: Helsinki,

[T] he films shot in Helsinki are mostly void of the scale and spectacle of Moscow and St Petersburg [...]. Cinematic Soviet Helsinki is sorely lacking in the iconic and the spectacular: it is small, grey, worn, and unable to impress with sights that would be instantaneously recognizable to an international audience.

(Paasonen 2013a: 45)

On the one hand, Helsinki is a cold northern European city, which makes it a close enough Moscow stand-in for Hollywood film-makers, but 'much like their human counterparts, city body doubles stand for something else and they do so through selected details, buildings and views' (Paasonen 2013a: 44). The historical specificity embedded in a city's built environment creates different meanings for local audiences than for outsiders, 
resulting in a 'symbolic discord' for Finnish viewers (Paasonen 2013a: 70). Peter Wollen notes that Hollywood film can create curious overlaps in histories, causing Finland and the Soviet Union/Russia to bleed into each other. 'To the student of architecture in the cinema', he claims, Helsinki, 'calls to mind Warren Beatty's film Reds, in which Helsinki doubled for Petersburg' (Wollen 2002: 199). But for viewers without knowledge of Finnish history and architecture or Hollywood history and architecture, a different set of meanings for the relationship between Finland and Russia/Soviet Union emerges in Gorky Park. The average American audience member would likely not read the use of the (Finnish) National Museum as an exterior establishing shot for the Kremlin as

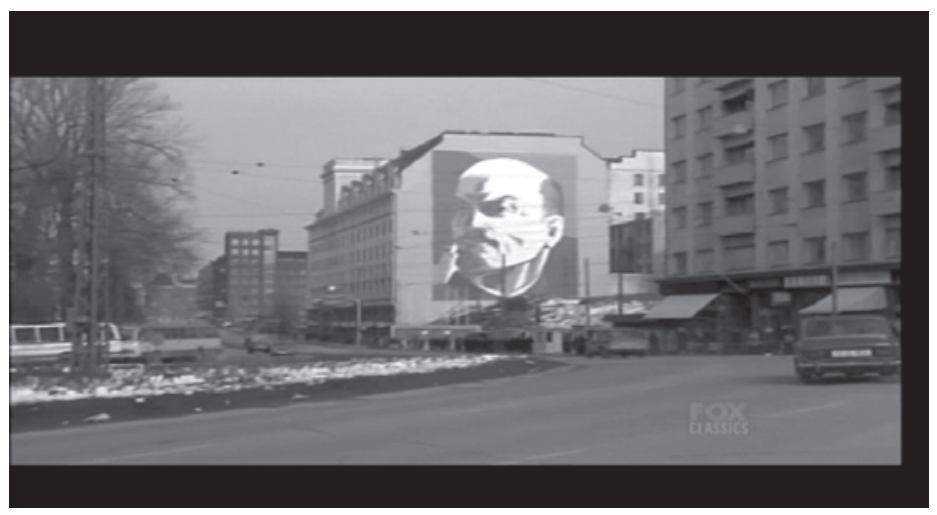

Image 34. Gorky Park Lenin portrait makes Helsinki Moscow.

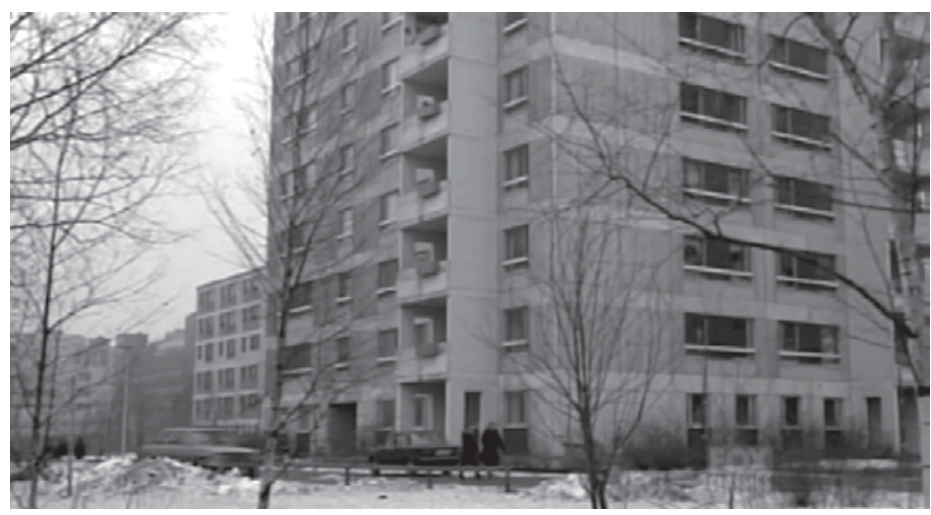

Image 35. Gorky Park Arkady's apartment building. 
Russia re-colonizing Finland, but rather as a diminution of Russian power of a particular film-location kind. As Paasonen puts it, 'stripping down of scale and volume is evident in most films featuring Helsinki as a body double for Moscow and St Petersburg' (2013a: 45). Helsinki is, after all, a much smaller city than Moscow, with about one-tenth the population and a much less imposing built environment. This means that Moscow's wide boulevards do not appear in establishing shots of various official buildings. The only time Gorky Park generates a sense of Moscow as a big city comes when the American Detective William Kirwill (Brian Dennehy) tries to trail Arkady Renko (William Hurt) and loses him in the crowd of people wearing the same coats and ushankas. With reduced-scale exterior establishing shots that introduce genre-familiar interiors inhabited by people who speak English, narrative, dialogue, and the costume design of ushankas and red stars carry much of the burden of registering 'Moscow, USSR'.

Shooting in Helsinki may have re-colonized Finland, but the grey, shabby nature of the Gorky Park's mise-en-scène doubles back on itself, shrinking and de-glamorizing Moscow. The reduction in size appears not only as exteriors of official buildings, but also in domestic spaces. Arkady and a number of his low-level co-workers and friends live in three- to eight-storey apartment buildings that are part of the urban fabric rather than the much larger microrayons built throughout the Soviet Union after World War II. Gorky Park's interior settings are often visually arresting but generically derivative: the investigator moves through the crime scene, the grimy station, a competing institution's spaces, the city's streets, and his simple home, interviewing suspects and informants at the high-end restaurant, the creepy workshop, the flashy spa, and so on. Stripped of the visual signature and scale of Moscow's built environment - Saint Basil's onion domes, Lenin's tomb, the Kremlin - Gorky Park as imagined through Helsinki's smaller scale reduces the film into a noir-ish detective story that happens to be set in wintry Moscow rather than New York or Los Angeles.

In terms of generic conventions, Gorky Park fits well within the detective film genre, and its style and mood have a noir tinge. Its adherence to detective film generic conventions, when combined with its visual style, allow Gorky Park to stake out a political position that imagines how the Soviet Union is more like the United States than it knows. The detective film, 'with its focus on an agent of investigation and its emphasis on detection' (Neale 2005: 72), though usually located in a large city, need not be located in an American city. In a Formalist approach to detective films, 'emphasis is placed on the means by which the revelation of the first story - the story of the crime - is forestalled by various digressive means and devices' (Neale 2005: 74). In addition, the detective film will often offer an antidetective - Watson is the best known example, and Arkady's subordinates Fet and Pasha serve this role in Gorky Park. As a police detective, Arkady represents the 'human face of state power'. But as Peter Messent puts it in The Crime Fiction Handbook, detectives

represent the larger state, but they also stand apart from it, motivated (and the extent of such mediating activity varies from text to text) by their own particular set of moral 
and social values. Such protagonists are often aware of individual rights and communal responsibilities that (abstract) law can compromise or overlook.

Arkady, like fellow movie (police) detectives Harry Callahan and Popeye Doyle, resists institutional control because he believes so fervently in his avowed mission - to solve the crime. In the pursuit of the solution to the crime, Arkady runs afoul of the higher-ups, and bends the rules not because he's a bad person, but because he wants to solve the case. Arkady works to find out the Truth, to see that justice is done, rather than the bidding of a corrupt/corruptible system. As a generic detective film, Gorky Park makes part of the Soviet system look better than might be expected in a Hollywood cold war film. That the part is the less-powerful local authority rather than the KGB means that Gorky Park can retain its overall negative view of the Soviet system while having a Soviet detective as the film's hero. Such an approach makes the generically familiar cop who doesn't always abide by the rules a 'good Russian', an individualist solution to the problem the Soviet Union's communist system presents.

For all the surveillance that the Soviets undertook, Arkady has a hell of a time solving the crime. He works in his office, sketching out a tree of connections and motives. During these scenes that visualize the case, Arkady's office is almost entirely dark, with only a tiny pool of light illuminating his desk. This use of darkness, especially in a film so full of snow-brightened exteriors, colours the film slightly noir. Nicholas Christopher, in Somewhere in the Night: Film Noir and the American City, calls film noir 'an utterly homegrown modern American form' (1997: 12), organized around a series of labyrinths:

First, the actual physical maze of the city: streets, sidewalks, bridges, automobile and subway tunnels [...] Second [...] a labyrinth constructed of plot twists and stratagems [...]. And, finally, the labyrinth of the hero's inner workings.

( Nicholas 1997: 17)

Arkady has little trouble navigating the city, but many people would have had a hard time navigating Moscow. Before Mikhail Gorbachev came to power, non-classified maps of Soviet cities were of little practical use, containing deliberate mistakes out of fear of spies and military using them (Keller 1988; Miller 2015: para. 19). The contending loyalties and conspiracies involving the KGB fit nicely into the contemporary sense of Kremlinology for inscrutable Russian politics. And Arkady's conflicted interior state reflects a key facet of the noir protagonist - moral ambivalence (Neale 2005: 155). Arkady's moral ambivalence as a Russian/Soviet character means that, like many hardboiled/noir detectives, he finds that the law and what is right conflict. By working his way through the physical and political labyrinths of Moscow and pursuing the truth, Arkady does more than work around small problems with the Soviet system - he also offers himself as a comfortable audience surrogate, a Soviet who wants to change the system. He uses the force of the 
Soviet system when it suits him - dangling witnesses out of high windows at one point but also makes common cause with an American and hides his actions from the KGB. In doing so he not only behaves as a generic Hollywood detective would in solving the mystery, but also makes a Russian policeman resemble a Hollywood film hero, quite an achievement for a film made in the early 1980s.

Arkady resembles a Hollywood film hero because Gorky Park's generic narrative Americanizes him. Throughout his investigation, Arkady expresses his frustration with the system by hiding information or talking back to KGB agents like a generic American detective deals with his superiors. Gorky Park shows Arkady able to resist all manner of rules, even for something as simple as professional appearance. For example, after being chided for not shaving before a meeting to update a KGB general, Arkady explains that he has not identified the murder victims (within four hours) because, 'the bodies were badly mutilated. No papers. No fingertips. No faces. They were clean shaven General, quite literally'. While the humourless Soviet General chides him, Arkady faces no serious punishment for thumbing his nose at authority. At the end of the film, after collaborating with an American policeman to foil a KGB plan and the villain Osborne's (Lee Marvin) plan, Arkady tells his romantic interest Irina (Joanna Pacula) that he must return to Moscow, otherwise the KGB will hunt her down. Returning to the Soviet Union does not represent a loss of freedom, he pretends. To explain himself, he says, 'Look at me. What do you see?' But rather than staying on the close-up of Arkady's face - a shot of what Irina sees - Apted cuts to Irina's face as Arkady answers his own question: 'A Russian. I never could be anything else. We do not see the Russian, we see the person who will leave the Soviet Union behind, physically and as an identity. When they say goodbye at the airport as Arkady returns to Moscow, he promises her, 'One day'. But in the film's last scene, Arkady's Russian voice gets replaced by the Russian-émigrés voice: Arkady reports for duty back in Moscow, and a slow dissolve returns to the farm that held the Russian sables the American Osborne wanted to bring to America. After opening all the cages, Arkady watches the sables run into the forest, with Irina's voice-over echoing Arkady's earlier promise, but with the affectionate diminutive ending, 'one day Arkasha, one day', something she never says in the film. As this final shot indicates, inside this Russian detective is a Russian émigré - which is to say, an American - waiting to get out. The honest and self-sacrificing detective's actions make Irina's freedom possible, and her migration out of the Soviet Union predicts his own desire to leave the Soviet Union. For all his protestations, Arkady does not belong in the Soviet Union: he resists the crooked KGB who infest the Soviet Union and he joins forces with Americans (even though that part of the plan works out poorly). Gorky Park thus uses generic conventions of the detective genre to show how Arkady is a temporarily embarrassed American. Gorky Park's detective narrative makes the faraway and foreign Moscow legible by adhering to genre formula, both narratively and visually, and in doing so treats a Moscow cop as if he were the same as an American cop doing a job of work, not the embodiment of the enforcement of the United States' global rival's political system. 


\section{The Emerald Forest: The Western and Renewable Energy Production}

John Boorman's The Emerald Forest, released in July 1985, retells The Searchers (Ford 1956), replacing John Wayne's ex-Confederate soldier with an American engineer aiding in the construction of a hydroelectric generating dam in Brazil. The Emerald Forest finished its theatrical run as the thirty-seventh-highest grossing movie of 1985, well behind the United States-Soviet Union faceoff in Rocky IV (Stallone, 1985) as well as the comic spy film Spies Like Us (Landis, 1985). A year later, The Emerald Forest was the seventeenth-most popular video rental, ahead of both Rocky IV and Spies Like Us, at numbers twenty-three and twenty respectively. The Emerald Forest trailer, especially its voice-over, makes its western generic identity quite clear. Over a series of shots of rainforests, a man's voice says, 'The Amazon. Mysterious. Powerful. Unchanged since the dawn of time. Until now' A rapid change from nature shots to heavy machinery, building a dam, is followed by a young girl's voice saying 'I'm scared'. Following up the girl's line, the voice-over continues,

Here a child was taken. Against all odds Bill Markham searched for his son. An adventure into the darkest regions of a savage wilderness. After ten years the journey seems over. But Bill Markham's greatest discovery lies ahead. From John Boorman, director of Deliverance and Excalibur, an adventure into the hidden places of the earth. And of the spirit. The Emerald Forest. Based on a true story.

The untamed wilderness opposed to encroaching civilization, the kidnapping of a white child by non-white natives, and the long search a white man undertakes - all echo westerns like The Searchers. Instead of railroads and towns, civilization is a hydroelectric station; the non-white natives are the indigenous people of the Amazon basin. The setting may have moved from western North America to the heart of South America, but the land remains mysterious and unchanged by technology until the engineer Bill Markham (Powers Boothe) appears and, like many western heroes, penetrates its hidden places to rescue a child who, much like Debbie Edwards in The Searchers, 'goes native', embracing the native peoples' ways. After the disaster of Heaven's Gate (Cimino, 1980), studios were not exactly churning out westerns in the 1980s, which may explain why The Emerald Forest is set in contemporary Brazil. However, in John Boorman's published journal, Money Into Light (1985), he recalls that an executive told him that no one was interested in South America. While any map of narrative locations will, in the main, affirm this position, a number of 1980s films were set in South America, including box office hits Raiders of the Lost Ark (Spielberg, 1981) and Romancing the Stone (Zemeckis, 1984), as well as critically lauded films such as Missing (Costa-Gavras, 1982) and The Mission (Jaffe, 1986). The Emerald Forest's setting in a new, South American, frontier allows it to more explicitly carry the ideological work of the western genre. The Emerald Forest embeds a non-Reaganite understanding of the importance of renewable energy production after 
the 1970s gas crisis into a more traditional-western story of taming the land, kidnapping, and rescue.

A ten-minute opening sequence establishes a number of western conventions, introducing the Markham family, the dam-building project, and the 'Indians' with whom six-year-old Tommy (William Rodriguez) disappears. After a frenzied search in reaction to Tommy's disappearance, Bill, his shirt torn, stops charging through the forest to arrive in a close-up. After remaining still for five or six seconds, Bill turns to look over his right shoulder. The camera follows his gaze and begins to rise, showing the enormity of the rain forest that Tommy has disappeared into in an extreme long shot. The oversized landscape shot of the rain forest represents the aspect of exotic locations that suffer in the transition to video. However, Tommy's disappearance comes at a dam construction site, and the loss of visual presence means that the familiar conventions to the western register more clearly. In Hollywood Genres: Formulas, Filmmaking, and the Studio System, Tom Schatz offers a formulation of the western's key thematics:

the Western depicts a world of precarious balance in which the forces of civilization and savagery are locked in a struggle for supremacy. As America's foundation ritual, the Western projects a formalized vision of that nation's infinite possibilities and limitless vistas, thus serving to 'naturalize' the policies of westward expansion and Manifest Destiny.

(Schatz 1981: 47)

The Markhams live in a city penthouse, but Bill, an engineer, is in Brazil to manage the construction of a dam that first needs to clear ten kilometres of trees in the wild rainforest before it can begin in earnest. Bill's entire purpose in the rain forest is to assert supremacy over the natural world so that the company he works for can profit from the infinite possibility contained by the limitless vistas of the Rain Forest. The recurrent landscape shots throughout the film, sometimes used as scene-shifting establishing shots, sometimes represented as a hawk's point of view, provide a sense of the size of the Amazon, not just to make Bill's eventual discovery of his missing son impressive, but also to establish the extent to which the Amazon represents a wild frontier space that an American like Bill is qualified to tame.

The Emerald Forest is not a revisionist western, but a traditional one transported into a new location, a feijoada western. It represents Brazil as a version of the United States in the nineteenth century, a country civilizing its frontier and coming into violent contact with the indigenous peoples who are being swept away by industrialized change. After Tommy disappears into the forest, Jean Markham (Meg Foster) not only retains a connection with children by working with a group that serves homeless children, she also becomes an anthropologist, learning about the indigenous tribes of the Amazon. She sets up Bill's errand into the Amazon by telling the journalist Uwe Werner (Eduardo Conde), 'This area that you and Bill are going to be going to - we know for a fact there are at least two tribes that have had no contact with the outside world'. In the ten years that Tommy has been missing, 


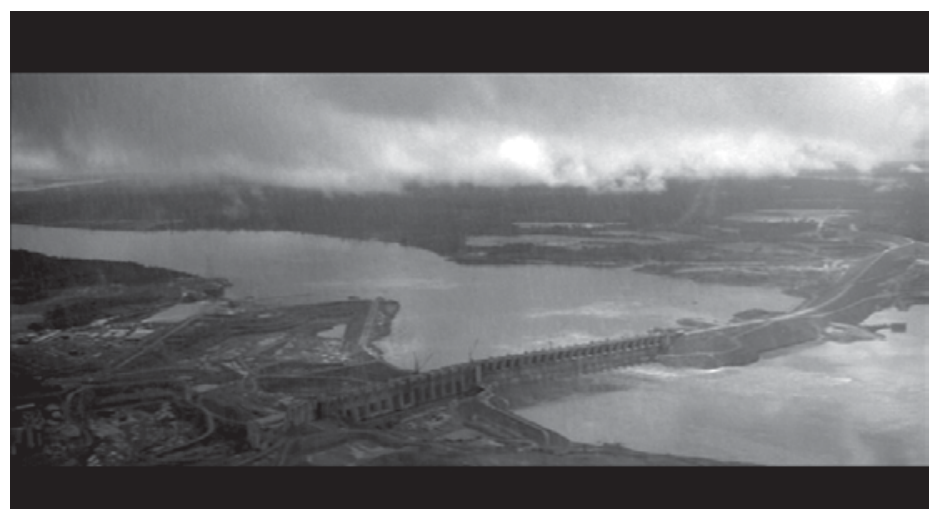

Image 36. The Emerald Forest building a hydroelectric dam in Brazil.

the boundary of explored land - both by the dam builders and the Markhams - moves deeper into the forest. As Schatz describes the western's relationship to such a boundary, 'as the community becomes more civilized and thus more institutionalized, capitalistic, and corrupt, it gradually loses touch with the natural world from which it sprang' (Schatz 1981: 51). Thus Jean must continue to study and help children in a situation that mirrors her son's, and Bill must return to the forest every year to continue the search, otherwise their tenuous connection to Tommy will be lost. In this way, the generic identity of the film shows how the United States (or at least its corporate residents), having exhausted its own frontier in civilizing the North American continent, looks further afield to keep touch with the frontier that gives it its economic energy and fuel.

The Emerald Forest was filmed in Brazil, but more or less disregards the particularities of Brazilian politics to concentrate on the experience of one American within a generic western framework. But the presence of the Brazilian Amazon as the narrative location not only offers a frontier for the film's generic western narrative, but also offers an historical context for an engagement with what motivated the building of the dam: a turn away from fossil fuel energy and towards locally produced renewable energy, a choice American viewers would recognize from their own experience with energy over the last decade, if not Brazil's. As a reaction to the 1973 Energy Crisis, Brazil and Paraguay planned the Itaipu Dam on their border as a way to end the need to import oil. A little more than ten years after the agreement (the time it takes Bill to find Tommy [played as a teenager by Charley Boorman] in the Rain Forest), the Itaipu Dam come on line, about a year before The Emerald Forest was released in theatres. At the time, it was the largest hydroelectric plant in the world. As a Reuters report from 24 October 1984 put it, 
The world's biggest hydroelectric project, the Itaipu dam on the Paranà River dividing Brazil and Paraguay, begins operating on Thursday. So far, two 700-megawatt turbines have been installed but when work is finished in 1990 the dam will generate 12,600 megawatts, about a third of Brazil's present electricity consumption. The $\$ 15$ billion project is a joint venture between Brazil and Paraguay.

('Dam's' 1984: D10)

In 1985 the United States' energy consumption was more than eight times that of Brazil, owing mostly to Brazil's lack of industrial electricity use. The thinking behind the construction of hydroelectric plants, much like the earlier building of Brasilia in the country's interior, was to spur economic development. Canada produced a great deal of non-fossil-fuel power in the 1980s, so much that they had a surplus of energy that they sold off to neighbouring states in the United States, which put downward pressure on electricity rates (Martin 1984: F4). With cheap electricity available from Canada, the United States could continue not learning the lesson of the 1973 Energy Crisis. The Three Mile Island near-meltdown of 1979 led to protests against nuclear power for the next few years (in San Luis Obispo, California and Seabrook, New Hampshire in particular), no new orders for nuclear plants in 1979, and President Carter installing solar panels on the White House. But in 1981 Reagan chopped back regulations to give nuclear power a boost (he took the solar panels down too) (Martin 1984: 3-24; Parisi 1981: 9). Reagan administration policy removed impediments to fossil fuel production, encouraged nuclear power generation, and encouraged letting market forces determine the extent of coal use (Katz 1984: 138-44). When The Emerald Forest hit theatres and then video, the United States showed very little interest in investing in renewable energy research and production - the administration reduced funding to solar and conservation programs, and floated the notion of eliminating the Department of Energy altogether (Katz 1984: 141-43) - which, given the film's generic form, makes the background noise of the film's hydroelectric dam a reminder of a possible alternative industrial/civilizing road not taken in energy policy.

In The Emerald Forest, an American, Bill Markham, oversees the film's dam project. However, on Brazilian hydroelectric projects, engineering expertise was local. As the New York Times reported during Itaipu's construction, 'Little of the project is foreign; 85 percent of the work and equipment was provided by Brazilians and 5 percent by Paraguay' (Kilborn 1983: D9). During the cold war, aid in the form of money and technical expertise to Third World countries to build infrastructure was a key form of foreign aid. In building the Aswan High Dam, the Egyptian government played the United States against the Soviet Union to increase the amount of aid money they received from both sides, and the Soviet Union provided technical assistance as well. In the place of Soviets as experts, The Emerald Forest shows American expertise not only helping to build a dam in a frontierconquering, industrializing Brazil, but also saving young women from being forced into prostitution. Such a vision of American generosity and magnanimity in South America 
offers a vision of a Good Neighbor Policy out of scale to what was actually happening in Latin American policy. The Emerald Forest smuggles in its environmental message by staying in line with the iconography and narrative of classical Hollywood westerns, clearing room for its vision of saving the rain forest and turning away from fossil fuel to more renewable sources.

\section{Under Fire: Contras, Sandinistas, and the News}

Under Fire died at the box office. It finished as the ninety-fourth highest-grossing film among 1983's theatrical releases, behind Woody Allen's fake documentary Zelig, the Canadian hoser Shakespeare adaptation Strange Brew (Moranis and Thomas, 1983), and the re-releases of Rear Window (Hitchcock, 1954) and Porky's (Clark, 1981) (Box Office Mojo 2016). But Under Fire finished 1984 as the number 22 video rental. Under Fire begins in Chad (helpfully identified by a title as 'Chad, Africa'), where allegedly apolitical photojournalist Russell (Nick Nolte) takes pictures of the start of a war. From there, Russell and his fellow journalists Claire (Joanna Cassidy) and Alex (Gene Hackman) go to Nicaragua to document and affect the course of the country's revolution. Russell and Claire find time to fall in love at the same time. Few films in the late 1970s and early 1980s were set in Central America or Africa. In the five years leading up to Under Fire's release, only three top-50 box office films were set in Africa: an unnamed country in Tarzan the Ape Man (Derek, 1981), and Egypt in Raiders of the Lost Ark (Spielberg, 1981) and part of History of the World Part I (Brooks, 1981). Central America also appeared infrequently, with The In-Laws (Hiller, 1979) partly set somewhere near Honduras, and

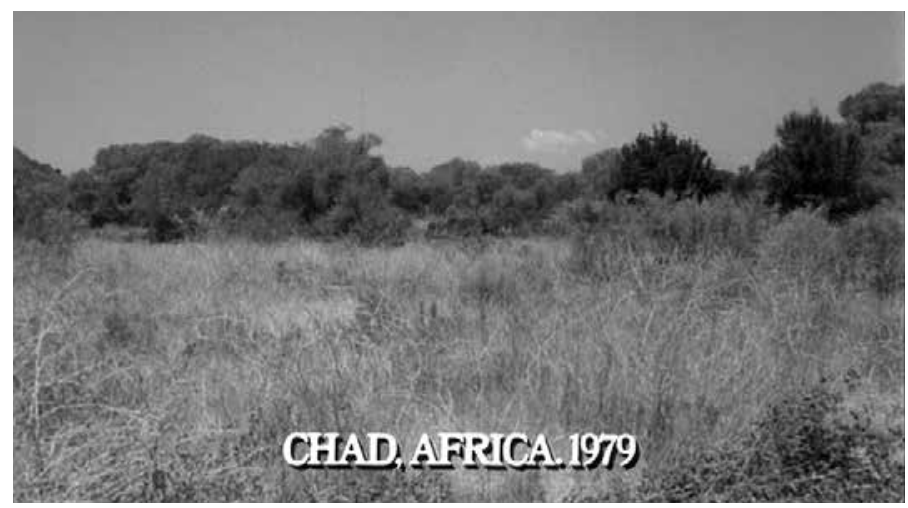

Image 37. Under Fire Chad, Africa, for the geographically illiterate. 
Up in Smoke (Adler, 1978), 10 (Edwards, 1979), Herbie Goes Bananas (McEveety, 1980), and Altered States (Russell, 1980) set, to some degree, in Mexico. While the film's Central American and African settings hint as Bond-style film tourism, its handheld camerawork and treatment of Nicaragua's revolution renders Under Fire a somewhat serious-minded political drama, which is not exactly a recipe for box office success.

The majority of analyses of Under Fire take it to task for, in essence, being a Hollywood film. Under Fire's theatrical trailer explains the film in a manner that shows how closely it adheres to a Hollywood understanding of the rest of the world and politics:

Nicaragua. 1979. Their job is reporting the news. They freeze truth in pictures. They put war into words. But they fell in love in a country under fire. Who can they trust? They are threatened by the army. Lied to by the president. What can they believe? They are used by the CIA. Betrayed by the mercenaries. Until they see too much. Until they feel too much. Until they must take action. Action that could cost them their lives. On this roll of film, in the camera of a US photojournalist, under fire on all sides, is one hell of a picture.

In Under Fire Nicaragua's revolutionary outcome is an American romantic couple; the important lessons all move through Americans. Nicaraguans are bit players in their own history. Under Fire gets historical facts wrong and adheres to the Great Man school of history. But rather than imagine what a revolutionary Under Fire would look like, I want to consider the film's Hollywood-standard narrative of incremental change that, as I argue, clearly registers and critiques US policy in Central America.

Under Fire assumes that its American audience is prepared to entertain the possibility that US policy in Central America serves neither the US national interest nor any Central American nation's interest. Such an assumption was not outlandish at the time. In The Clustering of America's breakdown of 'Pros and Contras', Michael Weiss breaks down the relative 'Central American Doves' clusters: Levittown, U.S.A. (most dovish), New Melting Pot (middle), and Furs \& Station Wagons (most hawkish). Writing in the mid-1980s, Weiss writes,

The threat of Nicaraguan invasion, for instance, is feared more by the conservative, upscale suburbanites from Furs \& Station Wagons than by the middle-class moderates of Levittown, U.S.A. According to nationwide surveys, Furs \& Station Wagons voters see Central America as a potential Vietnam - a horrifying notion given so many teenage sons so close to draft age. In Levittown, U.S.A., which has one of the lowest concentrations of children in America, Nicaragua is seen as less of a threat to American peace and prosperity. Republican Furs \& Station Wagons support aid to the contrarebels. Moderate Levittowners donate money to political candidates advocating a hands-off policy in Central America. 
In other words, the more affluent suburbanites most likely to have the disposable income to own a VCR and rent videos are interested and invested in the film's subject matter and are likely to hold a Sandinista-friendly position. As a Hollywood movie, Under Fire offers a soft critique of US policy as well as a sense of the real dangers present in Central America. Its failures to go further thus mark the far end of the horizon of possibility for discussions of US foreign policy in the Reagan era.

Central America was certainly in the news and in the US cultural imaginary during the early and mid-1980s. President Reagan showed a great deal of interest in Nicaragua and Central America, as his Reagan Doctrine shifted away from the cold war policy of containment under which 'the United States would try to "roll back" communism outside Europe by supporting, by any means necessary, anti-Soviet autocracies and diverse military insurgencies in pro-Soviet nations around the world' (Wilentz 2008: 157). Sean Wilentz argues that

The Reagan Doctrine contributed to the bloodbath in Central America, where as many as 200,000 people died in Nicaragua, El Salvador, and Guatemala fighting leftwing regimes or propping up right-wing regimes, with no discernible impact on the outcome of the cold war. Reagan's particular object of fixation, the Nicaraguan contras, certainly hurt the Sandinistas but never formed a credible political or military force, despite the attention and covert funding lavished on them.

(2008: 278)

In spite of the interest that Central America held for American foreign policy, with Nicaragua changing from one of the lowest- to highest-rated State Department embassy assignments, Under Fire adheres to a view that Americans are more or less ignorant of the geography of the hemisphere (McConnell 1983: 182). Soon after arriving in Nicaragua, Russell, Claire, and Alex are present at a night club bombing. Alex calls his American editor, telling him, 'Forget the Pope Charlie, you got the Pope some place every week. It's a big story down here cause it's the first sign of fighting in Managua. There is a long pause and Alex speaks slowly to explain, 'Get a map, Charlie. Look up Nicaragua. You drive to New Orleans, then you turn left'. The line works as a gag, but in fact an average movie-watcher would likely have been familiar with Nicaragua - it was on the front page of the New York Times, which is to say one of the major stories in the news, 34 times in the calendar year before Under Fire's theatrical release on 21 October. Only Lebanon, where the marine barracks bombing that caused 241 deaths was major news, Israel, which appeared in connection with Lebanon for the most part, and the Soviet Union, the nation's global rival, appeared on the front page more often in $1983 .{ }^{18}$

Nicaragua appeared on the front page frequently because it was a key location in President Reagan's anti-communist foreign policy. In Sleepwalking Through History: America in the Reagan Years, Haynes Johnson notes that Reagan 'had run on a Republican platform that singled out as a special danger to U.S. interests "the Marxist Sandinista 
takeover of Nicaragua and the Marxist attempts to destabilize El Salvador, Guatemala, and Honduras"' (2003: 253). The strong anti-communist stance that gave Reagan the credibility to negotiate with the Soviet Union applied to more than the Soviet Union, and Hollywood treatments of Nicaragua prove instructive in understanding how Reagan's policies and ideology trickled down to popular thinking about global politics. At one end of the political spectrum, the top-twenty box office and video rental hit Red Dawn (Milius, 1984), features the Nicaraguan military fighting alongside the Cuban and Soviet military in their invasion of the United States. While Red Dawn owed its popularity to a number of factors, its narrative of a partisan youth division foiling an invading force of communist aggressors certainly played a role. Moving away from Red Dawn towards the middle of the spectrum, we first find Under Fire; beyond Under Fire we no longer find Hollywood films, but rather independent productions like Walker (Cox, 1987) and locally produced works like La Decision de Vencer (Zero a la Izquierda, 1981) (Lesage 1982: para. 4). Being set in Nicaragua changes the relative political position of the films, as a greater amount of interaction with the people who deal with the repercussions comes to the fore. Hal Brands makes clear the extent of Reagan's foreign policy as complicit in the parlous state of countries like Nicaragua: 'The tragedy of the Central American civil wars was impossible to deny, but that didn't stop Ronald Reagan from trying' (2010: 223).

The political unrest and human rights nightmare in Central America was informed, in part, by the American policy of 'seeing all right wing dictators as opponents of communism and allies in a global struggle[;] Reagan cast them as freedom fighters on the front lines of America's battle against communism' (Schmitz 2006: 202). In the fight against communism, authoritarian rulers (usually backed by landowning elites) enjoyed US military and financial support. Under Fire gives its first strong political speech to the news producer Alex, not the photojournalist Russell, who tells his editor in the United States, 'look, we're backing a fascist government again I know that's not exactly news, but see if you can find an angle. Hub Kittle (Richard Masur), a public relations man who works for President Somoza, interjects, 'There's fascists and there's fascists. Let's not go throwing words like that around. Kittle reads from the same script in a later conversation with Russell, invoking a model of Realism that reproduces Reagan foreign policy advisor Jeanne Fitzpatrick's distinction between good (right-wing) authoritarian governments like Nicaragua's under Somoza, Iran's under the Shah, and South Africa's under Botha, and the bad (left-wing) totalitarian governments:

Hub: Let's grow up, huh? It's very easy to fall in love with the underdog, but there's an upside and a downside to this thing. Just wanna remind you all this stuff about a revolution of poets is crap.

Russell: It's great PR, though, isn't it, Hub? So what's the upside? 
Hub: Simple, and it could happen. Somoza destroys the terrorist insurgents. Rebuilds the country. Shitcans the purveyors of excess. Stabilizes the Cordoba and is finally beloved as the savior of Nicaragua. Our pal.

Throughout the conversation, Russell greets Hub's claims with a look of good-natured disbelief. As he reaches for his packet of cigarettes, the shot cuts away from the close-up of the conversation into a medium shot of the two men sharing a smoke. When Russell asks, 'What's the downside?' Hub immediately replies, 'Commies take over the world', with no cut. Spottiswoode accentuates Russell's incredulity and disbelieving half-laugh by cutting to a close-up reaction shot of Russell after Hub's doomsaying. That is, previously non-political Russell, the audience surrogate, doesn't buy any of what Somoza's flack is peddling. And this licence to laugh at the good-authoritarian anti-communist policy comes in the type of shot most suited to home video, the close-up, making the film's engagement with politics visible at a scale suited to home viewing. The tendency of Hollywood films to simplify politics to one person's experience of coming to consciousness means that its films do not make calls to class-based action. But for viewers trained on Hollywood films, Russell's reactions and consciousness establish the parameters of the thinkable as distinct from current US policy.

Hollywood films also simplify politics to a question of charismatic personality, as Under Fire's treatment of the revolutionary leader Rafael - and Russell's moral quandary over staging a picture of him 'alive' - demonstrates. When Russell seeks out Rafael in Matagalpa, Isela (Alma Martínez), one of the rebels (who earlier was working as a translator for Americans) mocks his self-interest, saying that 'it's a good story, you will be more famous'. In 'Hollywood in the age of Reagan', Stephen Prince argues that the Central America-set Under Fire, El Norte (Nava, 1983), Latino (Wexler, 1985), Salvador (Stone, 1986), and Romero (Duigan, 1989), all 'break with the dominant ideological assumption of the Reagan era, namely, that political unrest in Central America - and, indeed, anywhere in the world - was financed and directed by the Soviet Union as part of its plans for world domination' (Prince 2006: 240). In one scene, Under Scene moves in a different direction, for while Russell is certainly a white saviour for the Nicaraguan revolution, the film complicates that role slightly. When Russell frames the rebels' desire for a picture of Rafael to get out, as 'you mean the Western press needs a photograph', Isela quickly corrects him: 'The world is not divided into east and west any more. It's divided into north and south', re-orientating the globe's key axis. Under Fire remains interested in the coming-to-consciousness of its US characters, but briefly opens up the possibility that the United States-Soviet Union axis does not fully explain the world, that other nations have their own politics that are, to a large degree, not entirely determined by American (or Soviet) intervention. However, while Under Fire can offer gestures towards Nicaragua as its own place, it conceives of world politics as an arena in which the United States acts and other countries react. Even though Isela introduces the idea of the Global South to the film, she performs a function rather than drive any part of the narrative. Lesage, 
describing her field work in Nicaragua, writes that, 'the call to the citizenry to participate in the popular militia evokes a sense of both national and personal pride, especially among women, for over half of the Nicaraguan popular militia is women' (Lesage 1982: para. 27). By puffing up the Che Guevara-ed Rafael, Under Fire makes it impossible for a sense of national pride to emerge, and Isela, like all the Nicaraguan characters, is merely a functional character, which makes her personal pride more than the film can represent. The Global South gets one line of dialogue to convince Russell and his fellow journalist Claire that Americans are not the centre of the universe; Nick Nolte gets his name above the title and his heroism 'saves' Nicaragua anyway.

Under Fire frames Nicaragua's revolution in terms of the American characters, but its formal treatment of the revolution's decisive moments positions the violence as far away and mediated, not just politically, but also formally. After vacillating for some time before staging the photo of dead Rafael, Russell reacts differently when his American friend is killed. When Russell and Alex get lost chasing a story in Managua, Alex walks down a street to ask some soldiers for directions, and Russell stays in the car, taking pictures. Alex walks to the rear of the image, always in a long shot that shows Russell's point of view. By contrast, Russell appears in close-ups. Russell watches Alex interact with the soldiers, and while the point-of-view shots of Russell photographing Alex stay in the same long shot, the close-ups of Russell get progressively tighter. When a soldier casually shoots and kills Alex, a close-up shows Russell click the shutter, drop the camera from in front of his eye, and run towards the violence. The distance the camera places between Russell and the violence reappears when the photos of that violence get shown on television. A day later, Claire sees Russell's pictures of Alex getting shot on the TV news, and breaks down in tears. A woman asks her, 'Journalist? You knew the man who was killed?' then delivers another bit

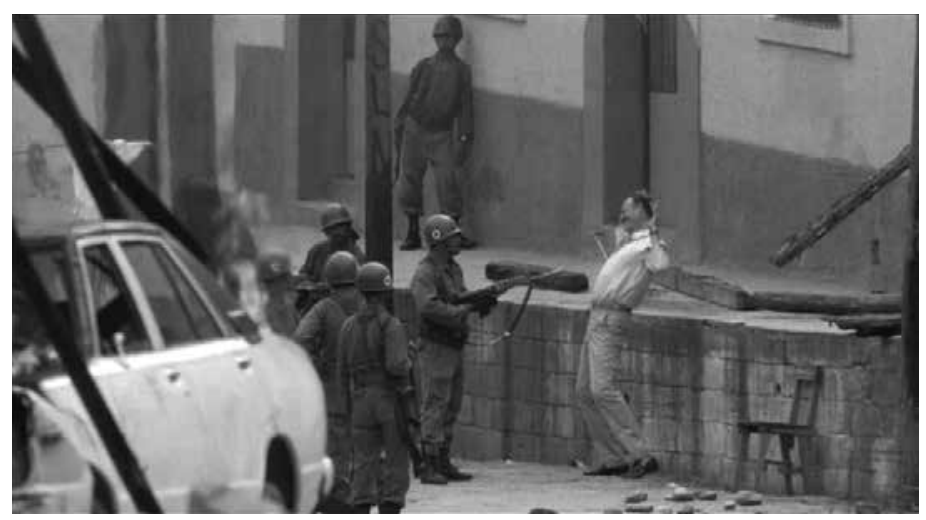

Image 38. Under Fire Alex gets shot in POV shot. 
of dialogue that squeezes in a moment for the Nicaraguan point of view, here consciously ironizing the 'white saviour' narrative: '50,000 Nicaraguans have died. And now a Yankee. Perhaps now Americans will be outraged at what is happening here [...]. Maybe we should have killed an American journalist fifty years ago. The quickness of Russell's decision to act, both to take the photo and to take other actions, shows that Russell's position towards the Nicaraguan revolutionaries is detached and somewhat intellectual, whereas his position towards the ruling junta is much more visceral. He is not quite sure about the rightness of the revolution, but he's sure that the ruling power is wrong.

Under Fire was released on home video in April 1984; in the same month, the Wall Street Journal reported that the CIA had mined harbours in Nicaragua. In the attempt to prevent Soviet ships from aiding Nicaragua, the mining had endangered all the ships arriving in Nicaragua (and two years after, Newsweek's 'A secret war for Nicaragua' brought US involvement in Nicaragua to a wider American audience). ${ }^{19}$ 'Agents who took part in the mining operation included Salvadorans, Hondurans, Argentinians (sic), Chileans, and Ecuadorians - but no contra Nicaraguans in whose name the mines had been laid' (Johnson 2003: 276-77). In 'For our urgent use: Films on Central America', a 1982 article in Jump Cut, Julia Lesage invokes the political role the $16 \mathrm{~mm}$ circuit plays as a political counterweight to Hollywood films: 'When someone goes to see a leftoriented film, slideshow, or videotape about Nicaragua or El Salvador', she writes, 'that act represents a judgment and a decision. The judgment is that the U.S. mass media are not offering enough information or only filtered and distorted information about Central America' (1982: para. 2). Putting aside the decline of the $16 \mathrm{~mm}$ circuit, the audience for a Hollywood movie is not the audience for a more politically engaged $16 \mathrm{~mm}$ circuit showing. But Under Fire's video availability right as the news of the harbour-mining broke, after Nicaragua's consistent presence in the news throughout the previous year likely informed more than a few decisions to rent the movie. And even though the film still ends with the revolution-forged romantic couple returning to the United States and the mercenary Oates (Ed Harris) predicting where the United States will next intervene, it does place these two United States-centric moments in the context of a revolutionary investiture of the very group the Reagan administration sought to displace. Under Fire is not a revolutionary film, but it does register a discomfort with the outsized and sometimes highly damaging role the United States plays in global politics that a sizable portion of the video-renting population was ready to hear.

\section{Conclusion}

The regime of mobility and privacy that Raymond Williams saw as generating the conditions for what he referred to as 'mobile privatization' has its roots in the decades before home video technology was in place. In Television: Technology and Cultural Form, Williams first establishes how radio functioned in the 1920s, when real gains had been 
made in immediate concrete conditions of everyday life. As Williams observes, those gains created new needs:

The new homes might appear private and 'self-sufficient' but could be maintained only by regular funding and supply from external sources [...]. This relationship created both the need and the form of a new kind of 'communication': news from 'outside', from otherwise inaccessible sources.

(2003: 20-21)

This kind of one-way communication with the outside world took place through broadcast media, first with radio and then with television. The post-WWII transition to television broadcasting on a wide scale came about because

[t] here was significantly higher investment in the privatised home, and the social and physical distances between those homes and the decisive political and productive centres of the society had become much greater. Broadcasting, as it had developed in radio, seemed an inevitable model: central transmitters and the domestic sets.

(Williams 2003: 23)

Home video and mobile privatization are not a perfect match, but the habit of watching movies on home video rather than in public at a cinema embodies the 'centralized transmission and privatised reception' (Williams 2003: 24) at the heart of mobile privatization. Frederick Wasser argues in 'Ancillary markets - Video and DVD: Hollywood retools' (2008) that mobile privatization can apply to home video, and it can also clarify the appeal of films with political messages rented on home video. In the early to mid-1980s, when the major studios entered into the home video market, the physical distance between suburban VCR-owning homes and political and production centres was matched by the psychological distance, whether in the form of anti-government sentiment or a sense of an increasing powerlessness in the face of de-industrialization and globalization. Lesage's work on the political usefulness of the $16 \mathrm{~mm}$ circuit to feminist film-makers and left-oriented activists appeared in the late 1970s and early 1980s, but "by the mid-1980s the perception that film was "being replaced by video" was becoming fairly widespread' (Knight and Thomas 2011: 113). As video became more popular and $16 \mathrm{~mm}$ was phased out, the United Kingdom saw a reduction in the kinds of films available for public viewing. Julia Knight and Peter Campbell Thomas, in Reaching Audiences: Distribution and Promotion of Alternative Moving Image, relate the story of Harris Films, a company with a library of $13,00016 \mathrm{~mm}$ prints that it distributed to film societies, schools, and other non-theatrical outlets, which went into liquidation in 1986: 'When no commercial company stepped forward to take over the Harris library, there was a very real risk that many of its titles would simply fall out of distribution, radically diminishing the diversity of moving image work available in the UK' (Knight and Thomas 
2011: 113). While Knight and Thomas focus on the $16 \mathrm{~mm}$ prints themselves, the places where those films were shown - non-theatrical outlets like schools, church basements, and community centres, to name a few - were also lost, replaced in large part by private homes. This shift replaced the public exhibition of a film - say Harlan County U.S.A. (Kopple, 1976) to a union hall full of people - with a couple sitting on their couch. The public action of film-going, whether to a cinema or non-theatrical space, and the political stance that would reveal, becomes privatized on home video, reducing the horizon of political action to a quick transaction in public, at a video store, followed by a private movie-watching experience.

Hollywood films tend to move from relative degrees of resistance to hegemony to narrative conclusions that ensure containment within the system. The Flamingo Kid, The Emerald Forest, Gorky Park, and Under Fire all offer some resistance and critiques to American economic and foreign policy, with gradual reformist positions built into happy endings that, in the end, affirm the essential rightness of the system. Resistance and containment is built into nearly every Hollywood film, so it's difficult to say that these four films did not succeed at the box office because they pushed a little harder on the resistance and concluded with a slightly more open containment.

In his Memoirs of a Suburban Boy, director John Boorman makes a fairly strong claim for the political importance of The Emerald Forest. The film, he writes, 'inspired many young people to devote their lives to conservation. It persuaded the Brazilian government to legalise organisations trying to protect the rainforest that had hitherto been banned' (2003: 269). Studio head Samuel Goldwyn is reputed to have said 'if you wanna send a message, call Western Union'. And it is doubtful that Brazilian President José Sarney told Boorman, 'so you're the little Englishman who directed the movie that started this great legislative shift. But Boorman's assertion of the power of The Emerald Forest's political message can explain both its box office stumble and its later home video appeal. To call The Flamingo Kid a political movie would stretch matters, but it resists the 'greed is good' Wall Street narrative that predominated in the Reagan era. Gorky Park makes Moscow just another city where the police solve crimes, a major political statement in itself given the time. The western The Emerald Forest takes two steps back, imagining Brazil as another frontier to tame, which is to say exploit; but some of that exploitation takes the form of renewable energy production. And Under Fire foregrounds the poor job mass media does in reporting on international politics and US foreign relations to make a clear, if gentle, critique of the United States' role in Nicaraguan politics.

What is clear that home video created a venue for political - but not too political movies to have a second chance to bring politics into leisure time. For all their faults, mostly due to being Hollywood films operating within genre constraints, these video hits locate their politics in less-known places they make more knowable. Introducing and explaining the privatized beaches on the edges of New York, the hydroelectric potential of the Amazon basin, a smaller-scale noir Soviet Union, or a Global South rather than Third World Nicaragua allows video hits like The Flamingo Kid, The Emerald 
Forest, Gorky Park, and Under Fire to establish the literal and political boundaries of these unfamiliar locations. In the creation of good guys, bad guys, and solutions to the protagonists' problems, these films, in their backgrounds, generate images of places in the news beyond the summit hotels and CBDs in news reports or still images in the newspaper. 


\section{Chapter 5}

Imagining More for Medium-Sized Cities, 1975-2000 

7 he Star Wars films are full of single-biome planets: the forest moon of Endor; the city planet of Coruscant; the swamp planet Dagobah; the ice planet of Hoth; the desert planet Jakku; and of course, Tatooine, the other desert planet where it all begins. These risibly simple conceptions of alien planethood highlight the rather allegorical nature of the Star Wars universe. More significantly - and in a less visible manner - this reductive approach to place also typifies mainstream cinema's depictions of mid-sized American cities. In film, cities like New York, Los Angeles, and Chicago appear as diverse, multi-faceted locations, settings appropriate for any film genre. But prestige films set in medium-sized cities - that is, the twentieth through seventy-fifth largest cities, places with populations between 175,000 and 500,000 - place otherwise complex narratives into cities that are simplified to one predominant trait, rendering them as simplistically as any of the single-biome planets in Star Wars. While most prestige films set in medium-sized cities represent them as something close to singlebiome planets, repeating the visual identity, implicit cultural history, and local identity, such films also go to great lengths to position their medium-sized cities as central rather than peripheral, usually in terms of the city's single-biome appeal - music for Nashville, gambling for Las Vegas, and steel for Pittsburgh. But asserting a medium-sized city's centrality and importance also locks its identity in place, making a change in identity and calling something for individuals rather than the city as a community. While all the films in this chapter push at the edges of their city's identity, all but one stay within the bounds of their single-biome planet identity. Nashville, Las Vegas, and Pittsburgh occupy specific places in the national imaginary, as centres of a very particular sort; music is central to Nashville in Nashville, Coal Miner's Daughter, and Wag the Dog; gambling and glitz to Rain Man, Bugsy, and Casino; and steel and bridges to Groundhog Day, Kalifornia, Bob Roberts, and Wonder Boys. The centrality medium-sized cities enjoy in one area of specialization reinforces their peripheral status to the extent that imagining a different or changed identity for a medium-sized city represents one of the most difficult propositions in Hollywood's imaginary human and cultural geography of America.

\section{Economic Geography: Higher-Order and Lower-Order City Brands}

The cities where films are consistently set between 1975 and 2000 - New York, Los Angeles, Chicago, San Francisco, Washington DC - are, in economic geography terms, 
higher-order cities. As Masahas Fujita, Paul Krugman, and Anthony Venables put it in The Spatial Economy: Cities, Regions, and International Trade,

the defining issue of economic geography is the need to explain concentrations of population and of economic activity: the distinction between manufacturing belt and farm belt, the existence of cities, the role of industry clusters. Broadly speaking, all these concentrations form and survive because of some form of agglomeration economies, in which spatial concentration itself creates the favorable economic environment that supports further or continued concentration.

The example Fujita, Krugman, and Venables use to explain agglomeration is the collection of bookshops in St Martin's Court, London. Such a clustering of economic activity occurs frequently in cities of every size - a strip of bars, furniture shops, panel beaters, and so on. The number and variety of these clusters can depend on the size and relative importance of a city. In a simple schematic, there are higher-order and lower-order cities: 'A higherorder city does everything a lower-order city does, and more' (Fujita et al 1999: 181). In medical terms, you can get a fish hook taken out of your eyelid at the Marshfield Clinic in Minocqua, Wisconsin, 160 miles north-east of Green Bay (I speak from experience), but for a liver transplant, you would go to The University of Minnesota Medical Center, which is nearly 250 miles to the south and west of Minoqua. By and large, the greater a city's population, the greater the variety of skills available - especially at the high end of the skills scale. Of the top-ten US News and World Report 'Best hospitals for adult cancer', nine are in major metropolitan regions - Houston, New York, Boston (twice), Seattle, Baltimore, Los Angeles, and San Francisco - with the Mayo Clinic in Rochester, Minnesota (population $100,000)$ the outlier. In cultural terms, Milwaukee may have a symphony orchestra, but Chicago has the Chicago Symphony Orchestra and the Chicago Lyric Opera and the Civic Opera House.

Consider Chicago, 'The second city'; it is plainly a higher-order city, but not the primary city in the United States. In 'American metropolitan evolution' (1967), John Borchert creates a national hierarchy of cities according to their size and functional complexity. 'Most American metropolitan areas', he writes, 'have functioned chiefly as collectors, processors, and distributors of raw materials and goods' and, in these roles, he speculates that 'changes in their growth would have been particularly sensitive to changes in (1) the size and resource base of the hinterland and (2) the technology of transport and industrial energy for the processing of primary resources. These two sets of variables are interrelated' (Borchert 1967: 2-3). This spatial understanding appears in William Cronon's history of Chicago, Nature's Metropolis: Chicago and the Great West (1991), which repeatedly links Chicago's rail and water access to the products of the great western hinterlands of the nineteenth century - livestock, grain, timber - to its massive growth and affluence. Borchert's hierarchy of US cities tilts towards older cities (Map 15): 
First order: New York

Second Order: Philadelphia, Boston, Chicago, Detroit, San Francisco-Oakland-San Jose, Los Angeles

Third Order: Washington DC, Pittsburgh, St Louis, New Orleans, Seattle-Tacoma, Denver, Dallas-Ft Worth, Miami-Fort Lauderdale

Fourth Order: Albany-Schenectady-Troy, New Bedford-Fall River, Scranton-Wilkes Barre-Hazelton, Birmingham, Omaha, Flint, Jacksonville, Phoenix

Fifth Order: Corpus Christi, Altoona, Charleston SC, Lubbock, Las Vegas.

This 1967 hierarchy is not as out of date as it might seem at first glance, with perhaps only Detroit falling in importance since the end of the 1960s. In spite of the growth of the New South, the number of cities that economic growth produced is fairly small - a strengthened Atlanta, an increasingly important Miami, and greater regional importance for Nashville and the Research Triangle. In the 1960s, Nashville, Pittsburgh, and Las Vegas - the cities depicted in the films I analyse in this chapter - were all third-order or lower. For all its economic growth, Nashville did not displace Atlanta or the rapidly expanding Miami in the southern hierarchy (Abler et al. 1977: 377). But if Detroit's economic decay changed it from a regional centre to a third-order city, none of the other second-order cities saw their influence decrease. Las Vegas, which Borchert ranked as a fifth-order city in the 1960s, for all its population and economic growth, does not have the broad economic reach of Phoenix (to say nothing of Los Angeles) in the south-western hierarchy. Within such a hierarchy, 'each second-order center acts as a regional metropolis for a vast portion of the United States market' (Abler et al. 1977: 374). Chicago is the 'second city' to New York, and similarly, Minneapolis processes some of Chicago's regional resource base but does not perform the higher-level specialty labour, such as the corn futures trading at the Chicago Board of Trade, making it Chicago's second city. ${ }^{20}$

A city's importance - and identity - depends on material conditions, including unchangeable aspects such as location, topography, and weather. In addition, the skeleton of the city and its connections to the rest of the country - the built environment, transportation links, and the city's economic base - play a part. Finally, a city's identity (and importance) also emerges from media representations that put the city, its people, and particular aspects of life in that city on screen. Colin McArthur uses a well-known novel by Alasdair Gray to show how familiar unknown places can be and how unknown familiar places can be: 
Lanark contains the following much-quoted passage: 'Glasgow is a magnificent city,' said Thaw. ' [...] Think of Florence, Paris, London, New York. Nobody visiting them for the first time is a stranger, because he's already visited them in paintings, novels, history books and films. But if a city hasn't been used by an artist not even the inhabitants live there imaginatively'.

(Gray, quoted in McArthur 1997: 19)

Two visions of New York appear throughout the opening monologue to Woody Allen's Manhattan (1979), the monumental and the quotidian. The film begins with an extreme long shot of part of the New York skyline, with the Chrysler Building's scalloped peak in the centre of the image. A number of New York's landmarks appear throughout the opening monologue's three-and-a-half minutes: the Chrysler Building as well as the UN Building, the Pan Am Building, the Queensboro Bridge, Washington Square, the interior of the Guggenheim, Central Park Central Park East and West, Broadway, Radio City Music Hall, and even (the Bronx's) Yankee Stadium with a subway train running in front of it. But in addition to this monumental New York, the opening sequence also shows brownstones, apartment buildings, the back side of tenements, a cleaners, a corner diner, fruit markets, what looks like part of the Garment District, a park's basketball court, a private school, garbage piled on the sidewalk, a horse-drawn carriage and all manner of street life on crowded sidewalks. Luxury brands appear - Henri Bendel and Gucci shops and the Parke-Bernet Galleries signal New York's importance to the art world. In other words, even though Woody Allen romanticizes the small upper-middle-class corner of Manhattan all out of proportion, the city has a distinct visual identity that combines the monumental with the smaller-scale with an eye towards the sorts of cultural activities that drive the city.

Urban film studies tends to concentrate on major urban centres, on first-order cities. Barbara Mennel's Cities and Cinema (2008), a textbook that, as its back cover promises, 'puts urban theory and cinema studies in dialogue', analyses the city film, film noir, and the French New Wave in terms of Berlin, Los Angeles, and Paris respectively. Students thus encounter and learn about the category of city films through a very limited selection. Although Mennel does give some extended attention to Beirut, Belfast, Tokyo, and Vienna, her choice of major cities fits into the general tendency of city-on-film studies. For instance, Berlin, London, Los Angeles, New York, and Paris are by far the most frequently mentioned cities across the seventeen chapters of the collection Cities in Transition: The Moving Image and the Modern Metropolis (2008). In Gavin Hogben's introduction to Part Two of Cinema \& Architecture: Méliès, Mallat-Stevens, Multimedia, 'The Modern City I: London/Paris/New York/Rome', he writes that '[w]ith cinema we step through a chink in time and space to visit our favourite cities, here London, Paris, New York and Rome' (Hogben 1997: 50). Teresa Castro's 'Mapping the city through film: From "Topophilia” to urban mapscapes' covers slightly more ground, adding a few Soviet cities and Milwaukee to New York, London, Paris, and Berlin. The architect Nezar AlSayyad's Cinematic 
Modernism: A History of the Modern from Reel to Real (2006) concentrates on London, New York, and Paris and trades Rome for Berlin. In Mark Shiel and Tony Fitzmaurice's two edited collections, Cinema and the City: Film and Urban Societies in a Global Context (2001) and Screening the City (2003), films set in New York, Paris, and Los Angeles appear far more than any other cities. Shiel's longstanding interest in urban cinema is frequently based in New York or Los Angeles. ${ }^{21}$ Urban film studies have concentrated on Berlin, New York, London, Los Angeles, and Paris for good reason; these cities appear more frequently on film than other cities.

In the United States, Hollywood hits and prestige pictures from 1960 to 2000 use New York and Los Angeles as narrative location more often than any other US city. Two films loom large over the imagination of Los Angeles on film: Chinatown and Blade Runner. As Norman Klein puts it, Chinatown 'more than any other [movie] ever made, has fixed in the public mind what the downtown [Los Angeles] myth looked like' (Klein 1997: 61), and, 'Blade Runner has indeed achieved something rare in the history of cinema. It has become a paradigm for the future of cities' (Klein 1997: 95). The past and future may be covered by Chinatown and Blade Runner, but the Los Angeles seen on film between 1960 and 2000 does not offer up the variety of the city, as Thom Anderson notes in Los Angeles Plays Itself. Most Los Angeles films are set 'in the swath of territory from Malibu to Culver City to the San Fernando Valley and Pasadena, [where] no resident would be shocked to spot the light reflectors, grips and trailers that signify a movie, TV commercial or video shoot' (Chase 2000: 53). Klein notes that 'comedies about "the good life"' generally concern 'West Side opulence, as in Shampoo, or Down and Out in Beverly Hills, or L.A. Stories (sic)', films set in Beverly Hills and Hollywood (for the most part) (Klein 1997: 249) rather than the more varied city that Anderson excavates from films set in lost neighbourhoods like Bunker Hill in The Music Box (Parrott, 1932) and The Exiles (MacKenzie, 1961). Shiel registers the long shadow a small group of major cities cast over their smaller neighbours, noting that 'less celebrated cities such as Phoenix, Houston, or Las Vegas' have a reduced cinematic presence and history of their own, 'featuring in Psycho (Alfred Hitchcock, 1960), The Right Stuff (Philip Kaufman, 1978), and Casino (Martin Scorsese, 1995), respectively' (Shiel 2003: 164). But while Phoenix, Houston, and Las Vegas are certainly postmodern cities, Shiel concludes with 'the quintessential postmodern urban environment, Los Angeles' (Shiel 2003: 164). This final shift back to Los Angeles maintains the primacy of Los Angeles in a consideration of urban cinema. Second-order (and lower) cities have $a$ movie as a reference point, whereas Los Angeles has movies. As Sanders argues, the sheer number of films set in major cities like Los Angeles and New York (his example) can be explained by the city's scale, which means that 'an unusually wide range of ideas and concepts are brought to dramatic life' (Sanders 2002: 10).

But what makes the dramatic life and identity of a small or medium-sized city, and how can film represent them? Neither Des Moines nor Wichita has an immediately recognizable visual identity - that is, the sort of identity establishing shots communicate. 
The Des Moines and Wichita metropolitan regions have a similar population (about half a million). The tallest building among Des Moines' thirty-five high rises is 801 Grand, which stands at 192 metres. The tallest building among Wichitas twenty high rises is the Epic Center at 117 metres. Neither city has a Chrysler Building or UN complex, and neither has attempted to generate its own Bilbao Effect with a starchitect-designed landmark. However, both cities have a cultural identity: an aviation aficionado might recognize Wichita’s skyline, or a political junkie Des Moines'. But Wichita and Des Moines have only appeared in a combined three films (Terms of Endearment [Brooks, 1983], Gypsy [LeRoy, 1962], Planes Trains and Automobiles [Hughes, 1987]), which creates a self-reinforcing cycle: the city does not have a clear cultural identity because it does not appear in media productions, but it does not appear in media productions because it does not have a clear and recognized cultural identity. ${ }^{22}$ In other words, the relative anonymity of many small and medium-sized cities is a question of branding.

Gert-Jan Hospers frames a city's tourism potential in terms that connect landmarks, a coherent cultural identity, and media prevalence:

[I]f we mainly visit places because we know them from photographic images, then city branding can help in providing and distributing these pictures [...]. Cities do not have to offer an authentic experience as such, but rather make sure they provide an experience that resembles the images used in their branding.

(Hospers 2011: 29)

To this end, local governments and film commissions attempt to find ways to get their community's best face on film or television. For example, to solidify a media-driven identity, Scranton, Pennsylvania hosted a convention for fans of the American television program The Office, which is set (but not filmed) there. Similarly, tiny Metropolis, Illinois has a statue of Superman to assert that it's the home town of Superman. Sometimes an entire country can be enlisted, as in New Zealand's embrace of The Lord of the Rings films (Jackson, 2001-3, 2012-14), which shares tourism marketing space with the ' $100 \%$ Pure NZ' slogan.

Hospers' advice to 'highlight some of their signs' suggests a version of the single biome planet for the less-well-known city - make yourself known for one big thing - a strategy that risks reducing a city to a single trait. Whereas Woody Allen could cycle through drafts of a love letter to New York in Manhattan and most of his film output in general, the tourism and development offices of America's mid-sized cites want something a little more direct. Keith Dinnie, in City Branding: Theory and Cases, describes the process a government office should follow to brand their city:

[T] develop a strong brand, policy makers need to identify a clear set of brand attributes that the city possesses and which can form the basis for engendering positive perceptions of the city across multiple audiences [...]. Imagination and an open mind 
are also necessary in the identification and selection of appropriate brand attributes that powerfully express the unique character of a city.

(Dinnie 2011: 5)

The ten or twenty largest US cities, by the 'first thing that comes to mind' metric, have a good brand. In cinematic terms, they have an identifiable skyline or landmark or relationship to natural surroundings. In human terms, the major cities in the United States have an identity. Medium-sized cities do not have as clear a brand, partly because the process of developing a brand is not easy and can be fraught with pitfalls. As Andrea Insch argues,

[C]ity authorities often become fixated with the visual aspects of the branding process, such as logos and slogans, since these are perceived to be the easiest to create and control. Consequently, cities spend much time, money and effort in transmitting a one-dimensional campaign, based on a particular phrase and logo that is not perceived to be credible, memorable, distinctive or sustainable, either by residents or external audiences.

(Insch 2011: 12)

The approach likely to fail focuses on things that happen on paper - logos and slogans not in the city itself. In the midst of a marketing analysis, Insch shows how corporatespeak conceives of a city's life in economic terms to its detriment. Catchphrases and logos are likely to fail; how many more I Heart City shirts do we need? But when a city considers its identity as something more than a logo or even a landmark, but rather as what constitutes the life of the city, that consideration of the human experience of the city will generate more effective branding. That is to say, ideally, a good city brand combines, in close to equal measures, a city's image carriers and the life that occurs in that city, and in this role cinema can play a significant part.

Varying degrees of three-dimensionality appear in films set in small and mediumsized cities, and such films are accidentally and incidentally educational in their effects. Tourists may go to a town to experience something they've already seen - Bella's Twilight (Hardwicke, 2008) house in Forks, Washington, the baseball field from Field of Dreams (Robinson, 1989) in Dyersville, Iowa - and the establishing shots that create such locations on screen feature a great deal of additional information, places visible in but not part of the film. The frequency with which the ten largest cities in the United States appear on film broadens the base from which movie-goers take their cultural knowledge of the place. The well-known 'chorus girl becomes a star' narrative happens in New York, on Broadway, and in Los Angeles, in Hollywood, not in Denver. Gangster movies usually take place in Chicago or New York, not Tacoma. New York, Los Angeles, Chicago, San Francisco, and Washington DC are the predominant locations for prestige films from the 1960s through the 1990s. But the small and medium-sized cities, cities number 21 
through 100, do not appear as frequently on film, and have a reduced cultural profile, perhaps in part owing to their infrequent presence in film and television. ${ }^{23}$

Of the 300 films cited in year-end best lists from Roger Ebert, the New York Film Critics Circle, the National Board of Review, the National Society of Film Critics, and the Oscars, as well as the American Film Institute's '100 Greatest Movies' list, 201 were set, at least in part, in the twenty largest cities and their immediate suburban surroundings (Map 16): 88 in the New York City Tristate region, 63 in the Los Angeles area, nineteen in Washington DC area, seventeen around Chicago, fifteen in the San Francisco Bay area, seven in Philadelphia, seven in Houston, six in the Boston area, five around San Diego, five in Baltimore, three around Detroit, two around Phoenix, two in Cleveland, two in Memphis, and two in Dallas (some films, like Malcolm X [Lee, 1992] take place in more than one large city). At the other end of the spectrum, 138 films were set in small towns or remote areas, notably westerns like Unforgiven (Eastwood, 1992), period dramas like The Color Purple (Spielberg, 1985), war films like Glory (Zwick, 1989), biopics like The People vs Larry Flynt (Forman, 1996), and quiet dramas like The Straight Story (Lynch, 1999).

Next to the frequency of the twenty largest cities, small towns and remote areas, medium and small cities are much less common in prestige films. From among the twenty largest cities in the country from 1975 to 2000, Columbus Ohio, Milwaukee, San Antonio, San Jose, and two cities that grew into the top twenty, Jacksonville and Austin, do not appear. Outside of the twenty largest, Akron, Albuquerque, Anchorage, Birmingham, Buffalo, Charlotte, Colorado Springs, Columbus GA, Corpus Christi, Denver (and Aurora), Grand Rapids, Honolulu, Lexington-Fayetteville, Lincoln, Lubbock, Madison, Montgomery, Newark, Norfolk, Omaha, Richmond, Rochester, Sacramento, Shreveport, Spokane, St Petersburg, Stockton, Tacoma, Tampa, Toledo, Tulsa, Virginia Beach, and Wichita do not appear. In addition, while there are a number of Bay area films, there are no specifically Oakland-set prestige films. Likewise, the two Texas films are set in Dallas, not Plano, Garland, or Fort Worth. Also absent from prestige lists are growing cities like Augusta-Richmond (Georgia), Bakersfield, Greensboro, Raleigh, and Stockton, as well as cities that are part of the wider expansion of metropolitan regions, such as Chesapeake (Norfolk-Virginia Beach), Fremont (San Francisco-Oakland-San Jose), Hialeah (Miami), and Mesa and Scottsdale (Phoenix). Finally, no films were set in the twelve cities that fell out of the 100 largest cities list, in the Rust Belt - Dayton, Syracuse, Warren, and Worcester - parts of the south - Chattanooga, Jackson (Mississippi), Knoxville, and Metairie (Louisiana), and in sections of the West that grew in different directions Huntington Beach and Salt Lake City (Map 17).

Of the remaining small and medium-size cities (Map 18), Kansas City appears in two movies, Broadcast News (Brooks, 1987) and Casino (Scorsese, 1995), but only in passing. For much the same reason I will pass over Mobile, which appears briefly in Forrest Gump (Zemeckis, 1992) and Driving Miss Daisy (Beresford, 1989). Portland, Oregon appears only in two period films, Drugstore Cowboy (Van Sant, 1989) and Reds (Beatty, 1981), set quite a long time apart. Minneapolis appears in Purple Rain (Magnoli, 1984) and Fargo 
(Coen Brothers, 1996). Atlanta already appears in my analysis of Burt Reynolds. New Orleans, Seattle, and Miami present a fascinating range of films, but for the sake of space I will not deal with them here. Finally, Albany, Bakersfield, Cincinnati, El Paso, Flint, Little Rock, Louisville, and Oklahoma City all appear in one prestige film, which precludes a comparative approach. From the cities that remain, three offer more than two films to compare representations of the cultural identity of medium-sized cities in the last quarter of the twentieth century: Nashville, Pittsburgh, and Las Vegas.

\section{Both Country and Western: Music City, USA}

The city of Nashville appears in three critically acclaimed films: Nashville (Altman, 1975), Coal Miner's Daughter (Apted, 1980), and Wag the Dog (Levenson, 1993). In all three, Nashville is very much Music City USA, to the near-exclusion of any other activity in the city. Some of this attention to music - recording and playing country and western plays a key narrative role in all three films - is to be expected. The 50,000 watt radio station WSN, original home to the Grand Ole Opry, reached homes across not just Tennessee but surrounding states, spread country music from the mid-1920s. With WSN's broadcast reach, Nashville (and what would become Music Row) was well-situated to become a key destination for musicians interested in both country and western music. The Lonely Planet travel guide, harnessing the power of cliché, makes clear the enduring power of this identity. The 'Introducing Nashville' page on its website begins,

So you're an aspiring country singer, arriving in downtown Nashville after days of hitchhiking. With nothing but your battered guitar on your back. Gaze up at the neon lights of lower Broadway, take a deep breath of smoky, beer-perfumed air, feel the boot-stompin' rumble from deep inside the crowded honky-tonks, and say to yourself 'I've made it.' This ain't no country club baby, this is Nashville. For country-music fans and wannabe songwriters all over the world, a trip to Nashville is the ultimate pilgrimage.

(Whitaker 2015: n.p.)

Similarly, Lonely Planet's list of the 'Top things to do in Nashville' considers more than half of the biggest attractions in the city to be music-based. Sights such as the Country Music Hall of Fame \& Museum, the Ryman Auditorium, the Blue Bird Café, the Gibson Bluegrass Showcase, Tootie's Orchid Lounge, the Grand Ole Opry, and concert-poster masters Hatch Show Print outnumber the Nash Trash bus tour, the Hermitage, Pancake Pantry, Prince's Hot Chicken, the Frist Center for the Visual Arts, and the Jack Daniel's Distillery (which is not even in Nashville-Metro Davidson County) (Howard 2015). The visual-cultural identity of a city, in terms of city branding, drives the thematic and ideological identity of a city, as the films set in 


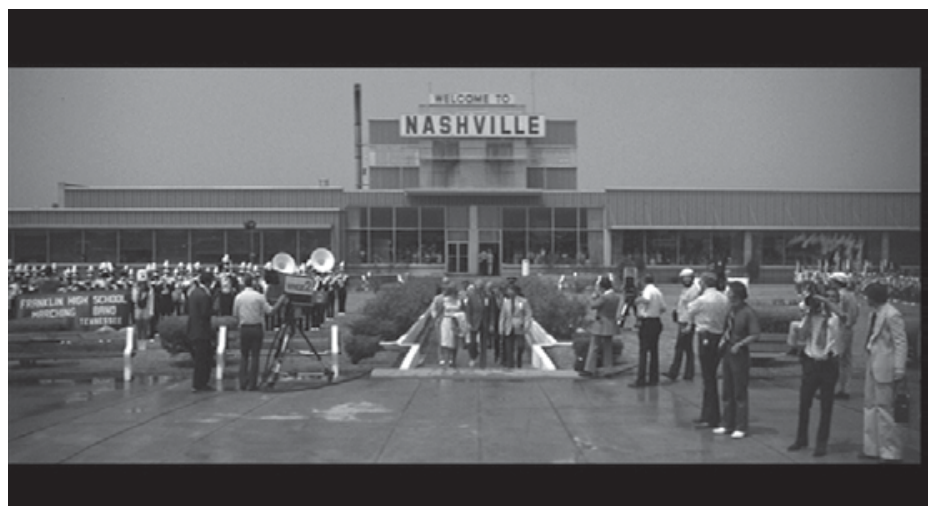

Image 39. Nashville Welcome to Nashville.

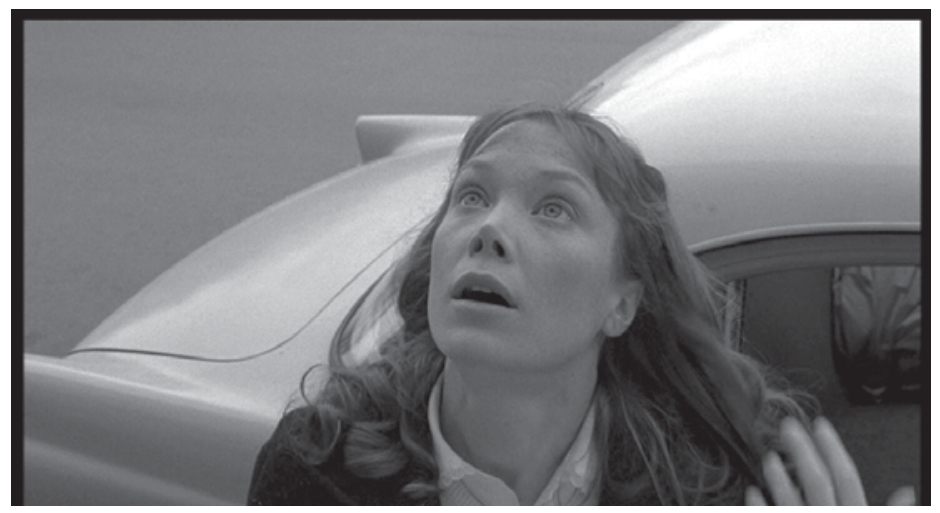

Image 40. Coal Miner's Daughter Grand Ole Opry establishing shot 1.

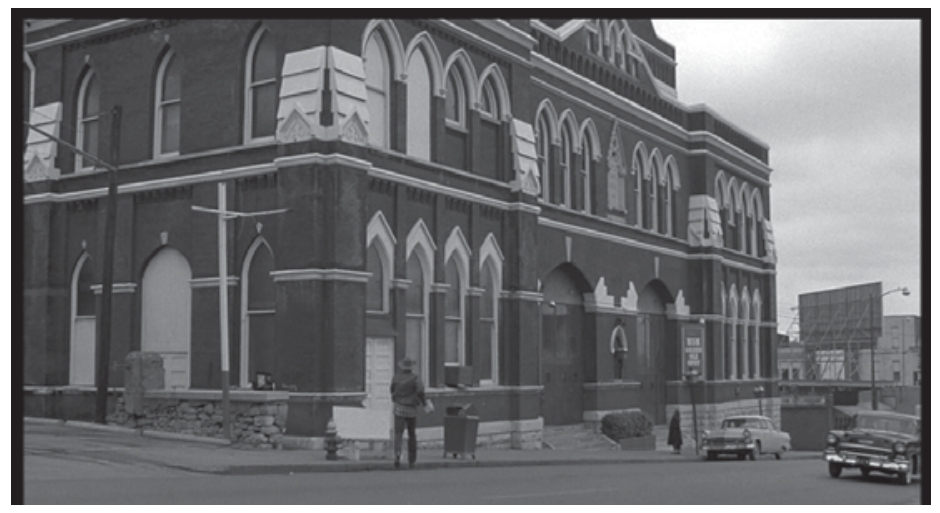

Image 41. Coal Miner's Daughter Grand Ole Opry establishing shot 2. 
Nashville show. The power of the Music City USA brand so ties the city's identity to the landmark Ryman Auditorium and the honky-tonks that line Broadway that the rest of the city disappears.

More or less every moment of Nashville takes place within the music industry's orbit the big stars at the top (Haven Hamilton, Barbara Jean), the working stiff musicians in the middle (Mountain Boys) to the dreamers and wannabes at the bottom (The Smokey Mountain Laurel and, tragically, Sueleen Gay) - in the places where music industry folk live, record, and play. When the film is not in recording studios or honky-tonks, or watching the everyday lives of musicians at home or in motels, it moves through a series of fairly anonymous spaces - the airport, the highway, a hospital for which the establishing shot, such as it is, comes from the hospital room interior, looking out at Peabody College's stone wall. Fictional album covers rotate in the background of the credit sequence, soon followed by two recording studio sessions, one of portentous country and western, one of gospel. Then, at the Nashville airport, quite a lot of local investment - the Chamber of Commerce and local television - greets the singer Barbara Jean's (Ronee Blakley) return home. At the same time in the airport, the crumbling band Bill and Mary and Tom arrive in Nashville to record, and the wannabe singer Sueleen (Gwen Welles) serenades a silent magician at an airport diner counter. At the end of the film, Walker's concert rally is briefly interrupted by a shooting, but the show must go on - and a lucky wannabe singer gets to perform for the crowd, showing that even in the face of political upheaval, the music industry remains constant.

The constancy and centrality of the music industry to Nashville also appears in the establishing shot in Coal Miner's Daughter. After driving up and down the highways of Kentucky and Tennessee, talking to every radio DJ they can find, Loretta (Sissy Spacek) and her husband Dolittle (Tommy Lee Jones) arrive in Nashville. Or, more accurately, they arrive at the Ryman Auditorium, home of the Grand Ole Opry. The scene begins with a close-up of Loretta, asleep in the front seat of a car. She wakes up, and looks out the window, her eyes growing larger. When she gets out of the car, director Michael Apted finally cuts to an exterior long shot of the Ryman. This sequence of shot treats the Ryman as a place of musical pilgrimage in Nashville, ignoring the rest of the city. In the course of Coal Miner's Daughter, Loretta succeeds and makes Nashville a second home. She also begins to tour a wider portion of the country, and her tour bus becomes home rather than Nashville and Hurricane Mills, Tennessee. As I argued earlier, this shift becomes clear in the film's closing credits, when Loretta's various homes throughout her life return. One other 'home' appears during the closing credits, Loretta's Nashville home. But rather than a domestic space, Nashville is represented by the Ryman Auditorium, equating the city with - and more or less reducing it to - country music.

Wag the Dog, unlike Coal Miner's Daughter, uses a traditional skyline establishing shot (from the south-east) to announce its Nashville sequence. The skyline shot is followed by a long shot of an alley, and then a recording studio interior, reducing the city to a downtown (rather than Music Row) recording studio. In Wag the Dog, as Conrad's (Robert 


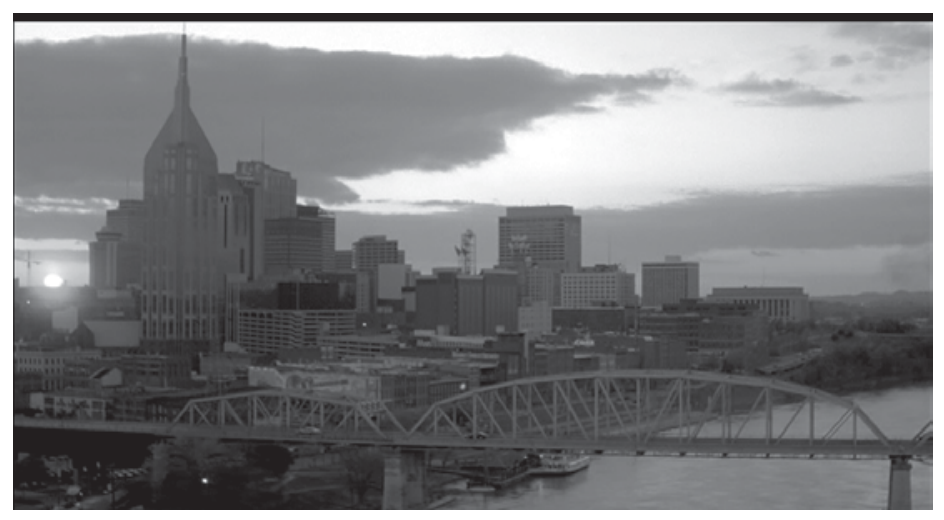

Image 42. Wag the Dog Nashville skyline establishing shot.

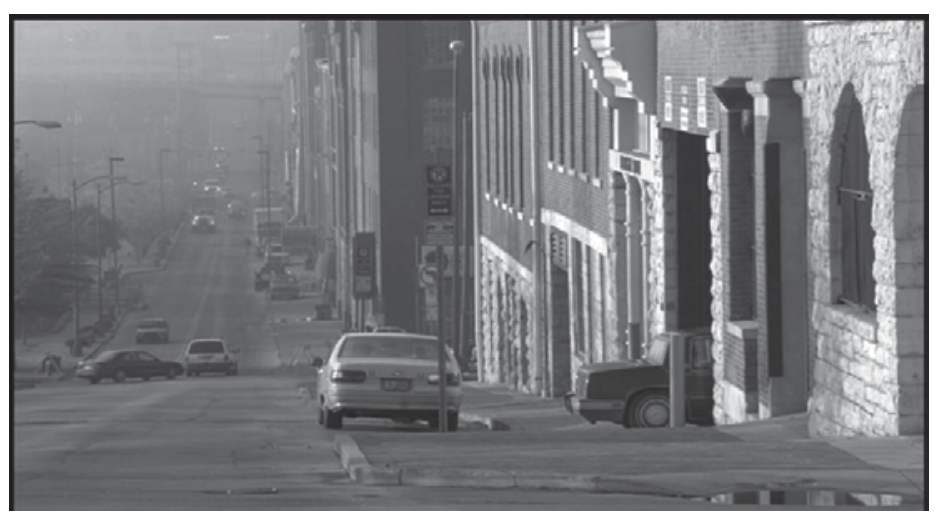

Image 43. Wag the Dog Nashville establishing shot 2.

DeNiro) taxi takes him over the Victory Memorial Bridge, Johnny (Willie Nelson) directs a multiracial chorus as they sing

there comes a time in the course of human events / when a threat must be answered with courage and strength / our forefathers earned the right to be free / now it's time to cut their dream / we've got our American borders / we've got the American Dream / We've got a right to fight for democracy / and keep our country free / we've got our American spirit / we've got the American dream / our country's built on the rock of liberty / and we as people must keep it free / it is for life, liberty the pursuit of happiness / free from tyranny [...]. 
The scene inside the studio resembles the opening scene in Nashville, in which Haven Hamilton sings an outlandishly patriotic Bicentennial song, which includes lyrics like:

My mother's people came by ship and fought at Bunker Hill / My Daddy lost a leg in France I have his medals still / My brother served with Patton I saw action in Algiers / We must be doing something right to last two hundred years / I pray my sons won't go to war but if they must they must / I share my country's motto and in God I place my trust / We may have had our ups and downs our times of trial and tears / But we must be doing something right to last two hundred years.

Wag the Dog thus builds not only on the connection of country music and patriotism but also on the history of big patriotic numbers in Nashville-set movies. The "We are the World'-style song gets played for laughs, which is fortunate, because the president's rival 'cut[s] a better deal' with the CIA and announces the phony war is over, rendering the 'We are the World'-style song superfluous. To extend their narrative, Stanley imagines a soldier left behind enemy lines, unaware the war is over. This new character in their fake war story needs his own song, and Stanley (Dustin Hoffman) requests one to be called 'Good Old Shoe' from Johnny. Soon after, listening to Johnny and the studio owner, a white-haired African American man (Roebuck Pops Staples), sing their new song, Conrad wonders if they can somehow make it 'sound old and scratchy, like a hiss'. On the narrative level, the song-recording achieves its goal, as the song ends up becoming a soundtrack to patriotic expression. In terms of city branding, the turn to Nashville to record an 'old' song acknowledges its place in American musical history, which might legitimately be credited as a victory for city branding. The presence of an African American man as a songwriter who can never receive recognition introduces an accidental, but still compelling thread of the debt American musical history owes to African Americans who have been rendered anonymous. African American session musicians certainly played and play in Nashville studios, as Patrick Huber has written in, 'Black hillbillies: African American musicians on old-time records'. But the bluesy sound of 'Good Old Shoe' distances the song from the country music selling the most records during Wag the Dog's early 1990s, the glossy big hat acts like Garth Brooks, Clint Black, Alan Jackson, and Tim McGraw that Nashville produced. And Willie Nelson, though he was a successful songwriter in Nashville early in his career, left it in the early 1970s, as part of the Outlaw Country genre that set itself in opposition to Nashville, its sound, and its ideas. But in the end, the strength of the Music City USA city brand papers over the irony and poor generic fit of the songs in Wag the Dog.

The three Nashville-set films that met with the greatest critical praise never move beyond Music City USA. In this way Nashville, though it retains a single-biome planet kind of identity on film, also provides a useful model for considering the identity of medium-sized cities on film. The relative importance of a city, especially one of the lowerorder cities like Nashville, Pittsburgh, and Las Vegas, can emerge from the cities against which it measures itself, and on what basis that measurement must be made. Nashville 
on film takes the form of a musical city, placing country and western music, its audience, and the (often falsely) presumed politics of the form at the heart of Nashville, Coal Miner's Daughter, and Wag the Dog. In this identity, Nashville on screen occupies a position that belies its fourth-order status, one visually identified with the Ryman Auditorium and the Grand Ole Opry. At no point does the south's regional hub, Atlanta, enter into any of the three films as a place where the successful or aspirational would go. While southern bank and corporate regional headquarters may be in Atlanta, and key moments in recent history took place in Birmingham, Little Rock, Montgomery, Neshoba County, and Selma to name a few, Nashville is a first-order city for music on film, the single-biome planet of Music City, USA.

\section{Learning in Las Vegas, or, Beyond the Strip}

Las Vegas films orbit around casinos. Thus while films like the comedy Lost in America (Brooks, 1985), the tragic romance Leaving Las Vegas (Figgis, 1995), and the comedydrama Melvin and Howard (Demme, 1980) all look at multiple facets of the city's life, they tend not to look beyond the strip. Legal gambling came to Las Vegas in 1931, and its large-scale competition did not appear until the 1970s, when casino gambling arrived in Atlantic City, New Jersey and Native American gambling appeared in 1979. This 40year head start firmly - and logically - established Las Vegas as the legal casino gambling centre of the nation. Rain Man, Bugsy, and Casino tell the history of the city's growth in the twentieth century, and also how Las Vegas' near-monopoly on casino-driven growth mirrors wider changes in American capitalism. In particular, the equation of the stock market with the economy in news coverage registers in Las Vegas films as well. In news coverage, the economy and the stock market (speculation) appear as near-synonyms; Las Vegas movies are set in Las Vegas casinos. The rarity with which the non-speculative part of the economy appears registers in the rarity of the everyday spaces of Las Vegas itself.

Las Vegas first appears as a blip in the Babbitt brothers' road trip in Rain Man, and only takes on importance when Raymond's skill at counting makes a blackjack scam possible. During the Babbitts' road trip from Cincinnati to Los Angeles, they first drive straight through Las Vegas, slowly driving past the huge neon signs of the Riviera, Algiers, Flamingo, Westward Ho, and Stardust casinos, among others. Charlie (Tom Cruise) glumly looks forward while Raymond (Dustin Hoffman) watches a Reds game on his little portable television. The two say nothing during the 45 seconds that they move along The Strip, a shot followed by a straight cut to a roadside diner. After a fade to black, the next image is of Charlie smoking in daylight, implying that they spent the night outside of Las Vegas, not in it. When Charlie discovers Raymond's talent for counting, they hightail it back to Vegas. The big-score gambling plan, following immediately after breezing through the town without stopping, figures Las Vegas as not even a stopping point, an obstacle on the road rather than a city in its own right. Las Vegas looks different 


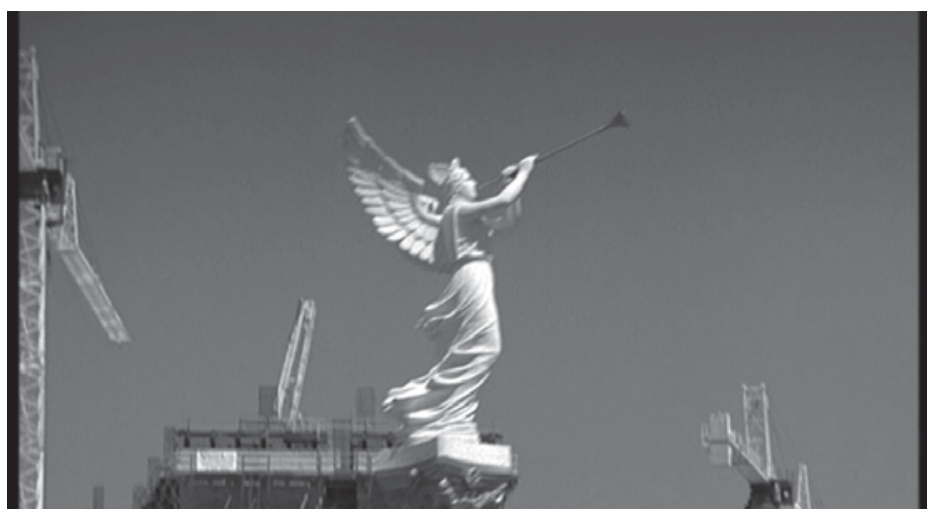

Image 44. Rain Man Las Vegas cranes.

in the daytime not only because the neon is less visible, but also because of what Rain Man director Barry Levinson uses as establishing shots to re-establish the Babbitt boys in the city. After showing the famous 'Welcome to Fabulous Las Vegas Nevada' sign on the highway, Levinson shows a close-up on Charlie's midsection as he takes off his watch outside a pawn shop, and then a low-angle shot of a faux-Greek statue blowing a trumpet. As the camera sweeps past the statue, the previously sky-blue background is filled with four cranes. The scene then shifts to the glitz of Caesar's Palace, suit shopping, and the no-risk high-return opportunity that Raymond's number-crunching autism makes possible, like a human version of the technologized financial sector that exploded during the Reagan era. The four-second shot of the statue that quickly reveals multiple cranes signals not just the contemporary growth Las Vegas experienced in the 1980s, but the importance of construction to Las Vegas in general.

Bugsy, also directed by Barry Levinson, imagines earlier stages of the construction of Las Vegas. Water makes it possible for Noah Cross (John Huston) to control the future in Chinatown's history of Los Angeles, and water is similarly powerful in Bugsy's version of the creation of Las Vegas. Bugsy fills in some of the details of how the neon Las Vegas of its 1991 release first came to be built. At Bugsy's heart is Benjamin Siegel's (Warren Beatty) desire to build the Flamingo Hotel and more in a place he calls 'an outhouse' and 'rancid little toilet bowl'. As Bugsy tells his financial backer Meyer Lansky (Ben Kingsley):

Sex, romance, money, adventure. I'm building a monument to all of them [...] I'm talking about a hotel. I'm talking about Las Vegas, Nevada. I'm talking about a place where gambling is allowed. Where everything is allowed. The whole territory is wide open. I'm talking about a palace. An oasis. A city. Do you know that when the Hoover 
Dam is finished electrical power is going to be available on a massive scale in Las Vegas?

When one of Meyer's sidekicks asks how 'the Hoover Dam and fucking are connected' Bugsy's answer explains what the Dam will power:

Air conditioning! It's the wave of the future! Everything will be air cooled. Every room seventy-two degrees, at all times. The casino will put Monte Carlo to shame. We'll have wall-to-wall carpeting. We'll have Italian marble. We'll have badminton courts, stables. We'll have a lightning fast train going from Los Angeles to Las Vegas in an hour. We'll have planes back and forth. Meyer, we'll have our own airport!

Much like the Tennessee Valley Authority opened up the south to development, the Hoover Dam will open up the desert southwest. Bugsy and Meyer agree that Las Vegas is 'a good place to trap people in to take their money'. But Bugsy sees that the city built on infrastructural investments in electricity and transport opens up something more. Development, as Bugsy's description of Las Vegas highlights, follows infrastructure. First and most important is the electrical grid, followed by multiple modes of transportation. 'If we do this thing right', Bugsy tells Meyer, 'if we follow the hotel with the schools and the churches and the synagogues - we build all the things that give a city backbone - we'll be in charge before you know it?. In other words, building a casino and then building a Las Vegas to serve those casinos create an actual city, not an outpost for, as Meyer puts it, nomadic 'Bedouins'. Control of that city would be a political power base to control the state, and from there, 'if you control a state, the whole country is within your reach. What matters first is Las Vegas' proximity not only to the Hoover Dam, but also, as the dream of a high-speed rail line indicates, to Los Angeles, from which it can draw gamblers. In this early version of the city, Las Vegas relies on a larger regional neighbour; and its production base - gambling money - doesn't stay in town but moves outward, making Bugsy's Las Vegas the very essence of a single-biome planet lower-order city.

Bugsy imagines how Las Vegas was built for gambling, Rain Man shows the allure its gambling holds, and Casino pulls back the curtain to show how the city works not just within city limits, but also at the national and even international scale of organized crime. The Flamingo Hotel from Bugsy opened in 1946 with performances from Xavier Cougat and Jimmy Durante. The Rat Pack were in Vegas in the early 1960s, and Elvis Presley returned to public performance with his residency in Las Vegas that ran from 1969 to 1976. In addition to entertainers, there are the dealers and other casino workers.

But of the main employers in Las Vegas and Clark County, casinos are only the secondlargest employer. The biggest employer in the city is Clark County and its school district. In addition, almost a quarter of the people employed in Las Vegas and Clark County work in construction, trades, transportation, and utilities - the sorts of jobs that a rapidly growing city depends on. But those people do not appear anywhere but the margins of Vegas-set 


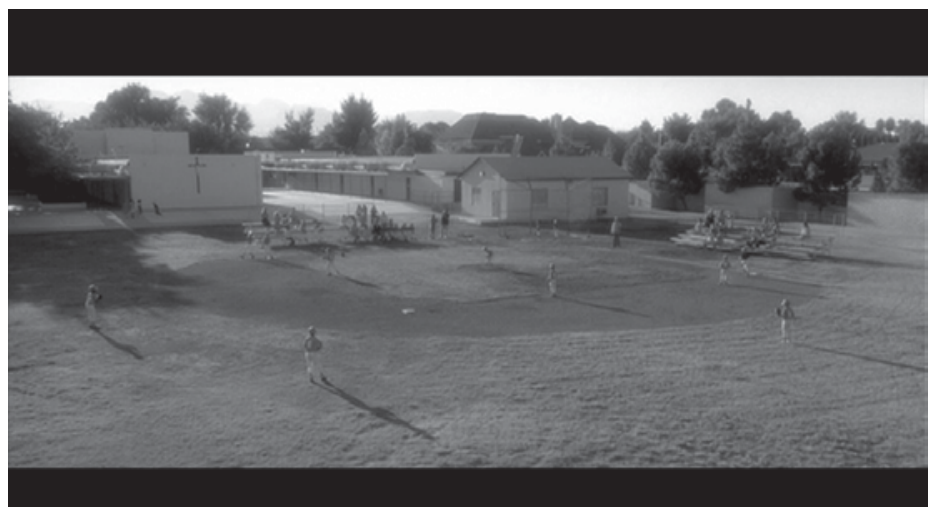

Image 45. Casino Catholic School and baseball field.

films (or as represented by cranes, as in Rain Man). A short, almost incidental scene in Casino, in which Nicky Santoro (Joe Pesci) establishes himself in Las Vegas, erases the neon to reveal how similar Las Vegas is to other cities, even if films tend not to show that similarity. Nicky tells Ace he's moving to Vegas, and after Nicky's routine is established in a sweeping tracking shot through a bookmaking parlour, the scene changes to Nicky's son giving a primary-school presentation on George Washington. The seeming incongruity of the Mafia enforcer Nicky as part of a primary-school presentation on one of the Founding Fathers calls attention to Las Vegas' backstage area - its residential spaces and all the civic infrastructure of schools, teachers, police, and government that comes with it. Nicky himself explains the small-town civic infrastructure of Las Vegas, saying that, 'Ace got my son Little Nicky involved with Little League, and it was great. Turned out to be that one of the other coaches was a fuckin' metro intelligence cop. But it didn't matter, I mean it was all about the kids. To punctuate Nicky's ability to look past the coach's day job for Clark County, Scorsese pulls back to a long shot of the baseball field. The background has two components that do not appear in Bugsy or Rain Man: a school to the left and a suburban-style housing development to the right. The 40 seconds Casino spends at Little Nicky's school is not much, but the film's brief attention to the city beyond The Strip ever so slightly expands the city's identity by acknowledging that non-casino workers live and work in Las Vegas too.

Little Nicky's school and his Little League represents perhaps the only part of Casino that doesn't imagine what happens in Vegas as merely a piece of a larger economic organization of the country. In general, Las Vegas, in Casino, represents a node in a nationwide network of mafia fronts. The extended voice-over explanations of how the casino works and its eastward orientation to make Las Vegas a lower-order city. Ace explains the business workings of casinos in his voice-over: 
For guys like me, Las Vegas washes away your sins. It's like a morality car wash. It does for us what Lourdes does for humpbacks and cripples. And along with making us legit comes cash. Tons of it. I mean what do you think we're doing out here in the middle of the desert? It's all this money. This is the end result of all the bright lights and the comp trips, of all the champagne and free hotel suites. And all the broads and all the booze. It's all been arranged just for us to get your money. That's the truth about Las Vegas. We're the only winners. The players don't stand a chance. And their cash flows from the tables to our boxes through the cage and into the most sacred room in the casino. The place where they add up all the money. The holy of holies, the Count Room.

The mise-en-scène throughout Casino tends towards the excessive, from Saul Bass' credit sequence that turns neon into hellfire, to 'the early sequences [in which] Scorsese visualizes Vegas as outer space' (Smith 1996: 61), to Ace Rothstein's 70 suit coats of many colours. But the Count Room is a fairly sedate room of white, grey, beige, and black, with men in white shirts and black pants. The small amount of colour in the Count Room takes the form of bands that hold together stacks of green dollars. After Ace narrates the entry to the Count Room, Nicky Santoro explains the skim in voice-over as a man leaves the count room and walks across the deep red carpet to a limo:

In. Out. Hello. Goodbye. And that's all there is to it. Just another fat fuck walkin' out of the casino with a suitcase. Now that suitcase was going straight to one place. Right to Kansas City, which was as close to Las Vegas as the Midwest bosses could go without getting themselves arrested [...] The bosses would come from all over the place: Detroit, Cleveland, Milwaukee, all over the Midwest. And they would meet in the back of this produce market in Kansas City. I mean nobody even knew [...]. Now these old greaseballs might not look it, but believe me, these are the guys who secretly control Las Vegas.

During Nicky's speech, a man carrying a suitcase full of cash walks out of the colourless Count Room and onto the luridly coloured casino floor. The man steps out the casino exit, into a limousine. The limo door shuts, and the next shot shows a plane exit door opening, collapsing the space into a single cut, demonstrating how quickly Vegas money reaches its mafia owners. A second cut switches to a low-angle shot of a sign that reads 'San Marino Italian Grocery', then a tilt-and-pan to a nondescript white brick building. Whereas the colours in the casino are saturated and bright, the Kansas City exteriors are washed out and grim, and the backroom menacingly dark, but unadorned. This contrast between the 'neon cathedrals of Las Vegas' and the grim realism of the Kansas City grocery store (Blake 1996: 4-5) reveals the glitz to be a disguise for something more mundane, revealing that financial control of Las Vegas happens from a distance.

Scorsese's strongest indictment of Las Vegas comes not in the form of the gambling that happens when Ace and Ginger and Nicky are riding high, but what comes after. 
Gavin Smith argues that ' $[w]$ ith his busiest and most tawdry visuals and most relentlessly assaultive style to date, Scorsese is grimly intent on materializing in sensory and dramatic form the spiritual economy of materialism - its emptiness, its sound and fury signifying nihilism' (Smith 1996: 59). This critique of Las Vegas (and the changing face of capitalism) certainly emerges from the film, but I think Smith misses some of the nostalgia not for a mafia-controlled Las Vegas, but for an earlier iteration of capitalism in place of the late 1990s neoliberal order. As Ace is loaded into an ambulance, a paramedic says, 'You sure are lucky, Mister', at which point the scene cuts to a seventh iteration of his car exploding (not counting the times it blows up earlier in the film), then stock footage of a multi-storey hotel getting detonated, which dissolves into a slow zoom on the lion at the entrance to the MGM Grand Casino, rhyming the decline of Las Vegas with the similar decline of Hollywood. Speaking of Las Vegas (and Hollywood), Ace says, 'The town will never be the same, and Scorsese cuts to yet another image of a multi-storey hotel implosion. Mixing the film's narrative, actual history, and economic critique, Ace's narration acts as ironic commentary of footage of the new Las Vegas:

After the Tangiers, the big corporations took it all over. Today it looks like Disneyland. And while the kids play cardboard pirates, mommy and daddy drop the house payments and junior's college money on the poker slots. In the old days dealers knew your name, what you drank, what you played. Today it's like checking into an airport [...] After the Teamsters got knocked out of the box, the corporations tore down practically every one of the old casinos. And where did the money come from to rebuild the pyramids? Junk bonds.

Unlike the prowling camera and bright colours of the previous two-and-a-half hours, the images of the new Las Vegas are stationary exteriors of new casinos the MGM Grand, the pirate-ship Treasure Island, the fake-castle Excalibur, the Mirage, and the Sphinx-guarded Luxor pyramid. The only time we see a casino interior, it's as Ace's vision of 'Disneyland', a hazy, back-lit slow motion shot; sweatpants and tracksuits have replaced Ace's suits and Ginger's couture. Without interiors, the human interactions of running a casino that Ace narrated disappear, erasing the human scale in favour of literally spectacular monuments to the abstraction of money. The casinos' corporate turn reveals the strength of Las Vegas' single-biome planet identity, both economically and imaginatively. Las Vegas was one of the fastest-growing cities of the 1980s and 1990s. The consistency of its imaginative identity as a city of gambling and entertainment papers over the shabbiness of it all, but Las Vegas, in its anonymity remains lower-order, owned by multinationals rather than the mafia, but nothing more than a hinterland - a single-biome gambling planet outpost that produces a raw material - cash - that will soon make its way to a higher-order city to be processed into more Wall Street investments. 


\section{Steel and Bridges, Bits and Books: Pittsburgh}

Pittsburgh grew and prospered based in large part on its proximity to the Pennsylvania anthracite coal fields, the river transportation of three rivers, the Allegheny, Monongahela, and Ohio, and railroad access, all of which made it possible to feed the city's smelters and ship out the steel produced. At one point Pittsburgh produced half the steel made in America. A single-biome Steel Town - which is to say industrial working class - still dominates Pittsburgh's public image, and is admittedly based in some fact: Pittsburgh is still home to US Steel, the operations base of ALCOA (aluminium rather than steel), and a couple hundred smaller companies within the steel production orbit. In its role as Steel Town, Pittsburgh figures a grim city full of burly white male heavy-industry workers who live and work in a city covered in the haze of industrial pollution. A number of wellknown and well-received films deploy such familiar imagery, foremost among them The Deer Hunter (Cimino, 1978), which takes place further up the Monongahela River, in Clairton and its rural surroundings. However, in 1980, Pittsburgh was one-quarter African American, and these Pittsburghers appear much less frequently on film. Alex Owens (Jennifer Beals) in Flashdance (Lyne, 1983) doesn't look much like the moustachioed white hard hats with whom she works, in terms of gender or race, but she's still, in the words of two of the songs she dances to, 'just a steel town girl on a Saturday night' 'in a world made of steel, made of stone. African Americans appear briefly as supporting characters in Pittsburgh-set prestige-list films: news anchor Kelly Noble (Lynne Thigpen), investigative journalist Bugs Raplin (Giancarlo Esposito), and campaign operative Franklin Dockett (Harry Lennix) in Bob Roberts, and Vernon Hardapple (Richard Knox) in Wonder Boys. Thus, a fairly blinkered vision of the who of Pittsburgh predominates. The sense of the what and where of Pittsburgh, its visual identity in the built environment and landscape, shows slightly more variety in the Pittsburgh-set films that appeared on prestige lists in the last quarter of the twentieth century: Kalifornia, Bob Roberts, and Wonder Boys (as well as Groundhog Day, a film with a different prestige pedigree).

Predictably, Pittsburgh often appears as a city of factories, and in the last quarter of the twentieth century, those factories tend to be empty. In the 1980s de-industrialization and the rise of Japanese steel led to an economic downturn in Pittsburgh, leading to an almost 14 per cent unemployment rate in Pittsburgh's Allegheny County at the end of 1982 (and unemployment was higher in all the counties surrounding Pittsburgh). John Hoerr begins And the Wolf Finally Came: The Decline of the American Steel Industry with a number of panoramic descriptions of Pittsburgh. In one, he introduces the scale of industrial capital: 'The industrial detritus of a fading culture stretches for mile upon unrelieved mile on these riverbanks: abandoned furnaces, mill buildings, railroad tracks and bridges, storage yards, pumping stations, pipelines, transmission towers. The American steel industry lies dying in its cradle' (Hoerr 1988: 3). Soon after, he reckons with the wages of the decline of American steel and industry in multiple registers, including the city's built environment, the regional identity, and the national myth: 
Now these giant sprawling places of enormous energy have become rusting hulks: silent and lifeless, like obsolete dreadnoughts sunk to their stacks in shallow water [...]. This isn't the Ruhr Valley, where old steel communities are kept alive even as their mills are torn down and replaced with other industry. This is wide, broad-shouldered America, where there is always room someplace else for people abandoned by their livelihood. Are you an unemployed steelworker in the Mon Valley? Well, move on, brother! The first hill is the hardest to cross.

(Hoerr 1988: 5, 12-13)

The sense of an old city crumbling, its population leaving, recurs in Pittsburgh films. Looking for a better situation appears both in box office hits and in prestige films. In Flashdance Richie the wannabe comic leaves for Los Angeles, reasoning, 'What am I gonna do here? Cook hamburgers and pretend I'm a comedian?' The allure of a less-depressed city attracts another joker, Groundhog Day's Phil Connors (Bill Murray), who brags to his colleagues that 'a major network' is interested in hiring him away from minor-market WPBG in Pittsburgh. In associating the city with tough economic times, making it the Rust Belt's avatar, Pittsburgh-set films not only establish economic struggle simply through setting, but also make the stakes for failure (and success) much clearer, and heightened.

The Rust Belt's potential to spur locals to seek their fortunes elsewhere motivates the artistically minded characters in Kalifornia. Roger Ebert was the lone critic to count Kalifornia as one of 1993's best films, comparing it to Taxi Driver, Badlands, and Henry: Portrait of a Serial Killer in his year-end list (1993b: para. 7). However, Ebert's main interest is in the road trip portion of the film, not the film's opening 25 minutes in Pittsburgh that introduce us to Adele (Juliette Lewis), Brian (David Duchovny), Carrie (Michelle Forbes), and Early (Brad Pitt). Kalifornia is a road movie, and its coming to terms with the 'murderous energies at loose in society' informs its destination and serialkiller-tracking itinerary (Ebert 1993a: para. 1). But its opening 25 minutes are important for what they establish about what Pittsburgh represents both to its characters and in American culture at large. Kalifornia's Pittsburgh sequences, in other words, establish the America that the 'artistic' outsiders Brian and Carrie define themselves in opposition to, and also the America that produces the Adeles and Earlys of the downwardly mobile working class and working poor. In doing so, Kalifornia sees Pittsburgh as a lower-order city, and uses that lower-order status to explain both the road trip and the lives that road trip leaves behind. For Brian and Carrie, the city's decaying industry lets them live in a cool loft (like Alex in Flashdance a decade earlier), and the university life in the city not only provides a ride share bulletin board, but also a social circle. At the other end of the social ladder, Early and Adele scrap for work in the de-industrialized areas not yet gentrified into lofts.

The declining fortunes Pittsburgh faces motivate Brian to propose his serial killer road trip to Carrie. Even though the couple has 'fascinating friends and their stimulating conversation', explores abandoned textile warehouses, and lives in a spacious loft, it 
doesn't take much to convince Carrie to leave. Brian begins his research for his serial killer book in an abandoned textile factory (a strange choice, given that Pittsburgh lost thousands of jobs in steel in the decade before Kalifornia's release) where 'nobody could hear her screams over the noise of the machines'. While the city makes a good home for Brian's ruin-porn visual aesthetic, Pittsburgh's art community doesn't suit Carrie, the 'would-be Mapplethorpe' (Ebert 1993a: para. 4), whose work gets rejected for being 'Too graphic. Too overt. Not suitable for mass consumption. I forget what else'. Brian reassures her by placing Pittsburgh at the periphery of the Art World: 'you don't want to be suitable for mass consumption. But rather than go to Mapplethorpe's New York, she urgently wants to go west: 'I'm dying here Brian. Why can't we just get out of here? Why can't we just get the hell out of here. Why can't we just go to California? Why not?' The 'here' in Carrie's complaint is literal: Pittsburgh represents isolation, stagnation, and inertia, its dead factories and debased taste fatal to artistic endeavour.

The generic conventions of the road movie push Kalifornia out of Pittsburgh quickly, whereas Bob Roberts touches lightly on the city for ideological reasons, both within and outside of the film. Named in the National Board of Review top ten for 1992, Bob Roberts follows a reactionary folk singer's (Tim Robbins) senatorial campaign that predicts Newt Gingrich's Contract With America-fuelled Republican takeover of Congress two years later. The getting-elected narrative arc means that Bob Roberts orients itself towards Washington DC as its destination, but the politics embedded in Bob Roberts' campaign mean that Pittsburgh and Philadelphia are treated as peripheral to the voters he chases in the Pennsylvania between them, often referred to as Pennsyltucky. Bob Roberts spends a great deal of time in Altoona, Scranton, and small Pennsylvania towns, creating a sense through setting that Pennsylvania's two major cities are anathema to the very people who would vote for someone like Bob Roberts or Newt Gingrich. Thus, Pittsburgh's brief appearance as bridges in the background of brief establishing shots and a television studio interior matches Bob's campaign view of the state. The consistent presence of not-Philadelphia and not-Pittsburgh in Bob Roberts acts as a gauge of the cities' relative importance to a conservative Republican running for Senate in Pennsylvania. The film critiques Bob's blinkered politics by showing how he ironically treats Pittsburgh as a centre for the western part of the state. By treating Pittsburgh as a means to get his message out to the hinterland rather than a place with a struggling working class of its own, Bob makes the higher-order media centre into a lower-order city that serves Washington DC rather than its more immediate surroundings.

Groundhog Day, which was released in the dead zone of February 1993, spends most of its time in Punxsutawney, Pennsylvania, an hour-and-a-half's drive outside of Pittsburgh. Its critical standing has improved markedly in the twenty years since its release. In the 2012 Sight and Sound poll, perhaps the best-regarded 'top-ten' list in world cinema, the only Hollywood films from the 1990s to receive more votes from both critics and directors were The Big Lebowski (Coen Brothers, 1998), Pulp Fiction (Tarantino, 1992), and Goodfellas (Scorsese, 1990). Three other films received more votes from directors: 


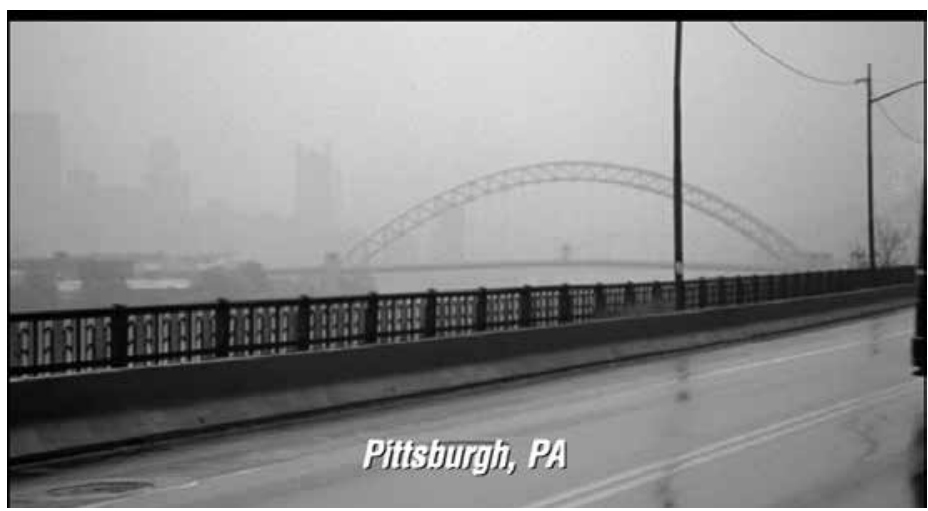

Image 46. Bob Roberts limited view of Pittsburgh.

Magnolia (Anderson, 1999), Fargo, and Reservoir Dogs (Tarantino, 1991). In this highly stylized, auteurist company, Groundhog Day stands out not only because it is a straightforward comedy (compared to The Big Lebowski's comic noir), but also because its style is more or less invisible, as the most traditionally studio production of all the bestregarded Hollywood films in the Sight and Sound list. Groundhog Day, like Kalifornia, begins in Pittsburgh and then takes to the road. Phil Connors works as the weatherman for WPBH - his practiced weather-report patter calls it the 'here in the three rivers area' and he's happy to report a smaller Pennsylvania city, Altoona, will see the worst weather but Groundhog Day and Phil leave Pittsburgh quickly, getting the WPBH van out of the city before the opening credits identify the Director of Photography, Screenwriters, or Director, because Phil wants to get out of town in a hurry.

Groundhog Day leaves Pittsburgh quickly to echo Phil's feelings about the city, and its method of leaving Pittsburgh clearly establishes it as a smaller city. Phil deputizes his colleague to deliver the weather report while Phil goes on location to cover the Groundhog Day festivities in Punxsutawney. Given the chance to extend his stay away from Pittsburgh, Phil says, 'I wanna stay an extra second in Punxsutawney? Please'. As Phil leaves the scene, a television studio's monitor shows an image of one of Pittsburgh's bridges, with the meeting point of the three rivers in the background. A slightly overlapping edit changes from the monitor's video image to a clearer, $35 \mathrm{~mm}$ film image of the downtown's tall buildings, bridges, a sports stadium, and some industrial sheds. As the shot travels over the city, hills covered in houses are dimly visible at the back. Other than the streets leading out of the city centre, there are no clear surface roads. A cut to a second helicopter shot comes closer to the tall buildings of the CBD, then pulls away from the centre to look down on the highway at the edge of the CBD. The 
camera zooms in on the van moving down a multi-lane highway, then zooms out to show the van negotiating a large highway interchange. Tall buildings and steel bridges no longer appear in the film, as the next (exterior) shot places the van in 'the country', in the form of a two-lane highway lined by farm-style houses, with hills receding into the background. Getting out of town in the course of two shots - less than 40 seconds of screen time - makes Pittsburgh feel small. This credits-sequence sequence of shots treats Pittsburgh both as a centre for places like Punxsutawney and as a lower-order city compared to a larger television market. But while Phil at first is interested in leaving for another network (implied to be in a bigger, that is to say higher-order, city), as he 'learns' Punxsutawney becomes more and more attractive, making Pittsburgh more and more central and higher-order to its surroundings.

Like Groundhog Day, Bob Roberts, and even the box office hit Flashdance, Wonder Boys features Pittsburgh's many bridges. In fact Wonder Boys features the city's more than four hundred bridges in more than just its establishing shots. One of the DVD release's special features include 'Pittsburgh interactive location map with commentary by Curtis Hanson'. In one of the seven short pieces in the interactive map, 'The Bridges', Hanson narrates a montage of shots from the film and archival images to place Wonder Boys in Pittsburgh's built-form:

Traversed by the Ohio, the Monongahela, and the Allegheny Rivers, Pittsburgh has more bridges than any other city in North America. A powerful visual reminder of Pittsburgh's potent past, the bridges are also an appropriate symbol for the yearning felt by the human characters in Wonder Boys, each of whom is trying to find their way from here to there, looking for a bridge that will allow them to leave the past behind and move on to the better version of themselves.

Hanson credits his production designer Jennine Oppewall and cinematographer Dante Spinotti for their work in creating the film world that occupies the background of images throughout the film. Hanson demystifies one of the director's jobs in the second half of his narration to 'The Bridges', explaining that

We snuck in bridges at key moments in the story - there are quite a few of them - like rabbits hidden in a cartoon tree [...]. As with most of the countless details that make up a movie, the idea wasn't that the audience would consciously think about these bridges, but that they might sense their presence, and they would add something on a subconscious level to the texture of the movie.

While it's always dangerous to take a director at his/her word about what their film or even a particular shot in it means, Hanson's account of his own mise-en-scène is compelling, and the ten images and one line of dialogue the special feature uses to illustrate his claim demonstrate the centrality of bridges to the film. If the film's bridges are to give form to 
the characters' transition from old to new identities, then the film's Pittsburgh setting must also reach the other side of the bridge to discover a new identity that can accompany the characters' happy endings. The bridges may lead to the same places, but what new things are happening in Wonder Boys' new Pittsburgh?

The new - better - version of Pittsburgh that Wonder Boys imagines more or less matches the city's new economic identity. Hanson's narration to the 'Pittsburgh' special feature collapses the distinction between city and characters in Wonder Boys:

Pittsburgh as much as any of the human characters in the story is a wonder boy. The one-time industrial center of America, Pittsburgh has this rich, glorious past that burned out and faded away along with the steel industry. It was impossible for Pittsburgh to go back, to become what it once was, so it was faced with the difficult and confusing task of moving forward, building on the embers of its past successes and failures, and becoming a new version of itself.

The city-identity that was impossible to go back to was that of Steel Town; the City of Bridges may retain its visual identifiers, but its economy operates differently. The Rust Belt's collapse in the 1970s and 1980s was followed by scattered rebirths in the 1990s and 2000s, and in most cases the cities tried to reinvent themselves through major building projects like Detroit's Renaissance Plaza, corporate-recruiting like Chicago's luring of companies like Boeing, and more diffuse attempts to re-orient their economies around research, as in Akron and Pittsburgh. In the 1950s, more than 40 per cent of the jobs in Pittsburgh were in the manufacturing sector, but that percentage fell every decade. A graphic in a 1985 Pittsburgh Press article (based on Bureau of Labor Statistics data) uses a cartoon of a man wearing a hard hat and safety goggles and operating a drill to show that by the mid-1980s manufacturing accounted for a little more than 16 per cent of jobs in Pittsburgh. However, at the same time, in Silicon Valley's San Jose, 36 per cent of jobs were in manufacturing (Hopey 1985: B5). In other words, during the 1980s and 1990s, Pittsburgh stabilized its economy by moving away from heavy industry and towards technology, medical research, and services, but retained the visual identity of a heavy industrial city. The city's many universities and colleges, like the unnamed university in Wonder Boys (Carnegie Mellon), played a role in this transition. In the conclusion to And the Wolf Finally Came, Hoerr sees some reason for optimism: 'Given the existence of this research capacity, Pittsburgh's hope of becoming a high-tech center is not entirely forlorn' (1988: 591).

To these larger economic trends, Wonder Boys adds questions of cultural value to the evolving identity of Pittsburgh. Kalifornia figures Pittsburgh as a place of stagnation and inertia that its artistic types must escape to succeed. Their destination is California, but Brian's serial killer road trip narrative with pictures from Carrie is not designed to be seen as a movie, it simply combines two publishing genres - true crime and coffee table art book. On the other hand, Wonder Boys responds to Grady Tripp's (Michael Douglas) 
stagnation and inertia in the form of James Lear's (Tobey Maguire) youthful potential. But this change in identity - for Grady in particular and Pittsburgh more generally couches its narrative of progress as film superseding literature. Early in their day-long sub-Ulysses travels around Pittsburgh, James tells Grady he's living in the bus station, and Grady responds in the voice-over, saying, 'James' story was the stuff of bad fiction', accompanied by a shot of the back of a woman holding a baby whose face is in the centre of the frame, just in front of a rack of slightly out-of-focus books by 'bad fiction' writers Mary Higgins Clark and Clive Cussler. Grady wonders 'where the page ended with [James] and real life began', but soon after James says that his family lives in Carville, outside of Scranton, referring to the All-American small town from the Andy Hardy movies, not a literary antecedent (and he watches a Mickey Rooney-Judy Garland movie soon after to reinforce the connection). And as the sun is setting, Grady explains his harsh judgment of James' work by dismissing the enterprise all together: 'Books - they don't mean anything. Not to anybody. Not anymore.' James immediately responds, 'Arsonist's Daughter meant something. It meant something to me. It's the reason I came to school here. To be taught by you. It's one of the reasons I wanted to become a writer'. Grady's self-recriminating, 'Well for that James, if nothing else, I'm really sorry' makes it clear that books do matter. But looking past the surface of the exchange reveals the industrial infrastructure of the city in the background of James' close-ups, linking yesterday's news of literature and Pittsburgh as Steel Town.

For Wonder Boys, literature and the literary is Grady (and vice versa). James singles out Grady's book The Arsonist's Daughter as formative. But for all his regard for Grady, James is less a walking encyclopaedia of literary history than he is a walking encyclopaedia of film history. At a faculty party he recites a laundry-list of classical Hollywood suicides. He carries a VHS copy of the Douglas Sirk film Written on the Wind (1956) in his bag and has a copy of Hollywood Babylon. Most tellingly, the film posters that cover the walls of his bedroom provide a concordance for the stories he's told throughout the film - Bus Stop (Logan, 1956), Picnic (Logan, 1955), Love Finds Andy Hardy (Seitz, 1938) - he has a pile of videotapes atop his television, and cites Against All Flags (Sherman, 1952) as a precedent for a ruse. Even when James writes, he cannot help but narrate the events of the film. His description of Grady's heart as one that beats 'only out of habit' sees a future not in the doorstop literature of Grady's never-ending second book, but in film.

In these Pittsburgh films, an understanding that steel is the past often leads to a sense that something needs to change, that something needs to replace it. Bob Roberts and the road trippers in Kalifornia treat Pittsburgh like a second- or third-order city, leaving it behind for greener pastures. Groundhog Day starts with a similar view, but the small town nostalgia that informs its happy ending means that it treats Pittsburgh as the major centre it was in the early post-war era, not the city it was in the early 1990s, and this backwardslooking stance offers a conservative, ideological, replacement for the now greatly depleted steel industry. Wonder Boys finds a slowly recovering Pittsburgh attaching its identity to something new, perhaps because it is chronologically the last of the four, and appeared 
after Pittsburgh had found a way to redefine itself as something other than a single-biome planet Steel City. The two versions of Grady's writing - his typewriter-written first novel and new work lost to the wind as opposed to the new, laptop-written film-adaptation ready novel - write a new chapter in his and the city's life. The novels-like-films ending puts forward an ambivalent sense of what Pittsburgh can do to move past its Industrial Revolution-linked steel and dense novel identity to a more tech-driven visual media identity in the twenty-first century.

\section{Conclusion}

Films set in Nashville and Las Vegas show a similar tendency to accent the key trait their cities are known for. Nashville films seem to find their way to recording studios, turning interiors into a visual shorthand for the city's cultural identity. Nashville, as represented by critically embraced films after 1975, more often than not combines the comfort of stereotypical representations with a sense that everyday lives are in fact not oriented towards higher-order cities but are directed inward, to the medium-sized city as a kind of centre. By contrast, Las Vegas has a fairly monolithic visual and cultural identity as The Strip and Sin City, and as a tourist attraction it has a very clear relationship with the rest of the nation. The only thing movies can imagine being produced in Las Vegas is money for the casinos, and that money flows outward in various legal and illegal channels, to Kansas City, to Chicago, to New York, and after junk bonds, to financial centres worldwide. Finally, films set in Pittsburgh certainly put the city's many bridges on view to perpetuate the city's strong visual identity, and usually accept the cultural identity of Steel City, even though the steel industry is now a tiny part of the city's economy. While first- and second-order cities like New York, Chicago, and Los Angeles are large enough and culturally vibrant enough (in the national imaginary) to contain multiple identities simultaneously, medium-sized cities are less suited to creating a new identity. Detroit, when it does appear in films - Blue Collar (Schrader, 1978), Mr Mom (Dragoti, 1983), Out of Sight (Soderbergh, 1998), Robocop (Verhoeven, 1987), True Romance (Scott, 1993) - it takes the form of a struggling industrial city. Wonder Boys, on the other hand, shows Pittsburgh's attempt to change from the industrial economy of Steel Town to the knowledge and service economy of Wordfest. The change is not complete, nor is its success certain, but among prestige films, Wonder Boys stands out for its attempt to imagine a second act - and a new identity - for a medium-sized American city. 



\section{Chapter 6}

Not Such a Small World After All: Disney Live-Action Films in the 1960s 

$\mathrm{I}$ n 1939 the Academy of Motion Picture Arts and Sciences presented Walt Disney with a special award - a big statue with seven little statues - for the significant innovation the feature-length animated film Snow White and the Seven Dwarfs (Hand, 1939) showed. Over the next decade and a half, Disney produced fifteen more animated films, such as Pinocchio (Luske and Sharpsteen, 1940), Fantasia (Ferguson, 1940), Dumbo (Sharpsteen, 1941), Bambi (Hand, 1942), Cinderella (Geronimi, Jackson and Luske, 1950), Alice in Wonderland (Geronimi, Jackson and Luske, 1951), Peter Pan (Geronimi, Jackson and Luske, 1953), Lady and the Tramp (Geronimi, Jackson and Luske, 1955), and Sleeping Beauty (Geronimi, 1959), most of which predominantly took place in fantastic locations. When the studio began producing films that combined animation and live action, their locations turned to the real world, as in Saludos Amigos (Jackson, Kinney, Luske and Roberts, 1943) and Three Caballeros (Ferguson, Geronimi, Kinney, Roberts and Young, 1945), throughout South America, and Song of the South (Jackson and Foster, 1946) in the US south. The studio's early focus on animated shorts and features, and the industry recognition of the first nine Oscars for Best Animated Short Film, as well as the special Oscar for Snow White, established the strong link between Disney and animation, one that continued with the nominations of Beauty and the Beast (Trousdale and Wise, 1991) for best picture, and the merchandise racks full of cartoon characters at Disney stores around the world. ${ }^{24}$ But starting in the 1950s, the studio went from every film featuring animation to a small percentage featuring animation. In the 1950s less than 20 per cent of the films released by Walt Disney studios were animated, and in the 1960s, less than 10 per cent were. In place of a limited number of animated features, the studio produced a great number of live-action films that have, by and large, occupied very little of the popular or critical engagement with both Disney films and film history. In this chapter I'll be looking at an under-investigated group of films - Disney live-action films - that, though set outside of the United States, address a range issues that were part of everyday life - and political life - in the 1960s in both expected and unexpected ways.

The usual argument about Disney films tends to focus on the cultural imperialism of the studio's animated films, perhaps most famously expressed in Ariel Dorfman and Armand Mattelart's How to Read Donald Duck (1984). Disney, in this account,

appropriates local stories, reinscribes them in the discourse of American imperialism, be it political, economic, or cultural, and sells the stories to all as portrayals of American cultural and political Others, revising old stereotypes in the current terms of 
American imperial expansion [...] [T] his reinscription process deprives the stories of their particular local geographies, and allows them to therefore be coopted and placed in ahistorical, ageographical ways in the creation of the Disney theme parks. This, in effect, allows [the Walt Disney Company] to set up representations of the world in the way that Disney would have wanted to see it - as an allegorical representation of the power of the United States.

(Scaffer 1996: para. 2, emphasis added)

But this is not exactly what happens in the live-action films of the 1960s. On the one hand, the majority of Disney live-action films from the 1960s are set in US locations and are adaptations of American source material. The geographical specificity of these films takes the form of a reified small-town Americana, a concept (not a literal location) detailed later in this chapter. On the other hand, the live-action films set outside the United States behave in a manner unlike the animated films. In this chapter I analyse In Search of the Castaways (Stevenson, 1962), Bon Voyage! (Neilson, 1961), and Monkeys Go Home! (McLagen, 1967), all of which are set almost completely outside of the United States. For these three films, non-US locations are essential to the narrative, which means that they do not entirely deprive their locations of their particular local geography, as that specificity comes in the service of positioning American ideology above it, triumphant.

In fact, it is precisely by recognizing the specificity of their non-US settings that these films establish a triumphant American identity. The children's adventure In Search of the Castaways, one of the year's top-ten hits, moves from Scotland to South America to Australia to end in Aotearoa-New Zealand, where a detailed misrepresentation of Māori civilization offers the greatest possible contrast to the American-identified family that re-connects upon escaping Te Ika-a-Maui, New Zealand's North Island. The successful family comedy Bon Voyage! - also a top-ten box office success - begins by pitting two versions of the American way of life, the east-coast establishment's and the salt-of-theearth Midwest's, against each other. When the Midwestern version wins out, it takes its world view to France, proving its value both to Americans and foreigners who can profit from the example. Finally, the trained chimpanzee picture Monkeys Go Home! wrestles with changes in the American diet, farm labour and unionization, and French film history to make its case for the essential rightness of American imperialism, both cultural and economic. In each case, Disney exports the American way of life and affirms it for the audience at home by setting its studio's live-action films in a variety of narrative settings that are recognized as specifically not-American, and unlikely to assume an Americanized identity in the short term. A more cynical reading would be that Disney films play the long game, establishing footholds for American cultural imperialism. My less cynical reading is that by moving outside the United States' literal boundaries, using a wide variety of locations in the past and present, Disney live-action films imagine the universal reach of hegemonic American ideology, but do so by acknowledging that geographical space outside of the United States has a variety of quite particular identities. The range 
of particular non-US landscapes in which Disney live-action films take place imagines a world that is, for the most part, completely unlike the idealized small-town Americana central to Disney ideology. The necessity of distinct worldwide locations for Disney liveaction films' cultural imperialism shows that it's not a small world, after all. In fact, the narrative locations that Disney live-action films encounter and colonize reveal a very large world, one much larger than the American small towns whose ideology they perpetuate.

\section{The Disney Ideology}

The most common reading of Disney films treats Walt Disney as the controlling voice of the films his studio produced (and still produces) rather than the director or star (I will use 'Walt' for the person and 'Disney' for the studio). Take, for example, the director Robert Stevenson, who in the 1960s directed films like Kidnapped (1960), The AbsentMinded Professor (1961), In Search of the Castaways (1962), Son of Flubber (1963), The Misadventures of Merlin Jones (1964), Mary Poppins (1964), The Monkey's Uncle (1965), That Darn Cat! (1965), The Gnome-Mobile (1967), Blackbeard's Ghost (1968), and The Love Bug (1968), which for the most part succeeded at the box office. Richard Maltby sees a disdain for commercially successful films as a reason for Stevenson's (and other nonauteur-identified directors') invisibility from film criticism:

This disjunction between critical and commercial centrality is hardly new: the voluminous critical attention paid to Orson Welles has never been justified by the relatively meager box-office receipts of his films, while there is hardly an article written on the oeuvre of Robert Stevenson, the most consistently profitable director in the history of Hollywood.

$(1983: 314)$

On the one hand, Maltby gets it right: the five pieces of academic criticism on Stevenson all analyse his prestige-picture adaptation of Jane Eyre (1943), starring Orson Welles, and the new cinema history's audience-driven approach fills in the gaps to present a fuller picture of films' circulation and meaning (from a search of the MLA bibliography, February 2015). But in the case of Disney films, Stevenson's absence from the critical literature can be more easily understood as a testament to the power of Walt's identity in the cultural imaginary; Walt and his biography predominate in readings of his studio's films, especially ideological readings. By and large, Walt's politics are described as smalltown conservative. Stephen Watts offers one of the more generous descriptions of the standard account of Walt's ideology:

Disney was a conservative Republican by the 1950s, but this fact hides more than it reveals. The real core of his politics lay in a 'sentimental populism.' He carried into 
adulthood an ideology - like his aesthetics, it was instinctive and emotional rather than systemic and articulate - that glorified ordinary Americans, blended democratic symphonies and cultural conservatism, and flowered from roots in his rural, Midwestern background.

A place full of ordinary, populist Americans who live in the rural Midwest - still a potent force in American political rhetoric, if not on the census rolls - describes the town Disney grew up in, Marceline, Missouri. For instance, the Philip Glass opera about Walt Disney, The Perfect American (2013), based on Peter Stephan Jungk's novel Der König von Amerika (2001), returns again and again to 'the soul of America', Marceline, and all that it represents, to understand Walt.

Like almost every Hollywood production, Disney films offer happy endings. On the one hand, works of popular culture, 'cannot be ideological without at one and the same time being implicitly or explicitly Utopian as well: they cannot manipulate unless they offer some genuine shred of content as a fantasy bribe to the public about to be so manipulated' (Jameson 1979: 144). On the other hand, Disney productions, tied up as they are in a larger system, tend not to be standalone texts but rather nodes in the Disney-industrial complex marketed to a youth market rather than to adults. Because of this, critics take a much dimmer view of the manufacture of happy endings. In the introduction to The Mouse That Roared: Disney and the End of Innocence, Henry Giroux frames his argument in terms of the psychological experience of the kid audience:

For children, Disney is a wish-landscape that combines fantasy, fun, and the opportunity to enter into a more colorful and imaginary world. Its animated films usher children into terrains that are exotic and other - filled with the fantasies of escape, romantic adventures, and powerful emotional themes about survival, separation, death, and loss - and provide points of identification and the capacity to mediate and experience in fantasy form realities that children have not yet encountered. Disney's theme parks invoke the romantic fantasy $[\ldots]$.

$(2001: 6-7)^{25}$

Later in the same book Giroux considers the cultural implications of the fantasies Disney offers. Disney culture, he writes,

offers a certain notion of history that is not only safe and middle class but also indifferent to racial, class, and social conflict. As distorted as Disney's dreamscape might be, it contains a utopian element in that it offers an antidote to the boredom, brutality, and estrangement that appear to be such a pervasive part of daily life.

(Giroux 2001: 148) 
This antidote, in Giroux's account, pervades daily life, and he uses 'landscape' and 'terrain' repeatedly in his introduction. But he uses these concrete spatial terms to describe ideology, not actual places. His critique misses live-action films in its focus on animated films and theme parks, as well as 'the Disnification of West Forty-second Street in New York City' (Giroux 2001: 157). I am sympathetic to Giroux's larger aim, 'raising questions about Disney itself, what role it plays [...] in shaping public memory, national identity, gender roles and childhood values' (2001: 10), but I take issue with the presumption that all the negative traits of Disney films can safely be placed in nonurban. Earlier I developed the idea of 'suburban taste' in terms of post-Jaws blockbusters; the distinction Giroux draws is between a desirable urban taste regime and a debased, undesirable, consumerist regime invading New York. The suburbanization of the city, in this account, represents less the economic triumph of corporatization than the cultural success of Disney narratives. Which is not to say that Disney narratives did not triumph over American mass culture, but rather to say that their imaginary geography is in no way limited to small-town America, neither on the level of ideology (there are Walt-like conservatives in San Francisco) nor even on the level of film narrative.

Disney animated films, theme parks, and merchandise-driven commercialization have received much more critical attention than the live-action films released as part of Disney's larger corporate synergistic strategy. As Douglas Gomery describes the studio's production history, between 1946 and 1966, Disney

fully annex[ed] the family film genre. Such films as Old Yeller (1957), The Shaggy Dog (1959), Toby Tyler (1960), The Absent Minded Professor (1961), Son of Flubber (1962), The Misadventures of Merlin Jones (1964), and That Darn Cat (1956) entertained a generation of baby boomers dragged to the movies by their parents. But this was simply not enough to sustain a major motion picture studio. Disney needed to do something else to create corporate survival. Innovation came through television and theme parks.

(1994: 75)

In this version of industrial history, the films as films more or less disappear, except to play the part of content in the integration of film production, television, theme park activities, and merchandizing. Disney live-action films were 'as risk-free a way of making movies as anyone ever devised' (Schickel 1997: 308), and one way to avoid risk is to avoid controversial subjects. Along these lines, one explanation for the disappearance of Disney live-actions films might be their relative lack of quality, although at the very least some are emotionally affecting (it would take a heart of stone to watch Old Yeller [Stevenson, 1957] without crying). But JG O'Boyle offers a different explanation of how boomers 'dragged' to the movies by their parents (how many parents were eager to see The Misadventures of Merlin Jones?) have neglected Disney's live-action films: 
The stylization inherent in the medium itself imparts a timeless quality to much of Disney's feature-length animation, but his live-action adventures age poorly. The evolution of acting styles, the fading of Disney stars, and the heightened expectations of the 1990s audience in terms of production values all combine to date the films as quaint artefacts.

(1996: 78)

The ordinary status of Disney live-action films makes them easy to miss and/or dismiss. But their datedness is precisely what makes them worth studying as artefacts of their culturalhistorical moment. In Search of the Castaways, Bon Voyage!, and Monkeys Go Home! make no attempt to tackle significant political issues. Instead, they operate in the comfort zone of small-scale personal problems that occur outside the boundaries of small-town America. Disney live-action films from the 1960s and 1970s are more or less invisible in accounts of what we might call Disney studies, as well as in film history. But these films are a key bridge from classical to post-classical cinema and the keys to the Disney corporation's early adoption of the kind of corporate synergy that became hegemonic in Hollywood in the last two decades of the twentieth century and beyond.

Disney live-action films were produced in a manner similar to classical Hollywood. 'Disney established a regular cast of stars who appeared in "wacky comedies" such as The Shaggy Dog (1959), The Absent-Minded Professor (1961), and Follow Me, Boys! (1966), literary adaptations such as Swiss Family Robinson (1960), and animal adventures such as That Darn Cat (1965)' (Wasko 2001:22). This cast will almost certainly feature a young star like Tommy Kirk (eleven films), Hayley Mills (six), or Kurt Russell (six, plus voice work in another). This youngster will have an older father-figure, played by Fred MacMurray or maybe Maurice Chevalier. In many cases the film will have trained animals - probably a dog, maybe a cat, but also horses and chimpanzees that will be called monkeys. But when it comes to location, the same actors get moved around the globe. From the standard reading you'd think that Disney movies were only set in small-town America, which is in fact not the case. While it is true that some films are in American small towns, such as Those Calloways (Tokar, 1965), One and Only Genuine Family Band (O'Herlihy, 1968), Rascal (Tokar, 1969), and Blackbeard's Ghost (1968), they are lonely dots on the map of the decade's films (Map 19). The Medfield College movies The Absent-Minded Professor, Son of Flubber, The Miseducation of Merlin Jones, and The Monkey's Uncle all feature the fictional half-California half-east-coast Medfield. Films like The Ugly Dachshund and That Darn Cat take place in contemporary suburbia, featuring the kind of people mass-circulation magazine like Life envisioned their readers to be: 'Midwestern, middle class, not very sophisticated, and definitely not intellectual' (Kozol 205). This is the Disney small-town world, obsessively returning to Marceline.

But there is another group of Disney movies - the American-city and internationally set ones - that similarly mythologize the Heartland, but from the outside, sometimes from well outside. Though Disney films tend not to be set in big cities, a few films - The Happiest Millionaire (Tokar, 1967), The Horse in the Gray Flannel Suit (Tokar, 1968) Never a Dull 
Moment (Paris, 1968), The Love Bug, The Parent Trap (Swift, 1961), and Summer Magic (Neilson, 1963) - figure their urban settings as lacking in relation to the happiness to be found in Americana-identified suburbs and small towns (Map 19). When Disney liveaction films leave the United States, they are as likely to be set in the wilderness as they are in urban centres. In addition to the London setting of the mega-hit Mary Poppins, other, less successful 1960s Disney films were set in international cities such Greyfriar's Bobby (Chaffey, 1961) in Edinburgh, Emil and the Detectives (Tewksbury, 1964) in Berlin, and Almost Angels (Previn, 1962) and Miracle of the White Stallions (Hiller, 1963) in Vienna. The Disney wilderness encompassed the Atlantic (Kidnapped) eastern and western Canada (Big Red [Tokar, 1962] and Incredible Journey [Markle, 1963]) (Map 20) and the islands of the South Pacific (Swiss Family Robinson and Lt Robin Crusoe USN [Paul, 1966]) (Map 21). I will focus in particular on two Disney live-action movies from the box office top tens, the Scotland-Chile-Argentina-Australia-New Zealand set In Search of the Castaways and the New York City-Paris-French Riviera-set Bon Voyage!, that establish the way in which international locations facilitate the clarification and reification of the Disney ideology. I will close with the minor hit Monkeys Go Home!, which goes one step further, and begins to change the international location into something that more closely resembles Walt's preferred version of small-town America.

\section{In Search of the Castaways}

In Search of the Castaways, based on Jules Verne's 1867 novel, follows Mary Grant (Hayley Mills), her little brother Robert (Keith Hamshere), and their French geography-professor friend Jacques (Chevalier) as they search for Mary's ship captain father (Jack Gwillim), who disappeared somewhere in the South Pacific, according to a message in a bottle that Jacques found. The film begins in Glasgow, where Mary, Robert, and Jacques convince Lord Glenarvan (Wilfrid Hyde White) and young John Glenarvan (Michael Anderson, Jr) to help them. Every stop on their trip results from Jacques' mis-reading the letter in some way. They survive a series of earthquakes in an unnamed South American country (Chile), a near-biblical flood on the Pampas, the briefly shown docks of Melbourne, a Tasman Sea double cross by the gun-runner Thomas Ayerton (George Sanders), imprisonment by the Māori, and an erupting volcano (an unnamed Mount Taranaki). In Search of the Castaways presents a curiously particular Aotearoa-New Zealand, a place that is very different from its Tasman Sea colonial neighbour, the white-Anglo docks-of-Melbourne (we only hear about Aboriginal people). The detailed representation of the Mãori, wrong as it is, casts light on the Disney ideology's need for a particularized setting in which to conclude its narrative. Drawing on an interview I conducted with Lloyd Carpenter, a lecturer in Māori Studies at Lincoln University in New Zealand, I will enumerate a number of the ways in which the film puts forward a 'plastic tiki' vision of Māori culture so that it can construct a fantastic but ideologically necessary other against which to show a triumphant American way of life. 


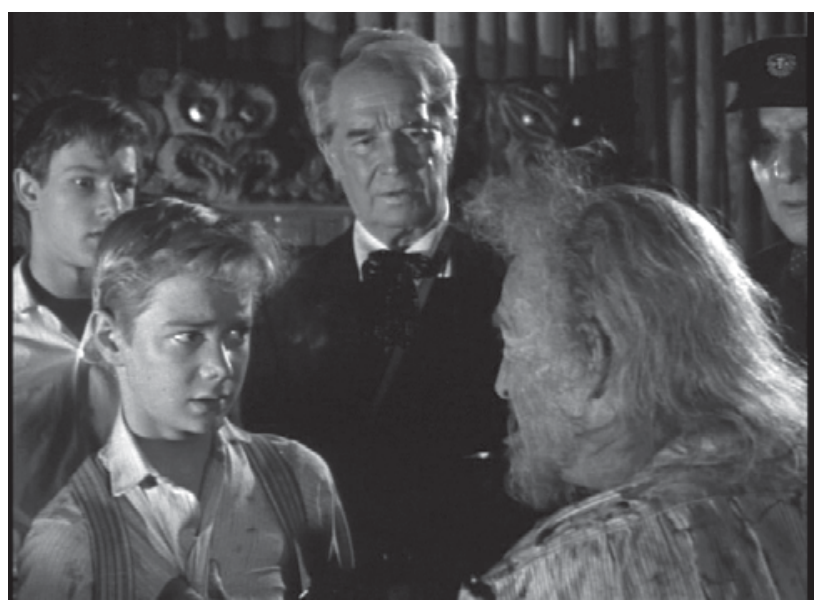

Image 47. In Search of the Castaways Māori carving with ping pong ball eyes.

In the film, not everything about Māori and Aotearoa-New Zealand is entirely wrong or exaggerated or invented. In the novel, Jacques offers snippets of anthropological detail from contemporary European knowledge about Māori culture. There is indeed a volcano in Taranaki. Whereas the Italian-born Antonio Cifariello plays the ever-helpful South American 'Indian' Chief Thalcave, there is no such blackface for the Mãori chief. The Māori actor and opera singer Inia Te Wiata leads the haka and represents, in multiple senses, his people. Some of the set and costume design is true to the historical record, notably the palisades surrounding the pa, and many of the carvings that use paua shells for eyes (but not the one that uses ping pong balls for eyes). During some of the haka shots, the warriors wear feathers in their hair to denote rank, and some of the cloaks resemble what would have been worn (although the cloaks would not be worn in a fight, as in the film). Finally, during the gun exchange, someone uses the Te Reo Māori word 'waka', which makes sense, as they're about to get into wakas.

The misrepresentations in In Search of the Castaways owe more to Hollywood representations of Native Americans than to actual Māori culture. The gun-running business is historically accurate; there was a gun trade between Australia and AotearoaNew Zealand during the mid-nineteenth century. Thus, Bill Gay (Wilfrid Brambell), in his own words, 'be smart' when he tells the Grant children that their father, 'learns the way to keep alive for they [the Māori] need him when they get more guns'. However, the film is set in 1858, in Taranaki, where relations were particularly good, thanks to Wiremi Kingi's leadership. Accordingly, there was no gun trade in the Taranaki, though there was 
elsewhere on the island. To name a few of the ersatz anthropological details: before even landing on shore, Glenarven says, 'Māoris. Hundreds of them. Deuce of a fix. No trinkets to bargain with. What have we got to offer?' The line invokes the purchase of Manhattan, but not the British colonial experience with Māori, displacing US settler-Native American encounters onto other encounters. The less said about the quality of the tikis that the men wear, the better. Some of the women (who would have been topless) wear headbands that seem more like something a Native American would wear in a Hollywood western. The Māori chief's moko appears to have upside down and sideways koru, half-complete spirals, and an unlinked forehead and cheek portion, although some of the characters who occupy the background have close approximations of actual mokos (albeit drawn in magic marker) (Image 48). As Carpenter pointed out in the interview, a people who wore flax-fibre clothes would not be likely to carry open torches, nor would there have been any source of pitch or tallow to fuel a torch in the first place. A great deal of the timber used looks to be pit sawn, with mitre joints, and nailed, which would have been a trick, as the Māori had no metal tools to create them or the brass hinges on the prison-house door (Carpenter 2015). Thus, by and large, In Search of the Castaways, even when it dips a toe into the history of the region, figures the Mãori from the cinematic vocabulary of westerns and African adventure tales.

Such a dependence on previous film representations of colonized people places the exaggeration of the film's mise-en-scène in Disney's hands. I present these details not to seek out continuity errors or out of the expectation that a children's adventure film represent with absolute accuracy a particular culture. Rather, the yoking of some

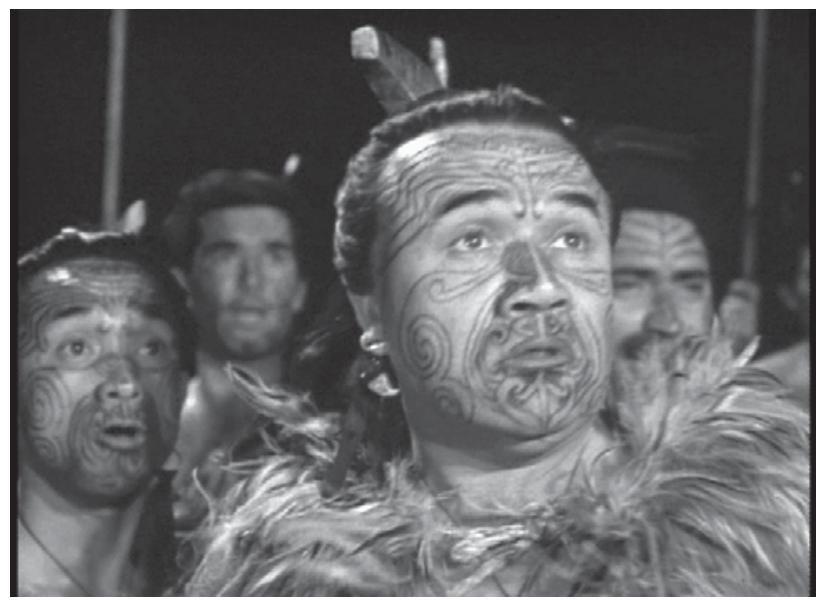

Image 48. In Search of the Castaways Rangatira (Chief) Inia Te Wiata and marker pen mokod toa (warriors). 
limited Māori historical details with a preponderance of film historical details reveals the way in which Disney films establish a credible film-world in which they can prove the worthiness of the American way of life, what we can call Walt's politics. In 1960, New Zealand would have been a more or less unknown place to the American filmgoing audience. Some members of the United States military might have been familiar with New Zealand, and even familiar with some aspects of Māori culture, as Rotorua was a popular R\&R destination and marae were key sites of intercultural communication (Ministry for Culture and Heritage 2012). Direct long haul air service from Los Angeles to New Zealand did not even begin until 1965 (McClure 2012: para. 1-2). Americans represented less than 10 per cent of tourist arrivals in New Zealand in the years leading up to In Search of the Castaways, with perhaps 10,000 in total visiting in the four years before the film was released (McClure 2014). In Search of the Castaways leaves AotearoaNew Zealand behind without having 'civilized' it so that Mary Grant, her brother, and father can return to England stronger and wiser. This strength comes from having seen and experienced places that are geographically very different than Britain - earthquakes, volcanoes, pampas, non-white people. That experience of difference, from the Māori who kidnap them to the mad Irishman who has a hand in saving them, shows that the Disney ideology needs places that are markedly different to 'win over', to convince its audience of the rightness of their mission. In this regard, In Search of the Castaways' yoking of a few accurate details in its Māori characters to stock-Hollywood 'savage tribe' behaviours reveals the ideological nature of Disney live-action films. New Zealand must be specific enough to be different from other locations - the Pacific islands in Swiss Family Robinson and the later Lt. Robin Crusoe USN, for example - but not so specific as to present a fullyformed culture. Too much specificity - too much of an actual civilization - would make the Americanization inherent in the narrative too much like the hard work of erasure, too much like an imperial project.

\section{Bon Voyage}

In Bon Voyage!, the Willard family leave their home in Terra Haute, Indiana for New York, then cruise across the Atlantic, and holiday in Paris and the Riviera. Before their ship sails for France, Harry (Fred MacMurray) must navigate a party hosted and peopled by his wife Katie's (Jane Wyman) family and friends, all of whom are Boston Brahmin still horrified that their Katie married a hick from Indiana. During this party the Willards' small-town middle-American ideology brushes aside a vacuous American east-coast elitism. Talking to his father-in-law, Harry makes light of the east coast's condescension for Indiana. When his father-in-law Horace Bidwell admits, 'I guess some of us will never forgive you for stealing our little girl and taking out to that Terre Haute or whatever it is out there. Harry can barely keep a straight face in his reaction shot. Once he's mastered his face, Harry exaggerates the difference between the wilds of the Midwest and Boston in 
terms of space and time. 'It's Terre Haute, sir', he offers, 'And it really isn't too bad. We have the Indians pretty well under control by now. Harry tries to reassure his father-in-law of the presence of culture in the Midwest, insisting that, 'we have television and we get up to Chicago for a weekend now and then, so'. But Bidwell is unimpressed and/or stuck in the nineteenth century, only grunting, 'Chicago? Well, why not' before walking away. This lopsided balance of prestige and esteem will reverse itself by the time the film ends, in large part because Harry invokes Terre Haute at regular intervals as the film's ideological true north, a synonym for traditional conservative hard-working American values - the very values that his wife's stodgy Boston family do not understand.

The east-coast establishment's lack of ability and/or desire to understand the value in the heartland is a fairly common phenomenon in US culture, as well as a motivation for populist flowerings of the cinema age (at the presidential campaign level, to offer a nationwide example) from William Jennings Bryan to H. Ross Perot. In From Walt to Woodstock: How Disney Created the Counterculture, Douglas Brode wrings the maximum amount of populism into Bon Voyage's Boston-versus-Terre Haute conflict:

Disney's films project his attitudes about the class system in America, particularly his deep distaste for pretension and faux sophistication. Consistently, the city that symbolizes this in the canon is Boston. Bon Voyage, a comedy-drama, concerns an Indiana family's trip to Europe, the Grand Tour almost ruined before it begins [...]. Shallow and superficial, the Bostonians are unable to grasp that Katie recognizes honesty, decency, and authenticity when she sees it, and she sees it in Harry.

(2004: 42)

'Honesty, decency, and authenticity' are, in this formulation, the very qualities Walt found in Marceline and wanted his films to spread. On the one hand, the top box office hits of 1962 weren't short on these qualities: Lawrence of Arabia (Lean), The Longest Day (Annakin, Martin, Wicki), To Kill A Mockingbird (Mulligan), and even That Touch of Mink (Mann) all valorise honesty, decency, and authenticity. But whereas The Longest Day imagines the global geopolitical contours of honesty, decency, and authenticity, Bon Voyage! shrinks them down into the never-seen but often-mentioned 35 square miles of Terre Haute. Boston figures in the national imaginary from the earliest days of colonization, Terre Haute much less so. Not much of the film-going audience would be likely to know much about Terre Haute, its population (about 70,000), its economy (some factories, agriculture-connected businesses), or its educational offerings (one growing teachers college). But an Indiana city with a plumbing contractor with enough money to take his family on a vacation to France signals a heartland which is about as far as possible from the main urban and countercultural centres of the decade. This peripheralized middle-American identity recurs throughout the film, both as critique and as affirmation.

Once in Paris, and later the Riviera, Harry finds it harder to brush aside France's appeal, especially to his children. Harry must convince his kids, Elliott (Tommy Kirk), 


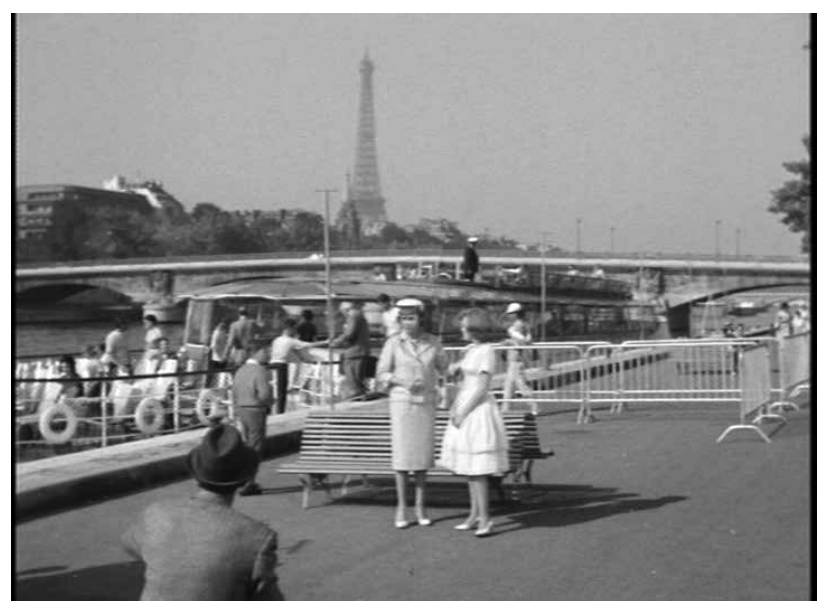

Image 49. Bon Voyage! Eiffel Tower in establishing shot.

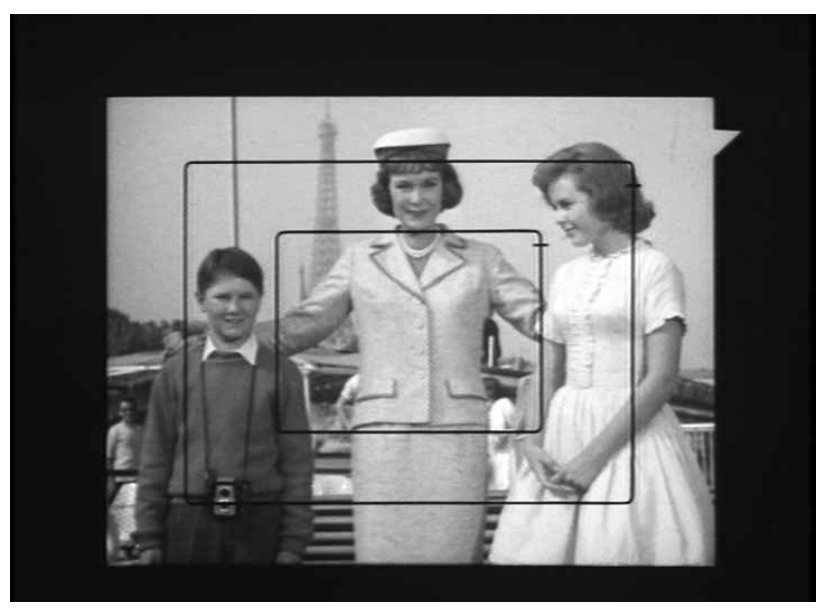

Image 50. Bon Voyage! Eiffel Tower in home movies.

who morphs into a faux-cosmopolitan, Amy (Deborah Walley), who falls in love with trust fund-abusing lout Nick (Michael Callan), and Skipper (Kevin Corcoran), who seems to be the most well-adjusted in the family after his mother, that even in Paris or the Riviera, Terre Haute is true north. The first thing Willards do together in France is visit the Eiffel Tower, which appears frequently in Bon Voyage!, as an establishing shot 
for Paris, as a background image for the vacationing family, and as a narrative location that motivates the Willards to think about middle America in relation to the rest of the world. Standing on the Tower's observation deck, Amy and Skipper have a brief exchange about the city they survey. The effusive, romantic 16-year-old Amy says, 'what a perfectly beautiful exciting city'. Her world-weary quip-spouting 12-year-old brother Skipper replies, 'Sure ain't Indianapolis'. Skipper can joke that Paris sure ain't Indianapolis, but by the end of Bon Voyage! Americans like the Willards, the French people they meet in romantic pursuits, and expat Americans like Amy's erstwhile beau Nick all learn and accept the strength and rightness of the conservative, middle-American ideology that calls places like Indianapolis and Terre Haute, Indiana home. In 1939 Dorothy Gale had to go to $\mathrm{Oz}$ and in 1962 families like the Willards had to go to France to be reassured that their home was, in fact, the centre of the world.

But that centre has a hard time holding in Bon Voyage!. The Willards more often than not go out alone or in pairs; Elliott, Amy, and Skipper all strike out on their own during what's supposed to be a family vacation. Left to their own devices, Elliott and Amy reject what Terre Haute stands for. Almost immediately upon arrival in Paris, Elliott complains about the family's Right Bank hotel, a location that clearly identifies them as square:

We oughtta be over on the Left Bank where all the interesting people are [...]. Don't you understand, Dad? You've got us here with a bunch of tourists. Next thing you know you're gonna be dragging us off to the Eiffel Tower for some corn flake routine like that.

Elliott's geographically informed opposition of the interesting, authentic people - Left Bank-oriented artists, bohemians and French locals - to Right Bank-oriented inauthentic (or authentically square) corn flake tourists from middle America gets Harry a bit riled. 'Look son', he replies sternly

let's get something straight around here. We are tourists. We're not playboys or business tycoons or international spies or anything like that. We're just plain tourists from Terre Haute, Indiana. Now for a start it might help if we stop showboating all over the place and pretending we're something we're not. Then maybe tourist won't be such a dirty word any more.

Rather than wield Terre Haute as an ironic rhetorical flourish, Harry invokes the humility and normalcy inherent in its literally middle-American location and embodies its fatherknows-best fantasy. And Harry walks the talk. A few days later, enjoying a quiet breakfast at a sidewalk café near the Louvre, Harry meets an attractive French woman (Françoise Prévost). After a bit of small talk handled in shot-reverse shot close-ups, a tighter closeup on her leads to her come-on to Harry. She says of France, 'Also there is romance'. The reverse shot of Harry is in a similar, tighter close-up. After a false start on a successful 
pickup, Harry tells the never-named woman, 'The thing is I love my wife very much. She's the most beautiful woman in the world. At least to me she is. And we have three kids and they're all kinda nutty one way or another. I'm crazy about them too'. With a look of admiration, the woman sighs, 'C'est vraiment riche, monsieur [....] I believe you truly are a rich American' and she leaves. Harry leaves the café and soon spots Elliott at a different sidewalk café, talking to the same woman. Her bored face barely registers Elliott's droning monolog about how, 'the ordinary person wouldn't know I had money, would they? See I don't think money should be an ostentatious thing. I think it should be sort of a basic feeling within you' but her eyes light up when she sees Harry. She asks, 'is this one of them?' Richard Schickel reads this scene as 'a disaster', as it shows Harry 'innocently involved with a prostitute', which falls outside the logic of Disney films (Schickel 1997: 303). But the strangeness of the presence of a prostitute in a Disney family picture hides something more pedestrian. Unlike his posing son, Harry cannot help but exhibit honesty, decency, and authenticity; wherever he goes, he's happy to be a moderately successful plumbing contractor from Terre Haute and nothing more.

Honesty about being a plain old Terre Hautan, and the prospect of working hard at a decent but not impressive job may triumph in the end, but Bon Voyage! shows a series of trials for the model of American ideology that Harry embodies. When the Willards reach the Riviera, Harry and Skipper sit on the beach, where Harry finally starts to relax. As he lounges in a beach chair, Harry says, 'You know Skipper, right now is probably the first moment of peace I've had since we left Terre Haute'. As if summoned by the city name, Amy appears in a revealing leopard print bikini and a massive matching hat. Moments later, her callow romantic interest Nick appears and starts to order her around, demanding that she change into something more modest. Amy brushes him off: 'Maybe I'm just a little tired of being sweet square Amy from Terre Haute. She runs away from him into the ocean, but he chases her in a boat and she swims back to shore, into Harry's arms. As he holds his crying, distraught daughter to his chest, Harry says, 'I'm sorry baby. So very sorry'. (This 'baby' line strongly echoes MacMurray's dialogue exchanges with Phyllis Dietrichson [Barbara Stanwyk], the femme fatale in Double Indemnity [Wilder, 1944] which, when combined with Harry's tendency to capture Amy's romantic escapades on the family $8 \mathrm{~mm}$ camera, introduces a creepy sexuality to their relationship.) After glaring briefly at Nick, Harry tells Amy, 'Only one more day, baby, and we'll be leaving for home, where we really belong. Maybe when we get back there all this won't seem all that important. The unfamiliar and unpleasant pressure Amy feels to be someone else, someone glamorous, comes from the Riviera. The geographer Sverker Sörlin argues that places like

The French Riviera and California can be called 'international landscapes' - if not 'globalized landscapes' - in the sense that they are mediated almost universally and serve as objects of pilgrimage and tourist resorts for people far beyond France and the United States. For precisely this reason it is no coincidence that their 'careers' as places 
have been possible through an international set of celebrities and through film, media and popular culture.

$(1999: 107)^{26}$

The reciprocal relationship of the Riviera with Terre Haute emerges quite clearly in Bon Voyage!. Middle Americans like the Willards visit the Riviera to try on alternate identities. Katie changes her look in Paris, Elliott wishes he could be at the Left Bank, spends his time in Paris pretending to be a cosmopolitan playboy, and Amy briefly changes from a sweet square into something more international, more worldly, on the Riviera. But for all their changes, the Willards find happiness in remaining authentically American. Harry, tightly linked to Terre Haute, stays the same, and the Willard family's French vacation offers them a brief view of what is really important, the lives and work they will return to in Terre Haute, from another, temporary, vantage point.

Harry's apparent stasis - he loves his family and Terre Haute unreservedly from start to finish - does not mean that he lacks awareness of the rest of the world or how the world perceives his American identity. On their last day in France, Harry demonstrates the value of his vacation abroad when he outsmarts a mother who demands money for the honour of her daughter, whom Elliott probably kissed. The scene begins with a series of quick references to Frenchness. Harry mangles some French while announcing to the hotel staff that he and Katie are planning to show the French how to celebrate Bastille Day. Then, when Elliott introduces Harry to Madame Clebert (Georgette Anys), a slowed-down bit from 'La Marseillaise' plays. Madame Clebert, fooled by Elliott's continued posing as a rich, cosmopolitan American, tries to swindle Harry. But Harry immediately proposes marriage, going so far as to open up Florelle's mouth to check her teeth like he would a horse: 'That's the way we do things back in Terre Haute. [...] Now let's see Madame, how old did you say your daughter was? Well she's not as young as she looks, is she? But that's alright, as long as she's a good worker'. The flummoxed Madame Clebert sputters as Harry builds an imaginary Indiana:

Is she strong? Yes, for the farm she's gonna have to work on the farm [...]. You see Madame you've got the wrong idea about Americans. They're not all rich, you know. Now you take us. We've just got this little rocky old farm back in Indiana. Now of course on our farm the women do most of the work. Like my wife and daughter work from way before sun up to way after sun down. And we could sure use another hand. Now how is Florelle with cows? [...] How about sheep?

Upon hearing 'sheep', Madame Clebert cries, 'Oh mon dieu! We just escaped the sheep. That is why we left Normandy - to escape the sheep!' Harry finally caps off his performance by proposing a champagne celebration. Returning to the ironic Indiana he painted for his father-in-law, Harry says, 'This is the way we open it up in the Wild West' as he breaks the bottle off at the neck. On top of using the language, mentioning the national 
holiday, drinking local wine, and non-diegetically introducing the national anthem, the scene adds a very specific and peculiar French touch that combines a stereotyped understanding of Indiana with a detailed understanding of French regional agriculture and cuisine. For all Harry's talk of cows and slopping pigs and feeding sheep, Indiana agriculture is predominantly geared to grain-production. Indiana had perhaps 1 per cent of the sheep in America's farms (and the United States has never farmed as many sheep as European nations, to say nothing of New Zealand). In returning to a parodic farm 'Indiana' Harry sets the stage for Madame Clebert to say something very specific about a particular region of France. His line about sheep sets up Madame Clebert's curiously accurate cry about escaping Normandy's sheep, the source of salt marsh lamb, a signature product of Normandy.

Bon Voyage! keeps Terre Haute off-screen, but its small-town American ideology occupies centre of its narrative, showing how hard work, family, and humility can generate the qualities Katie finds so attractive in Harry: honesty, decency, and authenticity. But Bon Voyage! does not buy into square values without some complications. On the one hand, Bon Voyage! toes the patriarchal line; Harry polices his children, especially their sexuality, by monitoring the age, nationality, and class of their potential partners. On the other hand, Harry seems to enjoy being cuckolded, and in addition to repeating Double Indemnity-like dialogue he shoots peeping tom footage (and Peeping Tom-like footage [Powell, 1959]) of his daughter's burgeoning sexuality. The film squares this perverse circle when Harry places his daughter's big-city boyfriend Nick on the right, middleAmerican track. Nick's problems, as Amy puts it, are 'The poor rich trash way he's been

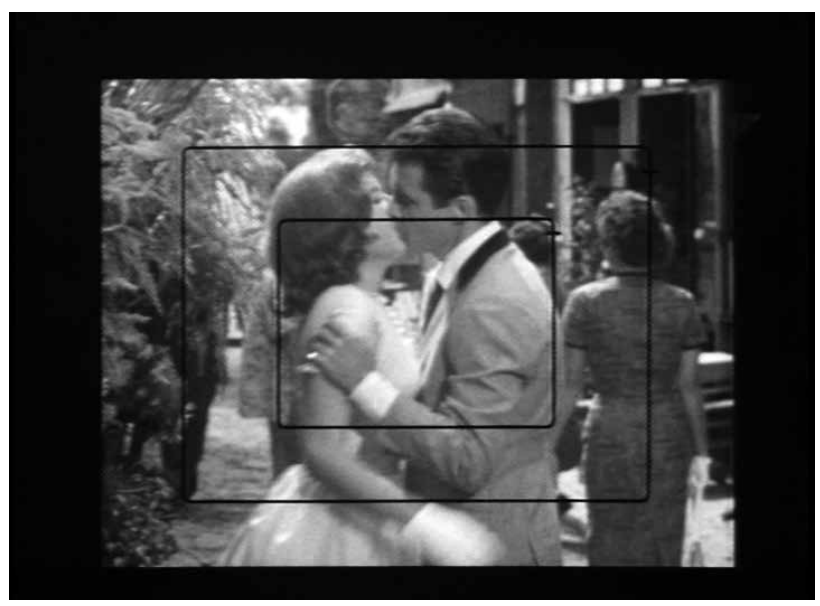

Image 51. Bon Voyage! peeping tom/Peeping Tom. 
brought up' and 'Without his mother [...] he couldn't get a job pouring water out of a boot'. But vacationing in France has opened Amy's eyes to alternatives, so she can also tell her father that Nick

doesn't like you at all [...] Not you specifically, I guess. Only people like you. Sort of dull respectable people with families and so forth [...]. Nick says that either people are hypocrites, just pretending to be happy and all that or else Nick says they're deluding themselves, and that's even worse!

Nick, the poor dear, is a trust-fund kid, and his mother is a Comtess. This combination of indolence and foreign influence causes Nick not to appreciate the hard work and satisfaction with the small-town version of success that the Willards enjoy, as his mother's professional dismissal of working your way to the top makes clear:

Starting in some dreary architect's office in the States. Can you imagine our Nicholas sharpening pencils, buying sandwiches, running errands? Nicky darling, if you don't like my money and want to earn a bit of your own, I'll speak to some of my dear, dull friends and you can have all the commissions you want building lovely buildings all over Europe. And he can have his own little people to run errands and sharpen pencils.

This vision - being served, but only because his mother provides for him - makes Nick difficult to get along with, but also makes him open to a different vision of life. It takes Nick a while to see the error of his coddled cosmopolitan ways, and the scales fall from his eyes when Harry appeals to his masculinity. When Nick learns that dull respectable Harry still has it in himself to punch out a Euro-sleaze for getting too familiar with Katie, he changes his view on Harry and what he represents. By repeatedly naming Terre Haute as the basis of his actions, Harry changes a peripheral small-town location into a central one, not geographically but ideologically. Nick promises not to go to Terre Haute, but to follow Terre Haute Harry's lead: 'I'm going back to New York, take that lousy job. Who knows - maybe I can make something out of myself'.

\section{Monkeys Go Home!}

While Bon Voyage! contents itself with one passing joke about farming, Monkeys Go Home! deals extensively with farming, from its location to narrative conflict to the contemporary political events it reflects. Other farming movies in the same period tend to be westerns, which deal with ranching and livestock rather than groves/farming: The Rare Breed (McLagen, 1966) is about cattle, The Fox (Rydell, 1967) a chicken farm, Hang 'em High (Post, 1968) has cattle rustling as its crime, and the Sons of Katie Elder (Hathaway, 1965) try to get back a ranch. However, the Clutters were wheat farmers in In 
Cold Blood (Brooks, 1968). Monkeys Go Home! is a film about contemporary American agriculture, and moving the farm to France allows the narrative to wrestle with antiimperialism, socialism, communism, and unionization. Monkeys Go Home! echoes the anti-imperialist cry of 'Yankee Go Home' in its title, and even uses the word 'imperialism' to show how the French villagers describe their situation. Three key undercurrents in the film - the American diet, agriculture and unionization, and French film history - reveal how an international setting not only makes Monkeys Go Home! a more overtly political film than the average Disney live-action picture but also sends a clear signal that Disney films would continue to advance Walt's ideology, even after his death.

The 480 olive trees that Hank inherits register and foreshadow changes in the everyday American diet of the 1960s. When he learns of his inheritance from the unscrupulous Emile Paraulis (Clement Harari), Henry 'Hank' Dussard (Dean Jones) announces that in his estimation, there 'Should be a real good living' in growing olives. Paraulis disagrees, and their argument turns financial quickly:

Paraulis: They are worthless [...]. The cost of labour, monsieur, the olives could never support it.

Hank: Now wait. My mother used to live in this town. She always told me there was money in olives.

Paraulis: Times change, monsieur. The world is watching its weight. Olive oil is out of fashion. Do yourself a favour and reconsider.

Hank: You almost had me fooled there for a minute. Real estate pitch in southern France is the same as the USA.

While this exchange certainly sets up the film's conflict, the easy dismissal of changing diets and olive oil in particular bears notice. Vegetarianism, for example, is equated with Hank and Americans, and figures in a half-dozen one-liners throughout the movie, which makes sense, as Hank's rival works as a butcher. But according to the usual diet of 1960s Americans, Hank would be better served by a cattle ranch or truck farm than an olive grove, as Americans simply did not consume a great deal of olive oil.

While the narrative is set in Provence, Monkeys Go Home! clearly addresses an American audience. Provençal cuisine makes extensive use of olive oil (and whole olives), so the diet change Paraulis describes more likely applies to Americans who, in the 1960s, weren't eating much olive oil to begin with. In fact, olive oil's contribution to the American diet was constant, but far below both butter and margarine throughout the 1960 s, a decade in which butter consumption fell as margarine consumption rose. It is worth noting that margarine has had a strange career in the American diet. In an article in the Journal of Economic History, Ruth Dupré traces the regulation of margarine and 
concludes that, 'margarine legislation in North America was largely determined by the interplay of the various agricultural interests at stake, particularly, the butter, beef, and cotton producers' (1999: 367). Early in the twentieth century,

the average consumption of margarine remained marginal at less than 10 percent that of butter. But with the improvement in its quality and the decline in its relative price, margarine steadily gained ground until it overcame butter in the 1950s, just after the repeal of the 1902 Oleomargarine Bill

(Dupré 1999: 375)

at which point margarine was regulated, like other food products, under the Food and Drugs Act. Finally able to be sold in a yellowish, buttery colour, margarine became the staple fat in American kitchens. With the bans on margarine colouring lifted, and with butter prices rising while margarine became cheaper, margarine consumption increased 3.4 pounds per capita between 1950 and 1960, while butter consumption decreased 3.1 pounds per capita. In 1960 per capita margarine consumption was 125 per cent that of butter (Dupré 1999: 358). This preference remained throughout the 1960s. Flipping through a magazine such as Better Homes and Gardens in 1966, the year Monkeys Go Home! was made, a reader would almost certainly see an advertisement for Chiffon and Golden Glow (in tubs), Fleischmanns, and Parkay (with recipes) (the talking-tub 'Parkay!' television ads did not start until 1973), but none for butter. In this dietary environment, US olive oil consumption increased from .21 litres per capita in 1964 to .3 litres per capita in 1967, well below the French average of more than a litre and a half per capita (index mundi). Even though Julia Child published The Art of French Cooking in 1961 and was cooking French food on public television soon after, wine consumption, which we can use as an imperfect proxy for French cooking, increased only marginally from .91 gallons per capita in 1960 to 1.03 gallons per capita in 1967 (total wine per resident), while in France wine consumption was more than one hundred and fifty times greater, at 160 litres per capita (Wine Institute 2015; Schofield 2013: para. 4-6). While there was certainly an interest in French culture in 1960s America, olive oil and French cuisine were not at the top of the nation's imagined food pyramid. This background helps to explain why Monkeys Go Home! takes place on a Provençal olive farm, to make a critical approach to farming in America without directly critiquing American farmers and small-town residents.

More specifically, as a trained-animal performer film, Monkeys Go Home! cannot help but draw attention to the role its titular 'monkeys' play in farming. After being told by both Paraulis and local parish priest Father Sylvain (Chevalier) that labour costs make the farm certain to lose money, Hank briefly disappears from town. Remembering four chimpanzees who never made it to space, Hank takes out a second mortgage on the farm and buys the four of them from the US Air Force, then brings them into France to pick olives on his farm, solving the problem of labour costs. Upon seeing the chimpanzees in training, Father Sylvain says, 'Marvellous. Simply Marvellous. Now I know what is 
meant by American enterprise. Do you realize they could revolutionize the entire olive industry? Can you not see these little ladies in every orchard in Provence?' The potential for chimpanzees to replace the local French workers drives the film's conflict, not just in the form of possible seasonal agricultural work for a foreign-owned concern lost or the change from the family farm to the agri-business model, but also in the form of significant local action against US imperialism.

The chimps exhibit American agricultural history's worst excesses: slavery, indentured servitude, and union-busting. Hank purchased his chimpanzees, Celeste, Delphine, Madeleine, Monique, and houses them in a single room with bars on its windows. Based on this, the butcher Marcel Cartucci (Bernard Woringer), Hank's romantic and political rival, argues during a town meeting that the chimpanzees' situation is

an example of capitalist oppression that would be unbelievable had not our secretarytreasurer seen it with his own two eyes! The American, Mesdames et messieurs, who now occupies St Piroutsen, has imported slaves to undermine the economy of our village. Henry Dussard has brought in monkeys and trained them to pick olives!

When Hank confronts Cartucci over the accusations of slavery, Cartucci, while cutting up a lamb carcass, points his knife and says, 'So go back to America and take your slave labour with you! [...] When you train monkeys to do a man's work, you create unemployment. What will become of us when your monkey army takes over?' While Hank briefly triumphs in his debate with Cartucci, he affirms Cartucci's indictment shortly after, offering his chimpanzees to pick every olive off every tree in the district to circumvent the olive monopoly - for free. When every farmer in the area shows interest, he admits, 'I coulda rented them out and made a fortune'. Monkeys Go Home!, like the majority of Disney live-action films in the 1960s, is a literary adaptation, in this case of GK Wilkinson's The Monkeys (1962). In the novel, a French civil servant returns home from Africa to take up residence in the farm he inherited, and employs monkeys, not retired Astrochimps, to pick olives. Thus from a book about France and decolonization, Disney made a film about American imperialism abroad and agriculture at home.

If we give Hank the benefit of the doubt, he's not a slave master, but rather a boss exploiting his work force. The degree to which Hank can exploit his imported workers, Cartucci argues at the town meeting, will 'cost you jobs, take the bread out of your mouth! [...]. We are confronted with creeping capitalism. I propose we stop it here and now, once and for all. Cartucci shows a curious degree of insightfulness for a one-dimensional heelfoil to Hank. In Monkeys Go Home!, Hank imports a docile labour force that economically stresses local workers. Such an approach resembles the Bracero program that ran from 1942 to 1964 in the United States. In the two decades before Monkeys Go Home! was made, as many as 400,000 agricultural workers were brought annually into the United States as Braceros. In his biography of Cesar Chavez, Robert Taylor writes that Braceros were 
Mexican-national contract workers, imported under special treaty with Mexico, to work for specific periods in specific 'labor-short' crops. The Braceros, first used during the World War II labor-short years, were becoming the 'ideal' farm labor force [...] coming from the poorest of circumstances, living in farmer-operated camps, dependent upon farmers for food and transportation, were totally subservient.

(Taylor 1975: 67)

In the two decades of the program,

With more than enough workers the grape farmer had no reason to increase his pay scale. The key to the vicious circle lay in the farmers' ability to set 'prevailing wages' so low local workers would not work the crop; this produced the 'labor shortage' needed to certify the crop for Braceros, and it produced a surplus of workers in other crops that had a chilling effect on the total farm wage structure.

(Taylor 1975: 68)

This chilling effect on local wages is precisely the basis for the protest Cartucci raises: Why pay a French worker when a chimp will do it for free? Dancing on the edge of slavery, deploying anti-capitalist and anti-imperialist arguments, and doing so in the context of agriculture, Monkeys Go Home! can profitably be read as Disney's response to nationallevel questions on industrialized farm labour. In the context of the Delano Strike - the labour action by predominantly Filipino and Mexican farm labourers that brought Cesar Chavez to national prominence - Monkeys Go Home! demonstrates how Walt's politics guided the films his studio produced, even after his death.

Perhaps the biggest story in agriculture and labour in the 1960s was the labour action and secondary strikes associated with the Delano grape strike, led by Larry Itliong, Dolores Huerta, and Cesar Chavez among others. The action in its various forms - strikes at the work site, at secondary sites, and in consumer boycotts - was ongoing from the time Monkeys Go Home! was filmed through its release in theatres, 'From 1966 to 1968, young college students joined with veteran organizers and aggrieved farm workers to build an effective boycott network that stretched across North America' (Garcia 2012: 6-7). As one of the organizers of the Delano strike, Jim Drake, remembered,

I'd never seen them picking for wine before. It was awful. They picked into buckets and pans and dumped them in gondolas that were pulled down the row by tractor. The workers were covered in juice and grime, and the gnats and flies were everywhere. It was really awful work.

(Taylor 1975: 135)

Attention to work conditions was one part of the action, while another was in forging alliances with other unions to increase pressure on management. Matthew Garcia reassesses 
the Delano strike by first acknowledging that, 'Numerous scholars and journalists have documented the history of the Delano grape strike and the beginning of the modern farm worker movement. Many tell the familiar story of how a reluctant Cesar Chavez was drawn into the strike by the more radical, union-oriented AWOC members, especially Larry Itliong' (Garcia 2012: 41), and then turning to the under-appreciated importance of the boycotts to the action's success. Because the United Farm Workers weren't party to the National Labor Relations Act, they could pursue secondary boycotts, which after 1947 have been illegal in the United States. At first they convinced fellow unionists to personally boycott the grapes, and then, 'Anecdotal knowledge of their success came from the front lines, where longshoremen, Teamsters, or restaurant and bar workers agreed not to convey grapes and wine to suppliers and customers' (Garcia 2012:44-45). By expanding the scope of the dispute, the farm workers combined middle-class consumer concerns with workingclass worker concerns over conditions on the job site. Accordingly, the farm workers' call to boycott grapes rooted its appeal in consumer actions having a moral dimension:

Prior to the farm worker movement, most unions had used the boycott to create class solidarity by asking fellow laborers not to purchase a particular product linked to the unfair treatment of workers. Chavez, however, transformed his campaign into a social movement akin to that of the abolitionists who appealed to northern consumers not to buy southern-made textiles as a protest against slavery, or that of the Montgomery bus boycotters who asked blacks and white allies not to use public transportation until the segregation of buses ended.

(Garcia 2012: 6)

In contrast, in Monkeys Go Home! Hank solves every problem he faces with a consumerist, market-driven approach. When his fiancée Maria asks him, 'Work! Money and work! Is that all you think about?', Hank does nothing to disprove this accusation when he offers all his neighbours the chimps' free labour to outsmart the olive millers' cartel. Thus the echoes of the Delano strike's calls for public boycotts on behalf of justice are turned to calls for public cooperation to increase profits.

Disney and Walt Disney have an interesting history when it comes to unionization and worker treatment. Critics like Judith Halberstam can credibly argue that animated children's films are some of the most communist/collectivist of Hollywood narratives, but the same argument cannot be made of Disney live-action films like Monkeys Go Home! (Halberstam, 2011). Eric Smoodin notes that during the Depression,

a number of Disney cartoons, which were clearly designed for an audience made up of as many adults as children, clearly took pro-working-class or pro-labor stances (despite Disney's own opposition to the period's growing labor movement in Hollywood).

(1994: 17) 
Like any good capitalist, Walt bracketed his personal opposition to unions when there was an extra dollar to make. But when unionization had the potential to increase the operating costs of his company, Walt was much less sanguine. In a 1940 account of Walt's relationship with his cartoonists, Paul Hollister describes the lead-up to a union vote, explaining that Walt's 'scoldings' of workers were 'loud and clear', but later he would be apologetic and tell them: 'I was just excited. When I am excited, I get loud. Getting loud when I am excited is just my nature. I can't help it. The cartoonists accepted his outbursts because they 'never found Walt's judgment lacking', continuing, 'we wouldn't be foolish not to use it all we can?' The running joke was, 'The only employee that's against Walt is the electric elevator'. Hollister reports that 'the staff voted not to unionize' at this point, but then revisited the issue (1994: 39).

Additional pressures - including moving to a new studio lot, still in use, in Burbank provoked a bitter strike in 1941. Walt Disney felt he was giving his one thousand employees an opportunity not available elsewhere in Hollywood; they felt they were not being given full credit, either in terms of publicity or money [...]. The American Federation of Labor had made Disney a target of a unionization drive, as the lone Hollywood studio without union coverage. The result of that 1941 strike, settled after several bitter months, named the Screen Cartoonists Guild as the official negotiator for studio employees. Bambi was delayed by three months; the studio shut down completely for a time; union activists quit.

(Gomery 1994: 74)

Smoodin notes the old Disney organization had a history of firing independentminded employees. Things got so bad that a group of employees went on strike against the Disney studio in 1941' (Smoodin 1994: 6). Later, Walt joined a group of Hollywood producers, actors, and writers to found the anticommunist Motion Picture Alliance for the Preservation of American Ideals in February 1944. In October 1947, during the Red Scare witch-hunt era, Disney was a 'friendly' witness for the House Un-American Activities Committee. In light of Walt's history of strong anti-communism, Monkeys Go Home! goes quite easy on the French communists. But its anti-union stance matches Walt's beliefs. The film transmutes the novel's displacement of decolonial immigration onto African monkeys into a different form of racist xenophobia, equating immigrant farm labourers, workers who have recently and successfully organized themselves and mobilized a wide array of allies, with trained chimpanzees.

Turning Hank Dussard into an American removes the novel's engagement with French colonialism and decolonization and in its place substitutes American imperialism. For a silly comedy, Monkeys Go Home! uses the words 'imperialism' and 'capitalism' quite freely, and not every kids' movie has a villain who looks a little bit like Jean-Paul Sartre. The resistance to Hank's presence in St Piroutsen takes the form of party meetings, faceto-face disagreements, and the graffiti that provides the film with a politically charged 


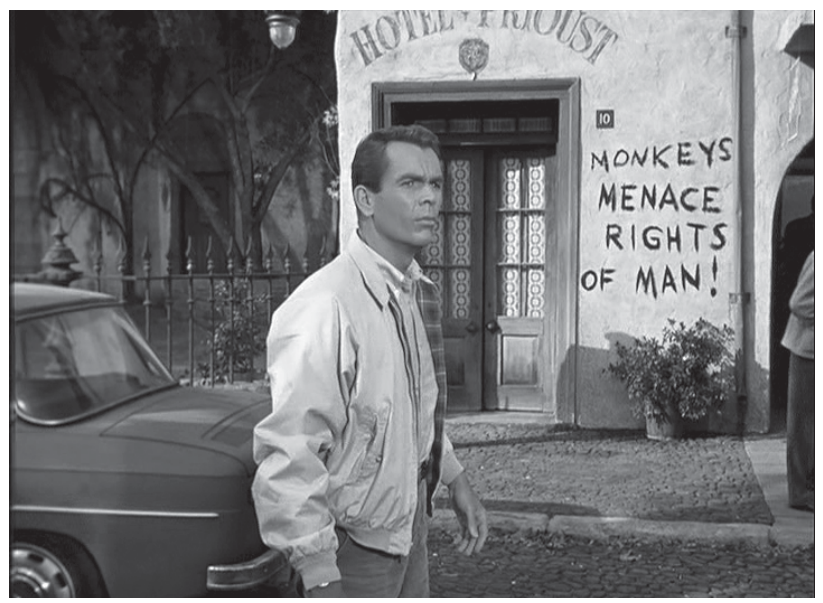

Image 52. Monkeys Go Home! slogan that echoes French revolution.

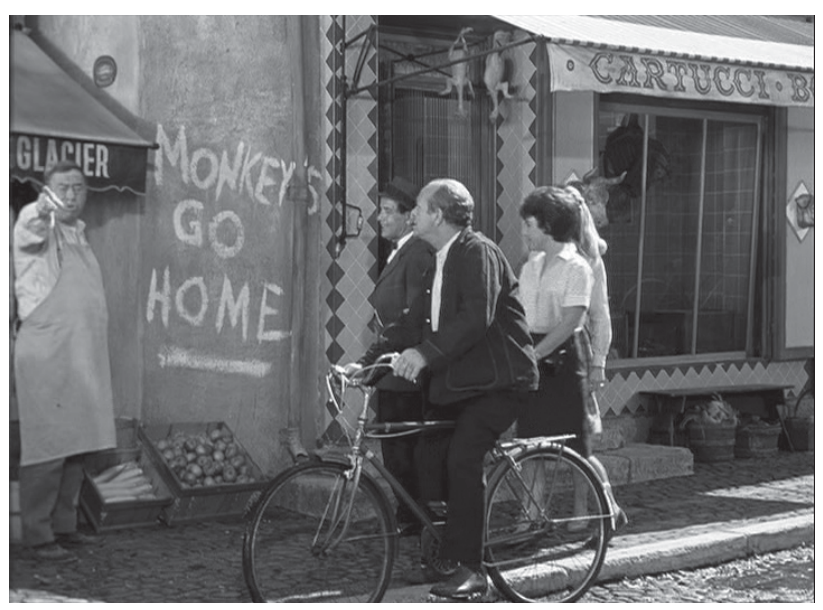

Image 53. Monkeys Go Home! slogan that echoes anti-imperialist call.

title. The film's imagination of political action, at least 'communist' political action, is fairly tame. During a meeting with good attendance but poor participation, Paraulis and Cartucci introduce topics, encounter apathy, make decisions that are neither supported nor opposed, and then repeat the process. Thus, Paraulis can shout out 'Resolved! That we alert the village against the Yankee imperialist by a series of slogans!', Cartucci can reply, 
'I second the motion! All in favour say aye all against say nay!' and respond to the silence with a confident, 'Carried unanimously!' The slogans, 'Monkeys Go Home!' and 'Monkeys Menace the Rights of Man' quickly appear all over town, including on the church. The next morning, as Father Sylvain paints over 'Monkeys Go Home!', he complains to Hank, 'You see what the godless propagandists have done? It's all over town, the same thing. When Hank asks about their motive, Sylvain frames the issue not as one of sincerely held belief, but of boredom. 'They've run out of causes [...]. Without causes they have no need for slogans. Without slogans they fade away and they are forgotten. You and your monkeys came just in time. This infantilizing of political action appears only once in the film, and, curiously, is disproved in favour of a social-justice approach to politics. Hank storms into the butcher shop, where Cartucci greets him with 'hah! The Yankee imperialist!' Then Cartucci, waving his boning knife, explains that the Yankee/Monkeys go home action was, 'The result of public indignity. A spontaneous group action. Naturally I played my part [...]. We are intelligent and resourceful. If there is injustice, we smell it out. To make a communist committed and intelligent - a worthy foe to Hank - with the blacklist in the recent past, makes Monkeys Go Home! fit uncomfortably in the Disney political spectrum. But it still fits, because Cartucci finds himself alone in his beliefs.

Monkeys Go Home! concludes in the traditional Hollywood manner, by turning the larger socio-economic forces in play in southern France into a matter of individuals. With the endorsement of Father Sylvain, the collusion of the mayor, and finally the spontaneous consent of the villagers, Monkeys Go Home! ends with Hank establishing the American way of life in southern France via French film history. This under-the-table church-and-government collaboration makes reference to recent French cinema history, in particular the French-Italian coproduction Le Petit Monde de don Camillo (Duvivier, 1952), one of the most successful early post-war films at the French box office, which more than 60 years later remains in the top-50 all-time French box office successes. ${ }^{27}$

While Cartucci may be staunch, the people of St Piroutsen never find the idea of trained chimps anything more than clever and funny. Out of a combination of self-interest and admiration, they embrace Hank's imperial presence, preferring American ingenuity to their own inefficient model. Unlike the communist mayor Peppone in Le Petit Monde de Don Camillo, the cobbler-mayor Gaston Lou (Marcel Hillaire) is a self-avowed nonpartisan politician. But, very much like Don Camillo, Gaston Lou finds ways to cooperate and collude behind the scenes. When Hank demands that the mayor remove all the antimonkey graffiti, Gaston Lou explains that

[i]f I do that they will accuse me of destroying the freedom of the press. I was elected, you see, by all shades of opinion. And I respect the right of everyone to his own beliefs [...]. But as one who has faith in the democratic processes I believe that every man has a right to express his opinions in the same way as his opponent. Even you monsieur. Must I speak any plainer? 
Hank and Father Sylvain almost dance out of the Mayor's office for all their excitement. They agree to meet at dawn for their surprise counter-assault of pro-monkey (read: proAmerican) graffiti as 'La Marseillaise' plays on the sound track. Whereas Bon Voyage! burlesques the French national anthem, using it as an ironic comment on Madame Clebert, Monkeys Go Home! seems to invoke another famous Hollywood use of the song to score resistance: Casablanca (Curtiz, 1942). In this way Monkeys Go Home! combines Hollywood and French film history to link imperialism and the spirit of resistance to tyranny. The meeting with the mayor links Hank's imperialist actions and noble resistance and his subsequent planning of a counterattack with Father Sylvain links religion and the US imperial project. To solidify this connection, Hank and Sylvain announce the appearance of their pro-monkey graffiti by ringing the church bells at sunrise the next morning. Ringing the bells calls the French of St Piroutsen to Walt's church of American capitalism, in which the church and business work together against communists with the tacit approval of the government. ${ }^{28}$

However, unlike the Don Camillo films, in which Peppone the communist mayor and Camillo the priest share a common interest in the well-being of the town and a history as partisan fighters during the war, the two sides in Monkeys Go Home! have less in common. Hank the alleged vegetarian and Cartucci the butcher disagree politically and have a romantic rivalry; their relationship is entirely antagonistic. The mayor declares himself to be non-partisan. Like Don Camillo never condemns Peppone himself, Father Sylvain is polite to the non-believer Cartucci. But whereas Le Petit Monde de Don Camillo places communism and Catholicism into conflict and conversation, with a priest and a communist finding ways to cooperate for the greater good, Monkeys Go Home! sidesteps any discussion of communist ideology in favour of a discussion of the importance of personal honesty in business dealings. Having learned that Cartucci is not a superficial child about matters of imperialism, Sylvain changes tack, basing his conversion appeal on morality of using a fake cousin to steal Hank's farm:

Sylvain: Did you know that Yolande Angelie, the alleged cousin of Monsieur Dussard has admitted to me that she is an imposter? She has asked me to make public apology to the entire village for conspiring with Monsieur Paraulis to rob Monsieur Dussard of his property.

\section{Cartucci: You lie!}

Sylvain: You dare to call me a liar in front of these witnesses when you are guilty of fraud, theft, and bribery?

Cartucci: That's not true. Paraulis told me that girl had a legitimate claim. I am an honest man. I am not ashamed of what I believe. And I'm not a liar or a thief. 
At this moment, after playing out in wider two shots, the scene finally deploys a close-up, of Father Sylvain, who delivers the killing blow to the anti-American, anti-imperialist position by making Cartucci's political beliefs driven by his credulity. 'Then you're a fool Marcel. A stupid tool for a sly and cunning man. The silent close-up reverse shot of Cartucci accentuates his coming to terms with the facts, writing the connection of honesty and capitalism (and dishonesty and communism) on his shocked face. Whereas Don Camillo and Peppone would argue in public but collude in private, Father Sylvain argues in public with Cartucci and colludes in private with his rival Hank. By shortcircuiting the potential to collaborate with the town's communist, Father Sylvain does not base his actions on what is best for the entire town, but rather bases his actions on what would be best for one individual, Hank. This turn away from community well-being invokes but re-orients one of the more popular films in French film history to fit more neatly in Walt's individualist (and Protestant) politics.

After dispensing with the political conflict underpinning the narrative conflict, Monkeys Go Home! offers a magical, ideological solution to the narrative conflict itself everyone works for Hank for free because he previously proposed to have his chimpanzees work at all the village's farms gratis. Paired with this second-hand neighbourliness is that old standby, the romantic couple. Not only do Hank and Marie pair off, but Marie finds a male chimpanzee mate for the four female chimps. Father Sylvain, unlike Don Camillo, picks a side and overtly collaborates. He helps the American capitalist; for his efforts he is paired off with Paraulis, who finds religion, or at least finds sanctuary from the mob in the church. Anti-imperialism and communism are thus redeemed by the exposure

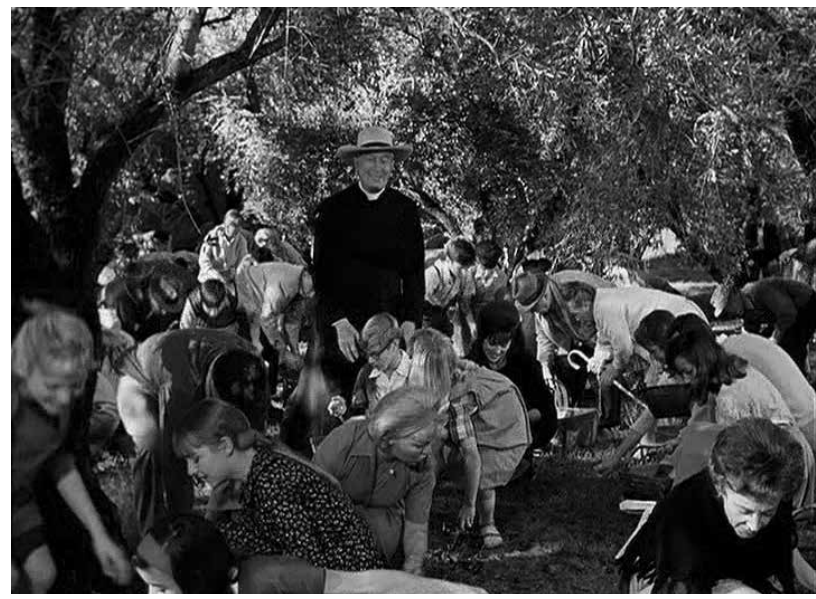

Image 54. Monkeys Go Home! free labour. 
of their faux-intellectual, Paraulis (he looks like Sartre after all). But Cartucci, the sincere communist who looked to have lost the argument about American imperialism, does not find religion, does not take part in the mass pro-American demonstration of volunteerism at the end of the film, and does not disavow his political beliefs. He just goes back, one assumes, to his dog-ravaged butcher shop to pick up the pieces. The logic of the Hollywood/Disney happy ending mistakes Cartucci's quiet departure and lack of romantic partner at the conclusion as being proven wrong, but otherwise Walt's antiunion, anti-communist populism clearly and joyously triumphs in the formerly unAmerican territory of St. Piroutsen, France.

\section{Conclusion}

As In Search of the Castaways circles the globe, each stop represents a somewhat 'real' place, tenuously rooted in reality. The outsized physical differences - earthquake-rattled mountains, flooded pampas, volcano-threatened villages - make concrete the fantastic ideological counterweight to the Disney ideology each stage of the journey offers. Curiously, at no point do the adventurers try to change the non-Anglo cultures they encounter (their double-crossing fellow Englishman/Australian, Thomas Ayerton, is another story). Bon Voyage! similarly represents France as a real place with a specific set of cultural norms, and uses these differences to contrast with the Disney ideology that calls a never-shown (but often invoked) Terre Haute, Indiana home. But like the Grants in In Search of the Castaways, the Willards do not enforce change on France. Rather, they act as something like soft power ambassadors for the American way of life. After trying on the French way of doing things, like good tourists/guests, the Willards clearly distinguish themselves from the French, and prepare to return home as a unified, happy family.

Monkeys Go Home! takes a slightly different approach to its international location, most likely because Hank, unlike the just-visiting Grants and Willards, stays in France. Monkeys Go Home! represents France as a place with its own clear ideology and even film history, to a degree that seems curiously communist-friendly for a Disney film. But this openness to the particularity of St Piroutsen, just like the Māori village, Paris and Riviera, functions as a way to show the power of Disney small-town American ideology. Even a place as geographically and politically distinct as St Piroutsen cannot resist. As the first Disney live-action film released after Walt's death, Monkeys Go Home! more or less completes Disney's cultural imperialist work: France, as a stand-in for the non-American world, gets Americanized. But this Americanization arrives after a serious conflict centred on the popular political will, rendering it democratically earned and validated.

The Americanization of international locations makes the Disney ideology portable. We never see an American small town in Bon Voyage!, In Search of the Castaways, or Monkeys Go Home!. Instead they present visually distinct narrative settings with familiar/ generic popular-narrative elements - savages, sexually forward French women, a perfume 
factory, Mediterranean diet agriculture, and so on - that let Americans and protoAmericans test out the Disney ideology in new locations. Such geographical displacement forces the films' protagonists to encounter places and cultures that register as other before bringing them under the Disney small-town umbrella. It always seems to work. 



\section{Conclusion}

Where Isn't Hollywood Cinema? 

$\mathrm{A}$ t every census, the United States Census Bureau locates the mean centre of the United States population, 'the point at which an imaginary, flat, weightless, and rigid map of the United States would balance if weights of identical value were placed on it so that each weight presented the location of one person on Census Day' (US Department of Commerce 2011: 1). In 1790, Kent County, Maryland was the mean centre. Kent County is on the western, Chesapeake Bay side of the Delmarva Peninsula, which is to say, on the Atlantic Ocean. In 1890, Decatur County, Indiana, about fifty miles east of Indianapolis, was the mean centre. In 1980, the nation's mean centre crossed the Mississippi River, and at the end of the twentieth century, Phelps County, Missouri, about one hundred miles southwest of Saint Louis, represented the centre of the country's population distribution. In terms of land, the expanding United States has had a number of literal geographic centres. The geographic centre of the contiguous lower 48 is in Lebanon, Kansas; including Alaska and Hawaii, the geographic centre is Belle Fourche, South Dakota.

No top-50 box office hit or prestige picture was set in Phelps County, Missouri in 1980 or at any other point between 1960 and 2000. While the mean centre of population does not appear on screen, the geographic centre of the country does, in the John Wayne film The Cowboys (Riddell, 1972), which topped the box office for two weeks in January 1972. Belle Fourche showing up in The Cowboys is an interesting curiosity, but in truth the most likely outcome for any location in the United States would be not to appear on screen, because the United States is a very large country, in terms of population (growing from 180 million in 1960 to 280 million in 2000), and especially in terms of land mass (3.8 million square miles or so, depending on how you count shorelines). The 1959 statehood of Alaska and Hawaii increased the total area the United States covers to about 3.8 million square miles. But most of the population lives in urbanized areas that take up about 3 per cent of that land. That is, an area comparable to the size of Arizona, 114,000 square miles, is urbanized to some degree, the sort of place in which people are most likely to live. The rest is rural open space, and more than 40 per cent of the land in the United States has no humans living on it (McCormack 2014: para. 6).

Even the parts of the United States where people do live are much more likely not to appear on screen. As I noted in Chapter 5, even among the 100 largest cities in the United States, a number do not appear in top- 50 box office hits or on major prestige lists. Adding up the populations of Hollywood-invisible Akron, Ohio; Dayton, Ohio; Aurora, 
Colorado; Anchorage, Alaska; Colorado Springs, Colorado; Charlotte, North Carolina; Raleigh, North Carolina; Spokane, Washington; Chattanooga, Tennessee; Knoxville, Tennessee and Tacoma, Washington creates an imaginary combined urban region of between 2 (1980 census) and 2.8 million people (2000 census), about the same as the city of Chicago in 2000. Thanks to the size of Anchorage, this imaginary region would cover an area similar to that of a combined Delaware, Rhode Island and Washington DC: 3250 square miles. And this imaginary invisible urban region does not include other small cities - some of which are capital cities - such as Sacramento, California; Erie, Pennsylvania; Boise, Idaho; Wheeling, West Virginia; Asheville, North Carolina and the Quad Cities in Illinois and Iowa that do not appear on screen. The non-presence of Akron and Dayton hints at the relative under-representation of Ohio, even though it is one of the ten largest states by population. While the more urban mitten of Michigan appears both in hits and prestige pictures, the Upper Peninsula has not appeared in a movie since Anatomy of a Murder (Preminger, 1959). Outside of a green screen joke in Wayne's World, Delaware does not appear at all between 1960 and 2000.

To look beyond major urbanized areas, small towns appear infrequently as well. Smalltown locations include Fargo's (Coen Brothers, 1996) Brainerd, Minnesota, The Bridges of Madison County's (Eastwood, 1995) Madison County, Iowa, Steel Magnolias' (Ross, 1989) Natchitoches, Louisiana, and the fictional Catskills towns of Scottsville and Auburn, New York in You Can Count on Me (Lonergan, 2000). Some films are set more than 30 miles from an interstate highway, which would put them well outside the orbit of not just a major metropolitan centre but also the connecting threads between major cities. Many of those locations are wide-open, consciously far from cities, as in westerns like A Man Called Horse (Silverstein, 1970), Big Jake (Sherman, 1971), and Jeremiah Johnson (Pollack, 1972), and action movies like Mission: Impossible 2 (Woo, 2000), Con Air (West, 1997), and Broken Arrow (Woo, 1996).

Thus to tell a story about people in a setting they are likely to inhabit limits the possible narrative locations quite drastically, leaving most of the United States out of Hollywood's imaginative geography. In addition, even when a Hollywood film takes place somewhere it also takes place at some time. As I argued about New Hollywood films and Burt Reynolds films, Hollywood films have tended to see the south as the past, and westerns - like the just-noted A Man Called Horse and Jeremiah Johnson - have long associated the West with the past as well, further shrinking the extent of visions of the contemporary United States locations. The five square miles of Monument Valley, representing the past, appear more frequently than the 674 square miles of Phelps County, the mean centre of the United States' population, or most of the places I have lived in the United States: the 8 square miles of Carpentersville, Illinois, the 18.4 square miles of Normal, Illinois, the 25 square miles of Iowa City, Iowa, and the 29 square miles of Dover, New Hampshire (I also lived in Nashville). In other words, it is far easier to answer the question 'where is Hollywood cinema?' than the question 'where isn't Hollywood cinema?', because Hollywood cinema does not imagine the United States as most places. 
Within the political boundaries of the United States, Hollywood box office hits and prestige films imagine a limited number of locations that also have a limited range of identities. The background of New Hollywood road movies across the west, southwest, Great Plains and south keep the nation's natural-resource extraction in the frame, acknowledging the power of oil in their imagination of freedom. But when New Hollywood films enter the contemporary Midwestern city, they confront the problems of de-industrialization and racial strife, problems that belong to a collective, and can be addressed collectively. Movies set in the suburbs tend not to be road movies, but that does not mean that the road and transportation do not factor in their imagination. Hit movies set in car-oriented suburban development represent the suburb-city relationship most clearly as the experience of moving through and between the suburbs and city, not as the escape New Hollywood movies desire, but as everyday motion. In Hollywood movies, the south generally appears as a backward, mostly rural and racially poisonous place either tied to or actually in the past. Burt Reynolds films offer an alternative view, of the growing New South of the 1970s that not only suburbanizes Hollywood's imagination of the south, but also offers a hopeful take on how economic and population growth might undo some of the racial strife in and marginalization of the region. That Reynolds' films had some success in pushing against the received wisdom about southern regional identity marks them as outliers among mass-audience movies. The consistency of regional identity across Hollywood films registers in the critically acclaimed films set in mediumsized cities, which almost uniformly retain the city's signature identity, regardless of its currency. Movies that put forward changes to the identity for a city or a region - to say nothing of the nation - are exceptionally rare in the top-50 box office and prestige lists, registering the power that received, established identities and their cultural legibility have on the imagination of the 'where' of Hollywood's United States.

Reaching beyond the borders of the United States, the ideology that operates in and organizes most Hollywood movies - especially box office hits and mainstream prestige pictures - enlists a variety of locations to its Americanization project. Disney live-action films take an interest in the folkways of non-American places, but in the end treat the entire world as a temporarily embarrassed American small town, regardless of whether it is a major European city like Paris, an agricultural region like rural Provence, or a small kainga in the South Pacific. Mid-to-late 1980s movies that did poorly at the box office but found a larger audience on video seem to offer a view of the negative effects of contemporary politics and policy. This more critical view of the status quo in the Reagan era takes place in less-frequently represented places - the holidaying edge of New York City, Nicaragua, and non-monumental Moscow. The United States locations analysed in depth in this book, taken from the top-25, and next-25, box office hits and year-end prestige lists include California, the south, the industrial Midwest, and the New York metropolitan area, but barely feature many other regions. In other words, Hollywood films that perform the best at the box office and in year-end prestige lists render a great deal of the United States - and the people who live there and their particular ways of life - invisible to their audiences. 


\section{Hollywood's Geography of American Locations and Landscapes}

The relationships between the ideological and physical landscapes create Hollywood's vision of 'America' the place and show how the idea of 'America' connects disparate locations within the United States and around the world. The 'where' of Hollywood movies' locations informs the 'how' of form (as in establishing shots and creative geography) and ideology, and vice versa. Much has been written about the Western and American identity; location and landscape matter a great deal in such arguments. I have argued elsewhere that France's relative cinematic neglect of its least-populated spaces looks strange next to continental-settler nations like the United States and Australia - two countries where westerns play a significant role in the national imaginary (Long, 2015). Locations in their variety make possible the stories that comprise a national or nation-describing cinema. Colin McArthur, writing about global cities in cinema, argues that

many national cultures, where they are not wholly dependent on Hollywood movies for cinematic representations of themselves, are certainly faced with a situation in which Hollywood movies offer the most popular and the dominant representations. With regard to the cinematic representation of geographic space, both urban and non-urban, sense of such space is overwhelmingly derived from Hollywood films. The problem is that, since the point of utterance of such representations is American, they reflect an American perception of the world.

(1997: 33, italics in original)

This is also true of American self-perceptions, of Hollywood's representations of locations inside the United States. Alaska is mountains, tundra, and pine forests. Alaska is not the city of Anchorage and its metro population of greater than 350,000, which is bigger than the Green Bay metro region that, in the US imagination, is Lambeau Field and little else. In the Hollywood imagination, South Dakota is Mount Rushmore (North by Northwest [Hitchcock, 1959]), the Badlands (Badlands) and Lakota lands (Dances With Wolves [Costner, 1990]), not its capital Pierre or its largest city Sioux Falls. In much the same way a landmark represents a city or region in an establishing shot, entire countries can have a visual landscape identity. In 'How countries are made: The cultural construction of European nations', Anne-Marie Thiesse writes that 'National landscapes are typically established through making distinctions' (2003: 31). Landmarks and landscapes make distinctions through repetition. In Thiesse's European examples,

Austria and its Alpine valleys is sharply distinguished from Hungary, which is represented by the Great Plain, depicted by painters as a sort of windswept continental sea and a symbol of fierce liberty. Switzerland, a small land bounded by powerful neighbors, is projected in sparkling peaks and glaciers. The national landscape of Norway is fjords, the snowy vertical cliffs which contrast with the green prairies of 
its ancient owner, Denmark, and with the no less green forests of its later owner, Sweden. A tree typifies other national landscapes: Russian birches, German oaks and Italian cypresses. Like historic monuments, emblematic landscapes were promoted in literature and images, and photography, postcards and posters later popularized them. (2003: 31)

Thiesse's examples give a sense of the variety of landscapes in Europe, and the United States, itself a continent, enjoys a similar diversity, although particular regions predominate in Hollywood's imagination of American national landscapes-plural. In other words, Hollywood represents a limited number of places as emblematic of a larger, 'American' whole. East-to-west expansion played a role in earlier imaginings of the American landscape, with New York enjoying an early advantage. Angela Miller's 'Everywhere and nowhere: The making of the national landscape' argues that mid-nineteenth century landscape painting performed an

essential task: it helped support the exceptionalist myth that the republic was more than the sum of its parts [...]. In these years the national landscape, synthesized out of discrete parts, became a construct capable of answering the call for native themes without becoming mired in local, place-specific associations.

What Miller calls the 'process of cultural consolidation around certain pivotal symbols' (1992:212) pertains not only to New York-centred nineteenth-century landscape painting, but also to popular cinema. As a synthesis of a limited number of parts, Hollywood cinema performs much the same function: the recently-closed western frontier hosts the most American of genres, for example.

The frequency of some locations and the absence of others in Hollywood productions creates what the geographer Barry Lopez calls 'false geographies'. While 'the real American landscape is a face of almost incomprehensible depth and complexity' and 'the land itself, vast and differentiated, defies the notion of a national geography' (Lopez 1989: 19, 20), Hollywood's limited set of landscapes simplifies United States' geography to create a very limited imagination of what America looks like and how its people live. False geographies depend on Romantic preconceptions to reduce the complexity and diversity of the American landscape (even of the city landscape) to attractive scenery or archetypal images. This aestheticization and simplification loses track of the multiple ways in which place is experienced in the United States. Lopez's main concern is not the cinema, but civic education about the incredible and fascinating physical and human geographies of the United States. A sense of place creates a sense of community and vice versa, something the multi-faceted physical and human geographies Rebecca Solnit and her co-authors create in Infinite City: A San Francisco Atlas (2010), Unfathomable City: A New Orleans Atlas (2013), and Nonstop Metropolis: A New York City Atlas (2016) make 
clear. Unfathomable City in particular addresses Lopez's key concern about the wages of geographical ignorance: the less you know about the geography around you, the more likely it is that you will not recognize when something terrible is done to it. As Lopez argues,

The more superficial a society's knowledge of the real dimensions of the land it occupies becomes, the more vulnerable the land is to exploitation, to manipulation for short-term gain. The land, virtually powerless before political and commercial entities, finds itself finally with no defenders. It finds itself bereft of intimates with indispensable, concrete knowledge. (Oddly, or perhaps not so oddly, while American society continues to value local knowledge as a quaint part of its heritage, it continues to cut such people off from any real political power. This is as true for small farmers and illiterate cowboys as it is for American Indians, native Hawaiians, and Eskimos.) (Lopez 1989: 20)

Lopez's connection of physical and human geographic knowledge with political power certainly appears in the limited way in which African American life appears in Hollywood movies. As I argued in the introduction, films with predominantly African American casts tend to be located in the rural south and major cities, not in the Plains or Northwest and certainly not the suburbs, even though the box office hit and prestige film Boyz $N$ the Hood takes place in the suburban form of South Central Los Angeles (as does Killer of Sheep [Burnett, 1978], in Watts). The lack of African American presence in Hollywood films is compounded by the limited number of places Hollywood show African American people living when they do appear on screen, and the same is true for the American Indians, native Hawaiians, and Eskimos' that Lopez cites, to say nothing of the Hispanics and Asian Americans who appear so infrequently on screen.

Perhaps the most powerful connection of manipulation of the land for short-term gain, political powerlessness, and Hollywood invisibility appears in terms of poverty. Coal mining areas overlap to a large degree with what the Census Bureau and United States Department of Agriculture call persistent poverty counties, counties where 20 per cent or more of the population of the county has lived under the poverty level over the last 30 years. The persistent poverty counties - coal mining areas, the Black Belt, the Mexican borderlands, and Indian reservations, by and large - do not appear with much frequency in Hollywood movies, especially as contemporary settings (Map 22).

Clearly, Hollywood's imaginary geography of the United States represents a false geography. All of the empty spaces in the map of Hollywood cinema locations point to how much work ideology must do to make the small number of common locations hold together as a coherent whole. That ideology papers over those empty spaces in Hollywood's films, and writes over the 'indispensable concrete knowledge' (Lopez 1989: 20) of the people who live in those never-seen landscapes. But that does not mean that Hollywood's false geography of the United States is not meaningful or important. Barbara Piatti and 
Lorenz Hurni, the co-directors of the Literary Atlas of Europe project, write that 'at first sight, you realize that one of the major contribution[s] of literary geography is to rend visibility to "overcrowded areas" and "unwritten regions" within the literary metaspace' (2007: 2). Much the same applies in film geography. New York City is an overcrowded area, whereas with the exception of the fictional Eastwick, Rhode Island is a more or less unwritten region. Rhode Island's cinematic identity between 1960 and 2000 comes from local boys the Farrelly Brothers, who use Providence as a starting point for Dumb and Dumber (1994) and There's Something About Mary (1998). But the overcrowding of New York City is much more specific. Manhattan appears with far greater frequency than the other boroughs, especially Staten Island, which tends to appear as a place to escape or overcome. Staten Island plays a key role in the maintenance of Hollywood's imaginary geography of New York City - life on the island is enough to give you a terminal brain cloud (Joe Versus the Volcano [Shanley, 1990]), crass white ethnics can be kept away from polite company (Easy Money (Signorelli, 1983), and striving white ethnics can, with pluck and luck, graduate to Manhattan (Working Girl [Nichols, 1988]) - and shows that the best possible articulation of Hollywood's false geography must be based on where films are in fact set, and not on selectively chosen examples that ignore or pass over the larger trends in narrative settings. Mapping Hollywood's actually existing false geography serves as a first step towards understanding Hollywood's spatial history and towards imagining ways to change and adapt with the country and people that it describes. Fully mapping the false geography Hollywood creates for the United States not only makes clear the contours of the ideology that makes that nation, but also makes clear how much Hollywood's domestic and international audiences are not seeing - as people, built environments, and landscapes - and how much more can find its way into Hollywood's imaginary geography of the United States. 



\section{References}

Abler, R., Adams, J. S. and Gould, P. (1977), Spatial Organization: The Geographer's View of the World, New York: Prentice Hall.

Abrahams, Jim, Zucker, David and Zucker, Jerry (1986), Ruthless People, Hollywood: Touchstone.

Acland, C. (2013), 'Senses of success and the rise of the blockbuster', Film History, 25:2, pp. 11-18.

Adler, Lou (1978), Up in Smoke, Hollywood: Paramount.

Alda, Alan (1981), The Four Seasons, Hollywood: Universal.

Aldrich, Robert (1974), The Longest Yard, Hollywood: Paramount.

Alifragkis, S. and Penz, F. (2015), 'Dziga Vertov's Man With a Movie Camera: Thoughts on the computation of style and narrative structure', Architecture and Culture, 3:1, pp. 33-55.

Allen, R. (2015), Going to the Show, http://docsouth.unc.edu/gtts/. Accessed 29 December 2015.

Allen, Woody (1979), Manhattan, Hollywood: United Artists.

(1983), Zelig, Hollywood: Orion/Warner Bros.

Almodóvar, Pedro (1988), Mujeres al borde de un ataque de nervios/Women on the Verge of a Nervous Breakdown, Barcelona: Laurenfilm.

AlSayyad, N. (2006), Cinematic Modernism: A History of the Modern from Reel to Real, New York: Routledge.

Altman, Robert (1970), Brewster McCloud, Hollywood: MGM.

— (1970), $M^{\star} A^{\star} S^{\star} H$, Hollywood: Twentieth Century Fox.

—_ (1971), McCabe and Mrs Miller, Hollywood: Warner Bros.

—_ (1973), Long Goodbye, Hollywood: United Artists.

—_ (1974), Thieves Like Us, Hollywood: United Artists.

—_ (1975), Nashville, Hollywood: Paramount.

Amiel, Jon (1995), Copycat, Hollywood: Warner Bros.

Anderson, Michael (1956), Around the World in Eighty Days, Hollywood: United Artists. Anderson, P. T. (1997), Boogie Nights, Hollywood: New Line.

_— (1999), Magnolia, Hollywood: New Line. 
Anderson, Thom (2003), Los Angeles Plays Itself, New York: Submarine Entertainment. Anderson, Wes (1998), Rushmore, Hollywood: Touchstone.

Andrew, D. (1995), 'Appraising French images', Wide Angle, 16:3, pp. 53-65.

Annakin, Ken (1965), Battle of the Bulge, Hollywood: Warner Bros.

Annakin, Ken, Marton, Andrew and Wicki, Bernhard (1962), The Longest Day, Hollywood: Twentieth Century Fox.

Anon. (1984), 'Dam's operation set', New York Times, 24 October, p. D10.

Antonioni, Michelangelo (1966), Blow-Up, Hollywood: MGM.

—— (1970), Zabriskie Point, Hollywood: MGM.

Apted, Michael (1980), Coal Miner's Daughter, Hollywood: Universal.

—— (1983), Gorky Park, Hollywood: Orion.

Ardolino Emile (1988), Dirty Dancing, Hollywood: Vestron.

—— (1992), Sister Act, Hollywood: Touchstone.

Armstrong, R. (2003), 'The Last Detail', Senses of Cinema, 26, http://sensesofcinema. com/2003/cteq/last_detail/. Accessed 3 January 2016.

Arsenault, R. (1984), 'The end of a long hot summer: The air conditioner and southern culture', The Journal of Southern History, 50:4, pp. 597-628.

Ashby, Hal (1971), Harold and Maude, Hollywood: Paramount.

_ _ (1973), The Last Detail, Hollywood: Columbia.

(1975), Shampoo, Hollywood: Columbia.

(1978), Coming Home, Hollywood: United Artists.

Attenborough, Richard (1987), Cry Freedom, Hollywood: Universal.

(1992), Chaplin, Hollywood: TriStar.

Auster, A. and Quart, L. (1978), 'The working class goes to Hollywood: "F.I.S.T." and "Blue Collar", Cineaste, 9:1, pp. 4-7.

Austin, B. (1990), 'Home video: The second-run “Theater" of the 1990s', in T. Balio (ed.), Hollywood in the Age of Television, Boston: Unwin Hyman, pp. 319-50.

Avildson, John (1970), Joe, Hollywood: Canon.

__ (1975), WW and the Dixie Dancekings, Hollywood: Twentieth Century Fox. (1976), Rocky, Hollywood: United Artists. (1984), The Karate Kid, Hollywood: Columbia.

Badham, John (1977), Saturday Night Fever, Hollywood: Paramount. (1983), WarGames, Hollywood: United Artists.

Baer, Max (1976), Ode to Billy Joe, Hollywood: Warner Bros.

Baird, Stuart (1996), Executive Decision, Hollywood: Warner Bros.

Banet Jr., A. C. (1991), Oil and Gas Development on Alaska's North Slope: Past Results and Future Prospects, Anchorage: US Department of the Interior Bureau of Land Management.

Barron, Steve (1990), Teenage Mutant Ninja Turtles, Hollywood: New Line.

Barron, Zelda (1989), Shag: The Movie, Beverly Hills: MGM.

Barton, Charles (1959), The Shaggy Dog, Burbank: Walt Disney. 
(1960), Toby Tyler, Hollywood: Walt Disney.

Bay, Michael (1998), Armageddon, Hollywood: Touchstone.

Beatty, Warren (1981), Reds, Hollywood: Paramount.

—— (1990), Dick Tracy, Hollywood: Touchstone.

Beatty, Warren and Henry, Buck (1978), Heaven Can Wait, Hollywood: Paramount.

Benjamin, Richard (1984), City Heat, Hollywood: Warner Bros.

—— (1988), My Stepmother is an Alien, Hollywood: Columbia.

Benson, George (1960), Communism on the Map, Harding College National Education

Program: Searcy.

Benton, Robert (1979), Kramer vs. Kramer, Hollywood: Columbia.

Beresford, Bruce (1989), Driving Miss Daisy, Hollywood: Warner Bros.

Bergman, Andrew (1996), Striptease, Hollywood: Columbia.

Berliner, T. (2010), Hollywood Incoherent: Narration in Seventies Cinema, Austin: University of Texas Press.

Berman, Ted, Rich, Richard and Stevens, Art (1981), The Fox and the Hound, Hollywood:

Walt Disney.

Berry, John (1974), Claudine, Hollywood: Twentieth Century Fox.

Billig, M. (1995), Banal Nationalism, London: Sage.

Biskind, P. (2007), Easy Riders and Raging Bulls: How the Sex 'N' Drugs 'N' Rock 'N' Roll Generation Saved Hollywood, London: Bloomsbury.

Blake, R. (1996), 'Redeemed in blood: The sacramental universe of Martin Scorsese', Journal of Popular Film and Television, 24:1, pp. 2-9.

Bloodworth-Thomason, Linda (1990-1994), Evening Shade, Hollywood: Columbia Broadcasting System.

Bluth, Don and Goldman, Gary (1994), Thumbelina, Burbank: Warner Bros.

Bluth, Don, Goldman, Gary and Kuenster, Dan (1989), All Dogs Go to Heaven, Hollywood: MGM/United Artists.

Bogdanovich, Peter (1968), Targets, Hollywood: Paramount.

—_ (1971), The Last Picture Show, Hollywood: Columbia.

—_ (1972), What's Up Doc?, Hollywood: Warner Bros. (1973), Paper Moon, Hollywood: Paramount.

Boorman, John (1967), Point Blank, Hollywood: MGM.

—— (1972), Deliverance, Hollywood: Warner Bros.

—_ (1985), The Emerald Forest, Hollywood: Embassy.

—_ (1985), Money Into Light: A Diary, London: Faber \& Faber.

—_ (2003), Adventures of a Suburban Boy, London: Faber \& Faber.

Borchert, J. (1967), 'American metropolitan evolution', Geographical Review, 57:3, pp. 301-32.

Bordwell, D. and Thompson, K. (2010), Film Art: An Introduction, 9th ed., New York: McGraw Hill.

Box Office Mojo (2015), '1983 Domestic grosses', http://www.boxofficemojo.com/yearly/ chart/?yr=1983\&p=.htm. Accessed 29 December 2015. 
Brands, H. (2010), Latin America's Cold War, Cambridge: Harvard University Press.

Brecher, J., Walcott, J., Martin, D. and Nissen, B. (1982), 'A secret war for Nicaragua', in P. Rosset and J. Vandermeer (eds), The Nicaragua Reader: Documents of a Revolution Under Fire, New York: Grove Press, pp. 208-15.

Brennan, J. (1997), 'Reynolds resurfaces', Los Angeles Times, 17 February, http://articles. latimes.com/1997-02-17/entertainment/ca-29636_1_kevin-reynolds. Accessed 27 September 2015.

Brest, Martin (1984), Beverly Hills Cop, Hollywood: Paramount.

—_ (1998), Meet Joe Black, Hollywood: Universal.

Brickman, Paul (1983), Risky Business, Hollywood: Warner Bros.

Brode, D. (2004), From Walt to Woodstock: How Disney Created the Counterculture, Austin: University of Texas Press.

Brooks, Albert (1985), Lost in America, Hollywood: Geffen.

Brooks, James L. (1983), Terms of Endearment, Hollywood: Paramount.

—_ — (1987), Broadcast News, Century City: Twentieth Century Fox.

Brooks, James L. and Burns, Allan (1970-77), Mary Tyler Moore, New York: Columbia Broadcasting System.

Brooks, Mel (1981), History of the World Part I, Century City: Twentieth Century Fox.

Brooks, Richard (1967), In Cold Blood, Los Angeles: Columbia.

(1977), Looking for Mr Goodbar, Hollywood: Paramount.

Butler, David (1935), The Littlest Rebel, Century City: Twentieth Century Fox.

Butler, Robert (1969), The Computer Wore Tennis Shoes, Burbank: Walt Disney.

Burnett, Charles (1978), Killer of Sheep, Los Angeles: Charles Burnett.

Burton, Tim (1988), Beetlejuice, Burbank: Warner Bros.

—_ (1989), Batman, Burbank: Warner Bros.

(1990), Edward Scissorhands, Century City: Twentieth Century Fox. (1992), Batman Returns, Burbank: Warner Bros.

Butler, David (1935), The Little Colonel, Century City: Twentieth Century Fox. Cameron, James (1991), Terminator 2: Judgment Day, Hollywood: TriStar.

_— (1994), True Lies, Century City: Twentieth Century Fox.

—_ (1997), Titanic, Hollywood: Paramount/Twentieth Century Fox.

Camp, Joe (1974), Benji, Biloxi: Mulberry Square.

Canby, V. (1969), 'Medium cool', New York Times, August 28, http://www.nytimes.com/ movie/review?res=9F05E4DF1031EE3BBC4051DFBE668382679EDE. Accessed 1 January 2016.

Capra, Frank (1942-45), Why We Fight, Washington DC: United States Army.

Caquard, S. (2011), 'Cartography I: Mapping narrative cartography', Progress in Human Geography, http://phg.sagepub.com/content/early/2011/11/06/0309132511423796. Accessed 3 January 2016.

—_ (2016), Mapping Cinematographic Territories, https://atlascineproject.wordpress. com/. Accessed 20 December 2016. 
Cardiff, Jack (1964), The Long Ships, Los Angeles: Columbia.

Cardullo, B. (2010), 'Through the looking glass: The American art cinema in an age of social change', The Midwest Quarterly, 52:1, pp. 86-101.

Caro, R. (1975), The Power Broker: Robert Moses and the Fall of New York, New York: Vintage.

Carpenter, John (1980), The Fog, Hollywood: AVCO Embassy.

Casper, D. (2011), Hollywood Film 1963-1976: Years of Revolution and Reaction, Hoboken: John Wiley \& Sons.

Castle, Nick (1984), Last Starfighter, Universal City: Universal/Lorimar. (1993), Dennis the Menace, Burbank: Warner Bros.

Cavell, S. (1990), Pursuits of Happiness: The Hollywood Comedy of Remarriage, Cambridge: Cambridge University Press.

Chaffey, Don (1961), Greyfriar's Bobby, Burbank: Walt Disney.

Chandler, J. (2004), 'Critical disciplinarity', Critical Inquiry, 30:2, pp. 355-60.

Chandrasekhar, Jay (2005), The Dukes of Hazzard, Burbank: Warner Bros.

Chase, J. (2000), Glitter Stucco \& Dumpster Diving: Reflections on Building Production in the Vernacular City, London: Verso.

Cimino, Michael (1978), The Deer Hunter, Universal City: Universal/EMI.

- _ (1980), Heaven's Gate, Beverly Hills: United Artists.

Clark, Bob (1981), Porky's, Century City: Twentieth Century Fox.

Clavell, James (1967), To Sir, With Love, Los Angeles: Columbia.

Clayton, Jack (1974), The Great Gatsby, Hollywood: Paramount.

Clemens, Ron and Musker, John (1992), Aladdin, Burbank: Walt Disney.

Cobb, J. (1993), The Selling of the South: The Southern Crusade for Industrial Development, 1946-1990, Urbana: University of Illinois Press.

Cockburn, Alexander (1988), Corruptions of Empire: Life Studies \& the Reagan Era, London: Verso.

Coen Brothers (1987), Raising Arizona, Century City: Twentieth Century Fox.

- — (1996), Fargo, Hollywood: Gramercy.

_— (1998), The Big Lebowski, Hollywood: Gramercy.

Cokliss, Harley (1987), Malone, Los Angeles: Orion.

Columbus, Chris (1990), Home Alone, Century City: Twentieth Century Fox.

__ _ (1992), Home Alone II: Lost in New York, Hollywood: Twentieth Century Fox.

Conley, T. (2007), Cartographic Cinema, Minneapolis: University of Minnesota Press.

Cook, D. (1996), A History of Narrative Film, 3rd ed., New York: Norton.

_ _ (2000), Lost Illusions: American Cinema in the Shadow of Watergate and Vietnam, 1970-1979, Berkeley: University of California Press.

Coppola, Francis Ford (1972), The Godfather, Hollywood: Paramount.

__ (1974), The Godfather Part II, Hollywood: Paramount.

(1979), Apocalypse Now, Beverly Hills: United Artists/Zoetrope.

(1983), The Outsiders, Burbank: Warner Bros/Zoetrope. 
(1986), Peggy Sue Got Married, Hollywood: TriStar.

Corman, Roger (1966), Wild Angels, Hollywood: American International Pictures.

Corrigan, T. (1991), A Cinema Without Walls: Movies and Culture After Vietnam, London: Routledge.

Costa-Gavras (1969), Z, Hollywood: Cinema V.

__ (1982), Missing, Universal City: Universal.

Costner, Kevin (1990), Dances With Wolves, Los Angeles: Orion.

Cowie, P. (2004), Revolution! The Explosion of World Cinema in the Sixties, New York: Faber \& Faber.

Cox, Alex (1987), Walker, Universal City: Universal/Walker Films Limited.

Cox, K. (2011), Dreaming of Dixie: How the South Was Created in American Popular Culture, Chapel Hill: The University of North Carolina Press.

Crofts, S. (2002), 'Reconceptualizing national cinema/s', in A. Williams (ed.), Film and Nationalism, New Brunswick: Rutgers University Press, pp. 25-51.

Cronon, W. (1991), Nature's Metropolis: Chicago and the Great West, New York: Norton. Crowe, Cameron (1996), Jerry Maguire, Hollywood: TriStar.

Crowe, Christopher (1989-90), B.L. Stryker, Universal City: Universal Television/ American Broadcasting Company.

Cucco, M. (2009), 'The promise is great: The blockbuster and the Hollywood economy', Media Culture Society, 31, pp. 215-30.

Cunningham, S. (1983), 'Australian film history and historiography', Australian Journal of Cultural Studies, 1:1, http://wwwmcc.murdoch.edu.au/readingroom/serial/ AJCS/1.1/Cunningham.html. Accessed 19 February 2017.

Curtiz, Michael (1942), Casablanca, Burbank: Warner Bros.

__ (1954), White Christmas, Hollywood: Paramount.

Damiano, Gerard (1971), Deep Throat, Miami: Gerard Damiano Film Productions.

Dante, Joe (1984), Gremlins, Burbank: Warner Bros.

Darabont, Frank (1994), The Shawshank Redemption, Los Angeles: Columbia.

__ (1999), The Green Mile, Burbank: Warner Bros.

Davis, Andrew (1993), Fugitive, Burbank: Warner Bros.

Dear, William (1987), Harry and the Hendersons, Universal City: Universal.

DeMille, Cecil B. (1956), The Ten Commandments, Hollywood: Paramount.

Demme, Jonathan (1980), Melvin and Howard, Universal City: Universal.

Demme, Ted (1994), The Ref, Burbank: Touchstone.

DePalma, Brian (1987), The Untouchables, Hollywood: Paramount.

—_ (1998), Snake Eyes, Hollywood: Paramount.

Derek, John (1981), Tarzan the Ape Man, Beverly Hills: MGM.

DeVito, Danny (1992), Hoffa, Century City: Twentieth Century Fox.

Dinnie, K. (2011), 'Introduction to the theory of city branding', in K. Dinnie (ed.), City Branding: Theory and Cases, Basingstoke: Palgrave Macmillan, pp. 3-7.

Dinner, Michael (1985), Heaven Help Us, Hollywood: TriStar. 
Dmytryk, Edward (1957), Raintree County, Beverly Hills: MGM.

Docter, Pete and Peterson, Boob (2009), Up, Emeryville/Burbank: Pixar/Walt Disney.

Doherty, T. (1999), 'Documenting the 1940s', in T. Schatz, History of the American Cinema

6: Boom and Bust: American Cinema in the 1940, Berkeley: University of California Press, pp. 397-421.

Donen, Stanley and Kelly, Gene (1952), Singin' in the Rain, Beverly Hills: MGM.

Donner, Richard (1978), Superman, Burbank: Warner Bros.

—— (1985), Goonies, Burbank: Warner Bros.

- - (1987), Lethal Weapon, Burbank: Warner Bros.

Dorfman, A. and Mattelart, A. (1984), How to Read Donald Duck: Imperialist Ideology in the Disney Comic, Translated by David Kunzle, New York: International General.

Dragoti, Stan (1983), Mr Mom, Century City: Twentieth Century Fox.

Duigan, John (1989), Romero, Burbank: Warner Bros.

Dupré, R. (1999), "If It's Yellow, It Must be Butter": Margarine regulation in North America since 1886, Journal of Economic History, 59:2, pp. 353-71.

Duvivier, Julien (1952), Le Petit Monde de don Camillo, Paris/Rome: Francinex/Rizzoli Amato.

—_ (1953), Le Retour de Don Camillo, Paris/Rome: Francinex/Rizzoli Amato.

Dyer, R. (1986), Heavenly Bodies: Film Stars and Society, London: Macmillan/bfi.

Eastwood, Clint (1983), Sudden Impact, Burbank: Warner Bros.

- — (1986), Heartbreak Ridge, Burbank: Warner Bros.

__ (1992), Unforgiven, Burbank: Warner Bros.

_ — (1995), The Bridges of Madison County, Burbank: Warner Bros.

Eaton, M. (1997), Chinatown, London: bfi Film Classics.

Ebert, R. (1969), 'Medium cool', http://www.rogerebert.com/reviews/medium-cool-1969. Accessed 1 January 2016.

__ (1993a), 'Kalifornia, Rogerebert.com, http://www.rogerebert.com/reviews/ kalifornia-1993. Accessed 14 September 2015.

__ (1993b), 'The 10 best movies of 1993', Rogerebert.com, http://www.rogerebert. com/rogers-journal/the-best-10-movies-of-1993. Accessed 14 September 2015.

Edwards, Blake (1960), High Time, Century City: Twentieth Century Fox.

—— (1979), 10, Los Angeles: Orion/Warner Bros.

Elsaesser, T. (2001), 'The blockbuster: Everything connects, but not everything goes', in J. Lewis (ed.), The End of Cinema as We Know It: American Film in the Nineties, New York: New York University Press, pp. 11-22.

_ _ (2004), 'The pathos of failure: American films in the 1970s: Notes on the unmotivated Hero, in T. Elsaesser, A. Horwath and N. King (eds), The Last Great American Picture Show: New Hollywood Cinema in the 1970s, Amsterdam: Amsterdam University Press, pp. 279-92.

__ (2005), European Cinema: Face to Face with Hollywood, Amsterdam: Amsterdam University Press. 
Faiman, Peter (1986), Crocodile Dundee, Hollywood: Paramount.

Fantel, H. (1985), 'Those big-screen TV's are growing in popularity', New York Times, 24 March, http://www.nytimes.com/1985/03/24/arts/those-big-screen-tv-s-aregrowing-in-popularity.html. Accessed 27 September 2015.

Farber, M. (1971), 'White Elephant Art vs. Termite Art', Negative Space: Manny Farber on the Movies, London: Studio Vista, pp. 134-44.

Farber, S. (1969-70), 'End of the road?' Film Quarterly, 23:2, pp. 3-16.

Fargo, James (1976), The Enforcer, Burbank: Warner Bros.

Farrelly Brothers (1994), Dumb and Dumber, Hollywood: New Line.

—_ (1998), There's Something About Mary, Hollywood: Twentieth Century Fox.

Feil, K. (2009), 'Sex, comedy and controversy: Kiss Me Stupid, What's New, Pussycat?,

New Hollywood, and metropolitan taste', Mediascape, http://www.tft.ucla.edu/ mediascape/Fall09_1960sSexComedy.html. Accessed 10 January 2016.

Ferguson, Norman (1940), Fantasia, Burbank: Walt Disney.

Ferguson, Norman, Geronimi, Clyde, Kinney, Jack, Roberts, Bill and Young, Harold (1945), Three Caballeros, Burbank: Walt Disney.

Figgis, Mike (1995), Leaving Las Vegas, Beverly Hills: MGM/UA.

Fitzpatrick, E. (1998), 'Repackaged and re-released: Catalog titles generate the lion's share of suppliers' revenue', Billboard, 110:2, 10 January, p. 62.

Fleischer, Richard (1967), Doctor Dolittle, Century City: Twentieth Century Fox. - (1973), Soylent Green, Beverly Hills: MGM.

Fleming, Victor (1939), Gone With the Wind, Beverly Hills: MGM.

- _ (1939), The Wizard of $\mathrm{Oz}$, Beverly Hills: MGM.

Ford, John (1956), The Searchers, Burbank: Warner Bros.

__ (1963), How the West Was Won, Beverly Hills: MGM.

Forman, Milos (1981), Ragtime, Hollywood: Paramount.

_- (1996), The People vs Larry Flynt, Los Angeles: Columbia.

Fosse, Bob (1972), Cabaret, Hollywood: Allied Artists.

—_ (1974), Lenny, Beverly Hills: United Artists.

_— (1979), All That Jazz, Los Angeles: Columbia/Twentieth Century Fox.

Frankel, David (2006), The Devil Wears Prada, Century City: Twentieth Century Fox.

Frankenheimer, John (1967), Grand Prix, Beverly Hills: MGM.

Franklin, Carl (1992), One False Move, Los Angeles: IRS Media.

Frawley, James (1979), The Muppet Movie, Hollywood: Henson Associates.

Friedkin, Wiliam (1971), The French Connection, Hollywood: Twentieth Century Fox.

—— (1973), The Exorcist, Burbank: Warner Bros.

(1977), Sorcerer, Hollywood: Paramount/Universal.

(1980), Cruising, Beverly Hills: United Artists.

Friedman, L. (2006), Citizen Spielberg, Urbana: University of Illinois Press.

Fujita, M., Krugman, P. and Venables, A. (1999), The Spatial Economy: Cities, Regions, and International Trade, Cambridge: MIT Press. 
Furie, Sidney (1972), Lady Sings the Blues, Hollywood: Paramount.

Gandy, M. (2003), 'Allergy and Allegory in Todd Haynes' [Safe]', in M. Shiel and T. Fitmaurice (eds), Screening the City, London: Verso, pp. 239-61.

Ganz, Lowell, Marshall, Garry and Rothman, Mark (1976-83), Laverne and Shirley, Hollywood: Paramount Television.

Garcia, M. (2012), From the Jaws of Victory: The Triumph and Tragedy of Cesar Chavez and the Farm Worker Movement, Berkeley: University of California Press.

Geronimi, Clyde (1959), Sleeping Beauty, Burbank: Walt Disney.

Geronimi, Clyde, Jackson, Wilfred and Luske, Hamilton (1950), Cinderella, Burbank: Walt Disney.

—_ (1951), Alice in Wonderland, Burbank: Walt Disney. (1953), Peter Pan, Burbank: Walt Disney. (1955), Lady and the Tramp, Burbank: Walt Disney.

Geronimi, Clyde, Luske, Hamilton and Reitherman, Wolfgang (1961), 101 Dalmatians, Burbank: Walt Disney.

Gibson, Brian (1993), What's Love Got to Do With It, Burbank: Touchstone.

Gilbert, Lewis (1966), Alfie, London/Hollywood: Lewis Gilbert/Paramount. (1979), Moonraker, Beverly Hills: United Artists.

Gilby, R. (2003), It Don't Worry Me: Nashville, Jaws, Star Wars and Beyond, London: Faber \& Faber.

Giroux, H. (2001), The Mouse That Roared: Disney and the End of Innocence, Lanham: Rowman \& Littlefield.

Godard, Jean-Luc (1967), Weekend, Paris/New York: Lira, Cinecidi/Grove Press.

Goldstein, S. (1998), 'The year in video: Sell-through catches up to rental, and anything goes', Billboard, 110:2, 10 January, p. 56.

Gomery, D. (1994), 'Disney's business history: A reinterpretation', in E. Smoodin (ed.), Disney Discourse: Producing the Magic Kingdom, New York: Routledge, pp. 71-86.

_ _ (1998), 'Hollywood corporate business practice and periodizing contemporary film history', in S. Neale and M. Smith (eds), Contemporary Hollywood Cinema, London: Routledge, pp. 47-57.

Gordon, A. (2007), Empire of Dreams: The Science Fiction and Fantasy Films of Steven Spielberg, New York: Rowman \& Littlefield.

Gould, P. and White, R. (1986), Mental Maps, 2nd ed., Boston: Allyn \& Unwin.

Graeber, D. (2015), Utopia of Rules: On Technology, Stupidity, and the Secret Joys of Bureaucracy, Brooklyn: Melville House.

Grant, B. K. (ed.) (2008), American Cinema of the 1960s Themes and Variations, New Brunswick: Rutgers University Press.

—_ _ . (1998), 'Rich and Strange: The Yuppie Horror Film', in S. Neale and M. Smith (ed.), Contemporary Hollywood Cinema, New York: Routledge, pp. 280-93.

Griffith, D. W. (1915), The Birth of a Nation, Hollywood: David W. Griffith Corporation. (1916), Intolerance, Hollywood: Triangle. 
Guillermin, John (1974), Towering Inferno, Hollywood: Twentieth Century Fox/Warner Bros.

——_ (1976), King Kong, Hollywood: Dino Di Laurentiis/Paramount.

Hackford, Taylor (1982), An Officer and a Gentleman, Hollywood: Paramount.

(1997), The Devil's Advocate, Burbank: Warner Bros.

Halberstam, J. (2011), The Queer Art of Failure, Durham: Duke University Press.

Hamilton, Guy (1964), Goldfinger, Beverly Hills: United Artists.

__ (1973), Live and Let Die, Beverly Hills: United Artists.

Hand David (1939), Snow White and the Seven Dwarfs, Burbank: Walt Disney. (1942), Bambi, Burbank: Walt Disney.

Hanson, Curtis (1992), The Hand that Rocks the Cradle, Burbank: Buena Vista.

—_ (2000), Wonder Boys, Hollywood: Paramount.

Hardwicke, Catherine (2008), Twilight, Hollywood: Summit Entertainment.

Harley, J. B. (1987), 'The map and the development of the history of cartography', in J. B. Harley and D. Wood (eds), The History of Cartography: Volume 1. Cartography in Prehistoric, Ancient, and Medieval Europe and the Mediterranean, Chicago: University of Chicago Press, pp. 1-42.

Harlin, Renny (1990), Die Hard 2, Century City: Twentieth Century Fox.

Harris, James (1965), The Bedford Incident, Los Angeles: Columbia.

Harvey, Anthony (1968), The Lion in Winter, Hollywood: AVCO/Embassy.

Haskell, M. (1987), From Reverence to Rape: The Treatment of Women in the Movies, 2nd ed., Chicago: University of Chicago Press.

Hathaway, Henry (1965), Sons of Katie Elder, Hollywood: Paramount.

Hayward, Steven (2005), French National Cinema, 2nd ed., London: Routledge.

_ _ (2009), The Age of Reagan: The Fall of the Old Liberal Order 1964-1980, New York: Crown.

Heckerling, Amy (1989), Look Who's Talking, Hollywood: TriStar.

Hellman, Monte (1966), The Shooting, Hollywood: Continental.

_- (1971), Two-Lane Blacktop, Universal City: Universal.

Henson, Brian (1992), The Muppet Christmas Carol, Burbank: Walt Disney.

Higgins, Colin (1982), The Best Little Whorehouse in Texas, Universal City: Universal.

Higson, A. (2002), 'The concept of national cinema', in A. Williams (ed.), Film and Nationalism, New Brunswick: Rutgers University Press, pp. 52-67.

Hill, George R. (1969), Butch Cassidy and the Sundance Kid, Hollywood: Twentieth Century Fox.

—_ (1973), The Sting, Universal City: Universal.

Hill, Walter (1982), 48 HRS., Hollywood: Paramount.

Hiller, Arthur (1963), Miracle of the White Stallions, Burbank: Walt Disney.

(1970), Love Story, Hollywood: Paramount.

(1979), The In-Laws, Burbank: Warner Bros.

(1984), Teachers, Beverly Hills: United Artists. 
- (1992), The Babe, Universal City: Universal.

Hitchcock, Alfred (1954), Rear Window, Hollywood: Paramount.

(1958), Vertigo, Hollywood: Paramount.

(1959), North by Northwest, Beverly Hills: MGM.

(1960), Psycho, Hollywood: Paramount.

Hoerr, J. (1988), And the Wolf Finally Came: The Decline of the American Steel Industry,

Pittsburgh: University of Pittsburgh Press.

Hogben, G. (1997), 'Introduction', in Cinema \& Architecture: Méliès, Mallat-Stevens, Multimedia, London: bfi, pp. 50-51.

Holland, Angieszka (1993), The Secret Garden, Burbank: Warner Bros.

Hollister, P. (1994), 'Genius at work: Walt Disney', in E. Smoodin (ed.), Disney Discourse: Producing the Magic Kingdom, New York: Routledge, pp. 23-41.

Holman, C. H. (1979), 'The southern provincial in metropolis', in L. D. Rubin (ed.), The American South: Portrait of a Culture, Washington, DC: United States Information Agency, pp. 260-72.

Hooper, Tobe (1982), Poltergeist, Beverly Hills: MGM.

Hopey, D. (1985), 'Service center: Pittsburgh's image belies workforce', Pittsburgh Press,

3 October, p. B5, https://www.newspapers.com/newspage/146390894/. Accessed 19 February 2017.

Hopper, Dennis (1969), Easy Rider, Los Angeles: Columbia.

Horwath, A. (2004), 'The impure cinema: New Hollywood 1967-1976', in T. Elsaesser, A. Horwath and N. King (eds), The Last Great American Picture Show: New Hollywood Cinema in the 1970s, Amsterdam: Amsterdam University Press, pp. 9-18.

Hospers, G-J. (2011), 'City branding and the tourist gaze', in K. Dinnie (ed.), City Branding: Theory and Cases, Basingstoke: Palgrave-Macmillan, pp. 27-35.

Howard, A. (2015), 'Nashville's greatest hits: Best things to do in music city', Lonely Planet, http://www.lonelyplanet.com/usa/travel-tips-and-articles/nashvilles-greatest-hitsbest-things-to-do-in-music-city. Accessed 1 January 2016.

Howard, Ron (1984), Splash, Burbank: Touchstone.

—— (1985), Cocoon, Century City: Twentieth Century Fox. (1989), Parenthood, Universal City: Universal.

Hughes Brothers (1993), Menace II Society, Hollywood: New Line.

Hughes, John (1984a), Sixteen Candles, Universal City: Universal.

—_ (1984b), The Breakfast Club, Universal City: Universal. (1986), Ferris Bueller's Day Off, Hollywood: Paramount. (1987), Planes Trains \& Automobiles, Hollywood: Paramount.

Hughes, Ken (1968), Chitty Chitty Bang Bang, Beverly Hills: United Artists.

Humphries, R. (2002), The American Horror Film: An Introduction, Edinburgh: Edinburgh University Press.

Hutner, G. (2009), What America Read: Taste, Class, and the Novel 1920-1960, Chapel Hill: University of North Carolina Press. 
Hyams, Peter (1988), The Presidio, Hollywood: Paramount.

Index Mundi (2015), 'United States olive oil domestic consumption by year', http://www.indexmundi.com/agriculture/? country=us\&commodity $=$ oliveoil\&graph=domestic-consumption. Accessed 25 January 2016.

Insch, A. (2011), 'Branding the city as an attractive place to live', in K. Dinnie (ed.), City Branding: Theory and Cases, Basingstoke: Palgrave Macmillan, pp. 8-14.

Jackson, Mick (1992), The Bodyguard, Burbank: Warner Bros.

Jackson, Peter (2001-03, 2012-14), The Lord of the Rings, Hollywood: New Line.

Jackson, Wilfred and Foster, Harve (1946), Song of the South, Hollywood: Walt Disney.

Jackson, Wilfred, Kinney, Jack, Luske, Ham and Roberts, Bill (1943), Saludos Amigos,

Burbank: Walt Disney.

Jaffe, Roland (1986), The Mission, Burbank: Warner Bros.

Jameson, F. (1979), 'Reification and utopia in mass culture', Social Text, 1, pp. 130-48.

Jameson, Jerry (1977), Airport '77, Universal City: Universal.

Jeffords, S. (1994), Hard Bodies: Hollywood Masculinity in the Reagan Era, New Brunswick:

Rutgers University Press.

Jewison, Norman (1967), In the Heat of the Night, Beverly Hills: United Artists. (1978), F.I.S.T., Beverly Hills: United Artists.

(1979), Norma Rae, Century City: Twentieth Century Fox.

(1984), A Soldier's Story, Los Angeles: Columbia.

(1999), The Hurricane, Universal City: Universal.

Johnson, H. (2003), Sleepwalking Through History: America in the Reagan Years, New York: Norton.

Johnson, Lamont (1983), Spacehunter: Adventures in the Forbidden Zone, Los Angeles: Columbia.

Johnson, Nunnally, (1956), Man in the Gray Flannel Suit, Century City: Twentieth Century Fox.

Johnson, Rian (2012), Looper, Hollywood: Sony.

Johnson, V. (2008), Heartland TV: Prime Time Television and the Struggle for U.S. Identity,

New York: New York University Press.

Jungk, P. S. (2001), Der König von Amerkia, Berlin: Suhrkamp Verlag.

Kaplan, Jonathan (1992), Unlawful Entry, Century City: Twentieth Century Fox.

Karlson, Phil (1973), Walking Tall, Hollywood: Cinerama Releasing Corporation.

Kasdan, Lawrence (1983), The Big Chill, Los Angeles: Columbia.

Katz, J. E. (1984), 'US energy policy: Impact of the Reagan administration', Energy Policy, $12: 2$, pp. 135-45.

Kaufman, Philip (1978), The Right Stuff, Burbank: Warner Bros.

Kaye, Tony (1998), American History X, Hollywood: New Line.

Keil, C. (2001), "American" Cinema in the 1990s and beyond: Whose country's filmmaking is it anyway?' in J. Lewis (ed.), The End of Cinema as We Know It: American Film in the Nineties, New York: New York University Press, pp. 53-60. 
Keller, B. (1988), 'Soviet aide admits maps were faked for 50 years', New York Times, 3 September, http://www.nytimes.com/1988/09/03/world/soviet-aide-admits-mapswere-faked-for-50-years.html. Accessed 4 October 2015.

Kelly, Gene (1969), Hello, Dolly, Century City: Twentieth Century Fox.

Kerner Commission (1968), Report of the National Advisory Commission on Civil Disorders, Washington DC: US Government Printing Office.

Kershner, Irwin (1983), Never Say Never Again, Burbank: Warner Bros.

Kilberg, Richard (1989), Adam Clayton Powell, Boston: WGBH.

Kilborn, P. (1983), 'Brazil's hydroelectric project: Dam is a sign of advances and troubles', New York Times, 14 November, p. D9.

King, G. (2000), Spectacular Narratives: Hollywood in the Age of the Blockbuster, London: I.B. Tauris.

- _ (2002), New Hollywood Cinema: An Introduction, London: I.B. Tauris. (2003), 'Spectacle, narrative, and the spectacular Hollywood blockbuster', in J. Stringer (ed.), Movie Blockbusters, London: Routledge, pp. 114-27.

King, N. (1983), 'Mersault goes west: Five easy pieces and art cinema', Framework, 20, pp. 37-40.

__ (2004), “'The Last Good Time We Ever Had”: Remembering the New Hollywood cinema', in T. Elsaesser, A. Horwath and N. King (eds), The Last Great American Picture Show: New Hollywood Cinema in the 1970s, Amsterdam: Amsterdam University Press, pp. 19-36.

Klady, L. (1997), 'Same old song and dance: The $22^{\text {nd }}$ annual "Grosses Gloss", Film Comment, 33:2, pp. 50-54.

Klein, N. (1997), The History of Forgetting: Los Angeles and the Erasure of Memory, London: Verso.

Klinger, B. (1997), 'The road to dystopia: Landscaping the nation in Easy Rider', in S. Cohan and I. R. Hark (eds), The Road Movie Book, London: Routledge, pp. 179-203. Knight, J. and Thompson, P. (2011), Reaching Audiences: Distribution and Promotion of Alternative Moving Image, Bristol: Intellect.

Koepp, David (1999), Stir of Echoes, Century City: Twentieth Century Fox.

Kolko, J. (2015), 'How Suburban are big American cities?', 21 May, Five Thirty Eight Economics, http://fivethirtyeight.com/features/how-suburban-are-big-americancities/. Accessed 27 December 2015.

Kopple, Barbara (1976), Harlan County U.S.A., New York: Cabin Creek/First Run. Koster, Henry (1950), Harvey, Universal City: Universal.

_ _ (1953), The Robe, Century City: Twentieth Century Fox.

Kowalski, Bernard (1969), Krakatoa, East of Java, Hollywood: Cinerama Releasing Corporation.

Kozol, W. (2005) “The Kind of People who Make Good Americans": Nationalism and Life's family ideal', in A. Cameron (ed.), Looking for America: The Visual Production of Nation and People, Malden: Blackwell, pp. 173-211. 
Kracauer, S. (2004), From Caligari to Hitler: A Psychological History of German Film, Revised and Expanded Edition (ed. L. Quaresima), Princeton: Princeton University Press.

Krämer, P. (2005), 'Big Pictures: Studying contemporary Hollywood cinema through its greatest hits', in J. Furby and K. Randell (eds), Screen Methods: Comparative Readings in Film Studies, London: Wallflower, pp. 124-32.

Kramer, Stanley (1963), It's a Mad, Mad, Mad, Mad World, Hollywood: United Artists.

- — (1967), Guess Who's Coming to Dinner, Los Angeles: Columbia.

Krugman, P. (1990), The Age of Diminished Expectations: U.S. Economic Policy in the 1990s, Cambridge: MIT Press.

Kubrick, Stanley (1960), Spartacus, Universal City: Universal. (1964), Dr. Strangelove, Or: How I Learned to Stop Worrying and Love the Bomb, Los Angeles: Columbia.

__ (1971), A Clockwork Orange, Burbank: Warner Bros.

_— (1980), The Shining, Burbank: Warner Bros.

Kuleshov, L. (1974), Kuleshov on Film: Writings by Lev Kuleshov (trans. and ed. R. Levaco), Berkeley: University of California Press.

Laderman, D. (2002), Driving Visions: Exploring the Road Movie, Austin: University of Texas Press.

Landis, John (1980), The Blues Brothers, Universal City: Universal.

—— (1985), Spies Like Us, Burbank: Warner Bros.

Lang, Walter (1956), The King and I, Century City: Twentieth Century Fox.

Lean, David (1957), The Bridge on the River Kwai, Los Angeles: Columbia.

__ (1962), Lawrence of Arabia, Los Angeles: Columbia.

_— (1965), Doctor Zhivago, Beverly Hills: MGM.

Lear, Norman, Blake, Whitney and Manings, Allan (1975-84), One Day at a Time, New York: Columbia Broadcasting System.

Leder, Mimi (1998), Deep Impact, Hollywood: DreamWorks/Paramount.

Lee, Spike (1989), Do the Right Thing, Universal City: Universal.

__ (1992), Malcolm X, Burbank: Warner Bros.

(1997), 4 Little Girls, Hollywood: HBO.

(1999), Summer of Sam, Burbank: Touchstone.

LeRoy, Mervyn (1951), Quo Vadis, Beverly Hills: MGM.

—_ (1962), Gypsy, Burbank: Warner Bros.

Lesage, J. (1982), 'For our urgent use: Films on Central America', Jump Cut, 27, pp. 15-20.

_ _ (1990), 'The political aesthetics of the feminist documentary film', in P. Erens (ed.), Issues in Feminist Film Criticism, Bloomington: Indiana University Press, pp. 222-37.

Lester, Richard (1980), Superman II, Burbank: Warner Bros.

Lev, P. (2000), American Films of the 70s: Conflicting Visions, Austin: University of Texas Press. 
(2003), History of the American Cinema Volume 7: The Fifties Transforming the Screen 1950-1959, Berkeley: University California Press.

Levenson, Barry (1982), Diner, Beverly Hills: MGM.

_—_ (1988), Rain Man, Beverly Hills: United Artists.

—— (1991), Bugsy, Hollywood: TriStar.

__ (1997), Wag the Dog, Hollywood: New Line.

Lewis, Fulton (1960), Operation Abolition, Washington DC: Federal Bureau of Investigation.

Lewis, J. (2001), 'The end of cinema as we know it and i feel...: An introduction to a book on nineties American film', in J. Lewis (ed.), The End of Cinema as We Know It: American Film in the Nineties, New York: New York University Press, pp. 1-8.

Lewis, Robert (1956), Anything Goes, Hollywood: Paramount.

Leyda, J. (2014), 'Demon debt: Paranormal Activity as recessionary post-cinematic allegory', JumpCut, 56, http://www.ejumpcut.org/currentissue/LeydaParanormalActivity/text.html. Accessed 1 January 2016.

Liman, Doug (2002), The Bourne Identity, Universal City: Universal.

Little, Dwight (1997), Murder at 1600, Burbank: Warner Bros.

Logan, Joshua (1955), Picnic, Los Angeles: Columbia.

—_ (1956), Bus Stop, Century City: Twentieth Century Fox.

__ (1958), South Pacific, Century City: Twentieth Century Fox.

_— (1969), Paint Your Wagon, Hollywood: Paramount.

London, Jerry (1987), Rent-a-Cop, Hollywood: Kings Road Entertainment.

Lonergan, Kenneth (2000), You Can Count on Me, Hollywood: Paramount Classics.

Long, C.(2013), 'Mapping Suburban Fiction', Journal of Language, Literature and Culture, $1: 3$, pp.193-213.

__ (2015), 'Where is France in French cinema, 1976-2013?', International Journal of Humanities and Arts Computing, 9:2, pp. 180-85.

Lopez, B. (1989), 'Mapping the real geography', Harper's, November, pp. 19-24.

Lowry, Dick (1983), Smokey and the Bandit Part 3, Universal City: Universal.

Lucas, George (1973), American Graffiti, Universal City: Universal.

__ (1977), Star Wars, Century City: Twentieth Century Fox.

Lukinbeal, C. (2004), 'The rise of regional film production centers in North America, 1984-1997', GeoJournal, 59, pp. 307-21.

_ _ (2005), 'Cinematic landscapes', Journal of Cultural Geography, 23:1, pp. $3-22$.

—_ (2006), 'Runaway Hollywood: Cold mountain, Romania', Erdkunde, 60:4, pp. 337-45.

Lukinbeal, C. and Zimmerman, S. (2008), The Geography of Cinema: A Cinematic World, Stuttgart: Franz Steiner-Verlag.

Lumet, Sidney (1965), The Pawnbroker, Hollywood: Allied Artists.

—_ (1975), Dog Day Afternoon, Burbank: Warner Bros. 
(1986), The Morning After, Century City: Twentieth Century Fox.

Luske, Hamilton and Sharpsteen, Ben (1940), Pinocchio, Burbank: Walt Disney.

Lynch, David (1999), The Straight Story, Burbank: Buena Vista.

Lyne, Adrian (1983), Flashdance, Hollywood: Paramount.

(1986), 9 1⁄2 Weeks, Beverly Hills: MGM.

(1987), Fatal Attraction, Hollywood: Paramount.

MacDonald, D. (1983), Against the American Grain, New York: Da Capo.

MacKenzie, Kent (1961), The Exiles, Hollywood: Kent Mackenzie.

Magnoli, Albert (1984), Purple Rain, Burbank: Warner Bros.

Malick, Terrence (1973), Badlands, Burbank: Warner Bros.

- — (1978), Days of Heaven, Hollywood: Paramount.

Maltby, R. (1983), Harmless Entertainment: Hollywood and the Ideology of Consensus, Metuchen: Scarecrow.

__ (2003), Hollywood Cinema, 2nd ed., Malden: Blackwell.

_ _ (2006), 'On the prospect of writing cinema history from below', Tijdschrift Voor Mediageschiedenis, 9:2, pp. 74-96.

—_ (2011), 'New cinema histories', in R. Maltby, D. Biltereyst and P. Meers (eds), Explorations in New Cinema History: Approaches and Case Studies, Chichester: Wiley Blackwell, pp. 25-107.

Maltby, R., Walsh, M., Bowles, K., Arrowsmith, C., Verhoeven, D. and Matthews, J. (2011), 'Mapping the movies: The changing nature of Australia's cinema circuits and their audiences 1956-1984', http://auscinemas.flinders.edu.au/2011. Accessed 29 December 2015.

Man, G. (1994), Radical Visions: American Film Renaissance, 1967-1976, Westport: Greenwood.

Mankiewicz, Joseph (1963), Cleopatra, Century City: Twentieth Century Fox.

Mann, Delbert (1962), That Touch of Mink, Universal City: Universal.

Markle, Fletcher (1963), Incredible Journey, Burbank: Walt Disney.

Marshall, Garry (1984), The Flamingo Kid, Century City: Twentieth Century Fox.

- — (1990), Pretty Woman, Burbank: Touchstone.

Marshall, Penny (1988), Big, Century City: Twentieth Century Fox.

- - (1992), A League of Their Own, Los Angeles: Columbia.

Martin, D. (1984), 'Quebec's overpowering utility', New York Times, 29 January, p. F4.

Massood, P. (2003), 'City spaces and city times: Bakhtin's chronotope and recent African-

American film', in M. Shiel and T. Fitzmaurice (eds), Screening the City, London:

Verso, pp. 200-15.

Maxwell, Ronald (1980), Little Darlings, Hollywood: Paramount.

Mazursky, Paul (1969), Bob \& Carol \& Ted \& Alice, Los Angeles: Columbia.

__ (1978), An Unmarried Woman, Century City: Twentieth Century Fox.

McArthur, C. (1997), 'Chinese boxes and Russian dolls: Tracking the elusive cinematic city', in D. B. Clarke (ed.), The Cinematic City, London: Routledge, pp. 19-45. 
McBride, J. and Riley, B. (1978), “The end” is just the beginning, Film Comment, 14:3, pp. 16-21.

McCarthy, P. (1983), 'Reactions vary to downing of flight 7', New York Times, 18 September, p. CN2.

McConnell, J. (1983), 'Counterrevolution in Nicaragua: The US connection', in P. Rosset and J. Vandermeer (eds), The Nicaragua Reader: Documents of a Revolution under Fire, New York: Grove Press, pp. 175-90.

McClure, M. (2012), 'Tourist industry - Long-haul air travel', Te Ara: The Encyclopedia of New Zealand, 13 June, http://www.teara.govt.nz/en/tourist-industry/page-5. Accessed 1 January 2016.

—_ (2014), 'Tourist industry - Tourism overview', Te Ara: The Encyclopedia of New Zealand, 18 December, http://www.teara.govt.nz/en/graph/23166/tourist-arrivals. Accessed 1 January 2016.

McCourt, J. (1998), 'The top 100 sellthrough titles 1992-1997', Video Store Magazine, 19-25 July, p. 12.

__ (2000), "'Green Mile," "Sixth Sense" Lead list of top rental titles of the year,' Video Store Magazine, 24-30 December, p. 14.

McCourt J. and Saccone M. (1999), 'The Top 50 Turns-per-Copy Titles, 1992-1998', Video Store Magazine, August 1-7, pp. 16-19.

McCourt, J. with Saccone, M. (1998), 'The top 100 sellthrough titles 1992-1996', Video Store, 19-25 July, pp. 20-29.

McCormack, D. (2014), 'Want to get away from it all?' Daily Mail Australia, 18 April, http:// www.dailymail.co.uk/news/article-2607431/Want-away-Interactive-map-showsstaggering-47-PERCENT-country-currently-uninhabited.html. Accessed 9 January 2016.

_ _ (1999), 'The top 50 turns-per-copy titles 1992-1998', 1-7 August, Video Store, pp. 16-19.

McDermott, P. dir. (2013), The Perfect American, opera performance, 22 January, Teatro Real, Madrid.

McDonagh, M. (2004), 'The exploitation generation. Or: How marginal movies came in from the cold', in T. Elsaesser, A. Horwath and N. King (eds), The Last Great American Picture Show: New Hollywood Cinema in the 1970s, Amsterdam: Amsterdam University Press, pp. 107-30.

McEveety, Vincent (1971), Million Dollar Duck, Burbank: Walt Disney.

- — (1980), Herbie Goes Bananas, Burbank: Walt Disney.

McGirr, L. (2001), Suburban Warriors: The Origins of the New American Right, Princeton: Princeton University Press.

McLagen, Andrew (1966), The Rare Breed, Universal City: Universal. - _ (1967), Monkeys Go Home!, Burbank: Walt Disney.

McNaughton, John (1986), Henry: Portrait of a Serial Killer, Hollywood: Greycat Films. McPhee, J. (1972), 'A reporter at large: The search for Marvin Gardens', The New Yorker, 9 September, p. 45. 
McQuarrie, Christopher (2012), Jack Reacher, Hollywood: Paramount. McTiernan, John (1988), Die Hard, Hollywood: Twentieth Century Fox. (1990), Hunt for Red October, Hollywood: Paramount. (1993), The Last Action Hero, Los Angeles: Columbia.

Melendez, Bill (1969), A Boy Named Charlie Brown, Hollywood: National General Pictures.

Menne, J. (2011), 'The cinema of defection: Auteur theory and institutional life', Representations, 114, pp. 36-64.

Mennel, B. (2008), Cities and Cinema, London: Routledge.

Messent, P. (2012), The Crime Fiction Handbook, London: Wiley.

Meyer, Nicholas (1982), Star Trek II: The Wrath of Khan, Hollywood: Paramount. Milius, John (1973), Dillinger, Hollywood: American International Pictures.

—— (1984), Red Dawn, Beverly Hills: United Artists.

Miller, A. (1992), 'Everywhere and nowhere: The making of the national landscape, American Literary History, 4:2, pp. 207-29.

Miller, G. (2015), 'Inside the secret world of Russia's cold war mapmakers', Wired, http:// www.wired.com/2015/07/secret-cold-war-maps/. Accessed 4 October 2015.

Miller, T., Govil, N., McMurria, J., Wang, T. and Maxwell, R. (2004), Global Hollywood 2, London: bfi.

Milliken, C. (2008), 'Movies and the counterculture', in B. K. Grant (ed.), American Cinema of the 1960s: Themes and Variations, New Brunswick: Rutgers University Press, pp. 217-38. Minnelli, Vincente (1944), Meet Me in St Louis, Beverly Hills: MGM.

—— (1951), An American in Paris, Beverly Hills: MGM.

___ (1960), Bells Are Ringing, Beverly Hills: MGM.

Monaco, J. (2009), How to Read a Film: Movies, Media and Beyond, Oxford: Oxford University Press.

Monaco, P. (2001), History of the American Cinema: Volume 8, The Sixties, Berkeley: University of California Press.

Moranis, Rick and Thomas, Dave (1983), Strange Brew, Beverly Hills: MGM.

Moretti, F. (1998), Atlas of the European Novel: 1800-1900, London: Verso.

__ (2005), Graphs Maps Trees: Abstract Models for Literary History, London: Verso.

—— (2013), Distant Reading, London: Verso.

Morris, N. (2007), The Cinema of Steven Spielberg, New York: Wallflower.

Morrison, J. (2010), Hollywood Reborn: Movie Starts of the 70s, New Brunswick: Rutgers University Press.

Mulcahy, Russell (1991), Ricochet, Burbank: Warner Bros.

Mulligan, Robert (1962), To Kill a Mockingbird, Universal City: Universal.

Myrick, Daniel and Sanchez, Eduardo (1999), The Blair Witch Project, Hollywood: Artisan Entertainment.

Nadel, A. (1997), Flatlining on the Field of Dreams: Cultural Narratives in the Films of President Reagan's America, New Brunswick: Rutgers University Press. 
National Park Service (2015), 'We shall overcome: Historic places of the civil rights movement', http://www.nps.gov/nr/travel/civilrights/sitelist.htm. Accessed 29 December 2015.

Nava, Gregory (1983), El Norte, Hollywood: Cinecom.

Neale, S. (2005), Genre and Hollywood, London: Routledge.

Neame, Ronald (1972), The Poseidon Adventure, Century City: Twentieth Century Fox.

Needham, Hal (1977), Smokey and the Bandit, Universal City: Universal.

—— (1978), Hooper, Burbank: Warner Bros.

__ (1980), Smokey and the Bandit II, Universal City: Universal.

—_ (1981), The Cannonball Run, Century City: Twentieth Century Fox.

—_ (1983), Stroker Ace, Universal City/Hollywood: Universal/Warner Bros.

__ (1984), Cannonball Run II, Century City: Twentieth Century Fox.

Neilson, James (1961), Bon Voyage!, Burbank: Walt Disney.

- _ (1963), Summer Magic, Burbank: Walt Disney.

Nelson, Ralph (1963), Lilies of the Field, Beverly Hills: United Artists. (1966), Duel at Diablo, Beverly Hills: United Artists.

Nelson, R., Donihue, M., Waldman, D. and Wheaton, C. (2001), 'What is an Oscar worth?' Economic Inquiry, 39:1, pp. 1-6.

Newell, Mike (1997), Donnie Brasco, Hollywood: TriStar.

Newman, Paul (1968), Rachel, Rachel, Burbank: Warner Bros./Seven Arts.

New Zealand Ministry for Culture and Heritage (2012), 'Americans and Māori', New Zealand History, https://nzhistory.govt.nz/war/us-forces-in-new-zealand/ americans-and-maori. Accessed 29 November 2016.

Nibbelink, Phil, Wells, Simon, Zondag, Dick and Zondag, Ralph (1993), We're Back! A Dinosaur Story, Universal City: Universal.

Nicholas, C. (1997), Somewhere in the Night: Film Noir and the American City, New York: Free Press.

Nichols, Mike (1966), Who's Afraid of Virginia Woolf?, Burbank: Warner Bros.

—_ (1967), The Graduate, Hollywood: Embassy.

—_ (1970), Catch-22, Hollywood: Paramount.

—_ (1971), Carnal Knowledge, Hollywood: AVCO/Embassy.

—_ (1983), Silkwood, Century City: Twentieth Century Fox.

__ (1988), Working Girl, Century City: Twentieth Century Fox.

Nolan, Christopher (2012), The Dark Knight Rises, Burbank: Warner Bros.

Noyce, Philip (1993), Sliver, Hollywood: Paramount.

Nystrom, D. (2004), 'Hard hats and movie brats: Auteurism and the class politics of the New Hollywood', Cinema Journal, 43:3, pp. 18-41.

_- (2009), Hard Hats, Rednecks, and Macho Men: Class in 1970s American Cinema, Oxford: Oxford University Press.

O'Boyle, J. G. (1996), “Be sure you're right, then go ahead”: The early Disney westerns', Journal of Popular Film \& Television, 24:2, pp. 69-81. 
O'Herlihy, Michael (1968), One and Only Genuine Family Band, Hollywood: Walt Disney. Oz, Frank (1999), Bowfinger, Universal City: Universal.

Paasonen, S. (2013a), 'Creative geography: Helsinki as "Body Double”, in Pietari Kääpä and Silja Laine (eds), World Film Locations: Helsinki, Bristol: Intellect, pp. 44-45.

—_ _ (2013b), 'Gorky Park (1983)', in Pietari Kääpä and Silja Laine (eds), World Film Locations: Helsinki, Bristol: Intellect, pp. 70-71.

Painter, N. I. (1993), 'Malcolm X across the genres', American Historical Review, pp. 43239.

Pakula, Alan (1971), Klute, Burbank: Warner Bros.

(1976), All the President's Men, Burbank: Warner Bros.

(1979), Starting Over, Hollywood: Paramount.

(1992), Consenting Adults, Burbank: Buena Vista.

Paris, Jerry (1968), Never a Dull Moment, Burbank: Walt Disney.

Parisi, A. (1981), 'Hard times for nuclear power', New York Times, 12 April, p. SM9.

Parker, Alan (1987), Angel Heart, Hollywood: TriStar.

_— (1988), Mississippi Burning, Los Angeles: Orion.

Parrott, James (1932), The Music Box, Hollywood: Hal Roach.

Paul, Byron (1966), Lt Robin Crusoe USN, Burbank: Walt Disney.

Payne, Alexander (2002), About Schmidt, Hollywood: New Line.

Peckinpah, Sam (1969), Wild Bunch, Burbank: Warner Bros./Seven Arts.

—_ (1972), The Getaway, Hollywood: National General.

Pellington, Mark (1999), Arlington Road, Hollywood: Screen Gems/Sony.

Penn, Arthur (1965a), The Chase, Los Angeles: Columbia.

__ (1965b), Mickey One, Los Angeles: Columbia.

__ (1967), Bonnie and Clyde, Burbank: Warner Bros./Seven Arts.

(1969), Alice's Restaurant, Beverly Hills: United Artists.

(1970), Little Big Man, Hollywood: National General Pictures.

Penn, Sean (1988), Colors, Los Angeles: Orion.

- (2001), The Pledge, Burbank: Warner Bros.

Penz, F. (2010), 'The real city in the reel city: Towards a methodology through the case of Amélie', in R. Koeck and L. Roberts (eds), The City and the Moving Image: Urban Projections, Basingstoke: Palgrave Macmillan, pp. 233-52.

Peterson, Wolfgang (1997), Air Force One, Los Angeles: Columbia.

Petrie, Daniel (1961), A Raisin in the Sun, Los Angeles: Columbia.

Petrie Jr., Daniel (1994), In the Army Now, Burbank: Buena Vista.

Phillips, K. (1970), The Emerging Republican Majority, Garden City: Anchor Books.

Piatti, B. and Hurni, L. (2007), 'Towards a European Atlas of Literature: Developing theories, methods, and tools in the field of "Literary Geography", Proceedings of the XXXIII ICA Conference, Moscow: International Cartographic Association.

—_ (2015), Literary Atlas of Europe, http://www.literaturatlas.eu/en/. Accessed 29 December 2015. 
Poitier, Sidney (1975), Let's Do It Again, Burbank: Warner Bros.

Polan, D. (1977), 'Bad News Bears: Sour American dream', JumpCut, 15, pp. 9-10, http:// www.ejumpcut.org/archive/onlinessays/JC15folder/BadBearsPolon.html. Accessed 1 January 2016.

Polanski, Roman (1974), Chinatown, Hollywood: Paramount.

Pollack, Sidney (1965), The Slender Thread, Hollywood: Paramount.

—— (1969), They Shoot Horses Don't They?, Hollywood: ABC Pictures International. - (1972), Jeremiah Johnson, Burbank: Warner Bros. (1973), The Way We Were, Los Angeles: Columbia. (1981), Absence of Malice, Los Angeles: Columbia.

Pomerance, M. (2004), An Eye for Hitchcock, New Brunswick: Rutgers University Press. Pontecorvo, Gillo (1967), Battle of Algiers, Hollywood: Rizzoli.

Post, Ted (1968), Hang 'em High, Beverly Hills: United Artists.

\section{__ (1973), Magnum Force, Burbank: Warner Bros.}

(1978), Go Tell the Spartans, Hollywood: Embassy.

Powell, Michael (1959), Peeping Tom, London: Anglo Amalgamated.

Preminger, Otto (1960), Exodus, Beverly Hills: United Artists.

__ (1959), Anatomy of a Murder, Los Angeles: Columbia.

Previn, Steve (1962), Almost Angels, Burbank: Walt Disney.

Prince, S. (2006), 'Hollywood in the age of Reagan', in L. Williams and M. Hammond (eds), Contemporary American Cinema, New York: Open University/McGraw-Hill, pp. 229-46.

QPMedia (2014), 'QP money making stars all years', QPMedia, http://qpmedia.com/app.php? \&view=stats\&v=5\&refID=1934\&chapter=The-Year\%20-\%202014\&section=QuigleyPoll:-Top-Ten-Money-Making-Stars\&category=Polls\&subsection=QP-MoneyMaking-Stars---All-Years\&sortby=year\&sortorder=DESC\&ispoll=yes. Accessed 10 January 2016.

Rafelson, Bob (1970), Five Easy Pieces, Los Angeles: Columbia.

__ - (1972), The King of Marvin Gardens, Los Angeles: Columbia.

Ramis, Harold (1993), Groundhog Day, Los Angeles: Columbia.

Ratner, Brett (2000), The Family Man, Universal City: Universal.

Ray, R. (1985), A Certain Tendency of the Hollywood Cinema, Princeton: Princeton University Press.

Reed, Adam (2009-16), Archer, Hollywood: FX Network.

Reed, Carol (1968), Oliver!, Los Angeles: Columbia.

Reiner, Carl (1979), The Jerk, Universal City: Universal.

(1987), The Princess Bride, Century City: Twentieth Century Fox.

Reiner, Rob (1986), Stand By Me, Los Angeles: Columbia.

Reitherman, Wolfgang (1967), The Jungle Book, Burbank: Walt Disney.

—_ (1970), The Aristocats, Burbank: Walt Disney.

Reitman, Ivan (1981), Stripes, Los Angeles: Columbia. 
_ (1984), Ghostbusters, Los Angeles: Columbia.

(1988), Twins, Universal City: Universal.

Reynolds, Burt (1976), Gator, Beverly Hills: United Artists.

_- (1981), Sharky's Machine, Los Angeles: Orion.

(1985), Stick, Universal City: Universal.

Reynolds, Kevin (1995), Waterworld, Universal City: Universal.

_— (1997), 187, Burbank: Warner Bros.

Richards, Dick (1986), Heat, Hollywood: New Century Vista.

Ritchie, Michael (1976), The Bad News Bears, Hollywood: Paramount.

__ (1977), Semi-Tough, Beverly Hills: United Artists.

Ritt, Martin (1961), Paris Blues, Beverly Hills: United Artists.

—_ (1970), The Great White Hope, Century City: Twentieth Century Fox.

_ _ (1972), Sounder, Century City: Twentieth Century Fox.

__ (1983), Cross Creek, Universal City: Universal.

Robbins, Tim (1992), Bob Roberts, Santa Monica: Miramax.

Roberts, G. (2003), 'Circulations of taste: Titanic, the Oscars, and the middlebrow', in J.

Stringer (ed.), Movie Blockbusters, London: Routledge, pp. 155-66.

Roberts, L. (2010), 'Projecting place: Location mapping, consumption, and cinematographic tourism', in R. Koeck and L. Roberts (eds), The City and the Moving Image: Urban Projections, Basingstoke: Palgrave Macmillan, pp. 183-204.

Robinson, Phil Alden (1989), Field of Dreams, Universal City: Universal.

Robson, Mark (1974), Earthquake, Universal City: Universal.

Rodriguez, Robert (1996), From Dusk Till Dawn, Santa Monica: Miramax.

Roman, Phil (1992), Tom and Jerry: The Movie, Burbank: Warner Bros.

Romao, T. (2004), 'Guns and gas: Investigating the 1970s car chase film', in Y. Tasker (ed.), Action and Adventure Cinema, London: Routledge, pp. 132-34.

Rosenbaum, J. (2002), 'Multinational pest control: Does American cinema still exist?' in

A. Williams (ed.), Film and Nationalism, New Brunswick: Rutgers University Press, pp. 217-29.

Rosenberg, Stuart (1979), The Amityville Horror, Hollywood: American International Pictures.

—— (1980), Brubaker, Century City: Twentieth Century Fox.

Rosenblum, T. M. (1995), 'In a family way', Billboard, 107:1, 7 January, 48+.

Ross, Herbert (1975), Funny Lady, Los Angeles: Columbia.

__ (1983), Max Dugan Returns, Century City: Twentieth Century Fox.

(1984), Footloose, Hollywood: Paramount.

(1989), Steel Magnolias, Hollywood: TriStar.

Rossinow, Doug (2015), The Reagan Era: A History of the 1980s, New York: Columbia University Press.

Russell, Charles (1996), Eraser, Burbank: Warner Bros.

Russell, Ken (1980), Altered States, Burbank: Warner Bros. 
Russell, M., Glaberman, M., Joyce, F., The Spark, Goodman, J. (1978), 'Blue collar: Detroit moviegoers have their say', Cineaste, 8:4, pp. 28-31.

Ryan, M. and Kellner, D. (1988), Camera Politica: The Politics and Ideology of Contemporary Hollywood Film, Bloomington: Indiana University Press.

Rydell, Mark (1967), The Fox, Hollywood: Claridge Pictures.

—_ (1969), The Reivers, Hollywood: National General Pictures.

(1972), The Cowboys, Burbank: Warner Bros.

- _ (1981), On Golden Pond, Universal City: Universal.

Said, E. (1994), Orientalism, New York: Vintage.

Sanders, J. (2002), Celluloid Skyline: New York and the Movies, London: Bloomsbury.

San Filippo, M. (2013), 'Boardwalk Xanadu: Time and place in The King of Marvin Gardens and Atlantic City', Senses of Cinema, 13, http://sensesofcinema.com/2001/70s-uscinema/boardwalk/. Accessed 3 January 2016.

Santley, Joseph (1941), Sis Hopkins, Studio City: Republic.

Sargent, Joseph (1973), White Lightning, Beverly Hills: United Artists.

Sarris, A. (1980), 'Why sports movies don't work', Film Comment, 16:6, pp. 49-53.

Schaffer, S. (1996), 'Disney and the Imagineering of Histories', Postmodern Culture, 6.3, n.p.

Schaffner, Franklin (1968), Planet of the Apes, Century City: Twentieth Century Fox.

—_ (1970), Patton, Century City: Twentieth Century Fox.

Schatz, T. (1981), Hollywood Genres: Formulas, Filmmaking, and the Studio System, Boston: McGraw Hill.

__ (1993), 'The New Hollywood', in J. Collins, H. Radner and A. P. Collins (eds), Film Theory Goes to the Movies, New York: Routledge, pp. 8-36.

__ (2003), 'The New Hollywood', in J. Stringer (ed.), Movie Blockbusters, London: Routledge, pp. 15-44.

Schatzberg, Jerry (1987), Street Smart, Hollywood: Cannon Group.

Scheerer, Robert (1973), The World's Greatest Athlete, Burbank: Walt Disney.

Schickel, R. (1997), The Disney Version: The Life, Times, Art and Commerce of Walt Disney, 3rd ed., Chicago: Elephant Paperback.

Schlesinger, John (1969), Midnight Cowboy, Beverly Hills: United Artists.

—_ (1990), Pacific Heights, Century City: Twentieth Century Fox.

Schmitz, D. (1999), Thank God They're on Our Side: The United States \& Right-Wing Dictatorships, 1921-1965, Chapel Hill: University of North Carolina Press.

__ (2006), The United States and Right-Wing Dictatorships, 1965-1989, Cambridge: Cambridge University Press.

Schofield, H. (2013), 'Why are the French drinking less wine?' BBC News Magazine, 26 March, http://www.bbc.com/news/magazine-21929287. Accessed 10 January 2016.

Schrader, Paul (1978), Blue Collar, Universal City: Universal.

Schroeder, Barbet (1992), Single White Female, Los Angeles: Columbia. 
Schulman, B. (1991), From Cotton Belt to Sun Belt: Federal Policy, Economic Development, and the Transformation of the South, New York: Oxford University Press.

Schumacher, Joel (1999), 8MM, Los Angeles: Columbia.

Schwartz, V. (2007), It's So French: Hollywood, Paris and the Making of Cosmopolitan Film, Chicago: University of Chicago Press.

Scorsese, Martin (1972), Boxcar Bertha, Hollywood: American International Pictures. (1973), Mean Streets, Burbank: Warner Bros. (1974), Alice Doesn't Live Here Anymore, Hollywood: Warner Bros. (1976), Taxi Driver, Los Angeles: Columbia. (1980), Raging Bull, Beverly Hills: United Artists. (1990), Goodfellas, Burbank: Warner Bros. (1995), Casino, Universal City: Universal.

Scott, Ridley (1982), Blade Runner, Burbank: Warner Bros. Scott, Tony (1987), Beverly Hills Cop II, Hollywood: Paramount.

__ (1993), True Romance, Burbank: Warner Bros. (2002), True Romance: Unrated Director's Cut, commentary track, Burbank: Warner Bros.

Seaton, George (1970), Airport, Universal City: Universal.

Seitz, George (1938), Love Finds Andy Hardy, Beverly Hills: MGM.

Sena, Dominic (1993), Kalifornia, Hollywood: Gramercy.

Shanley, John P. (1990), Joe Versus the Volcano, Burbank: Warner Bros.

Sharpsteen, Ben (1941), Dumbo, Hollywood: Walt Disney.

Shary, T. (2002), Generation Multiplex: The Image of Youth in Contemporary American Cinema, Austin: University of Texas Press.

Shavelson, Melville (1968), Yours Mine and Ours, Beverly Hills: United Artists.

Shelton, Rod (1988), Bull Durham, Los Angeles: Orion.

Shelton, Toby, Stones, Tad and Zaslove, Alan (1994), The Return of Jafar, Burbank: Walt Disney Home Video.

Sherman, George (1952), Against All Flags, Hollywood: Universal International Pictures.

_— (1971), Big Jake, Hollywood: National General Pictures.

Shiel, Mark (2001), 'Cinema and the city in history and theory', in M. Shiel and T. Fitzmaurice (eds), Cinema and the City: Film and Urban Societies in a Global Context, Oxford: Blackwell, pp. 1-18.

__ (2003), 'A nostalgia for modernity: New York, Los Angeles, and American Cinema in the 1970s', in M. Shiel and T. Fitzmaurice (eds), Screening the City, London: Verso, pp. 160-79.

- _ (2012), Hollywood Cinema and the Real Los Angeles, London: Reaktion.

Shiel, Mark and Fitzmaurice, Tony (2003), 'Introduction', in M. Shiel and T. Fitzmaurice (eds), Screening the City, London: Verso, pp. 1-14.

Shyer, Nancy (1991), Father of the Bride, Burbank: Touchstone. 
Siegel, A. (2003), 'After the sixties: Changing paradigms in the representation of Urban Space, in M. Shiel and T. Fitzmaurice (eds), Screening the City, London: Verso, pp. $137-59$.

Siegel, Don (1974), Dirty Harry, Burbank: Warner Bros.

Signorelli, James (1983), Easy Money, Los Angeles: Orion.

Silverstein, Elliot (1970), A Man Called Horse, Hollywood: National General Pictures.

Singleton, John (1991), Boyz $n$ the Hood, Los Angeles: Columbia.

Sirk, Douglas (1956), Written on the Wind, Hollywood: Universal International Pictures.

Sklar, R. (1975), Movie-Made America: A Cultural History of American Movies, New York: Vintage.

__ (1987), 'When looks could kill: American cinema of the sixties', Cineaste, 16:1/2, pp. 50-52.

Sloane, Paul (1929), Hearts in Dixie, Hollywood: Fox Film Corporation.

Smith, G. (1996), 'Two thousand light years from home: Scorsese's Big CAsino', Film Comment, 32:1, pp. 59-63.

Smith, Kevin (1997), Chasing Amy, Santa Monica: Miramax. (1999), Dogma, Santa Monica: Miramax.

Smith, Mel (1994), Radioland Murders, Universal City: Universal/Lucasfilm.

Smoodin, E. (1994), 'Introduction: How to read Walt Disney', in E. Smoodin (ed.), Disney Discourse: Producing the Magic Kingdom, New York: Routledge, pp. 1-20.

Snelson, T. (2014), 'The (Re)Possession of the American Home: Negative Equity, Gender Inequality, and the Housing Crisis Horror Story', in D. Negra and Y. Tasker (ed.), Gendering the Recession: Media and Culture in an Age of Austerity, Durham: Duke University Press, pp. 161-80.

Sobchack, V. (1986), 'Child/Alien/Father: Patriarchal crisis and generic exchange', Camera Obscura, 5:3, pp. 6-35.

_ _ (1993), 'Baseball in the Post-American Cinema, or life in the minor leagues', East West Film Journal, 7:1, pp. 1-23.

Soderbergh, Steven (1998), Out of Sight, Universal City: Universal.

Solanas, Fernando and Getino, Octavio (1968), La hora de los hornos: Notas y testimonies sobre el neocolonialismo, la violencia y la liberacion/Hour of the Furnaces, Buenos Aires: Grupo Cine Liberacion/Solanas/Tricontinental.

Solnit, R. (2010), Infinite City: A San Francisco Atlas, Berkeley: University of California Press. Solnit, R. and Jelly-Schapiro, J. (2016), Nonstpo Metropolis: A New York City Atlas, Berkeley: University of California Press.

Solnit, R. and Snedeker, R. (2013), Unfathomable City: A New Orleans Atlas, Berkeley: University of California Press.

Sonnenfeld, Barry (1991), The Addams Family, Los Angeles: Orion/Paramount.

Sörlin, S. (1999), 'The articulation of territory: Landscape and the constitution of regional and national identity', Norsk Geografisk Tidsskrift / Norwegian Journal of Geography, 53:2-3, pp. 103-12. 
Spheeris, Penelope (1992), Wayne's World, Hollywood: Paramount. Spielberg, Steven (1971), Duel, Universal City: Universal Television.

_— (1974), Sugarland Express, Universal City: Universal.

__ (1975), Jaws, Universal City: Universal. (1977), Close Encounters of the Third Kind, Los Angeles: Columbia. (1981), Raiders of the Lost Ark, Hollywood: Paramount/Lucasfilm. (1982), E.T.: The Extra-Terrestrial, Universal City: Universal. (1985), The Color Purple, Burbank: Warner Bros. (1991), Hook, Hollywood: TriStar. (1993), Jurassic Park, Universal City: Universal. (1998), Saving Private Ryan, Hollywood: DreamWorks/Paramount.

Spottiswoode, Roger (1983), Under Fire, Los Angeles: Orion.

Stallone, Sylvester (1979), Rocky II, Beverly Hills: United Artists. (1982), Rocky III, Beverly Hills: United Artists. (1985), Rocky IV, Beverly Hills: United Artists/MGM. (2012), The Expendables 2, Hollywood: Lionsgate.

Stanley, Joseph (1941), Puddin' Head, Studio City: Republic Pictures. Stanton, Andrew (2008), WALL-E, Emeryville/Burbank: Pixar/Disney.

Stein, J. (2010), Pivotal Decade: How the United States Traded Factories for Finance in the Seventies, New Haven: Yale University Press.

Stevens, George (1965), The Greatest Story Ever Told, Beverly Hills: MGM. Stevenson, Robert (1943), Jane Eyre, Century City: Twentieth Century Fox. —— (1957), Old Yeller, Burbank: Walt Disney.

___ (1960a), Kidnapped, Burbank: Walt Disney.

_— (1960b), Swiss Family Robinson, Burbank: Walt Disney.

__ (1961), The Absent-Minded Professor, Burbank: Walt Disney.

_ _ (1962), In Search of the Castaways, Burbank: Walt Disney.

__ (1963), Son of Flubber, Burbank: Walt Disney.

__ (1964a), The Misadventures of Merlin Jones, Burbank: Walt Disney.

—_ (1964b), Mary Poppins, Burbank: Walt Disney.

__ (1965a), That Darn Cat!, Burbank: Walt Disney.

- _ (1965b), The Monkey's Uncle, Burbank: Walt Disney.

__ (1967), The Gnome-Mobile, Burbank: Walt Disney.

—_ (1968a), Blackbeard's Ghost, Burbank: Walt Disney. (1968b), The Love Bug, Burbank: Walt Disney.

Stiller, Ben (2008), Tropic Thunder, Hollywood: DreamWorks/Paramount.

Stokes, M. and Maltby, R. (2008), Identifying Hollywood's Audiences: Cultural Identity and the Movies, London: bfi.

Stone, Oliver (1986), Salvador, Hollywood: Hemdale.

Stringer, Julian (2003), 'Introduction', Movie Blockbusters, in Julian Stringer (ed.), London: Routledge, pp. 1-14. 
Sturges, Preston (1941), Sullivan's Travels, Hollywood: Paramount.

Sugrue, T. (1996), Origins of the Urban Crisis: Race and Inequality in Postwar Detroit, Princeton: Princeton University Press.

Sukhatme, P. V., Om, P. A. and Hurley, R. (1971), Report on the 1960 World Census of Agriculture, Volume V: Analysis and International Comparison of Census Results, Rome: Food and Agriculture Organization of the United Nations.

Swift, David (1961), The Parent Trap, Burbank: Walt Disney.

Tarantino, Quentin (1991), Reservoir Dogs, Santa Monica: Miramax.

—— (1994), Pulp Fiction, Santa Monica: Miramax.

Tavernier, Bertrand (1986), Round Midnight, Burbank: Warner Bros.

Taylor, Don (1973), Tom Sawyer, Beverly Hills: United Artists.

Taylor, R. (1975), Chavez and the Farm Workers, Boston: Beacon Press.

Tennessee Valley Authority, 'From the new deal to a new century', https://www.tvakids. com/whatistva/history_timeline.htm. Accessed 28 November 2016.

Tewksbury, Peter (1964), Emil and the Detectives, Burbank: Walt Disney.

Thiesse, A-M. (2003), 'How countries are made: The cultural construction of European nations', Contexts, 2:2, pp. 26-32.

Thomson, D. (1996), 'Who killed the movies', Esquire, December, pp. 56-63.

Thompson, Lee J. (1987), Death Wish 4: The Crackdown, Hollywood: Cannon.

Tillman, George (1997), Soul Food, Hollywood: Fox 2000.

Tokar, Norman (1962), Big Red, Burbank: Walt Disney.

__ (1965), Those Calloways, Burbank: Walt Disney.

—_ (1966a), Follow Me, Boys!, Burbank: Walt Disney.

__ (1966b), The Ugly Dachshund, Burbank: Walt Disney.

—_ (1967), The Happiest Millionaire, Burbank: Walt Disney.

_ _ (1968), The Horse in the Gray Flannel Suit, Hollywood: Walt Disney. (1969), Rascal, Burbank: Walt Disney.

Trousdale, Gary and Wise, Kirk (1991), Beauty and the Beast, Hollywood: Walt Disney.

United States Department of Commerce Geography Division US Census Bureau (2011), Centers of Population Computation for the United States, 1950-2010, Washington DC: US Census Bureau.

United States International Trade Association (2011), The Migration of US Film Television Production: The Impact of 'Runaways' on Workers and Small Businesses in the US Film Industry, Washington DC: US Department of Commerce.

Unkrich, Lee (2010), Toy Story 3, Pixar/Disney: Emeryville/Burbank.

Van Horn, Buddy (1988), The Dead Pool, Burbank: Warner Bros.

Van Sant, Gus (1989), Drugstore Cowboy, Hollywood: Avenue Picture Productions.

Verhoeven, Paul (1987), Robocop, Los Angeles: Orion.

__ (1990), Total Recall, Hollywood: Carolco/TriStar.

(1992), Basic Instinct, Hollywood: TriStar.

(1995), Showgirls, Hollywood: Carolco/United Artists. 
Verne, J. (2014), In Search of the Castaways; or the Children of Captain Grant, Amazon Digital Services, Ebook.

Vidor, King (1929), Hallelujah, Beverly Hills: MGM.

Vogel, H. (2007), Entertainment Industry Economics: A Guide for Financial Analysis, 7th ed., Cambridge: Cambridge University Press.

Von Doviak, S. (2005), Hick Flicks: The Rise and Fall of Redneck Cinema, Jefferson: McFarland.

Wachowski, Lilly and Wachowski, Lana (1999), The Matrix, Burbank: Warner Bros.

Waller, Anthony (1997), An American Werewolf in Paris, Burbank: Buena Vista.

Walters, Charles (1960), Please Don't Eat the Daisies, Beverly Hills: MGM.

Warhol, Andy and Morrissey, Paul (1966), The Chelsea Girls, New York: Andy Warhol.

Wasko, J. (2001a), Understanding Disney, Cambridge: Polity.

_ _ (2001b), 'Is it a small world, after all?', in Dazzled by Disney? The Global Disney Audiences Project, London: Leicester University Press, pp. 3-30.

Wasser, F. (2008), 'Ancillary markets - Video and DVD: Hollywood retools', in P. McDonald and J. Wasko (eds), The Contemporary Hollywood Film Industry, Malden: Blackwell, pp. 120-31.

—— (2010), Steven Spielberg's America, Cambridge: Polity.

Waters, John (1972), Pink Flamingos, Baltimore: Dreamland/Saliva Films.

Watson, J. (2011), 'Mapping out a postsouthern cinema: Three contemporary films', in D.

Barker and K. McKee (eds), American Cinema and the Southern Imaginary, Athens:

University of Georgia Press, pp. 219-52.

Watts, S. (1995), 'Walt Disney: Art and politics in the American Century', The Journal of American History, 82:1, pp. 84-110.

Wayne, John (1960), The Alamo, Beverly Hills: United Artists.

Wayne, John and Kellogg, Ray (1968), The Green Berets, Hollywood: Warner Bros./Seven Arts.

Webber, A. and Wilson, E. (eds) (2008), Cities in Transition: The Moving Image and the

Modern Metropolis, New York: Columbia University Press/Wallflower Press.

Weir, Peter (1990), Green Card, Burbank: Touchstone.

Weisman, Sam (1994), D2: The Mighty Ducks, Burbank: Buena Vista.

Weiss, M. (1988), The Clustering of America, New York: Perennial Harper \& Row.

Wellman, William (1931), The Public Enemy, Burbank: Warner Bros.

West, Simon (1997), Con Air, Burbank: Touchstone.

Wexler, Haskell (1969), Medium Cool, Hollywood: Paramount.

—— (1985), Latino, Marin: Lucasfilm

Whitaker, Forest (1995), Waiting to Exhale, Century City: Twentieth Century Fox.

Whiteaker, D. (2015), 'Nashville: Hotter (and sproutier) than a pepper sprout', Lonely Planet, http://www.lonelyplanet.com/best-in-travel/cities/9?detail=1. Accessed 1 January 2016.

White, M. (2007), 'Movies and the movement', in L. Friedman (ed.), American Cinema of the 1970s Themes and Variations, New Brunswick: Rutgers University Press, pp. 24-47.

Wilder, Billy (1944), Double Indemnity, Hollywood: Paramount. 
(1954), Sabrina, Hollywood: Paramount.

Wilentz, S. (2008), The Age of Reagan: A History, 1974-2008, New York: Harper.

Wilinsky, B. (2001), Sure Seaters: The Emergence of Art House Cinema, Minneapolis: University of Minnesota Press.

Wilkinson, G. K. (1967), The Monkeys, New York: Avon.

Williams, A. (2002), 'Introduction', in A. Williams (ed.), Film and Nationalism, New Brunswick: Rutgers University Press, pp. 1-24.

Williams, R. (2003), Television: Technology and Cultural Form, London: Routledge.

Wincer, Simon (1993), Free Willy, Burbank: Warner Bros.

Wine Institute (2015), 'Wine consumption in the U.S.', Wineinstitute.org, http://www. wineinstitute.org/resources/statistics/article86. Accessed 10 January 2016.

Wirls, Daniel (1992), Buildup: The Politics of Defense in the Reagan Era, Ithaca: Cornell University Press.

Wise, Robert (1965), Sound of Music, Century City: Twentieth Century Fox.

- — (1971), The Andromeda Strain, Universal City: Universal.

Wollen, P. (2002), Paris Hollywood: Writings on Film, London: Verso.

Woo, John (1996), Broken Arrow, Century City: Twentieth Century Fox.

—_ (2000), Mission: Impossible 2, Hollywood: Paramount.

Wood, R. (2003), Hollywood from Vietnam to Reagan... and Beyond, New York: Columbia University Press.

Woodford Bray, M. (1984), 'Under Fire: Romantic Gringo,' Jump Cut, 29, p. 11.

World Bank (2016), 'Arable land (\% of land area)', The World Bank: Data, http://data. worldbank.org/indicator/AG.LND.ARBL.ZS/countries. Accessed 9 January 2016.

Wyler, William (1959), Ben-Hur, Beverly Hills: MGM.

_—— (1968), Funny Girl, Los Angeles: Columbia.

Yates, Peter (1968), Bullitt, Burbank: Warner Bros./Seven Arts.

Yau, N. (2015), 'TV size over the last 8 years', Flowing Data, http://flowingdata. com/2009/09/23/tv-size-over-the-past-8-years/. Accessed 27 September 2015.

Young, P. (2009), 'Star Wars', in J. White and S. Haenni (eds), Fifty Key American Films, London: Routledge, pp. 177-84.

Young, Terence (1965), Thunderball, Beverly Hills: United Artists.

Zeffirelli, Franco (1968), Romeo and Juliet, Hollywood: Paramount.

Zemickis, Robert (1984), Romancing the Stone, Century City: Twentieth Century Fox.

- _ (1985), Back to the Future, Universal City: Universal.

(1988), Who Framed Roger Rabbit?, Burbank: Touchstone.

(1992), Forrest Gump, Hollywood: Paramount.

Zero a la Izquierda (1981), La Decision de Vencer (Los primeros frutos), San Salvador: Zafra Films.

Zinnemann, Fred (1966), A Man for All Seasons, Los Angeles: Columbia.

Zucker, Jerry (1990), Ghost, Hollywood: Paramount.

Zwick, Edward (1989), Glory, Hollywood: TriStar. 



\section{Notes}

1. I made draft maps in the free software tableau, and the maps I used to write this book can be found at https://public.tableau.com/profile/memoryindex2\#!/. I collaborated with a mapmaker, Uri Gilad, to produce maps in GIS for publication.

2. Moretti admits that the maps he uses in Atlas of the European Novel 1800-1900 and in Graphs Maps Trees are, in fact, diagrams that get at geometry rather than geography: '[I]f I keep making diagrams', Moretti explains, 'it is because for me geometry "signifies" more than geography. More, in the sense that a geometrical pattern is too orderly a shape to be the product of chance. It is a sign that something is at work here - that something has made the pattern the way it is' (2005: 56, original emphasis). Understanding the pattern by considering location as the driving force will re-orient our understanding of Hollywood cinema history or, at worst, fruitfully misread that history in a way that calls attention to and seeks to answer previously unasked questions.

3. Poitier's films show a great deal of geographic spread, taking place in small-town Mississippi, urban San Francisco, and rural Arizona, and his 1960s films are set in Palestine (The Greatest Story Ever Told [Stevens, 1965]) the Arctic Sea (The Bedford Incident [Harris, 1965]), the Mediterranean (The Long Ships [Cardiff, 1964]), Paris (Paris Blues [Ritt, 1961]), London (To Sir, With Love [Clavell, 1967]), as well as US locations like Arizona (Duel at Diablo [Nelson, 1966]), Chicago (A Raisin in the Sun [Petrie, 1961]), and Seattle (The Slender Thread [Pollack, 1965]), among others.

4. In Los Angeles Plays Itself, Thom Anderson identifies the Watts Towers as the most accessible civic monument of the 1960s. Perhaps unsurprisingly, the Watts Towers appear in a number of films that hail an African American audience, such as Colors (1988), Ricochet (1991), and Menace II Society (1993).

5. To translate Burt Reynolds's box office into 2012 dollars (assuming an average ticket price of \$8.12): Smokey and the Bandit would have made around $\$ 458,000,000$, or slightly more than 2012's The Dark Knight Rises (Nolan). Smokey and the Bandit II $\$ 198,000,000$, Deliverance $\$ 219,000,000$, The Longest Yard $\$ 184,000,000$, Semi-Tough $\$ 133,000,000$, and the non-Southern The Cannonball Run: $\$ 210,000,000$ would have been top-25 hits. Sharky's Machine $\$ 93,000,000$ would have been outside of the top 
25, but above action star movies like The Expendables 2 (Stallone, 2012), Looper (Johnson, 2012), and Jack Reacher (McQuarrie, 2012).

6. Family-friendly hits included A Boy Named Charlie Brown (Melendez, 1969), Blackbeard's Ghost (Stevenson, 1968), Chitty Chitty Bang Bang (Hughes, 1968), The Computer Wore Tennis Shoes (Butler, 1969), Follow Me Boys! (Tokar, 1966), The Gnome-Mobile (Stevenson, 1967), The Happiest Millionaire (Tokar, 1967), The Jungle Book (Reitherman, 1967), The Love Bug (Stevenson, 1967), Million Dollar Duck (McEveety, 1971), Oliver! (Reed, 1968), Sounder (Ritt, 1972), Tom Sawyer (Taylor, 1973), The World's Greatest Athlete (Scheerer, 1973), and Yours Mine and Ours (Shavelson, 1968) as well as re-releases of Snow White and the Seven Dwarfs (Hand, 1939), The Aristocrats (Reitherman, 1970), 101 Dalmatians (Geronimi, Luske and Reitherman, 1961), Mary Poppins (Stevenson, 1964), and The Sound of Music (Wise, 1965).

7. New Hollywood hits included Alice's Restaurant (Penn, 1969), American Graffiti (Lucas, 1973), Carnal Knowledge (Nichols, 1971), Chinatown (Polanski, 1974), Deliverance (Boorman, 1972), Dog Day Afternoon (Lumet, 1975), Easy Rider (Hopper, 1969), Getaway (Peckinpah, 1972), The Godfather (Coppola 1972), The Godfather Part II (Coppola, 1974), The Graduate (Nichols, 1967), Klute (Pakula, 1971), Little Big Man (Penn, 1970), $M^{\star} A^{\star} S^{\star} H$ (Altman, 1970), Midnight Cowboy (Schlesinger, 1969), Paper Moon (Bogdanovich, 1973), Taxi Driver (Scorsese, 1976), They Shoot Horses, Don't They? (Pollack, 1969), What's Up Doc? (Bogdanovich, 1972), and The Wild Bunch (Peckinpah, 1969) among others.

8. Derek Nystrom's 'Hard hats and movie brats: Auteurism and the class politics of the New Hollywood' (2004: 18-41) covers some of this ground.

9. The turn to digital once again finds Spielberg and Lucas in the middle of industrial change. In June 1993, digital sound came into use: Jurassic Park (Spielberg, 1993) in Digital Theater Sound (DTS) and The Last Action Hero (McTiernan, 1993) in Sony Dynamic Digital Sound (SDDS). SDDS originally intended to release Spielberg's Hook (1991) as the first digital sound film, but project delays prevented that from happening. DTS was founded, with Spielberg as an investor, right around the time Hook wasn't making it to digital sound. In digital effects, George Lucas's 1994 project Radioland Murders extensively used computer-generated imagery in non-spectacular settings.

10. In the second half of the 1990s, Washington DC was an even more frequent setting for action films: True Lies (Cameron, 1994), Eraser (Russell, 1996), Air Force One (Peterson, 1997), Deep Impact (Leder, 1998), Armageddon (Bay, 1998), and some of Executive Decision (1996, Baird).

11. As suburban as its Winnetka, Illinois shooting location is, Home Alone takes place in Chicago: the burglar Harry Lime (Joe Pesci) cases the McAllister house dressed as a Chicago police officer checking on family holiday plans, and later when the McAllisters call the police, the cops answering the phone are Chicago police. 
12. Jack Campbell (Nicholas Cage) learns this lesson in The Family Man (Ratner, 2000), trading his multi-million dollar Manhattan apartment for the New Jersey suburbs.

13. Poltergeist is clearly set somewhere west of the Mississippi, far from I74, which runs from North Carolina to Iowa.

14. Reagan appears as a period marker in histories like The Reagan Era: A History of the 1980s (2015) by Doug Rossinow and The Age of Reagan: The Fall of the Old Liberal Order 1964-1980 (2009), by Steven Hayward, political analyses like Corruptions of Empire: Life Studies \& the Reagan Era (1988) by Alexander Cockburn and Buildup: The Politics of Defense in the Reagan Era (1992) by Daniel Wirls, and cultural studies like Hard Bodies: Hollywood Masculinity in the Reagan Era (1994) by Susan Jeffords.

15. By the mid-1980s, 16mm was the past. 'However, as the domestic video boom increased institutional users' familiarity with the medium and increasingly conditioned them to opt for using video, there was a growing concern about the future of distributors' $16 \mathrm{~mm}$ print collections' (Knight and Thomas 2011: 113). In the 2000s, the documentarian Robert Greenwald has encouraged house-party group viewings of his films in a domestic version of the $16 \mathrm{~mm}$ circuit.

16. Animated movies included Thumbelina (Bluth and Goldman, 1994) and We're Back!: A Dinosaur Story (Nibbelink, Wells, Zondag and Zondag, 1993) and Tom and Jerry: The Movie (Roman, 1992). Family pictures included Free Willy (Wincer, 1993), Dennis the Menace (Castle, 1993), The Secret Garden (Holland, 1993), D2: The Mighty Ducks (Weisman, 1994), The Muppet Christmas Carol (Henson, 1992), and Home Alone 2 (Columbus, 1992).

17. Many video-hit DVDs include 'special features' that tend to be bare bones. But one common inclusion is the 'theatrical trailer', which can offer an idea of how the film was sold at the time of its release.

18. Nicaragua appeared on the front page on 19, 17, 16, 6, and 2 October; 9 September, 26, 16, 4 August; 30, 29, 27, 25, 24, 22, 21, 20, 19, 18, 15 July, 7 June, 8 June, 14 June, 15 June, 19 June, 2 May, 4 May, 5 May, 7 May, 13 May, 23 May, 24 May, 30 April, and 22 April. Nicaragua appeared on the front page more frequently than Poland, France, El Salvador, Syria, South Korea, Chad (the setting for Under Fire's first twelve and a half minutes), and Latin America as a region. The nation's two main economic rivals, West Germany and Japan, combined did not appear as frequently as Nicaragua on the front page of the paper of record.

19. See Brecher et al. (1982).

20. As below, so above. Such a notion of a hierarchy based on the complexity of tasks performed is not without precedent. In the Utopia of Rules: On Technology, Stupidity, and the Secret Joys of Bureaucracy (2015), David Graeber notes with some amusement that 'Medieval and Renaissance theologians produced endless speculative tracts about angelic hierarchies that if anything represented the universe as more systematically bureaucratic than anything ancient philosophers had imagined' (171-72). In the 
image from the Meteorologica cosmtca that he reproduces, each rank of angels has a particular job, increasing in complexity as the scale goes up.

21. See, for example, Shiel $(2003,2012)$

22. Then again, Columbus, Indiana enjoys more iconic architecture per capita than pretty much anywhere in the United States, with seven buildings on the national historic register, works from major figures like Richard Meier, I. M. Pei, Cesar Pelli, Eero Saarinen, and Robert Venturi, as well as a sizable collection of public art. All the same, Columbus, Indiana has never been the location for a Hollywood film.

23. Midwestern third-and fourth-order cities were at the heart of 1970s and 1980s television hits: Indianapolis (One Day at a Time), Milwaukee (Laverne and Shirley), and Minneapolis (Mary Tyler Moore Show).

24. Up (Docter and Peterson, 2009) and Toy Story 3 (Unkrich, 2010), from Disneyowned Pixar, were also nominated for Best Picture, to say nothing of Best Animated Feature Film winners Wall-E (Stanton, 2008) and Up (2009).

25. See also Thomas Elsaesser's 'The blockbuster: Everything connects, but not everything goes' in The End of Cinema as We Know It: American Film in the Nineties: 'if you get children used to something early, they'll stick with it all their lives. What we do in our formative years will always remain a utopia, maybe a backward utopia since we always will want to go home. To make our childhood synonymous with the cinema: this has been the secret of the Disney principle. Earlier than any other studio, the Disney Corporation had "realized" that the modeling - and marketing - of time is the cinema's deepest fantasy' (2001: 20-21).

26. See also Vanessa Schwartz's It's So French: Hollywood, Paris and the Making of Cosmopolitan Film (Chicago: University of Chicago Press, 2007), which deals with the Riviera as a film setting that informed and fed international jet-setting tourism.

27. Le Petit Monde de Don Camillo sold almost thirteen million tickets in a country with a population of around 42 million (the same level of ticket sales enjoyed by Forrest Gump [Zemeckis, 1992]), making it the sixth-highest grossing French production. Its first sequel, Le Retour de Don Camillo (Duvivier, 1953) is the thirty-second-highestgrossing French production.

28. In this regard, Monkeys Go Home! obliquely addresses the other national co-producer of the Don Camillo films, Italy. The United States, nervous of the power of the Communists in Italy after World War II, provided extensive funding to the Christian Democrats to ensure that the Communists would not take power. 


\section{Index}

10158

101 Dalmatians 270

16 mm film 138, 143, 163-165, 271

187 141-142

1960s $6,19,23,26,30,31,37,59,60,62-63$, $64-65,68,69,76,83,85,101,103-$ $104,137-138,144,147,171,175$, 184, 199-201, 204-205, 216-217, 218, 219,269

1968 Democratic National Convention 5, $75,76-78,80,84,91$

1970s 7, 22, 23, 26, 29, 30, 35-36, 37-41, 44-47, 52, 55-56, 59, 62, 63, 64-69, 83, 84-85, 90, 96, 100, 101, 103-104, 111-112, 138, 139, 154, 157, 164, 181, 182, 193, 204, 233, 272

1980s 7, 9, 22, 23, 30, 36, 40, 46, 54-56, 75-

$76,87,102-104,105,108,111,122$, 137-144, 146-147, 153, 156, 157, 158-159, 164, 183, 187, 188, 193, 233, 271,272

1990s 7, 9, 23, 47, 95-96, 104, 105, 139, 140$143,175,181,187,190,193,194$, 204, 270

$35 \mathrm{~mm}$ film 10, 191

4 Little Girls 22, 23

48 HRS. 17, 104

$8 M M 143$

$91 / 2$ Weeks 143
A

A Boy Named Charlie Brown 270

A Clockwork Orange 65

A Different World 55

A League of Their Own 105

A Man Called Horse 232

A Man for All Seasons 6

A Raisin in the Sun 269

A Soldier's Story 22

Absent-Minded Professor, The 201, 203, 204

Academy of Motion Picture Arts and Sciences see Oscar

Adam Clayton Powell 22

Addams Family, The 105

African Americans 5, 20-29, 37, 45, 53, 74, 76-84, 79, 81, 82, 86, 88-90, 91, 119, 120, 140, 146, 181, 188, 236, 269

Against All Flags 194

air conditioning 42, 44, 47, 184

Air Force One 270

Airport '77 38

Airport 61, 90, 104

Akron, OH 176, 193, 231, 232

Alabama 20, 23-24, 171, 176, 182, 220

Aladdin 140

Alameda, CA 104

Alamo, The 101

Alaska 29, 31 60, 71, 73, 176, 231, 232, 234, 242 
Albany, NY 171, 177

Albuquerque, NM 176

Alfie 64

Alice Doesn't Live Here Anymore 65

Alice in Wonderland 199

Alice's Restaurant 63, 75, 270

All Dogs Go to Heaven 55

Allen, Woody 66, 157, 172, 174

Almost Angels 205

Altered States 158

Altoona, PA 171, 190, 191

Amazon 30, 153-155, 165

American Film Institute 12, 176 see also

$$
\text { prestige }
$$

American Graffiti 104, 270

American History $X 143$

Americanization 29, 150-152, 200, 208, 226, 233

Amityville Horror, The (1979) 30, 97, 105, 108, 110, 116, 117

An American in Paris 13

An American Werewolf in Paris 13

An Officer and a Gentleman 22, 23, 137

An Unmarried Woman 35

Anchorage, AK 31, 176, 232, 242

Anderson, Thom 15-16, 70, 173, 269

Andromeda Strain, The 104

Angel Heart 143in

animated film 59, 102, 139, 140, 141, 199203, 220, 271, 272

anti-communism 137-138, 148, 159-160, 221

Anything Goes 13

Apocalypse Now 65

Appalachia 76, 77

Archer 55

Arctic Sea 269

Argentina 205

Aristocats, The 270

Arizona 9, 23, 143, 171, 176, 231, 269

Arkansas 24, 38, 39, 47, 55, 177, 182

Arlington Road 143

Armageddon 270
Around the World in Eighty Days 101

artificial landscape see geography, creative

Art Institute of Chicago 109

Asheville, NC 232

Astoria OR 105

Aswan High Dam, Egypt 156

Atlanta, GA 23, 25, 38, 42, 44, 46-50, 48, 53, $69,171,177,182$

Atlantic City, NJ 68-69, 73, 143, 182

Augusta-Richmond, GA 176

Aurora, CO 176, 231-232

Aurora, IL 113, 114, 115-116

Austin, TX 176

Australia 7, 17, 22, 96, 102, 103, 200, 205, 206, 226, 234

Austria 102, 172, 205, 234

automobility 108, 113, 114

B

B.L. Stryker 55

Babe, The 26, 28

Back to the Future 97, 105

Bad News Bears, The 30, 97, 105, 108, 111 -

$112,116,117$

Badlands 66, 70, 72, 73, 73, 189, 234

Badlands, SD 234

Bahamas 102

Bakersfield, CA 176, 177

Baltimore, MD 170, 176

Bambi 199, 221

Basic Instinct 17

Batman 104

Batman Returns 104

Battle of Algiers 83

Battle of the Bulge 101

Beatty, Warren 56, 149, 183

Beauty and the Beast 140, 199

Bedford Incident, The 269

Beetlejuice 105

Beirut, Lebanon 172

Belfast, Northern Ireland 172

Belgium 102

Belle Fourche, SD 231 
Bells Are Ringing 6

Ben-Hur (1959) 101

Benji 104

Berlin, Germany 18, 50, 172, 173, 205

Bermuda Triangle 38

Best Little Whorehouse in Texas, The 55

Beverly Hills Cop 104

Beverly Hills Cop II 104

Beverly Hills, CA 51, 104, 112, 173

Big 97, 104, 105, 106-108, 110, 113, 116

Big Chill, The 148

Big Jake 232

Big Lebowski, The 190, 191

Big Red 205

Biltmore, NC 51

Birmingham AL 23, 171, 176, 182

Birth of a Nation, The 15, 37

Biscayne Bay FL, 50

Biskind, Peter 59, 63, 66

Blackbeard's Ghost 201, 204, 270

Blade Runner 173

Blair Witch Project, The 99

blockbuster 30, 54-55, 56, 61, 67, 90, 96, 99$105,117,203$ see also presence, large scale and spectacle/spectacular

Blow-Up 64, 83

Blue Collar 29, 60, 66, 74, 84-90, 87, 91, 195,

Blues Brothers, The 104

Bob \& Carol \& Ted \& Alice 65, 104

Bob Roberts 31, 169, 188, 190, 191, 192, 194

Bodyguard, The 104

Bogan County, AR 47

Boise, ID 232

Bon Voyage! 31, 200-201, 204, 205, 208-215, 210, 214, 224, 226

Bonnie and Clyde 6, 62, 64, 66, 69, 74

Boogie Nights 55

Boorman, John 153,165

Borchert, John 130, 170-171

Bordwell, David and Kristin Thompson 13, 36, 63

Boston, MA 26, 27, 50, 62, 74, 104, 170, 171, 176, 208, 209
Bourne Identity, The 13

Bowfinger 21

Boxcar Bertha 65

Boyz $n$ the Hood 22, 236

Bracero program 218-219

Brainerd, MN 232

Brazil 30, 144, 153-156, 155, 165

Breakfast Club, The 144

Brewster McCloud 65

Bridge on the River Kwai, The 101

Bridges of Madison County 232

Broadcast News 176

Broken Arrow 232

Bronx, NY 66, 172

Brooklyn Dodgers 111

Brooklyn, NY 66, 111, 143, 144, 145, 146

Brooks, Albert 55-56

Buffalo, NY 176

Bugsy 31, 169, 182, 183-184, 185

built environment 14, 16, 17, 49, 50-51, 51, 52, 96, 97-98, 99, 106, 148-150, 171, $188,192,237$

Bull Durham 55

Bullitt 17, 52, 104

Burma/Myanmar 101

Bus Stop 194

Butch Cassidy and the Sundance Kid 65

Butcher Hollow KY 37

C

\section{Cabaret 65}

California 3, 5, 9, 13, 15-16, 17, 22, 23, 24, $29,31,38,39,46,50,56,60,62,65$, 69, 70, 73, 74, 96, 104, 105, 111-113, $138,143,150,156,169,170,171$, $172,173,175,176,177,182,183$, $184,187,189,190,193,195,203$, 204, 208, 212, 232, 233, 235, 236, 269

Canada 11, 18, 22, 70, 102, 156, 205

Cannonball Run II, The 55

Cannonball Run, The 39, 46, 52, 55, 269

canon 6, 8, 12, 19, 21-22, 62, 63-64, 67, 75-

$76,90,201$ 
Cape Horn, Chile 102

capitalism 83, 100, 182, 187, 218, 221, 224, 225

Caquard, Sébastien 8-9

car chase 52-53, 54, 109-110

card games 144, 146-147

Carnal Knowledge 66, 67, 69, 74, 270

Carpenter, Lloyd 205, 207

Carpentersville, IL 232

Carter, Jimmy 54, 156

Casablanca 13, 140, 224

casino 182-184, 185-187, 195

Casino 31, 169, 173, 176, 182, 184-187, 185, 195

Casper, Drew 6, 8, 63-64

Catch-22 65

Catskills, NY 232

Cavell, Stanley 35, 56

Centerville, IA 36

Central America 56, 129, 137, 144, 157, 158, 159-160, 161, 163 see also Latin America

Chad 157, 157, 271

Chaplin 26, 28

Charleston, SC 171

Charlotte, NC 176, 232

Chase, The 64

Chasing Amy143

Chatsworth CA 111

Chatsworth Reservoir 113

Chattanooga, TN 176, 232

Chavez, Cesar 218-220

Chelsea Girls, The 64

Chesapeake Bay 231

Chesapeake, VA 176

Cheyenne, WY 73

Chicago Board of Trade 109, 171

Chicago, IL 5, 9, 15, 23, 29, 42, 50, 56, 60, $62,66,70,74-83,88,90,104,105$, $107-110,113,115-116,140,143$, $169,170,171,175,176,193,195$, 209, 232, 269, 270 children 26, 30, 96-97, 101, 105-106, 108,

$113,139,154,155,158,202,209-210$,

$214,220,272$

Chile 102, 163, 205

Chinatown 65, 67, 74, 104, 173, 183, 270

Chitty Chitty Bang Bang 270

Choctaw Ridge, MS 37

Cincinatti, OH 25, 177, 182

Cinderella 199

cinema, national 4, 10 17-20, 232-237

city branding 174-176, 177, 179, 181

City Heat 55

city-suburb relationship 50, 97, 98, 105-117, 233

city, as single-biome planet $30,169,174$,

181-182, 184, 187, 188, 194-195

Civil Rights Movement 23-24, 39, 119

Clark County, NV 184-185 see also Las Vegas, NV

Claudine 22

Cleopatra 101

Cleveland, $\mathrm{OH} 42,176,186$

Cliffside Heights, NJ 106

Clinton, Bill 105

Close Encounters of the Third Kind 97-99

clustering 158-159, 170

coal 37, 188, 236

Coal Miner's Daughter 30, 37, 169, 177, 178, 179, 181-182

Cocoon 55

Cold War 18, 148, 151, 156, 159

collective action 29, 60, 74, 88-91, 218-221, 222-223, 225

Color Purple, The 22, 55, 176

Colorado 103, 171, 175, 176, 231-232

Colorado Springs, CO 176, 232

Colors 269

Columbus, GA 176

Columbus, IN 272

Columbus, $\mathrm{OH} 176$

Coming Home 65

communism 159, 216, 218, 220, 222-225, 272 
commuting 105-111, 116

Computer Wore Tennis Shoes, The 270

Connecticut 143

Consenting Adults 143

conservatism $8,29,56,62-63,77-78,90$, 137-139, 158, 190, 201-202

construction 43, 154, 156, 183, 184, 203

consumerism 71, 87, 88-90, 203, 220

Copycat 143

Corpus Christi, TX 171, 176

Cosmopolitan (magazine) 36

cosmopolitan 23, 31, 67, 84, 102, 210-213, 215,272

Cowboys, The 231

Cox, Karen 37

crime, financial 146-147

Crocodile Dundee 104

Cronon, William 170

Crosby, Bing 6, 38

Cross Creek 22, 23

Cruise, Tom 38-39, 56, 106, 182

Cry Freedom 22

Cuba 102, 160

Culver City, CA 173

Cyprus 102

\section{D}

D2: The Mighty Ducks 271

Dallas (TV) 20

Dallas, TX 53, 171, 176

Dances With Wolves 234

Dark Knight Rises, The 269

Day, Doris 38, 46, 105

Days of Heaven 66, 70, 74

Dayton, OH 176, 231, 232

Daytona, FL 69

de-industrialization 60, 68-70, 84-91, 164, 188-190, 233

Dead Pool, The 17

Death Wish 4: The Crackdown 15

Decatur County, IN 231

Deep Impact 270

Deer Hunter, The 188
Delano Strike and Boycott 219-220

Delaware 31, 232

Deliverance 39, 43, 43-44, 47, 65, 66, 153 , 269,270

DeNiro, Robert 56, 66, 180

Dennis the Menace 271

Denver CO 171, 175, 176

Des Moines, IA 173-174

Detroit, MI 25, 29, 40, 42, 56, 60, 66, 74, 8490, 104, 105, 171, 176, 186, 193, 195

Devil Wears Prada, The 13

Devil's Advocate, The 143

Devil's Island, French Guiana 102

Devil's Tower, WY 98

Dick Tracy 105

Die Hard 104

Die Hard 2105

diet 216-217, 227

Dillinger 66, 74

Diner 144

direct address 80-84, 81, 82, 88, 108

Dirty Dancing 144, 146

Dirty Harry 17, 38, 46

Disney ideology 31, 200-205, 208, 211, 216, 225, 226-227, 233, 272 see also small town ideology

Disney live-action films 6, 31, 61, 140, 199201, 203-205, 208, 216, 218, 220-221, 226, 233

Disney, Walt 63, 199, 201-203, 205, 220-221

Distant reading 10-11

Doctor Dolittle (1967) 61

Doctor Zhivago 6, 101, 140

documentary 15-16, 22, 74, 76-83, 84, 88, 138

Dog Day Afternoon 66, 270

Dogma 143

Donnie Brasco 143

Dorfman, Ariel and Armand Mattelart 199200

Double Indemnity 212, 214

Dover, NH 232

Down and Out in Beverly Hills 173 
Dr Strangelove, Or: How I Stopped Worrying and Love the Bomb 6

Dreyfuss, Richard 66, 67, 97

drivers license 106-108, 112, 113

Driving Miss Daisy 22, 23, 55, 176

Drugstore Cowboy 176

Duel 65

Duel at Diablo 269

Dukes of Hazzard, The 55

Dumb and Dumber 237

Dumbo 199

Dyer, Richard 36, 46

Dyersville, IA 175

E

E.T.: The Extra-Terrestrial 30, 97-99, 105, 108

Earthquake 104

Eastwick, RI (fictional town) 237

Eastwood, Clint 17, 35, 38, 55, 104, 176, 232

Easy Money 237

Easy Rider 59, 61, 62, 64, 65, 66, 67, 68, 69, $73,75,76,84,270$

economy $29,31,36,69-70,85-86,90,102-$ $103,139,144,146-148,170,182,193$, $195,209,218$

education 17, 24, 137, 138, 147, 235

Edward Scissorhands 16

Egypt 101, 102, 156, 157

Eiffel Tower 13, 210, 210, 211

El Norte 161

El Paso, TX 143, 177

El Salvador 159-160, 163, 271

elevated train, 107, 109, 145, 172

Elsaesser, Thomas 18, 19, 62, 100, 272

Emerald Forest, The 30, 139, 143, 144, 153$157,155,165-166$

Emil and the Detectives 205

Encino CA 112

energy 139, 153-154, 155-156, 165, 170 see also hydroelectric power, renewable energy and solar power

energy crisis 154-56
Enforcer, The 17

England 14, 17, 22, 50, 101, 102, 170, 172, $173,205,208,269$

environmentalism 137, 139, 153, 157, 165

Eraser 270

Erie PA 232

establishing shot 13-16, 50, 51, 98, 109, 112 $113,115-116,149-150,154,173-174$, 175, 178, 179, 180, 183, 190, 192, 210-211, 234

Ethiopia 102

Evening Shade 55

Executive Decision 270

Exiles, The 173

Exodus 101

Exorcist, The 65, 104

Expendables, The 270

\section{F}

F.I.S.T. 86

Fairfax, VA 143

Fall River, MA 171

false geographies 235-237

Family Man, The 271

family, domesticity 96, 97-101, 105, 106, 117

Fantasia 199

Fargo 176, 191, 232

farm $37,38,41,66,90,98,152,170,213$ -

$214,215-217,219-220,224$

Farrelly Brothers 237

Fatal Attraction 104, 105

Father of the Bride 105

Ferris Bueller's Day Off 30, 97, 105, 107-110, 109, 116, 117

Field of Dreams 175

film distribution $4,7,37,74,76,96,102$, $139,164-165$

film geography 8-10

film history and criticism, formal 74, 77, 84, 95, 150

film history and criticism, ideological 5-7, $8,10,64,76,77,84,89,95,137$, 146-147 
film history and criticism, industrial 3, 100, 102-103, 203

film history and criticism, spatial 4, 5, 7, 8, 9-10, 10-12, 29, 31, 233-237

film history, France 13, 18, 200, 216, 223 226, 272

film tourism 158, 172, 175 see also tourism financialization 147-148

Finland 148-150, 149

Fitzpatrick, Jeane 160

Five Easy Pieces 63, 66, 67, 69, 70-71, 74

Flamingo Kid, The 30, 139, 143, 144-148, 145, 165-166

Flashdance 188, 189, 192

Flint, MI 171, 177

Florence, Italy 172

Florida 9, 25, 37, 38, 40, 41, 42, 44, 46, 50$51,51,53,5569,104,143,171,176$ , 177

Fog, The 110

Follow Me, Boys! 204, 270

Fonda, Jane 66, 141

Fonda, Peter 73

football 44-46, 55

Footloose 105, 144

Ford, Harrison 46, 56

foreign policy $30,137,139,143,144,159$ 161,165

Forks, WA 175

Forrest Gump 176, 272

Fort Knox, KY 38

Fort Lauderdale, FL 38, 171

Fort Worth, TX 171, 176

Fox and the Hound, The 140

Fox, The 215

France 5, 7, 13, 14, 18, 31, 50, 101, 102, 172, 173, 181, 200, 205, 208-215, 210, $211,216-218,223,226,233,234,269$, 271,272

Free Willy 271

freeze frame 74, 88, 89

Fremont, CA 176

French Connection, The 3, 104
French Guiana 102

From Dusk Till Dawn 143

Fugitive, The 143

Funny Girl 5

Funny Lady 104

G

Gainesville, FL 143

gambling 30-31, 112, 169, 182-187, 195

Garland, TX 176

Gator 46, 47, 52

genre $3,19,39,56,61,65,84,102,144,150$ -

$152,153,165,169,226$

genre, biopic 25-26, 28, 37, 176

genre

caper $38,86-87$

crime $17,52,86$

detective 150-152

family 203

real estate horror 110-111

road movie 29, 59-60, 61, 65, 68, 70-74, 90, $182,189-190,193,233$

Southsploitation 29, 37, 39, 46-47, 52, 56

trained animal film 31, 200, 204, 217

western 16, 65, 153-155, 157, 207, 232, 234, 235

Geographic Information Systems (GIS) 4 geography, creative 12-16, 234

Georgia 23, 25, 37, 38, 39, 42, 44, 46-50, 48, 49, 50, 53, 54, 69, 171, 176, 177, 182

Germany 18, 50, 102, 172, 173, 205, 271 see also West Germany

Getaway, The 270

Ghost 22, 142

Ghostbusters 104, 108

Giroux, Henry 202-203

Glasgow, Scotland 172, 205

Glass, Philip 202

Global South 161-163, 165

globalization 4, 46, 164

Glory 22, 176

Gnome-Mobile, The 201, 270

Go Tell the Spartans 64 
Godfather Part II, The 37, 63, 104, 270

Godfather, The 63, 65, 66, 100, 104, 140, 270

Golden Gate Bridge 13, 14

Golden Girls 55

Goldfinger 101

Goldwyn, Samuel 165

Gone With the Wind 37, 104, 140

Good Neighbor Policy 156

Goodfellas 190

Goonies, The 105

Gorbachev, Mikhail 151

Gorky Park 30, 139, 143, 144, 148-152, 149, 165-166

Graduate, The 62, 63, 64, 65, 73, 75, 104, 270

Grand Ole Opry 37, 177, 178, 179, 182

Grand Prix 102

Grand Rapids, MI 176

Great Depression 41, 74, 220

Great Gatsby, The 104

Great Northern Migration 23, 24, 87, 91 see also migration, internal

Great White Hope, The 22, 23

Greatest Story Ever Told, The 269

Greece 102

Green Bay, WI 170, 234

Green Berets, The 6

Green Card 143

Green Mile, The 22

Greensboro, NC 176

Gremlins 105

Greyfriar's Bobby 205

Groundhog Day 31, 169, 188-192, 194

Guatemala 159, 160

Guess Who's Coming to Dinner 22, 23

Guevara, Che 162

Gypsy 174

H

Hallelujah 37

Hand that Rocks the Cradle, The 110

Hang 'em High 215

Hanks, Tom 38, 39, 106

Hanson, Curtis 31, 110, 192-193
Happiest Millionaire, The 204, 270

Harlan County U.S.A. 165

Harlem, NY 28-29

Harold and Maude 65

Harry and the Hendersons 143

Harvey 140

Hawaii 176

Hayes Code 62

Hazelton, PA 171

Heartbreak Ridge 55

Hearts in Dixie 37

Heat (1986) 55

Heaven Can Wait 64, 65

Heaven Help Us 144

Heaven's Gate 153

Hello, Dolly! 102

Helsinki, Finland 148-150, 149

Henry: Portrait of a Serial Killer 189

Herbie Goes Bananas 158

Hialeah, FL 176

High Time 6

higher-order city 170-173, 190, 192, 195

History of the World Part I 157

Hoerr, John 188, 193

Hoffa 26, 28

Hoffman, Dustin 56, 181, 182

Hollywood Babylon 194

Hollywood, CA 39, 65, 173, 175, 187

Home Alone 270

Home Alone II: Lost in New York 9, 104, 271

Honduras 157, 160

Hong Kong 101, 102

Honolulu, HI 176

Hook 105, 270

Hoover Dam 183-184

Horse in the Gray Flannel Suit, The 204

Horwath, Alexander 63

Hour of the Furnances 83

House Un-American Activities Committee 221

Houston, TX 143, 170, 173, 176

How the West Was Won 101

Huerta, Dolores 219-220 
Hunt for Red October 105

Huntington Beach, CA 176

Hurricane Mills, TN 37, 179

Hurricane, The 22

hydroelectric power 43, 43, 44, 153, 155-

$157,155,165,183-184$ see also renewable energy

I

Idaho 232

identity, national 3-5, 11, 12, 17, 19, 20, 31, $36,54,203,213,234$

ideology, suburban 95-96, 97-99, 105-108, 110-111, 115-116, 203

Illinois $5,9,15,23,29,42,50,56,60,62,66$, 70, 74-83, 88, 90, 104, 105, 107-110, 109, 113, 114,115-116, 140, 143, 169, $170,171,174,175,176,193,195$, $209,232,269,270$

imperialism 14-15, 31, 199-201, 207, 208, $216,218,221-223,224-226$

imperialism, cultural 31, 199, 200-201, 226

In Cold Blood 66, 74, 215-16

In Search of the Castaways 31, 200-201, 204, 205-208, 206, 207, 226

In the Heat of the Night (TV) 55

In the Heat of the Night 22, 23, 55

In-Laws, The 157

Incredible Journey 205

India 101

Indiana 97-98, 208-215, 226, 231, 272

Indianapolis, IN 98, 211, 231, 272

Indigenous people 153-154

industrialization 41-44, 68, 154, 156

international landscape 212-213

Intolerance 15

Iowa 36, 74, 173-174, 175, 232, 271

Iowa City, IA 232

Iran 160

Ireland 102

Israel 102, 159

It's a Mad, Mad, Mad, Mad World 101

Itaipu Dam 155-156
Italy $101,102,172,173,272$

Itliong, Larry 219-220

J

Jackson, MS 176

Jacksonville, FL 171, 176

Jacob Riis Park 145, 146, 147

Jake Reacher 270

Jamaica 56, 102

Jane Eyre (1943) 201

Jane Fonda workout videos 141

Japan 19, 96, 101, 102, 103, 172, 188, 271

Jaws 37, 65, 67, 90, 95, 100, 101, 104, 125, 203

Jeffords, Susan 36, 271

Jeremiah Johnson 232

Jerry Maguire 22, 23

Jersey Shore, NJ 143

Joe 64, 66

Joe Versus the Volcano 237

John Birch Society 137-138

Johnson, Lyndon Baines 24

Jordan 102

Jungle Book, The 270

Jurassic Park 270

K

Kalamazoo, MI 85

Kalifornia 31, 169, 188, 189-190, 191, 193, 194-195

Kansas 24, 74, 98, 173-174, 176, 231

Kansas City, MO 176, 186, 195

Karate Kid, The 30, 97, 105, 108, 111-113, 116. 117

Kent County, MD 231

Kentucky 37, 38, 41, 176, 177, 179

Kenya 17, 102

Kerner Report 24-25, 119

KGB 151-152

Kidnapped 201, 205

Killer of Sheep 236

King and I, The 101, 140

King Kong (1976) 104 
King of Marvin Gardens, The 67, 68-69, 73

King, Dr Martin Luther 5, 23, 26

Klute 66, 270

Knoxville, TN 176, 232

Krakatoa, East of Java 102

Kramer vs. Kramer 35, 64

Kremlin 149-151

L

L.A. Story 173

La Decision de Vencer 160

'La Marseillaise' 213-214, 224

labour, farm 41, 200, 213, 218-220, 221, 225, 225

labour, industrial 41, 70, 85-86, 193

Lady and the Tramp 139, 199

Lady Sings the Blues 22, 23, 28, 37

landmark 13, 14, 49, 172-175, 179, 234-235 see also Devil's Tower, WY, Eiffel Tower, Golden Gate Bridge, Monument Valley, Mount Rushmore, Peachtree Plaza, White House, Wrigley Field, Yankee Stadium

landscape 4, 7, 8, 16, 28-29, 30, 70, 103, 111, $154,188,201,202-203,236$

artificial 15 see also creative geography industrial 68, 70, 112, 154, 156

international 212

national 4, 5, 16, 17, 19, 20, 24, 31, 111, 234235,237

natural resource extraction 29, 59-60, 66, 69-74, 69, 72, 73, 90

Las Vegas NV 30-31, 143, 169, 171, 173, 177, 181, 182-187, 183, 185, 195 see also Clark County, NV

Last Action Hero, The 270

Last Detail, The 67, 68, 69, 73-74

Last Picture Show, The 66, 70, 72, 73

Last Starfighter 143

Latin America 157, 271 see also Central America, South America

Latino 161

Laverne and Shirley 115, 272
Lawrence of Arabia 6, 101, 209

Lawrence, KS 98

Le Petit Monde de don Camillo 223-225, 272

Le Retour de don Camillo 272

League of Revolutionary Black Workers 85

Leaving Las Vegas 182

Lebanon 159, 172

Lebanon, KS 231

Lenin, Vladimir Ilyich 138, 149, 149, 150

Lethal Weapon 104

Levenson, Barry 30, 31, 144, 177, 183

Lexington-Fayetteville, KY 176

Life magazine 204

Lilies of the Field 22

Lincoln, NE 176

Lion in Winter, The 5

Little Big Man 65, 270

Little Colonel, The 37

Little Rock, AR 24, 39, 177, 182

location

narrative $3,4,7,8,10-12,12,16,18,22,23$, $31,36,37-38,39,60,65-67,85,96-97$,

101-103, 104-105, 142-144, 148, 173, 174, $175,176-177,200,204-205,236$

shooting 3, 8-9, 10, 15-16, 85, 103, 148-150, 155,270

London, England 50, 170, 172, 173, 205, 269

Long Goodbye, The 65

Long Island, NY 104, 143

Long Ships, The 269

Longest Day, The 101, 209

Longest Yard, The 39, 44-46, 50, 53, 104, 269

Look Who's Talking 104

Looking for Mr Goodbar 62, 66

Looper 270

Lopez, Barry 235-236

Lord of the Rings, The 174

Lordstown, OH 85-86

Los Angeles Plays Itself 15-16, 70, 173, 269

Los Angeles, CA 3, 5, 9, 15-16, 22, 23, 31, $46,56,62,70,74,96,104,111-113$, $143,150,169,170,171,172,173$, $175,176,182,183,184,189,195$, 
208, 236, 269 see also Beverly Hills, Chatsworth, Chatsworth Reservoir, Culver City, Encino, Pasadena, Reseda, San Fernando Valley, Venice, Watts

Lost in America 182

Louisiana 29, 37, 38, 44, 55, 60, 69, 70, 143, $159,171,176,177,232,235$

Louisville, KY 177

Love Bug, The 61, 104, 201, 205, 270

Love Finds Andy Hardy 194

Love Story 104

Lowe, Rob 115

lower-order city 170, 171, 181, 184, 185, 187, 189, 190, 192

Lt Robin Crusoe USN 205, 208

Lubbock, TX 171, 176

Lucas, George 95-96, 270

M

$M^{\star} A^{*} S^{\star} H(\mathrm{TV}) 20$

$M^{\star} A^{\star} S^{\star} H$ 63, 65, 270

Madison County, IA 232

Madison, WI 176

Magnolia 191

Magnum Force 17

Malcolm X 22, 25-29, 27, 28, 176

Malibu, CA 104, 173

Malone 55

Maltby, Richard 7-8, 13, 16, 17, 201

Man in the Gray Flannel Suit 107, 204

Man in the Gray Flannel Suit, The 107

Manchester, England 17

Mandela, Nelson 26, 27

Manhattan 172, 174

Manhattan, NY 13, 66, 74, 105, 106, 172, 207, 237, 271

Manifest Destiny 154

Māori culture 31, 205-208, 206, 207, 226

Marceline, MO 202, 204, 209

Marine Parkway Bridge 145-146, 145, 147

Mary Poppins 6, 201, 205, 270

Mary Tyler Moore Show 272
Maryland 170, 176, 231

Mason-Dixon Line 40, 53

mass media 11, 77-84, 163, 165, 171, 174

Massachusetts 26, 27, 50, 62, 74, 104, 170, $171,176,208,209$

masscult-midcult 21 see also taste, middlebrow and prestige

Matlock 55

Matrix, The 142

Max Dugan Returns 148

McCabe and Mrs Miller 65

McHenry, IL 143

McNairy County, TN 37

Medfield, CA (fictional town) 204

Mediterranean 269

Medium Cool 29, 60, 62, 66, 74-84, 79, 81, $\mathbf{8 2}, 85,88,90,91$

medium-sized cities 30-31, 131, 169-177, 195,233

Meet Joe Black 143

Meet Me In St Louis 105

Melbourne, Australia 17, 205

Melvin and Howard 182

Memphis, TN 176

Menace II Society 269

mental map 10, 14, 20

Mesa, AZ 176

Metairie, LA 176

Metropolis, IL 174

Mexico 102, 158, 219

Miami FL 37, 38, 42, 44, 46, 50-51, 51, 53, $171,176,177$

Miami Vice 55

Michigan 25, 29, 31, 40, 42, 54, 56, 60, 66, 74, 84-90, 104, 105, 171, 176, 177, $186,193,195,232$

Mickey One 66, 74

Midnight Cowboy 22, 64, 66, 75, 270

Midwest 23, 25-26, 29, 31, 40, 41, 60, 62-63, 66-67, 69, 74, 84-85, 90-91, 105, 186, 200, 202, 204, 208-209, 211, 233, 272

migration, internal 41, 42 see also Great Northern Migration 
Million Dollar Duck 270

Milwaukee, WI 115, 170, 172, 176, 186, 272

Minneapolis, MN 171, 176-177, 181, 272

Minnesota 20, 23, 37, 74, 170, 171, 176-177, $181,182,232,269,272$

Minocqua, WI 170

Miracle of the White Stallions 205

Misadventures of Merlin Jones, The 201, 203, 204

Missing 137, 153

Mission, The 153

Mission: Impossible 2232

Mississippi 23, 37, 176, 269

Mississippi Burning 22

Mississippi River 231, 271

Missouri 74, 105, 171, 176, 186, 195, 202, 204, 209, 231, 232

mobile privatization 163-165

Mobile, AL 176

Mombasa, Kenya 17

Monkey's Uncle, The 201, 204

Monkeys Go Home! 31, 200-201, 204, 205, 215-226, 222, 225, 226, 272

Montana 29, 60, 73

Montgomery, AL 23-24, 176, 182, 220

Monument Valley 16, 232

Moretti, Franco 3, 10-11, 269

Moretti, Franco Atlas of the European Novel 1800-1900 269

Moretti, Franco Graphs, Maps, Trees 269

Morning After, The 143

Moscow, Russia/USSR 30, 144, 148-152, 165, 233

Moses, Robert 145-146

Motion Picture Arts Association 199 see also Oscars

Mount Rushmore 234

Mount Taranaki, New Zealand 205

Mr Mom 105, 195

Mujeres al borde de un ataque nervois 20

Muncie, IN 97-98

Muppet Christmas Carol, The 271

Muppet Movie, The 38
Murder at 1600143

Murphy, Eddie 21, 56

music 22, 30, 70, 116, 141, 169

country and western 177-182

Music Box, The 173

Music City, USA 179,182 see also Nashville, TN

My Stepmother is an Alien 143

$\mathbf{N}$

NASCAR 55

Nashville 30, 178, 179, 181-182

Nashville TN 30, 37, 39, 169, 171, 177-182, 195,232

Natchitoches, LA 232

National Advisory Commission on Civil Disorders see Kerner Report

National Board of Review 12, 176, 190 see also prestige

national identity 3, 4, 19-20, 54, 203

national imaginary 39, 169, 195, 209, 234

National Park Service 23-24, 119

National Society of Film Critics 12, 176 see also prestige

Native American, film representations 173, 206-207, 209, 236

Nebraska 25-26, 25, 171, 176

Needham, Hal 39-40

Neshoba County, MS 182

Netherlands 102

Nevada 30-31, 143, 169, 171, 173, 177, 181, 182-187, 183, 185, 195

Never a Dull Moment 204-205

Never Say Never Again 148

New Bedford, MA 171

New Brunswick, NJ 25

New Cinema History 7-8

New England 20, 38, 41, 50, 69

New Hampshire 74, 156, 232

New Hollywood 29, 59-91, 95, 116, 232, 233, 270

New Jersey 9, 25, 106, 143, 182, 271

New Jersey 9, 25, 68-69, 73, 106, 111-112, $143,176,182,271$ 
New Mexico 176

New Orleans, LA 38, 44, 69, 143, 159, 171, 177,235

New York Film Critics Circle 12, 176 see also prestige

New York state 3, 5, 9, 12, 13, 14, 16, 23, 25, $28-29,30,31,38,41,50,56,60,62$, $66,74,104,105-107,111,112,127$, $143,144,145-146,145,147,150$, $165,169,170,171,172,173,174$, $175,176,177,187,190,195,203$, $205,208,215,232,233,235,237,271$

New York Times 76, 142, 148, 156, 159

New York, NY 3, 5, 9, 12, 13, 14, 16, 23, 25, $30,31,38,41,50,56,60,62,66,74$, 104, 105-107, 127, 143, 150, 165, $169,170,171,172,173,174,175$, $176,190,195,203,205,208,215$, $232,233,235,237,271$

New Zealand (Aotearoa) 174, 200, 205-208, 214

Newark, NJ 25, 111-112, 176

Nicaragua 30, 144, 157-163, 165, 233, 271

Nicholson, Jack 62, 66, 67-74

Nixon, Richard 5, 35, 40, 62 see also Southern Strategy

Norfolk, VA 74, 176

Norma Rae 87

Normal, IL 232

Norman, OK 24

North America 153, 155, 192, 217, 219

North by Northwest 234

North Carolina 9, 51, 55, 87, 176, 232, 271

Northern Ireland 172

nostalgia $61,144,147-148,187,194$

Nystrom, Derek 39, 44, 56, 66, 85-86, 89, 270

O

Oakland, CA 171, 176

Ode to Billy Joe 37

Office, The (US) 174

Ohio 25, 42, 54, 74, 176, 177, 182, 186, 193, 231,232
Ohio River 188, 192

Oklahoma 24, 70, 177

Oklahoma City, OK 177

Old Yeller 203

Oliver! 5, 270

Omaha, NE 25-26, 25, 171, 176

On Golden Pond 137

One and Only Genuine Family Band 204

One Day At A Time 272

Orange County, CA 138

Oregon 9, 105, 176

Oscar, Best Actor/Actress 21, 22, 26, 28, 119

Oscar, Best Animated Feature Film 272

Oscar, Best Animated Short Film 199

Oscar, Best Documentary 22, 119

Oscar, Best Picture 5, 6, 12, 22, 23-24, 25,

119, 130, 131, 176, 199, 272

Oscar, Best Score/Best Song 22, 119

Oscar, Best Screenplay/Adapted Screenplay 22, 119

Oscars 20-22 see also prestige

Out of Sight 195

Outsiders, The 144

$\mathbf{P}$

Pacific Heights 110

Pacino, Al 56, 66

Paint Your Wagon 61, 102

Palestine 101, 102, 269

Palm Beach, FL 104

Paper Moon 66, 69, 74, 270

Para, Brazil 144

Paraguay 155, 156

Parent Trap, The 205

Parenthood 105

Paris Blues 269

Paris, France 13, 50, 172, 173, 205, 208, 209210, 211, 213, 226, 233, 269, 272

Pasadena, CA 104, 173

past, films set in $36-38,65,74,143,144,146$, $173,194-195,200,232,233$

Pasternak, Joe 62

Patton 102 
Pawnbroker, The 64

Peachtree Plaza 48-50, 48, 49, 50

Peeping Tom 214, 214

Peggy Sue Got Married 144

Pennsylvania 9, 31, 41, 68, 104, 156, 169, $171,174,176,177,181,188-195,232$

People vs Larry Flynt, The 176

Perfect American, The 202

periodizing 64-65, 96, 270,271

persistent poverty county $236-237$

Peru 103

Peter Pan 199

Phelps County, MO 231, 232

Philadelphia, PA 68, 104, 171, 176, 190

Philippines 102

Phoenix, AZ 23, 171, 173, 176

Piatti, Barbara and Lorenz Hurni 7, 236-237

Picnic 194

Pierre, SD 234

Pink Flamingos 140

Pinocchio 140, 199

Pittsburgh, bridges 188, 191, 191, 192-193

Pittsburgh, PA 31, 169, 171, 177, 181, 188195

Plainfield, NJ 25

Plains 23, 60, 112, 233, 236

Planes Trains and Automobiles 174

Planet of the Apes 104

Please Don't Eat the Daisies 105-106, 107

Point Blank 17, 64, 65

Poitier, Sidney 22-24, 38, 269

Poland 271

Poltergeist 30, 97-99, 105, 108, 110, 116, 271

Porky's 157

Portland, OR 9, 176

Portsmouth, NH 74

Portugal 102

Poseidon Adventure, The 104

presence, large-scale 142-144, 154 see also

blockbuster, spectacle/spectacular

Presidio, The 17

prestige $4,7,10,11,12,16,19,21-22,30-31$,

$120,130,131,134,169,173,175-$
177, 188-189, 195, 201, 231, 232, 233, 236 see also American Film Institute, masscult-midcult, National Society of Film Critics, Oscars, taste, metropolitan, and taste, middlebrow

Pretty Woman 104

Princess Bride, The 143

privatization 146, 148

production, runaway 3, 9, 18, 103

professional-managerial class (PMC) 39, 42, 44

Provence, France 216-218, 226, 233

Providence, RI 237

Psycho 173

Public Enemy, The 15

public transportation 145-146, 220 see also train, elevated train

Puddin' Head 37

Puget Sound, WA 70

Pulp Fiction 22, 190

Punxsutawney, PA 190, 191-192

Purple Rain 176

Q

Quad Cities IL/IA 232

Quo Vadis 101

R

Rachel, Rachel 5-6

Racine, WI 105

Radioland Murders 270

Ragtime 22

Raiders of the Lost Ark 46, 153, 157

Rain Man 30-31, 169, 182-183, 183, 184, 185

Raintree County 101

Raising Arizona 143

Raleigh, NC 176, 232

Rare Breed, The 215

Rascal 204

Ray, Robert 11, 100

Reagan Doctrine 159-161, 163

Reagan, Ronald 35, 54, 56, 144, 156, 160, 271 
Reaganism 30, 108, 111, 137-139, 143, 153, $156,160,163,183$

Rear Window 140, 157

Red Dawn 160

Redford, Robert 35, 38, 56

Reds 149, 176

Ref, The 143

Reivers, The 23

renewable energy 153-156, 165 see also hydroelectric power

Rent-a-Cop 55

Reseda CA 111-113

Reservoir Dogs 191

Return of Jafar, The 140

Reynolds, Burt 29, 35-36, 38-40, 45-56, 65, $100,177,232,233,269-270$

Rhode Island 232, 237

Richmond, VA 176

Ricochet 269

Right Stuff, The 173

Risky Business 30, 97, 105-107, 108, 110, 113, 116,117

Riviera 205, 208, 209, 210, 211, 212-213, 226,272

Robe, The 101

Robocop 195

Rochester, MN 170

Rochester, NY 176

Rockaway Peninsula, NY 143, 145-146

Rockford, IL 105

Rocky 64

Rocky II 104

Rocky III 104

Rocky IV 104, 153

Romancing the Stone 153

Romania 9

Rome, Italy 101, 172, 173

Romeo and Juliet (1968) 5

Romero 161

Rotorua, New Zealand 208

Round Midnight 22

rural 15, 24, 29, 31, 36-38, 41, 44, 50, 62, 74, $90,104,188,202,231,233,236,269$
Rushmore 143

Russia 101, 102, 149-152, 235 see also Soviet Union

Rust Belt 40-41, 42-43, 176, 188-189, 193194 see also Midwest

Ruthless People 105

Ryan, Michael and Douglas Kellner 68, 76, $77,80,137,146-147$

S

\section{Sabrina 13}

Sacramento, CA 176, 232

Sakhalin Island, Russia/USSR 148

Salt Lake City, UT 9, 31, 176

Saludos Amigos 199

Salvador 137, 161

Samoa 101

San Antonio, TX 176

San Diego, CA 9, 176

San Fernando Valley CA 111, 112, 173

San Francisco, CA 9, 13, 17, 23, 38, 50, 104, $143,169,170,171,175,176,203$, 235,269

San Jose, CA 171, 176, 193 see also Silicon Valley

San Luis Obispo, CA 156

Sandinista 143, 157-163

Saturday Night Live 97

Saudi Arabia 101, 102

Savannah, GA 39, 47

Saving Private Ryan 143

scale, on film 95, 101, 141-144, 148, 150, $157,161,165,172,173,187,204$

scale, physical 17, 18, 43, 50, 84, 106, 107, 115

Schenectady, NY 171

school 26, 27, 42, 105, 107, 110, 111, 113, 138, 164-165, 172, 184-185, 185

Scotland 172, 200, 205

Scottsdale, AZ 176

Scranton, PA 171, 174, 190, 194

Seabrook, NH 156

Searchers, The 16, 153 
Sears Tower 109

Seattle, WA 9, 23, 143, 170, 171, 177, 269

Secret Garden, The 271

Selma, AL 23-24, 182

Semi-Tough 39, 46, 50-51, 51, 269

Shag: The Movie 144

Shaggy Dog, The 203, 204

Shampoo 65, 104, 173

Sharky's Machine 39, 46-52, 48, 49, 50, 52, 53, 269

Shawshank Redemption, The 22, 141-42

Shermer, IL (fictional town) 107-110

Shining, The 110

Shooting, The 64

Showgirls 143

Shreveport, LA 176

Sight and Sound poll 190-191

Silkwood 137

Singin' in the Rain 140

Single White Female 110

Sioux Falls, SD 234

Sis Hopkins 37

Sister Act 142

Sixteen Candles 144

Sklar, Robert 62, 75, 77

slavery 218-220

Sleeping Beauty 199

Slender Thread, The 269

Sliver 110

small city 104, 105, 173-175, 176, 232

small town $3,23,31,37,42,59,63,68,74$, $90,104,105,176,190,194,200,201$, 203-205, 208, 215, 217, 226-227, 232, 233, 269

small town ideology 31, 68, 201-205, 208209, 214, 226-227 see also Disney ideology

Smokey and the Bandit 36, 39, 40, 46, 51, 51, 52-54, 100, 269

Smokey and the Bandit II 39, 53-54, 269

Smokey and the Bandit Part 355

Snake Eyes 143

Snow White and the Seven Dwarfs 199, 270 solar power 156 see also renewable energy

solidarity 45, 53, 85, 220

Solnit, Rebecca 17, 235-236

Son of Flubber 201, 203, 204

Song of the South 37, 199

Sons of Katie Elder 215

Sorcerer 65

Soul Food 140-141

Sound of Music, The 5, 6, 59, 101, 140, 270

Sounder 22, 23, 24, 37, 270

South Africa 160

South America 102, 129, 153, 156-157, 199, 200, 205, 208 see also Latin America

South Carolina 171

South Dakota 73, 74, 231, 234

South Korea 148, 271

South Pacific 101

Southern Strategy 40-42, 56

Soviet Union 5, 15, 30, 101, 102, 139, 143, $144,148-152,153,156,159,160$, $161,163,165,172,233,235$ see also Russia

Soylent Green 104

Spacehunter: Adventures in the Forbidden Zone 148

Spain 20, 101, 102

Spartacus 6, 101

spectacle/spectacular 54, 101, 142-144, 148, 187,270 see also blockbuster, presence

Spielberg, Steven 67, 95-96, 97-99, 270

Spies Like Us 153

Splash 104

Spokane, WA 176, 232

Sri Lanka (Ceylon) 101

St Louis, MO 105, 171, 231,

St Petersburg, FL 176

St Petersburg, Russia 148, 149, 150

Stand By Me 144

Star Trek II: The Wrath of Khan 141

Star Wars 3, 36, 39-40, 64, 67, 95, 100, 137, 169

Starting Over 35 
Staten Island, NY 66, 237

steel 31, 145, 169, 188-194, 195

Steel Magnolias 55, 232

Stevenson, Robert 201

Stick 55

Sting, The 66, 74, 104

Stir of Echoes 143

Stockton, CA 176

Straight Story, The 176

Strange Brew 157

Street Smart 22

Streisand, Barbara 35, 66

Strip, The 182-183, 195

Striptease 55

Stroker Ace 55

studio 30, 60, 63-65, 75, 95, 96, 102, 139, $140,153,164$

ownership 18, 96, 103

system $10,26,67,90,154$

suburbanization 24, 43, 51, 111, 203, 233

suburbs 30, 51, 52, 62-63, 95-96, 97-99, 100, $101,105,109-110,113,116,117$, 204,233

diversity in 112,117

moving through 99, 108-117, 114

Sudden Impact 17, 104

Sugarland Express 65, 73

Sugrue, Thomas 90

Summer Magic 205

Summer of Sam 143

Sun Belt 36, 39, 40-41, 66 see also US South

Superman 104

Superman II 46, 104

Swiss Family Robinson 204, 205, 208

Switzerland 102, 234

Syracuse, NY 176

Syria 271

T

Tacoma, WA 171, 175, 176, 232

Tampa, FL 25, 44, 46, 176

Tanzania 102

Taranaki, New Zealand 206
Targets 64

Tarzan the Ape Man 157

Tasman Sea 205

taste 11,190

metropolitan 12, 59, 60-63, 66, 67-68, 74, 90

middlebrow 12, 21, 22, 90, 91

suburban 30, 95-96, 98, 203 see also masscult-midcult, middlebrow and prestige

Taxi Driver 66, 189, 270

Teenage Mutant Ninja Turtles 104

Television, broadcasting18, 20, 39, 53, 115, $141,162,164,174,176,179,182$, $190,203,209,217,272$

community access 113

screen size 142-144, 148

Tempe, AZ 143

Ten Commandments, The 101

Tennessee 30, 37, 39, 169, 171, 176, 177-182, 178, 179, 182, 195, 232

Tennessee Valley Authority (TVA) 41-44, 184

Terminator 2: Judgment Day 96

Terms of Endearment 174

Terre Haute, IN 208-215, 226

Texas $9,41,53,65,70,73,74,143,170,173$, 176

That Darn Cat! 201, 203, 204

That Touch of Mink 209

The Way We Were 104

theme park 187, 200, 202, 203

There's Something About Mary 237

They Shoot Horses, Don't They? 65, 270

Thieves Like Us 65

Those Calloways 204

Three Caballeros 199

Three Mile Island, PA 156

Thumbelina 271

Thunderball 101

Titanic 142

To Kill a Mockingbird 23, 209

To Sir, With Love 269

Toby Tyler 203 
Tokyo, Japan 172

Toledo, $\mathrm{OH} 176$

Tom and Jerry: The Movie 271

Tom Sawyer 270

Tonight Show, The 53-54

Topeka, KS 24

Total Recall 104

tourism $27,38,58,123,130,188-189,195$, 208, 211-215, 226, 272 see also film tourism

Towering Inferno 104

Toy Story 3272

train $107,117,146,184$ see also public transportation

Tropic Thunder 21

Troy, NY 171

True Lies 270

True Romance 40, 195

Turkey 102

Twilight 175

Twins 104

Two-Lane Blacktop 65, 66

$\mathbf{U}$

Ugly Dachshund, The 204

Under Fire 30, 137, 139, 143, 144, 157-163, 157, 162, 165-166, 271

unemployment 188-189, 218

Unforgiven 176

union $28,36,84-90,91,137,138,165,200$, 216, 217, 218-221, 226

United Auto Workers (UAW) 85, 87

United States 4, 10, 14, 18, 20, 23-26, 30, $31,35,36,50,60,65,68,69,74,90$, 98, 101-103, 142, 144, 150, 155, 156, 159-161, 163, 170-175, 199-200, 204, 212, 218, 231-233, 237

United States Football League 46

Unlawful Entry 110

Untouchables, The 104

Up 272

Up in Smoke 158

Upper Peninsula, MI 31 urban 3, 23-24, 25-26, 30, 38, 50, 60, 68, 83, 104, 143, 150, 172-173, 204-205, 209, $231,232,234,269$

US Census 74, 99, 231, 232, 236

US South 20, 23, 29, 35-56, 65, 68-70, 73, $100,171,232,233$

US West 23, 38, 40-41, 60, 65, 66, 68, 90, $171,176,184,232,233-235$,

Utah 9, 31, 176

V

Venice, CA 73, 143

Vermont 105

Vertigo 9

video 139

rental 11, 30, 126-129, 138, 139, 141-144, $148,153,157,160$

sales (sell-through) 139, 140-141

Vienna, Austria 172, 205

Vietnam 102

Vietnam War 5, 59, 70, 137, 147, 158

Virginia 38, 74, 143, 176, 231

Virginia Beach, VA 176

Von Doviak, Scott 46-47

W

Wag the Dog 30, 169, 177, 179-182, 180

Waiting to Exhale 141

Walker 160

Wall Street 147, 165, 187

Wall Street Journal 163

Wall-E 272

Wallace, George 26, 27

Walt Disney Studios 31, 63, 140, 199-201, 203, 219, 221, 272 see also Disney, Walt, Disney ideology, and theme park

WarGames 137

Warren, MI 176

Washington DC 5, 13, 14, 50, 74, 104, 105, $143,156,169,171,175,176,190$, 232, 270

Washington state 9, 23, 37, 70, 74, 143, 170, $171,175,176,177,232,269$ 
Waterworld 141-142

Watts, CA 24, 236, 269

Wayne, John 6, 38, 153, 231

Wayne's World 30, 97, 105, 108, 113-117, 114, 232

We're Back!: A Dinosaur Story 271

Weekend 83

West Germany 271 see also Germany

West Palm Beach, FL 50-51

West Virginia 232

Wexler, Haskell 75-78, 80

What's Love Got to Do With It 22, 23, 28

What's Up Doc? 270

Wheeling WV 232

White Christmas 140

White House 13, 14, 156

White Lightning 39, 46-47, 52

Who Framed Roger Rabbit? 104

Who's Afraid of Virginia Woolf? 64

Why We Fight 138

Wichita, KS 173-174, 176

Wild Angels, The 65, 66, 70, 72, 73

Wild Bunch, The 65, 270

Wilkes Barre, PA 171

Williams, Raymond 14, 163-164

Winnetka, IL 270

Wisconsin 105, 115, 170, 172, 176, 186, 234, 272

Wizard of $\mathrm{Oz}$, The 140

Wonder Boys 31, 169, 188, 192-194, 195

Worcester, MA 176

working class 39, 66, 74, 84-90, 111-112, $146-147,179,188-190,220$

Working Girl 237

workplace safety 87-89

World's Greatest Athlete, The 270

Wrigley Field 109, 109

Written on the Wind 194

Wyoming 73, 98
Y

'Yankee Go Home' 216, 222, 222

Yankee Stadium 28, 172

You Can Count on Me 232

Yours Mine and Ours 104, 270

Yugoslavia 102

$\mathrm{Z}$

Z 45, 83

Zabriskie Point 65

Zeffirelli, Franco 5

Zelig 157 



\section{. \\ THE IMAGINARY GEOGRAPHY OF HOLLYWOOD CINEMA $1960-2000$}

The Imaginary Geography of Hollywood Cinema 1960-2000 combines digital cartography with close readings of representative films from 1960-2000. Christian B. Long offers a unique history of twentieth-century Hollywood narrative cinema, one that is focused on the intersection of the geographies of narrative location, production, consumption and taste in the era before the rise of digital cinema. Long redraws the boundaries of film history, both literally and figuratively, by cataloguing films' narrative locations on digital maps in order to illustrate where Hollywood actually locates its narratives over time.

Christian B. Long works at Queensland University of Technology and is an honorary research fellow at the University of Queensland.

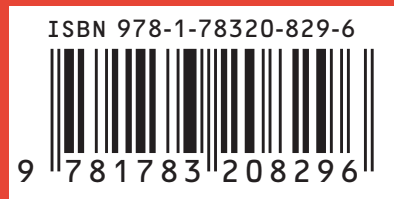

intellect | www.intellectbooks.com 